\title{
Discovery of ligands for Frizzled and their promises for the diagnosis and treatment of cardiovascular disease
}

Citation for published version (APA):

Laeremans, H. (2010). Discovery of ligands for Frizzled and their promises for the diagnosis and treatment of cardiovascular disease. [Doctoral Thesis, Maastricht University]. Datawyse / Universitaire Pers Maastricht. https://doi.org/10.26481/dis.20100519hl

Document status and date:

Published: 01/01/2010

DOI:

10.26481/dis.20100519hl

Document Version:

Publisher's PDF, also known as Version of record

Please check the document version of this publication:

- A submitted manuscript is the version of the article upon submission and before peer-review. There can be important differences between the submitted version and the official published version of record.

People interested in the research are advised to contact the author for the final version of the publication, or visit the DOI to the publisher's website.

- The final author version and the galley proof are versions of the publication after peer review.

- The final published version features the final layout of the paper including the volume, issue and page numbers.

Link to publication

\footnotetext{
General rights rights.

- You may freely distribute the URL identifying the publication in the public portal. please follow below link for the End User Agreement:

www.umlib.nl/taverne-license

Take down policy

If you believe that this document breaches copyright please contact us at:

repository@maastrichtuniversity.nl

providing details and we will investigate your claim.
}

Copyright and moral rights for the publications made accessible in the public portal are retained by the authors and/or other copyright owners and it is a condition of accessing publications that users recognise and abide by the legal requirements associated with these

- Users may download and print one copy of any publication from the public portal for the purpose of private study or research.

- You may not further distribute the material or use it for any profit-making activity or commercial gain

If the publication is distributed under the terms of Article $25 \mathrm{fa}$ of the Dutch Copyright Act, indicated by the "Taverne" license above, 
Discovery of ligands for Frizzled and their promises for the diagnosis and treatment of cardiovascular disease 
Discovery of ligands for Frizzled and their promises for the diagnosis and treatment of cardiovascular disease

Thesis, Maastricht University, Maastricht, The Netherlands

ISBN 978-90-5278-939-2

(C) Copyright Hilde Laeremans, Maastricht 2010

Design and Layout: Hilde Laeremans

Printing: Datawyse | Universitaire Pers Maastricht

Financial support by BSIK 


\title{
Discovery of ligands for Frizzled and their promises for the diagnosis and treatment of cardiovascular disease
}

\author{
PROEFSCHRIFT \\ Ter verkrijging van de graad van doctor aan de Universiteit Maastricht, \\ op gezag van de Rector Magnificus, Prof. mr. G.F.M.F. Mols \\ volgens het besluit van het College van Decanen, \\ in openbaar te verdedigen op woensdag 19 mei 2010 om 14.00 uur \\ door \\ Hilde Laeremans \\ Geboren op 5 juli 1980 te Diest
}

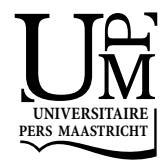




\section{Promotores}

Prof. dr. J.F.M. Smits

Prof. dr. H.C.J. Ottenheijm

\section{Copromotor}

Dr. W.M. Blankesteijn

\section{Beoordelingscommissie}

Prof. dr. H.J.G.M. Crijns (voorzitter)

Prof. dr. T. Andersson, Lund University, Malmö, Sweden

Dr. J.G. Maessen

Prof. dr. F.C.S. Ramaekers

Dr. M. Schmidt, Universiteit Groningen 


\section{Contents}

List of abbreviations 6

Chapter 1 General introduction and aims of the thesis 9

Chapter 2 The pharmacology of Wnt/Frizzled interactions 29

Chapter 3 Wnt/Frizzled signaling modulates the migration and 49 proliferation of immortalized cardiac fibroblasts

Chapter 4 Differentiation of muscle cell lines is modulated by activation of 69 Wnt/Frizzled signaling

Chapter 5 A fragment of Wnt5a blocks Frizzled-1 and -2 with high affinity in vivo and in vitro

Chapter 6 Development of tools for visualization of Frizzled-1 and -2 111

$\begin{array}{lll}\text { Chapter } 7 & \text { The role of Wnt/Frizzled signaling in atherosclerosis } & 125\end{array}$

$\begin{array}{lll}\text { Chapter } 8 & \text { General discussion and conclusions } & 135\end{array}$

$\begin{array}{lll}\text { Chapter } 9 & \text { Summary } & 141\end{array}$

$\begin{array}{lll}\text { Chapter } 10 \text { Samenvatting } & 145\end{array}$

$\begin{array}{ll}\text { Dankwoord } & 151\end{array}$

$\begin{array}{lr}\text { Curriculum Vitae } & 155\end{array}$

$\begin{array}{lr}\text { List of publications and Patent } & 159\end{array}$ 


\section{List of abbreviations}

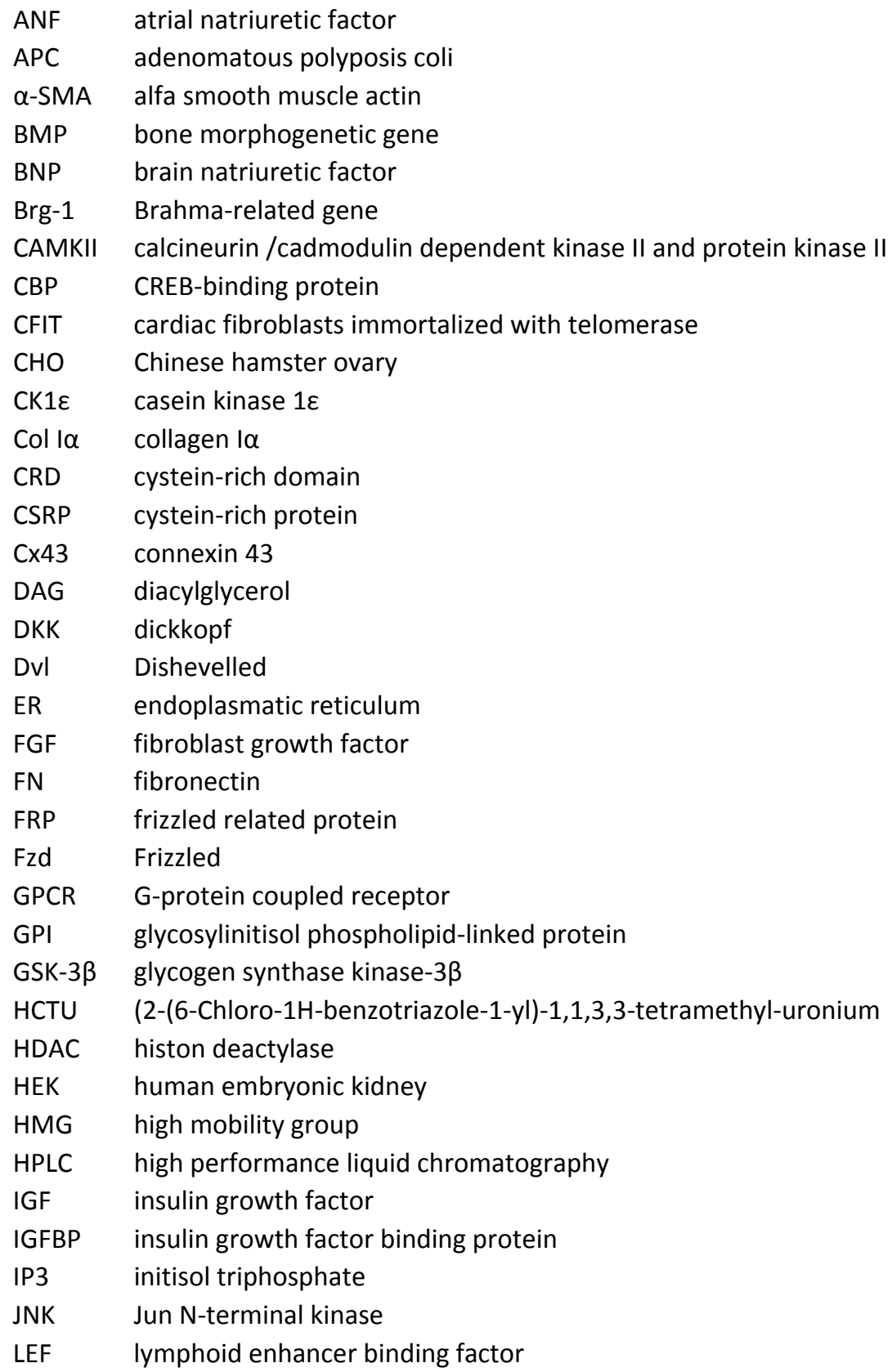




$\begin{array}{ll}\text { LiCl } & \text { lithium chloride } \\ \text { LRP } & \text { lipoprotein related-receptor protein } \\ \text { MI } & \text { myocardial infarction } \\ \text { Myh6 } & \text { myosin heavy chain } 6 \\ \text { NFAT } & \text { nuclear factor of activated T-cells } \\ \text { NSAID } & \text { non-steroidal anti-inflammatory drugs } \\ \text { PARP-1 } & \text { poly-adenosine phosphate ribose polymerase-1 } \\ \text { PBS } & \text { phosphaat buffered saline } \\ \text { PDE6 } & \text { phosphodiesterase } 6 \\ \text { PKA } & \text { protein kinase A } \\ \text { PKC } & \text { protein kinase C } \\ \text { qPCR } & \text { quantitative polychain reaction } \\ \text { ROR } & \text { receptor tyrosine kinase-like orphan receptor } \\ \text { RT-PCR } & \text { real-time polychain reaction } \\ \text { SEM } & \text { standard error of the mean } \\ \text { SFRP } & \text { soluble Frizzled related proteins } \\ \text { SHH } & \text { Sonic Hedgehog } \\ \text { STV } & \text { superTOPFlash } \\ \text { TCF } & \text { T-cell specific transcription factor } \\ \text { TGF } & \text { transcription growth factor } \\ \text { WIF } & \text { Wnt inhibitor factor } \\ \text { Wg } & \text { Wingless } \\ \text { WTX } & \text { Wilms tumor gene } \\ \end{array}$





\section{1 \\ General introduction}




\section{The Wnt/Frizzled signal transduction cascade}

Frizzled (Fzd) proteins are structurally related to the family of 7 transmembrane receptors. Fzd was originally discovered as an important mediator in Drosophila wing development, particularly in the orientation and polarity of the wing epithelium. The unorganized, 'frizzled' appearance of the wings of Drosophila that lack a functional Fzd protein in fact supplied the name for this protein. The natural ligands for Fzds are proteins from the Wnt family. Wnt/Fzd signaling is involved in the regulation of a wide range of processes during development and disease $e^{1,2}$. Normally, Wnt signaling activity is low in adulthood, but the signaling can be reactivated during remodeling processes and different pathologies. This reactivation is part of the so-called re-expression of the fetal gene program, leading to cell proliferation, differentiation and migration. In this way, the Wnt/Fzd pathway can contribute to the repair and recovery of tissues and organs, like for example intestine, liver, kidney and the heart ${ }^{3}$. In this Introduction, our focus will be on Wnt/Fzd signaling in the development and pathology of the cardiovascular system. However, before discussing what is known about this subject we will provide a general introduction on Wnt and Fzd proteins and their signaling.

\subsection{The ligands: Wnt proteins}

The name Wnt originates from wingless $(\mathrm{Wg})$ and INT, an oncogene ${ }^{4}$. Wnts are highly conserved secreted lipid-modified glycoproteins of 350-400 amino acids, with an important function in the cell-to-cell signaling during development and disease. Wnts are the regulators of normal and pathological endocrine functions ${ }^{5,6}$. Until now, 19 different human and rodent Wnts have been identified.

Traditionally, Wnts are subdivided into two different subclasses, the Wnt1- and Wnt5a-class. The Wnt1-class signals through $\beta$-catenin and duplicates the body axis during the developing Xenopus embryo, a common test for abnormal embryonic development. In the nucleus, $\beta$-catenin forms a complex with the T-cell-specific transcription factor/lymphoid enhancer binding factor (TCF/LEF), thereby promoting the transcription of genes that contain the appropriate promoter sequences. The Wnt5a-class does not signal via $\beta$-catenin but can activate the calcium pathway; Wnt5a can therefore be considered as a $\beta$-catenin independent Wnt protein. The activity of the Wnt1-class can be blocked by Wnts from the Wnt5a-class by suppression of TCF/LEF transcriptional activity. In summary, the calcium pathway antagonizes the Wnt1-class and initiates morphogenetic movement ${ }^{7-9}$. This illustrates that a rigid classification of Wnts into either the Wnt1- or Wnt5a-class is too simple, because the signal transduction pathway(s) that are activated or inhibited appear to be intertwined and also depend on the receptor that is involved. 
This gives rise to the high degree of complexity of the Wnt/Frizzled pathway, which will be further discussed in section 1.3 of this Introduction.

In order to become functional, Wnt proteins undergo extensive posttranslational modifications. A common modification is the palmitoylation of the Wnt protein on the first conserved cysteine residue. This palmitoylation of Wht proteins provides the hydrophobic character. Two more palmitoylations will follow but these exert a lower impact on the activity. Palmitoylations are necessary for glycosylation and have therefore been thought to be necessary for secretion and the activity of the ligand $^{10}$. Kurayoshi et al., however, proved that palmitoylation is not essential for secretion $^{11}$. A possible explanation for these seemingly contradictory results is that large amount of unpalmitoylated Wnt can be secreted in the same manner as low levels of palmitolayted and glycosylated Wnt proteins.

To exert their activity, Wnts are secreted into the extracellular environment. The Wnt transporter protein Wingless (W/s), an evolutionary well-conserved partner of Wnt, is necessary for Wnt excretion. Wnts are transported together with glycosylinositol phospholipid-linked (GPI-linked) proteins, called argosomes, which are exogenously derived lipoproteins. It has been suggested that Wls is essential in Wnt-mediated cell-to-cell communication. Heparin sulfate proteoglycan and VPS35 , a subunit of a retromer complex for intracellular protein trafficking, also contribute to the function of Wls in these Wnt sending cells ${ }^{10,12-14}$. Porcupine, on the other hand, can inhibit the palmitoylation of Wnts and can therefore limit the secretion of Wnts. However, it is not known whether or not it influences the binding capacity and functional activity of $\mathrm{Wnt}^{15}$.

Wnts are difficult to obtain in a purified, soluble, biologically active form ${ }^{16}$. In fact it has taken more than two decades before purified Wnts that are still biologically active became available to the research community ${ }^{17}$. For this reason, conditioned medium of L-cells that stably express Wnt constructs are commonly used instead of purified Wnt proteins to study the Wnt effects in vitro. In vivo applications of Wnts were even more problematic, because these proteins tend to stick to membranes and extracellular matrix proteins. However, it was recently shown that liposome packaging of Wnt proteins offers an effective approach for in vivo administration ${ }^{18}$.

\subsection{The receptors: Frizzled}

Over two decades of extensive research, combined with the results of genome-wide sequencing, have resulted in the identification of a large family of Fzd-proteins. The ten different Fzds, identified in mammals, can be divided into four main clusters (Fzd-1/2/7, Fzd-8, Fzd-4/9/10 and Fzd-3/6), based on their sequence homology. The length ranges from 537-706aa. The Fzds all have a seven transmembrane structure with a very long amino-terminal extension, called the cysteine-rich domain (CRD) or 
content-dependent regulatory domain (Fig 1). This part of the receptor protein functions as a recognition site for Wnt proteins ${ }^{8}$. The CRD is a conserved domain of 120 amino acids containing 10 invariant cysteines suggesting that this region can form disulfide bonds, either internally or with its ligand ${ }^{19}$. The free sulfhydryl groups of the CRD have also been implicated in Fzd dimerization, but in solution the amino terminal part is a monomer ${ }^{20}$.

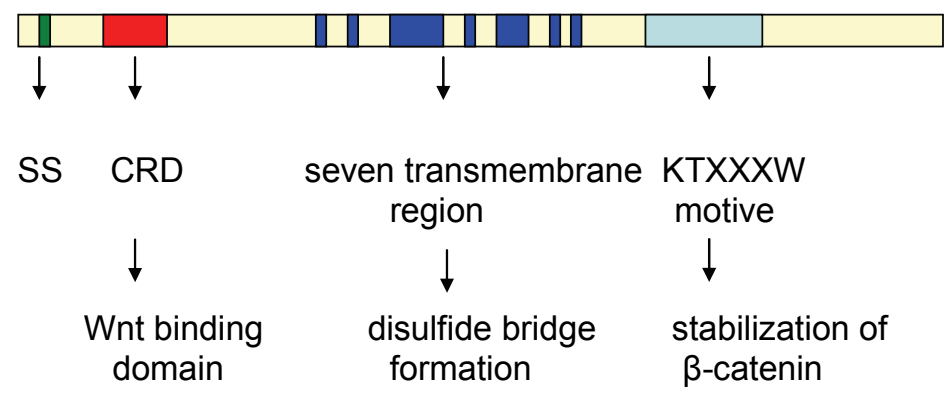

Fig 1: Schematic representation of Frizzled. (CRD= cysteine-rich domain)

Upon Wnt binding, the Wnt/Fzd signal transduction cascade is activated. Where the CRD is involved in the docking of Wnt to the Fzd protein, it is an intracellular domain of the receptor, the Lys-Thr-xxx-Trp motive, which is involved in the activation of the intracellular parts of Wnt signaling. So the CRD is essential for Wnt binding, but not necessary for propagation of the signal ${ }^{21}$. The C-terminal part of Fzds also possesses a Ser/Thr-xxx-Val motive, necessary for phosphorylation by protein kinase $A$ and $C$ and casein kinase II. The largest sequence variations between different members of the Fzd family are found in this C-terminus ${ }^{22,23}$.

The importance of the internalization of the receptor or the receptor-ligand complex is still open for debate. Blitzer et al. examined the role of endocytosis on Wnt/Fzd signaling. They concluded that internalization facilitated certain aspects of cellular signaling. Lithium chloride ( $\mathrm{LiCl}$ ) and a temperature of less than $4^{\circ} \mathrm{C}$ inhibited this internalization ${ }^{24}$. $\mathrm{LiCl}$ may therefore have a dual role in the Wnt/Fzd signal transduction cascade, namely inhibition of endocytosis and antagonizing a downstream element of the signal transduction pathway, namely glycogen synthase

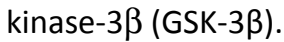

\subsection{The Wnt/Fzd signal transduction cascade}

The Wnt/Fzd signal transduction pathway is very complex and can be subdivided into three main signaling cascades (Fig 2). Most Fzd proteins can activate all three pathways but with different efficiencies. Activation of a certain pathway is 
dependent on the Wnt ligand, the co-receptor and the cell type in which the signaling is studied.

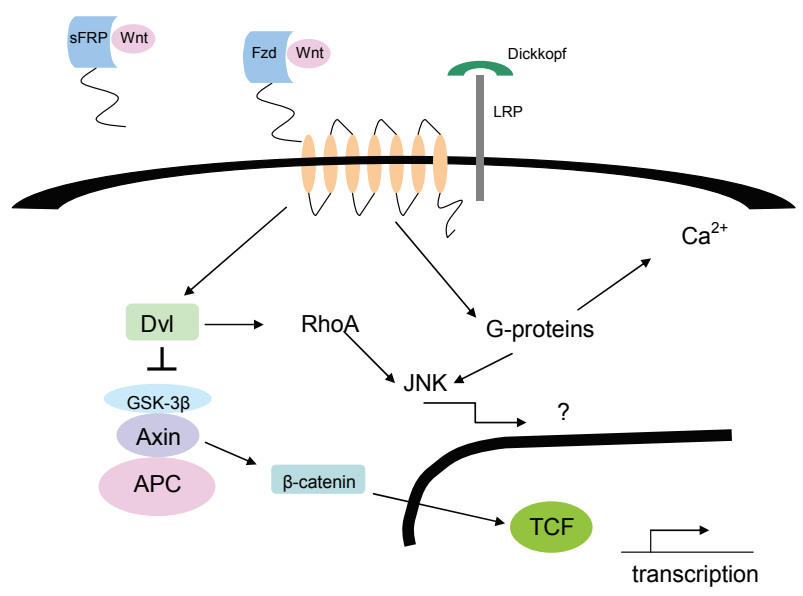

Fig 2: Schematic representation of different signal transduction pathways of Frizzled. Proteins of the Wnt family can bind to Frizzled and this can lead to the activation of different signal transduction cascades.

\subsubsection{The 6-catenin dependent pathway}

The $\beta$-catenin dependent pathway is also known as the canonical pathway. The first downstream protein is Dishevelled (Dvl). Dvl encodes a ubiquitously present cytoplasmatic protein containing 4 domains that are highly conserved among all known homologues. At the N-terminus, Dvl contains a Dishevelled-Axin (DIX) domain. Direct interaction between DVl and axin via the DIX domain, which they both contain, elevates the cytoplasmatic $\beta$-catenin ${ }^{25}$.

Dvl can interact directly with intracellular parts of Fzd. Three murine homologues of Dvl have been described ${ }^{26-28}$. The extensive overlap in spatial and temporal expression patterns and the high homologies suggest that these genes have mutually redundant functions.

Another important protein involved in the regulation of $\beta$-catenin content is the adenomatous poliposis coli (APC) protein. Together with axin and several other proteins, APC forms the so-called $\beta$-catenin degradation complex. The APC protein binds directly to $\beta$-catenin by two sets of related repeats towards the centre of the molecule. Two APC genes and several protein isoforms have been described. Based on its role in $\beta$-catenin degradation, APC can be considered to act as a functional antagonist of Wnt/Fzd signaling but might also have additional functions in Wnt signaling independent of his role in the downregulation of $\beta$-catenin ${ }^{21}$.

In the absence of activated Dvl, the $\beta$-catenin degradation complex promotes

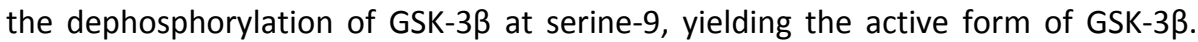


This results in the phosphorylation of $\beta$-catenin at amino acid 45 , so that it can be recognized by $\beta$-Trcp, targeted for ubiquitination and degraded by proteasomes. Upon Wnt activation, $\beta$-catenin is stabilized by the inhibitory effect of Dvl on GSK$3 \beta$, as well as by destabilization of axin through LRP6, a co-receptor in the Wnt/Fzd complex $^{29}$ (see paragraph 1.5). This results in an accumulation of $\beta$-catenin in the cytoplasm. $\beta$-catenin is a member of the Armadillo repeat protein family ${ }^{30}$. It is present in three different cellular compartments: the plasma membrane, the cytoplasm and the nucleus. The Wnt pathway is an important regulator of the cytoplasmatic pool. An increasing level of endogenous $\beta$-catenin results in its accumulation in the nucleus, where it can form a complex with TCF/LEF and promote gene transcription. Further details on the cellular effects of $\beta$-catenin will be provided in section 1.4 of this Introduction.

\subsubsection{The 6-catenin independent pathway}

The second Wnt signaling pathway is the $\beta$-catenin independent pathway, also known as the non-canonical pathway ${ }^{31-33}$. Wnt will activate Dishevelled, leading to the activation of phosphodiesterase 6 (PDE6), and inhibition of protein kinase $G$ (PFG) and calcium or to the activation of diacylglycerol (DAG) and inositol triphosphate (IP3), eventually leading to increased levels of calcium. CamKII (calcineurin/cadmodilin dependent kinase II and protein kinase II) and protein kinase $C$ (PKC) are two calcium sensitive enzymes ${ }^{33,34}$. Downstream of these elements resides the nuclear factor of activated T cells (NFAT), which becomes activated by the Wnt/Ca ${ }^{2+}$ pathway. In its phosphorylated form, NFAT gets degraded in the cytoplasm. On the other hand, calcineurin, a calcium/cadmodulin-dependent phosphate, dephosphorylates NFAT. Unphosphorylated NFAT can move to the nucleus upon Wnt/Fzd activation and acts as a transcription factor.

\subsubsection{The Planar Cell Polarity pathway}

The third and last Wnt/Fzd pathway is the planar cell polarity pathway, which involves the small GTPases Rho and CDC42 as well as C-jun N-terminal kinase (JNK). JNK, another target of Wnt/Fzd signal transduction cascade, needs strong calcium depletion for its activation ${ }^{35}$. This pathway in its turn can activate up to 8 different downstream signaling pathways, but this is beyond the scope of this thesis.

\section{4 $\beta$-catenin can exert diverse functions in the cell}

B-catenin can be found in three different cellular pools, namely in the cytoplasm, necessary for signaling, at the plasma membrane in adherens junctions, discussed later, and in the nucleus. Because $\beta$-catenin lacks a nuclear localization signal, a vehicle is required to translocate $\beta$-catenin to the nucleus. In the nucleus, $\beta$-catenin can enter a protein complex consisting of active transcription factors, however 
lacking any specific $\beta$-catenin binding site ${ }^{36}$. The functionality of this complex can be explained by two different nuclear models: The first and most likely model is that $\beta$ catenin forms a heterodimeric complex in the nucleus with the transcriptional factor TCF/LEF. The alternative model is that $\beta$-catenin exports TCF/LEF from the nucleus to relieve its repressive activity or activates this protein in the cytoplasm. The first model has been further examined and the results indicate that $\beta$-catenin works by augmenting the enzymatic activity of RNA polymerase ${ }^{37,38}$. A possible coactivator of this system is poly-ADP ribose polymerase-1 (PARP1) which works specifically on $\beta$-catenin and $\mathrm{TCF}^{39,37}$. In the absence of $\beta$-catenin, groucho, a histone deactylase (HDAC) will act as a repressor and make DNA refractive to transcription. CREB-binding protein (CBP) and Brahma-related gene 1 (Brg1), on the other hand, can serve as co-activators of TCF/LEF together with $\beta$-catenin, and favour transcription by remodeling of chromatin. CBP- $\beta$-catenin in its turn can be modulated by ICG- $\beta$, a small molecule that blocks the interaction ${ }^{40}$.

The TCF/LEF binding site contains an 80 amino acid high mobility group (HMG) box. The HMG box binds to the minor groove of DNA as monomers, and bends the DNA helix. This creates the recognition and spatial organization of enhancer binding sites. LEF/TCF can also bind $y$-catenin, which is an effective activator of c-myc expression in immortalized cells and is controlled by the Wnt/Fzd signal transduction cascade ${ }^{8}$.

Besides its function in gene transcription, $\beta$-catenin is also essential for cell adhesion. It forms a link between E-cadherin or type I cadherins and the actin skeleton or $\alpha$-catenin ${ }^{41}$. This membrane-bound fraction of $\beta$-catenin is increased after Wnt3a stimulation, thereby suggesting that the structural and functional integrity of the cadherin-catenin complex is regulated by phosphorylation ${ }^{42}$. But not only tyrosine kinase, but also insulin growth factor (IGF) II, can lead to disintegration of the membrane complex. Where tyrosine kinase breaks down $\beta$-catenin, IGF II will transfer the $\beta$-catenin to the nucleus and make nuclear signaling possible ${ }^{43}$. This membrane bound pool is more stable, compared to the dynamic cytoplasmatic pool.

\subsection{Other Wnt (co-)receptors: LRP5-6, ROR2 and Ryk}

The complexity of Wnt/Fzd signaling is further increased by the discovery of coreceptors for Fzd and alternative Wnt receptors. In Figure 3, an overview of different Wnt receptors and co-receptors is provided ${ }^{44}$. Members of the low density lipoprotein receptor related protein family, LRP5 and LRP6, are now well recognized as co-receptors for the Wnt/Fzd signal transduction cascade ${ }^{45,46}$. The five PPPSPXP motives, present in LRP5 and LRP6, provide a docking site for axin ${ }^{13,47}$. GSK-3 $\beta$ promotes these interactions between LRP5 and axin, where axin acts as a scaffolding protein to promote GSK-3 $\beta$ mediated receptor phosphorylation. 
Phosphorylation of a conserved serine/threonine residue (site II), three amino acids downstream of each GSK-3 $\beta$ phosphorylation site (site I) in LRP5/6, is required for Wnt signaling ${ }^{25}$. The exact function of LRP, however, is still obscure. Some studies indicate that LRP is necessary for signaling, whereas others suggest that LRP is not required for Dvl phosphorylation, but is more involved in the specificity of the signal transduction cascade that is activated ${ }^{21}$. Furthermore, Liu et al. reported that LRP6 $\triangle$ C, a mutant LRP6 that lacks the intracellular part, binds Wnt5a, thereby antagonizing the $\beta$-catenin independent pathway and activating the $\beta$-catenin dependent Wnt signaling ${ }^{46}$.

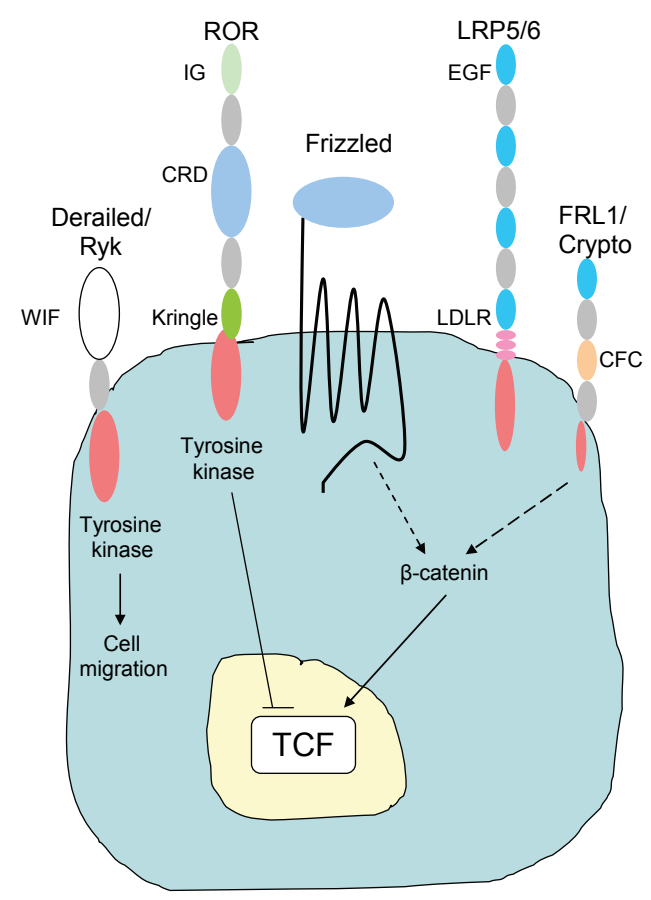

Fig 3: The different Wnt receptors on the cell membrane.

Another Wnt binding receptor is ROR, an orphan receptor that is a member of the tyrosine kinase family. RORs share the cysteine-rich domain with Fzds but, in contrast to $\mathrm{Fzd}$, are restricted to one signal transduction pathway namely the $\beta$ catenin independent pathway, ${ }^{7,48}$. As all Wnt receptors, RORs exhibit selectivity for association with certain members of the Wnt family. Not only binding with Wnt can influence the ROR2 signal transduction cascade, but also the dimerization between for example ROR2 and Fzd-2 has been suggested ${ }^{49}$.

Apart from ROR, Ryk, another member of the tyrosine kinase family, can serve as an alternative receptor for Wnt. Ryk functions by forming a ternary complex with 
Wnt and Fzd and can therefore be categorized into the family of co-receptors, similar to the LRPs ${ }^{21,50}$.

\subsection{Antagonists and agonists of the Wnt/Fzd pathway}

\subsubsection{Endogenous antagonists}

Several secreted protein families antagonize or modulate the Wnt/Frizzled pathway. Wnt/Frizzled antagonist can be subdivided into four different groups, depending on their functioning. The first group of antagonists, comprising of the soluble frizzled related proteins (SFRP) and Wnt inhibitor factor (WIF), can scavenge the Wnt ligand and therefore prevent both $\beta$-catenin dependent and $\beta$-catenin independent signaling ${ }^{51,52}$. The second group of inhibitors prevents the complex formation of Fzd and LRP. Examples of this group are Dickkopf (DKK) and Crescent ${ }^{53,54}$. The third group of Fzd antagonists consists of the Shisa protein, which prevents the movement of Fzd from the endoplasmatic reticulum (ER) to the plasma membrane. This retention of Fzd in the ER inhibits its activation by Wnt proteins ${ }^{55}$. The fourth and last class of antagonists has multiple functions, ranging from scavenging of the Wnt protein to inhibition of the (co-) receptors. This group exists of four different proteins, namely Cerberus, Nodal, insulin growth factor binding protein 4 (IGFBP-4) and bone morphogenetic protein (BMP) ${ }^{4}$. Two other antagonists that are known are Wilms tumor gene (WTX) and Diversin. These antagonists work more downstream in the signal transduction cascade. WTX promotes the complex formation of APCAxin and $\beta$-catenin, thereby targeting $\beta$-catenin for ubiquitination ${ }^{56}$. Diversin can also enhance ubiquitation of $\beta$-catenin, but it will recruit casein kinase $1 \varepsilon$ (CK1 1 ) to phosphorylate $\beta$-catenin ${ }^{57}$.

\subsubsection{Endogenous agonists}

Besides the Wnt ligands, described in section 1.1 of this Introduction, only two naturally occurring agonists are known for the Frizzled, namely Rspondin and Norrin. Rspondin can increase the dimerization of the Frizzled with LRP, probably by antagonizing $\mathrm{DKK}^{58}$. Norrin on the other hand, facilitates the association between Frizzled and $\mathrm{LRP}^{4}$.

\subsubsection{Synthetic antagonists and agonists}

There is significant interest in finding synthetic agonists and antagonists for the Wnt/Frizzled pathway, because this pathway is involved in a broad range of different pathologies and development. This search has led to the identification of compounds interfering at the different levels of the signaling pathway. Here, we will describe some of these compounds and their targets, starting at the level of Wnt secretion and processing and subsequently following the pathway downstream. 
The first group of compounds aims at the secretion and processing of Wnt proteins. Inhibitors of Porcupine, an enzyme that is necessary for the secretion of Wnt protein, have been shown to block Wnt activity ${ }^{59}$. Alternatively, the liposomal packaging of Wnt proteins can be inhibited by Ant1.4 $\mathrm{Cl} / \mathrm{Br}$, which renders the Wnt proteins inactive ${ }^{18}$.

The second group of modulators of Wnt/Frizzled signaling aims at the level of the Frizzled. Fragments of Wnt proteins have been identified that can modulate the Wnt/Frizzled signaling: starting with a peptide fragment of Wnt5a that is almost identical to UM206 (see chapter 5), Foxy5 and homologous peptides have been developed that act as mimetics of Wnt5a in migrating breast cancer cells ${ }^{60}$. Foxy 5 has been tested in vivo in breast cancer metastasis and inhibits the metastasis of $4 T 1$ breast cancer cells ${ }^{61}$. Box5, a peptide identical to Foxy5 but with an $\mathrm{N}$-terminal BOC-group instead of a formyl group, was shown to act as a blocker for Wnt signaling $^{62}$. The Frizzled-5 protein has been suggested to be the most likely molecular target for these peptides. An alternative way of modulating Wnt/Frizzled signaling is by manipulating the endocytosis of Frizzled proteins. The anti-helminthic compound Niclosamide has been shown to promote the internalization of Frizzled- $1^{63}$, thereby inhibiting Wnt signaling.

Moving into the cell, the dishevelled protein is an upstream regulator of both catenin-dependent and independent signaling. NSC668036, an organic compound, can bind to the Dvl PDZ domain, thereby inhibiting the signaling induced by Wnt $3 a^{64}$. Moreover, the compound FJ9 has been shown to disrupt the interaction between Frizzled-7 and the PDZ domain of Dishevelled ${ }^{65}$.

Activation of $\beta$-catenin-mediated Wnt signaling has commonly been achieved by inhibiting GSK-3. LiCl and valproate are frequently used compounds in this context ${ }^{66}$. Over the last years, the range of GSK-3 $\beta$ inhibitors has expanded considerably and now includes SB-216763, SB-415286 ${ }^{67}$ and 6-bromoindirubin-3'-oxime $(\mathrm{BIO})^{68}$. These compounds are selective cell permeable inhibitors of GSK-3. Alternatively, stabilization and activation of Axin has also been employed as an approach to inhibit Wnt signaling at the level of $\beta$-catenin. Again, several compounds have been described, including a group of compounds called "inhibitors of Wnt response" ${ }^{59}$ and the tankyrase inhibitor, XAV939 ${ }^{69}$.

Activators and inhibitors of the interaction between $\beta$-catenin and TCF form a group of compounds that act the most downstream of Frizzled at the level of the nucleus. Deoxycholic acid (DCA) increases phosphorylation of $\beta$-catenin, thereby activating the signaling pathway ${ }^{70}$. Other small molecules of this group are however inhibitors, namely 2,4-diamino-quinazoline ${ }^{71}$, quercetin ${ }^{72}$, ICG-001 ${ }^{73}$ and PKF115$584{ }^{74}$ (Summary see Table 1 ). 
Table 1: Compounds

\begin{tabular}{lll}
\hline Compound & Target & Effect on signaling \\
\hline WAY-316606 & sFRP & Activates \\
IWP & Porcupine & Inhibits \\
Ant1.4 Cl/Br & Wnt & Inhibits \\
niclosamide & Frizzled-1 & Inhibits \\
Foxy-5 & Frizzled-5 & Activates \\
Box5 & ? & Inhibits \\
FJ9 & Frizzled-7 & Inhibits \\
NSC668036 & Dvl & Inhibits \\
SB-216763 & GSK-3 & Activates \\
SB-415286 & GSK-3 & Activates \\
6-bromoindirubin-3'-oxime (BIO) & GSK-3 & Activates \\
LiCl & GSK-3 & Activates \\
Tankyrase & Axin & Inhibits \\
IWR & Axin & Inhibits \\
DCA & $\beta-c a t e n i n$ & Activates \\
2,4-diamino-quinazoline & TCF/ $\beta$-catenin & Inhibits \\
quercetin & TCF & Inhibits \\
ICG-001 & TCF & Inhibits \\
PKF115-584 & TCF/ $\beta$-catenin & Inhibits \\
IQ1 & PP2A & Inhibits \\
QS11 & ARFGAP1 & Activates \\
(hetero) arylpyrimidines & $?$ & Activates \\
2-amino-4-[3,4-(methylenedioxy0benzyl- & $?$ & Activates \\
amino]-6-(3-methoxyphenyl)pyrimidine & & \\
\hline & & \\
\hline
\end{tabular}

All small molecules stated in this chapter.

\section{Developmental biology and pathology}

\subsection{Development in general}

The Wnt/Fzd pathway is involved in many aspects of development, ranging from patterning and orientation of the embryo to cell proliferation and differentiation. As discussed in section 1.1 of this Introduction, Wnt proteins can be subdivided into two classes, based on their ability to form a secondary body axis during development: The Wnt1-class, signaling through $\beta$-catenin, can form a secondary axis whereas Wnts from the Wnt5a-class or the $\beta$-catenin independent Wnts are unable to do $\mathrm{so}^{82}$. It has been suggested that the gradient of Wnt protein determines the body axis and that this gradient is formed by the activation of a biological clock during development. $\beta$-catenin is also a key regulator of apoptosis and may influence development in this manner ${ }^{83}$. Below, we will discuss the role of Wnt in cardiac and muscle development, and in cardiac remodeling. 


\subsubsection{Wnt signaling in cardiogenesis}

The heart is the first functional organ in a developing embryo, which ensures the distribution of vital nutrients within the growing organism. For decades, scientists have been fascinated by the well-orchestrated morphological and molecular events that result in the formation of this complex organ. The three signaling pathways that have received most attention as primary stimuli of cardiogenesis are the regulators of fibroblasts growth factor (FGF), Bone Morphogenic Protein (BMP) and Wnt signal transduction. BMP and FGF are known positive regulators of cardiac specification and differentiation. Wnts and Frizzleds however play an opposite role. Several Wnt ligands and Fzds have been shown to be expressed in a spatially and temporally regulated manner, consistent with a function during early heart development. The $\beta$-catenin dependent pathway on one hand is repressed during early cardiogenesis, whereas this pathway is activated later $\mathrm{on}^{84}$. This may explain the contradictory results reported by different groups concerning the involvement of $\beta$ catenin in heart development.

Proof for the involvement of the $\beta$-catenin independent pathway in cardiogenesis has been provided by Pandur et al. Extensive research led to the conclusion that Wnt11 is required in cardiogenesis and signals through the calcium pathway and protein kinase $\mathrm{C}^{85}$. When looking more specifically to the anterior and posterior axis of cardiogenesis, it is clear that the Wnt signal is antagonized in the anterior axis. The main antagonists present are Crescent and Dickkopf. These antagonists create a gradient of Wnt signaling activity which gives rise to the correct orientation of the heart in de anterior-posterior axis, where BMP is more involved in the dorsal-ventral axis $^{86}$. This indicates the importance of a correct regulation of Wnt/Fzd signaling in space and time.

\subsubsection{Wnt signaling in muscle development}

Wnt proteins control different steps in myogenesis in combination with other signaling molecules such as Sonic hedgehog (Shh) and Bone Morphogenetic Proteins (BMPs). Wnts, more specifically Wnt1, Wnt3a and Wnt4, dramatically amplify the expression of paraxis, a helix-loop-helix transcription factor which is essential for the epithelialization of the paraxial mesoderm and somite formation. Besides Wnt secreting cells, also cells expressing Fzd-1, -2 and -7 have been shown to be present in the segmental plate and the somites. The Wnt antagonist, WIF-1, is expressed in the presomitic mesoderm. Since $\beta$-catenin dependent Wnt signaling leads to an accumulation of $\beta$-catenin, which links the cadherins to the cytoskeleton, Wnts have been suggested to promote the process of segmental plate epithelialization. It remains, however, challenging to identify the complex signaling pathways involved in proliferation, differentiation and migration of muscle precursors. Exact analysis of the Wnt and Frizzleds with loss and gain of function may offer some new insights in this complex matter ${ }^{87}$. 


\subsection{Wnt signaling in myocardial infarction}

\subsubsection{Myocardial infarction}

Myocardial infarction (MI) is one of the main heart-related causes of mortality and morbidity in Western countries. It is the result of an interruption of the coronary blood flow, usually due to rupture of an atherosclerotic plaque and thrombotic occlusion of a coronary artery. This leads to an inadequate supply of oxygen and nutrients to the affected part of the myocardium, resulting in cardiomyocyte death. Treatment of acute MI with thrombolytic and anti-arrhythmic agents has improved the survival of acute $\mathrm{Ml}$, resulting in an increased number of patients entering the phase of wound healing. The patients that recover from Ml frequently have a reduced cardiac output. This reduction activates diverse cardiac compensatory mechanisms ${ }^{88}$. These mechanisms initially compensate the impaired function, but often result in the further deterioration of the cardiac function, eventually leading to congestive heart failure. Heart failure is a progressive disorder with a poor prognosis. The cardiac remodeling that takes place after $\mathrm{Ml}$ induces accumulation of interstitial collagen in the non-infarcted myocardium, causing abnormal stiffness and left ventricular dysfunction. Because current pharmacological therapies only slow down the progressive deterioration of cardiac function after MI rather than stopping or reversing the adverse cardiac remodeling, the only rational therapy for heart failure is to prevent its development ${ }^{89-92}$.

Heart failure is the result of adverse remodeling of the heart and is characterized by a decreased pump function of the heart. To understand how adverse remodeling after $\mathrm{Ml}$ can be prevented, it is important to know what happens after cardiac ischemia. After injury, wound healing will start. This is a dynamic process, regulated by mechanical and neurohumoral factors. The wound healing process can be subdivided in four different phases, as shown in Fig 4: The first phase is characterized by cell death, either resulting from apoptosis or necrosis. This will lead to the onset of the second phase, the recruitment of inflammatory cells, in particular polymorphonuclear granulocytes. During the third phase of wound healing, new vessels are formed in the injured area. This process is called neovascularization, comprising of both angiogenesis and arteriogenesis. Moreover, myofibroblasts migrate into the infarct area in this phase of the wound healing. These cells share the contractile properties of smooth muscle cells with the synthetic potential of fibroblasts, and are responsible for the deposition of extracellular matrix in the infarct area. A characteristic that distinguishes these cells from regular fibroblasts is the expression of alpha smooth muscle actin ( $\alpha$-SMA). The last phase of wound healing is characterized by the formation of scar tissue. This tissue is rich in extracellular matrix proteins, but has lost much of its blood vessels ${ }^{93}$. An important difference between scar tissue in heart and e.g. skin is that myofibroblasts will stay present in a well-healed cardiac scar for many years but disappear rapidly from a 
skin scar. This underscores the importance of maintenance of the extracellular matrix in a cardiac scar, which is subjected to wear and tear due to the repetitive strain exerted on it by the beating heart ${ }^{93-96}$. The unique characteristics of this cell type will be discussed in the following section of this Introduction.

A 12-18 hours: cell death

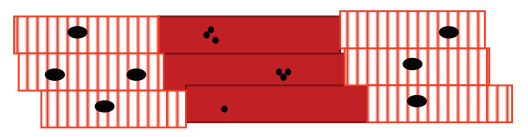

B 1-2 days: inflammation

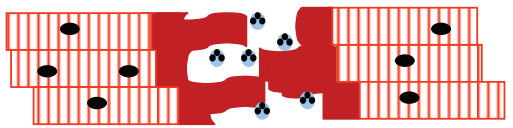

macrophage

myofibroblast
C 1-2 weeks: granulation tissue

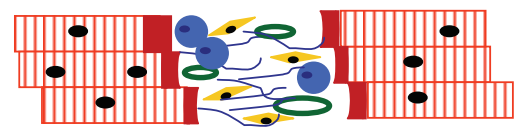

D > 3 weeks: scar maturation

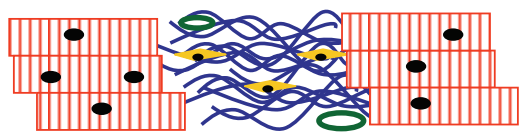

bloodvessel

polymorphonuclear granulocyt

Fig 4: The four phases of wound healing.

\subsubsection{Wnt/Fzd signaling in myocardial infarction}

Several groups, including ours, have shown that the expression of components of the Wnt/Fzd signal transduction cascade are upregulated during wound healing after infarction, particularly in the myofibroblast ${ }^{56,61,97}$. In an earlier study from our group it was shown that the expression of Fzd-2 is upregulated during myofibroblast migration in the granulation tissue, but this study did not provide information about the functional relevance of this observation.

Because of the lack of pharmacological tools to intervene in Wnt/Frizzled signaling in vivo, only genetic interventions have been reported so far in studies on the role of Wnt signaling in infarct healing. Barandon et al. were the first to show a beneficial effect of overexpression on infarct healing of FrzA, a bovine homologue of soluble frizzled-related protein-1 (sFRP1). They observed a decreased infarct size with elevated numbers of myofibroblasts and increased angiogenesis in the infarcted FrzA transgenic mice ${ }^{62}$. In the mean time, the beneficial effects of sFRP overexpression on infarct healing have been confirmed by Kobayashi et al. ${ }^{98}$. To investigate the functional relevance of Fzd-2 overexpression during infarct healing, an Fzd-2 knockout mouse was generated by our group and subjected to MI. These mice showed an increased number of myofibroblasts, a small reduction in infarct expan- 
sion and a slightly better preservation of cardiac function, compared to wildtype littermates (S. Janhunen et al., unpublished observations). Taken together, these reports point to a beneficial effect of inhibiting Wnt/Frizzled signaling on the wound healing process after MI.

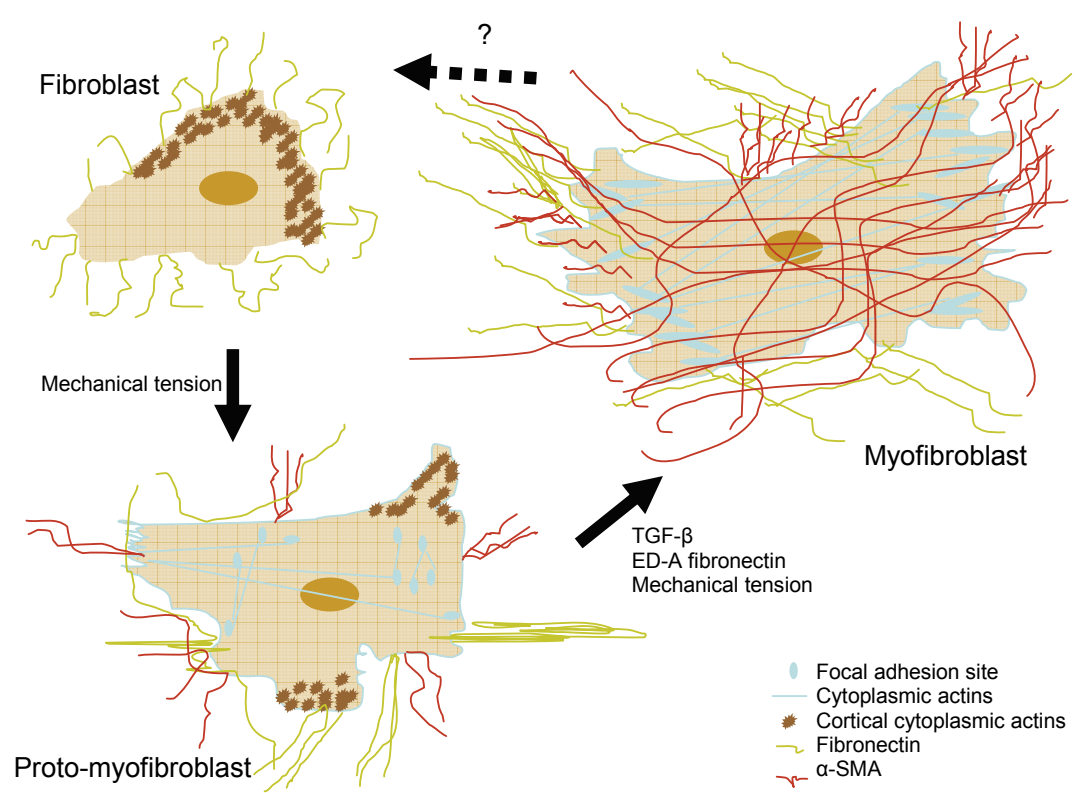

Fig 5: Fibroblast differentiation is a process regulated by different stressors. Fibroblasts differentiated into proto-myofibroblasts by mechanical tension. Therefore, culturing primary fibroblast in a culture flask will differentiated them into to myofibroblast after a few passages. Proto-myofibroblasts, on their turn, can differentiate into myofibroblasts by different substances, like TGF- $\beta$, ED-A fibronectin and mechanical tension. The dedifferentiation, however, remains a question mark, because substantial prove is lacking.

\section{Aim of the thesis}

As indicated in this Introduction, Wnt/Fzd signaling is activated in cardiovascular diseases, but our understanding of its specific role in these diseases is still very limited. This research field would benefit significantly from compounds that would allow pharmacological interventions in the disease process. However, to our knowledge no synthetic ligands have been described that can specifically interact with Fzd-1 and Fzd-2 proteins. Therefore, the aims of this thesis were threefold: First, we set out to identify compounds that can interfere with the interaction between Wnt and Fzd-1 and -2, the receptors that were shown to be upregulated after myocardial infarction. Second, we wanted to test these compounds in relevant 
cardiovascular disease models, both in vitro and in vivo, to elucidate the role Fzd-1 and -2 in infarct healing and atherosclerosis. Third, we explored the applicability of these compounds in visualizing Fzd-1 and -2 proteins in healthy and diseased tissue, because at present there is still a lack of reagents that can be used in this respect. Finally, the implications of these findings will be discussed and future applications will be evaluated.

\section{References}

1. Cadigan KM,Nusse R. Wht signaling: a common theme in animal development. Genes Dev 1997;11:3286-305.

2. Wodarz A,Nusse R. Mechanisms of Wnt signaling in development. Annu Rev Cell Dev Biol 1998;14:5988.

3. Nusse R. Wnt signaling in disease and in development. Cell Res 2005;15:28-32.

4. MacDonald BT, Tamai K,He X. Wnt/beta-catenin signaling: components, mechanisms, and diseases. Dev Cell 2009;17:9-26.

5. Brade T, Manner J,Kuhl M. The role of Wnt signalling in cardiac development and tissue remodelling in the mature heart. Cardiovasc Res 2006;72:198-209.

6. Shimizu H, Julius MA, Giarre M, Zheng Z, Brown AM,Kitajewski J. Transformation by Wnt family proteins correlates with regulation of beta-catenin. Cell Growth Differ 1997;8:1349-58.

7. Mikels A, Minami Y,Nusse R. Ror2 receptor requires tyrosine kinase activity to mediate Wnt5A signaling. J Biol Chem 2009;284:30167-76.

8. Arce L, Yokoyama NN,Waterman ML. Diversity of LEF/TCF action in development and disease. Oncogene 2006;25:7492-504.

9. Pukrop T, Klemm F, Hagemann T, Gradl D, Schulz M, Siemes S et al. Wht 5a signaling is critical for macrophage-induced invasion of breast cancer cell lines. Proc Natl Acad Sci U S A 2006;103:5454-9.

10. Mikels AJ,Nusse R. Wnts as ligands: processing, secretion and reception. Oncogene 2006;25:7461-8.

11. Kurayoshi M, Yamamoto $\mathrm{H}$, Izumi S,Kikuchi A. Post-translational palmitoylation and glycosylation of Wnt-5a are necessary for its signalling. Biochem J 2007;402:515-23.

12. Banziger C, Soldini D, Schutt C, Zipperlen P, Hausmann G,Basler K. Wntless, a conserved membrane protein dedicated to the secretion of Wnt proteins from signaling cells. Cell 2006;125:509-22.

13. He X,Axelrod JD. A WNTer wonderland in Snowbird. Development 2006;133:2597-603.

14. Cheng CW, Smith SK,Charnock-Jones DS. Wnt-1 signaling inhibits human umbilical vein endothelial cell proliferation and alters cell morphology. Exp Cell Res 2003;291:415-25.

15. Miura GI,Treisman JE. Lipid modification of secreted signaling proteins. Cell Cycle 2006;5:1184-8.

16. Smolich BD, McMahon JA, McMahon AP,Papkoff J. Wnt family proteins are secreted and associated with the cell surface. Mol Biol Cell 1993;4:1267-75.

17. Mikels AJ,Nusse R. Purified Wnt5a protein activates or inhibits beta-catenin-TCF signaling depending on receptor context. PLoS Biol 2006;4:e115.

18. Morrell NT, Leucht P, Zhao L, Kim JB, ten Berge D, Ponnusamy K et al. Liposomal packaging generates Wnt protein with in vivo biological activity. PLOS ONE 2008;3:e2930.

19. Wang Y, Macke JP, Abella BS, Andreasson K, Worley P, Gilbert DJ et al. A large family of putative transmembrane receptors homologous to the product of the Drosophila tissue polarity gene frizzled. J Biol Chem 1996;271:4468-76.

20. Huang HC,Klein PS. The Frizzled family: receptors for multiple signal transduction pathways. Genome Biol 2004;5:234.

21. Cadigan KM,Liu YI. Wnt signaling: complexity at the surface. J Cell Sci 2006;119:395-402.

22. Wang LK,Shuman S. Structure-function analysis of yeast tRNA ligase. Rna 2005;11:966-75. 
23. Takada R, Hijikata $\mathrm{H}$, Kondoh $\mathrm{H}$, Takada $\mathrm{S}$. Analysis of combinatorial effects of Wnts and Frizzleds on beta-catenin/armadillo stabilization and Dishevelled phosphorylation. Genes Cells 2005;10:919-28.

24. Blitzer JT,Nusse R. A critical role for endocytosis in Wnt signaling. BMC Cell Biol 2006;7:28.

25. Heeg-Truesdell E,LaBonne C. Wnt signaling: a shaggy dogma tale. Curr Biol 2006;16:R62-4.

26. Klingensmith J, Yang Y, Axelrod JD, Beier DR, Perrimon N,Sussman DJ. Conservation of dishevelled structure and function between flies and mice: isolation and characterization of Dvl2. Mech Dev 1996;58:15-26.

27. Sussman DJ, Klingensmith J, Salinas P, Adams PS, Nusse R,Perrimon N. Isolation and characterization of a mouse homolog of the Drosophila segment polarity gene dishevelled. Dev Biol 1994;166:73-86.

28. Tsang M, Lijam N, Yang Y, Beier DR, Wynshaw-Boris A,Sussman DJ. Isolation and characterization of mouse dishevelled-3. Dev Dyn 1996;207:253-62.

29. Kimelman $\mathrm{D}, \mathrm{Xu} \mathrm{W}$. beta-Catenin destruction complex: insights and questions from a structural perspective. Oncogene 2006;25:7482-91.

30. Miller JR,Moon RT. Signal transduction through beta-catenin and specification of cell fate during embryogenesis. Genes Dev 1996;10:2527-39.

31. Kestler HA,Kuhl M. From individual Wnt pathways towards a Wnt signalling network. Philos Trans $R$ Soc Lond B Biol Sci 2008;363:1333-47.

32. Wang HY,Malbon CC. Wnt signaling, $\mathrm{Ca} 2+$, and cyclic GMP: visualizing Frizzled functions. Science 2003;300:1529-30.

33. Spinsanti P, De Vita T, Caruso A, Melchiorri D, Misasi R, Caricasole A et al. Differential activation of the calcium/protein kinase $C$ and the canonical beta-catenin pathway by Wnt1 and Wnt7a produces opposite effects on cell proliferation in PC12 cells. J Neurochem 2008;104:1588-98.

34. Kohn AD,Moon RT. Wnt and calcium signaling: beta-Catenin-independent pathways. Cell Calcium 2005;38:439-46.

35. Veeman MT, Axelrod JD,Moon RT. A second canon. Functions and mechanisms of beta-cateninindependent Wnt signaling. Dev Cell 2003;5:367-77.

36. Mulholland DJ, Dedhar S, Coetzee GA,Nelson CC. Interaction of nuclear receptors with the Wnt/betacatenin/Tcf signaling axis: Wnt you like to know? Endocr Rev 2005;26:898-915.

37. Asally $\mathrm{M}$, Yoneda $\mathrm{Y}$. Beta-catenin can act as a nuclear import receptor for its partner transcription factor, lymphocyte enhancer factor-1 (lef-1). Exp Cell Res 2005;308:357-63.

38. Cong $\mathrm{F}$, Schweizer L, Chamorro M,Varmus $H$. Requirement for a nuclear function of beta-catenin in Wnt signaling. Mol Cell Biol 2003;23:8462-70.

39. Shitashige M, Hirohashi S,Yamada T. Wnt signaling inside the nucleus. Cancer Sci 2008;99:631-7.

40. McMillan M,Kahn M. Investigating Wnt signaling: a chemogenomic safari. Drug Discov Today 2005;10:1467-74.

41. Cadigan KM. Wnt-beta-catenin signaling. Curr Biol 2008;18:R943-7.

42. Yokoyama N, Yin D,Malbon CC. Abundance, complexation, and trafficking of Wnt/beta-catenin signaling elements in response to Wnt3. J Mol Signal 2007;2:11.

43. Nelson WJ,Nusse R. Convergence of Wnt, beta-catenin, and cadherin pathways. Science 2004;303:1483-7.

44. Hendrickx M,Leyns L. Non-conventional Frizzled ligands and Wnt receptors. Dev Growth Differ 2008;50:229-43.

45. Mi K,Johnson GV. Role of the intracellular domains of LRP5 and LRP6 in activating the Wnt canonical pathway. J Cell Biochem 2005;95:328-38.

46. Liu G, Bafico A,Aaronson SA. The mechanism of endogenous receptor activation functionally distinguishes prototype canonical and noncanonical Wnts. Mol Cell Biol 2005;25:3475-82.

47. Yamamoto H, Komekado H,Kikuchi A. Caveolin Is Necessary for Wnt-3a-Dependent Internalization of LRP6 and Accumulation of beta-Catenin. Dev Cell 2006;11:213-23.

48. Green JL, Kuntz SG,Sternberg PW. Ror receptor tyrosine kinases: orphans no more. Trends Cell Biol 2008;18:536-44. 
49. Oishi I, Suzuki H, Onishi N, Takada R, Kani S, Ohkawara B et al. The receptor tyrosine kinase Ror2 is involved in non-canonical Wnt5a/JNK signalling pathway. Genes Cells 2003;8:645-54.

50. Liu Y, Shi J, Lu CC, Wang ZB, Lyuksyutova Al, Song XJ et al. Ryk-mediated Wnt repulsion regulates posterior-directed growth of corticospinal tract. Nat Neurosci 2005;8:1151-9.

51. Bovolenta P, Esteve P, Ruiz JM, Cisneros E,Lopez-Rios J. Beyond Wnt inhibition: new functions of secreted Frizzled-related proteins in development and disease. J Cell Sci 2008;121:737-46.

52. Satoh W, Matsuyama M, Takemura H, Aizawa S,Shimono A. Sfrp1, Sfrp2, and Sfrp5 regulate the Wnt/beta-catenin and the planar cell polarity pathways during early trunk formation in mouse. Genesis 2008;46:92-103.

53. Semenov MV, Zhang X,He X. DKK1 antagonizes Wnt signaling without promotion of LRP6 internalization and degradation. J Biol Chem 2008;283:21427-32.

54. Semenov MV, Habas R, Macdonald BT,He X. SnapShot: Noncanonical Wnt Signaling Pathways. Cell 2007;131:1378.

55. Yamamoto A, Nagano T, Takehara S, Hibi M,Aizawa S. Shisa promotes head formation through the inhibition of receptor protein maturation for the caudalizing factors, Wnt and FGF. Cell 2005;120:223-35.

56. Rivera MN, Kim WJ, Wells J, Driscoll DR, Brannigan BW, Han M et al. An X chromosome gene, WTX, is commonly inactivated in Wilms tumor. Science 2007;315:642-5.

57. Schwarz-Romond T, Asbrand C, Bakkers J, Kuhl M, Schaeffer HJ, Huelsken J et al. The ankyrin repeat protein Diversin recruits Casein kinase lepsilon to the beta-catenin degradation complex and acts in both canonical Wnt and Wnt/JNK signaling. Genes Dev 2002;16:2073-84.

58. Binnerts ME, Kim KA, Bright JM, Patel SM, Tran K, Zhou M et al. R-Spondin1 regulates Wnt signaling by inhibiting internalization of LRP6. Proc Natl Acad Sci U S A 2007;104:14700-5.

59. Chen B, Dodge ME, Tang W, Lu J, Ma Z, Fan CW et al. Small molecule-mediated disruption of Wntdependent signaling in tissue regeneration and cancer. Nat Chem Biol 2009;5:100-7.

60. Safholm A, Leandersson K, Dejmek J, Nielsen CK, Villoutreix BO,Andersson T. A formylated hexapeptide ligand mimics the ability of Wnt-5a to impair migration of human breast epithelial cells. $J$ Biol Chem 2006;281:2740-9.

61. Safholm A, Tuomela J, Rosenkvist J, Dejmek J, Harkonen P,Andersson T. The Wnt-5a-derived hexapeptide Foxy-5 inhibits breast cancer metastasis in vivo by targeting cell motility. Clin Cancer Res 2008;14:6556-63.

62. Jenei V, Sherwood V, Howlin J, Linnskog R, Safholm A, Axelsson L et al. A t-butyloxycarbonyl-modified Wnt5a-derived hexapeptide functions as a potent antagonist of Wnt5a-dependent melanoma cell invasion. Proc Natl Acad Sci U S A 2009;106:19473-8.

63. Chen M, Wang J, Lu J, Bond MC, Ren XR, Lyerly HK et al. The anti-helminthic niclosamide inhibits Wnt/Frizzled1 signaling. Biochemistry 2009;48:10267-74.

64. Shan J, Shi DL, Wang J,Zheng J. Identification of a specific inhibitor of the dishevelled PDZ domain. Biochemistry 2005;44:15495-503.

65. Fujii N, You L, Xu Z, Uematsu K, Shan J, He B et al. An antagonist of dishevelled protein-protein interaction suppresses beta-catenin-dependent tumor cell growth. Cancer Res 2007;67:573-9.

66. Klein PS,Melton DA. A molecular mechanism for the effect of lithium on development. Proc Natl Acad Sci U S A 1996;93:8455-9.

67. Coghlan MP, Culbert AA, Cross DA, Corcoran SL, Yates JW, Pearce NJ et al. Selective small molecule inhibitors of glycogen synthase kinase-3 modulate glycogen metabolism and gene transcription. Chem Biol 2000; 7:793-803.

68. Sato N, Meijer L, Skaltsounis L, Greengard P,Brivanlou AH. Maintenance of pluripotency in human and mouse embryonic stem cells through activation of Wnt signaling by a pharmacological GSK-3specific inhibitor. Nat Med 2004;10:55-63.

69. Huang SM, Mishina YM, Liu S, Cheung A, Stegmeier F, Michaud GA et al. Tankyrase inhibition stabilizes axin and antagonizes Wnt signalling. Nature 2009;461:614-20. 
70. Pai R, Tarnawski AS,Tran T. Deoxycholic acid activates beta-catenin signaling pathway and increases colon cell cancer growth and invasiveness. Mol Biol Cell 2004;15:2156-63.

71. Chen Z, Venkatesan AM, Dehnhardt CM, Dos Santos O, Delos Santos E, Ayral-Kaloustian S et al. 2,4Diamino-quinazolines as inhibitors of beta-catenin/Tcf-4 pathway: Potential treatment for colorectal cancer. Bioorg Med Chem Lett 2009;19:4980-3.

72. Park $\mathrm{CH}$, Chang JY, Hahm ER, Park S, Kim HK,Yang CH. Quercetin, a potent inhibitor against betacatenin/Tcf signaling in SW480 colon cancer cells. Biochem Biophys Res Commun 2005;328:227-34.

73. Emami KH, Nguyen $\mathrm{C}$, Ma H, Kim DH, Jeong KW, Eguchi $\mathrm{M}$ et al. A small molecule inhibitor of betacatenin/CREB-binding protein transcription [corrected]. Proc Natl Acad Sci U S A 2004;101:12682-7.

74. Lepourcelet M, Chen YN, France DS, Wang H, Crews P, Petersen F et al. Small-molecule antagonists of the oncogenic Tcf/beta-catenin protein complex. Cancer Cell 2004;5:91-102.

75. Li F, Chong ZZ,Maiese K. Vital elements of the Wnt-Frizzled signaling pathway in the nervous system. Curr Neurovasc Res 2005;2:331-40.

76. Chen L, Wu Q, Guo F, Xia B,Zuo J. Expression of Dishevelled-1 in wound healing after acute myocardial infarction: possible involvement in myofibroblast proliferation and migration. $J$ Cell Mol Med 2004;8:257-64.

77. Eisenberg LM,Eisenberg CA. Wnt signal transduction and the formation of the myocardium. Dev Biol 2006;293:305-15.

78. Pandur $\mathrm{P}$, Lasche $\mathrm{M}$, Eisenberg $\mathrm{LM}, \mathrm{Kuhl} \mathrm{M}$. Wnt-11 activation of a non-canonical Wnt signalling pathway is required for cardiogenesis. Nature 2002;418:636-41.

79. Marvin MJ, Di Rocco G, Gardiner A, Bush SM,Lassar AB. Inhibition of Wnt activity induces heart formation from posterior mesoderm. Genes Dev 2001;15:316-27.

80. Christ B,Huang R. Wnts in muscle development. in Wnt signaling in development (ed. Kuhl, M.) 146155 (Kluwer academic press, New York USA, 2003).

81. LaFramboise WA, Bombach KL, Dhir RJ, Muha N, Cullen RF, Pogozelski AR et al. Molecular dynamics of the compensatory response to myocardial infarct. J Mol Cell Cardiol 2005;38:103-17.

82. Yang F, Liu YH, Yang XP, Xu J, Kapke A,Carretero OA. Myocardial infarction and cardiac remodelling in mice. Exp Physiol 2002;87:547-55.

83. Cleutjens JP, Blankesteijn WM, Daemen MJ,Smits JF. The infarcted myocardium: simply dead tissue, or a lively target for therapeutic interventions. Cardiovasc Res 1999;44:232-41.

84. Smits JF, van Krimpen C, Schoemaker RG, Cleutjens JP,Daemen MJ. Angiotensin II receptor blockade after myocardial infarction in rats: effects on hemodynamics, myocardial DNA synthesis, and interstitial collagen content. J Cardiovasc Pharmacol 1992;20:772-8.

85. Pfeffer MA,Braunwald E. Ventricular remodeling after myocardial infarction. Experimental observations and clinical implications. Circulation 1990;81:1161-72.

86. Frangogiannis NG, Michael LH,Entman ML. Myofibroblasts in reperfused myocardial infarcts express the embryonic form of smooth muscle myosin heavy chain (SMemb). Cardiovasc Res 2000;48:89100.

87. Blankesteijn WM, Essers-Janssen YP, Verluyten MJ, Daemen MJ,Smits JF. A homologue of Drosophila tissue polarity gene frizzled is expressed in migrating myofibroblasts in the infarcted rat heart. Nat Med 1997;3:541-4.

88. Willems IE, Havenith MG, De Mey JG,Daemen MJ. The alpha-smooth muscle actin-positive cells in healing human myocardial scars. Am J Pathol 1994;145:868-75.

89. van den Borne SW, van de Schans VA, Strzelecka AE, Vervoort-Peters HT, Lijnen PM, Cleutjens JP et al. Mouse strain determines the outcome of wound healing after myocardial infarction. Cardiovasc Res 2009;84:273-82.

90. Barandon L, Dufourcq P, Costet P, Moreau C, Allieres C, Daret D et al. Involvement of FrzA/sFRP-1 and the Wnt/frizzled pathway in ischemic preconditioning. Circ Res 2005;96:1299-306.

91. Barandon L, Couffinhal T, Dufourcq P, Ezan J, Costet P, Daret D et al. Frizzled A, a novel angiogenic factor: promises for cardiac repair. Eur J Cardiothorac Surg 2004;25:76-83. 
92. Barandon L, Couffinhal T, Ezan J, Dufourcq P, Costet P, Alzieu P et al. Reduction of infarct size and prevention of cardiac rupture in transgenic mice overexpressing FrzA. Circulation 2003;108:2282-9.

93. Kobayashi K, Luo M, Zhang Y, Wilkes DC, Ge G, Grieskamp T et al. Secreted Frizzled-related protein 2 is a procollagen $C$ proteinase enhancer with a role in fibrosis associated with myocardial infarction. Nat Cell Biol 2009;11:46-55. 


\section{2 \\ The pharmacology of Wnt/Frizzled interactions}

Laeremans H., Vervoort H.T.M, Lijnen P.M., Ottenheijm H.C.J., Smits J.F.M., Blankesteijn W.M. 


\begin{abstract}
The Wnt/Frizzled signaling pathway is involved in normal development as well as a variety of pathologies. The roles of Wnt proteins and Frizzleds in the Wnt/Frizzled signaling pathway have been known for some time. Yet, we have just an incipient appreciation of the contribution of the different players in the pathway, like the role of the endogenous Wnt receptors and the functional role of the co-receptor, lowdensity lipoprotein receptor-related protein (LRP5/6). To this complexity one has to add the species differences. Some of these issues are addressed here.

We have quantified the amount of Wnt proteins in conditioned medium and have tested multiple Wnts in combination with Frizzled-1 and Frizzled-2. The function of LRP5/ 6 has been studied and we have also addressed the differences between species on receptor level and downstream signaling components.

The data obtained indicate that the use of Wnt conditioned medium can be standardized and that only a few Wnts activate the $\beta$-catenin dependent pathway. Furthermore, we conclude that LRP will facilitate the binding of the Wnt proteins to Frizzled and that species differences do not occur at the receptor level, but only at the level of the downstream signaling components.
\end{abstract}

\title{
Keywords
}

Wnt/Frizzled signal transduction; Wnts and Wnt receptors; cell line specificity 


\section{Introduction}

The Wnt/Frizzled (Wnt/Fzd) signal transduction cascade is conserved throughout the animal kingdom and is a regulator of normal and pathological endocrine functions ${ }^{1}$. To activate signaling, Wnt proteins bind to a receptor complex. This can evoke different intracellular responses, involving signaling through either $\beta$ catenin $^{2}$, calcium ${ }^{3}$ or Rho kinase ${ }^{4}$. In the present study, we focused on the so called $\beta$-catenin dependent pathway. Two distinct receptor families are critical for Wnt/ $\beta$ catenin signaling: the Fzd seven-pass transmembrane receptors ${ }^{5}$ and the coreceptors, low-density lipoprotein receptor-related protein 5 and 6 (LRP5/6) ${ }^{6}$.

The mammalian genome harbors $10 \mathrm{Fzd}$ genes, most of which have variable capacities to activate the $\beta$-catenin dependent pathway when co-expressed with Wnt and LRP5 $/ 6^{7}$. Wnt proteins bind directly to a long amino-terminal extension on Fzd, called the cysteine rich-domain $(C R D)^{8}$, to activate the $\beta$-catenin dependent pathway.

LRP5 and LRP6 belong to a class of single pass transmembrane receptors. The exact function of LRP5/6 has not been clearly defined, although it is clear that they both play key roles in the $\beta$-catenin dependent pathway. They are generally cell surface endocytic receptors that bind and internalize extracellular ligands for degradation by lysosomes ${ }^{9}$. Further, it has been demonstrated that overexpression of several Wnts and Fzds together with LRP5 or 6, results in $\beta$-catenin activation ${ }^{10}$. However, the mechanism of this activation is still unknown.

A third Wnt receptor that was recently discovered is ROR2, an orphan receptor from the tyrosine kinase family. Just like Fzd, it consists of a conserved CRD and can activate the $\beta$-catenin independent pathway ${ }^{11,12}$.

The ligands for these three receptors are the Wnt proteins ${ }^{9,10}$. Wnts are secreted, cysteine-rich glycoproteins that are highly conserved among species. In mice and humans, there are $19 \mathrm{Wnt}$ members ${ }^{11}$. The pharmacology of the Wnt-Fzd interactions, however, is not clear yet and gives rise to conflicting data ${ }^{13,14}$. For example, Wnt5a is implicated in both the $\beta$-catenin independent and dependent pathway ${ }^{13}$, where others state that Wnt5a plays only a role in the $\beta$-catenin independent pathway ${ }^{13,15}$. The same holds for the role of Frizzled-1 and -2 : it is unclear whether they play a role in the $\beta$-catenin dependent or independent pathway or in both pathways.

The aim of this study is to resolve some of the questions resulting from the conflicting literature data. For that purpose, we have addressed the different points of variants in the experimental set-ups used previously. First, we have quantified the amount of Wnt proteins in the conditioned medium that has been commonly used. One has to realize that differences in protein content may well lead to false negative results, which might explain some of the conflicting literature data. Second, the inhibition of Wnt5a on the $\beta$-catenin dependent pathway has been 
further defined. We have also studied the role of 11 different Wnts in combination with Frizzled-1 and -2 in the $\beta$-catenin dependent pathway. These two receptors are linked to a wide range of pathologies, yet, little is known about their pharmacology. Third, species differences have been examined as well as the function of the coreceptors in signaling. A last point addressed is the cell line dependence of the $\beta$ catenin dependent pathway. To this end, we have examined the pathway on the receptor level and downstream components in three cell lines, namely human embryonic kidney cells (HEK293), Chinese hamster ovary cells (CHO) and kidney cells of the green monkey (COS-7).

This study provides further insight into the complex pharmacology of the WntFzd interactions, the co-receptor involvement and the resulting activation of the signal transduction cascade in different species.

\section{Materials and Methods}

\section{Cell culture and transient transfection}

The cell lines were cultured in $75 \mathrm{~cm}^{2}$ culture flasks (Costar Corning, Schiphol, the Netherlands) in Dulbeco's modified essential medium with L-glutamine (2mM), 10\% fetal calf serum (Invitrogen, Merelbeke, Belgium), and gentamycin (Sigma-Aldrich, Zwijndrecht, The Netherlands). Before starting the experiment, the cell lines were treated with plasmocin $25 \mu \mathrm{g} / \mathrm{ml}$ (Invivogen, Toulouse, France) and were tested with a mycoalert mycoplasma detection kit (Lonza, Rockland, ME, USA). When tests were negative, plasmocin treatment was stopped and the mycoalert test was repeated every two months. The cells were transiently transfected with plasmid DNA, pcDNA3.1/hygro (Invitrogen, Merelbeke, Belgium) containing the gene of Fzd$1,-2$ or -4 and Wnts 3a-5a (developed in our lab by W.M. Blankesteijn) or with plasmid DNA, pcDNA3.0 (Invitrogen, Merelbeke, Belgium) containing the gene of $\beta$ catenin or Fzd-5 or with siRNAs for Fzd-1, -2 or GFP (Dharmacon, Chicago, IL, USA). Transient transfections were performed with $3 \mu$ l Fugene6 (Roche, Indianapolis, IN, USA) and $1 \mu \mathrm{g} / \mathrm{ml}$ plasmid DNA. After transfection, the cells were cultured for 24 more hours in conditioned medium, collected from the cultured L-cells, L-cells with Wnt3a or 5a (Invitrogen, Merelbeke, Belgium).

\section{Quantitative PCR and Western blotting}

On the first day, cells were plated in a 12 wells plate and the next day, at $70 \%$ confluence; these cells were either transfected or treated with a calcium agonist, BayK8644 or calcium antagonist, ( \pm )-verapamil hydrochloride. RNA was isolated using the Trizol method (Invitrogen, Merelbeke, Belgium), and RNA levels and purity 
were defined before cDNA preparation. For the RT-PCR, the iscript ${ }^{\mathrm{TM}}{ }_{\mathrm{CDNA}}$ synthesis kit (Bio-Rad, Hercules, CA, USA) was used. With quantitive PCR, the most prominent Frizzleds and Wnts were determined, as also the co-receptors LRP5/6. We also looked into the signal transduction cascade with Dvl 1-2-3 and to the alternative Wnt receptor, ROR2. Rat cyclophilin served as the house keeping gene (Primer sequences in Table 1).

Table 1: Primers

\begin{tabular}{lll}
\hline Genes & Forward primer & Reverse primer \\
\hline Frizzled-1 & AGCAGCACATTCTGAGGGAGGAG & TCTCTCACCCATCAGTCAGTCCAC \\
Frizzled-2 & CTGCACTCGTGGAGGAAGTTC & TTCACACGGTGGTCTCTCCAT \\
Frizzled-4 & TGCCAGAACCTCGGCTACA & ATGAGCGGCGTGAAAGTTGT \\
ROR2 & GCGAGGCCATCAGCTG & TGGAACTGTGTGACGTACCC \\
Wnt3a & ACAGCCTGGCCATCTTTGG & GGCATGGACAAAGGCTGACT \\
Wnt5a & GTCAACAGCCGCTTCAACTCC & CTCGCAGCCGTCCATCCC \\
Dvl 1 & CCTTCCATCCAAATGTTGCT & GTGACTGACCATAGATCTG \\
Dvl 2 & ACTGGTGCGGTCTAGGTTTTGA & GGAAGACGTGCCCAAGGA \\
Dvl 3 & AGGGCCCCTGTCCAGCT & AAAAGGCCGACTGATGGAGA \\
B-catenin & GTTAAACTCTGCACCCACCAT & TGTCGTGGAATAGCACCCT \\
Cyclophilin & TTCCTCCTTTCACAGAATTATTCCA & CCACCAGTGCCATTATGG \\
LRP 5 & CTATCCGCAGGGCGTACCTG & CGAGTCACCTCAATTCTGTCAG \\
LRP 6 & AGTCAGAAGAGCGCCATCAAC & CCGAAGGCTGTGGATAGGAA \\
\hline
\end{tabular}

Forward and reverse sequences of all primers stated in this chapter.

For Western blot, cell pellets were placed in $500 \mu$ ice-cold Laemmli buffer $(6.6 \%$ glycerol, $1.5 \% \mathrm{SDS}, 4.15 \mathrm{mmol} / \mathrm{I} \mathrm{Tris} / \mathrm{HCl}, \mathrm{pH}=8.0$ ) and homogenized. After 30min on ice and centrifugation, the supernatans was collected and protein content was measured using the BCA protein assay (Pierce Biotechnology Inc., Rockford, IL, USA); $10 \mu \mathrm{g}$ of total protein was denatured by boiling in Laemmli sample buffer (BioRad, Hercules, CA, USA) separated on a 10\% SDS-page gel, and transferred onto a Hybond $\mathrm{C}$ nitrocellulose membrane (Amersham Biosciences, Little Chalfont, United Kingdom). After blocking ( $5 \%$ non-fat dry milk (BioRad), $0.1 \%$ Tween in TBS) for $1 \mathrm{~h}$, membranes were incubated overnight at $4^{\circ} \mathrm{C}$ with primary antibodies directed against $\beta$-catenin 1/2000, GSK-3 $\beta$ total and active $1 / 1000$ (BD Biosciences, Franklin Lakes, NJ, USA) and GAPDH 1/2000 (Sigma, Bornem, Belgium). Anti-rabbit or antimouse immunoglobulin G $1 / 5000$ (Vector Labs Inc.) was used as the secondary antibody, and the membranes were developed using the Supersignal West Pico chemiluminescence kit (Pierce). Images of the blots were analyzed with image analysis software (Qwin Leica, Cambridge, United Kingdom). 
For the luciferase experiments, the cells were additionally transfected with a TOPFlash construct, 16 TCF/LEF binding sites cloned into the Mlu1 site of a pTA-Luc vector, kindly provide by Dr. J. Nathans. Luciferase activity was measured using a luciferase assay system (Promega, Madison, WI, USA).

\section{Statistical analysis}

All values are shown as mean \pm S.E.M. Differences between groups were examined for statistical significance using two-way ANOVA with the Bonferroni posthoc-test (Graph Pad Prism). A $P$ value less than 0.05 was considered to indicate a statistically significant difference.

\section{Results}

\section{The Wnt protein}

\subsection{Conditioned medium}

We first studied the reliability of the TOPFlash construct. This construct consists out of 16 TCF repeats with a luciferase cassette. So, when $\beta$-catenin goes to the nucleus and binds to TCF, it also binds to the 16 TCF repeats transfected into the cell line and luciferase is expressed. A FOPFlash construct, with a mutant in the transcription site was studied as a negative control. With this construct no luciferase expression was observed, indicating the specificity of the TOPFlash construct (Not shown).

We then used this TOPFlash construct to look at the transfection procedure. We tested empty vector transfection and the influence of the transfection agent. These conditions had no influence on the luciferase activity (Not shown).

Like others, we initially used conditioned Wnt medium. However, as there is no quantification method to measure the amount of Wnt protein present in the medium, different batches of conditioned medium may well have varying amounts of protein, which may lead to varying results. We have approached this problem as follows. We compared the results from the luciferase assays done with different dilutions of conditioned medium of Wnt3a with the results obtained from using a concentration gradient of recombinant Wnt3a protein. The $\mathrm{EC}_{50}$ value for rWnt3a was $5,8 \cdot 10^{-9} \mathrm{M}$, which is comparable to a 20 fold dilution of the conditioned medium. All of the conditioned medium batches used were calibrated this way to guarantee the use of equal amounts of Wnt protein in all experiments. For all of the following experiment; Wnt3a was used in a $1.10^{-8} \mathrm{M}$ concentration (Fig 1). 


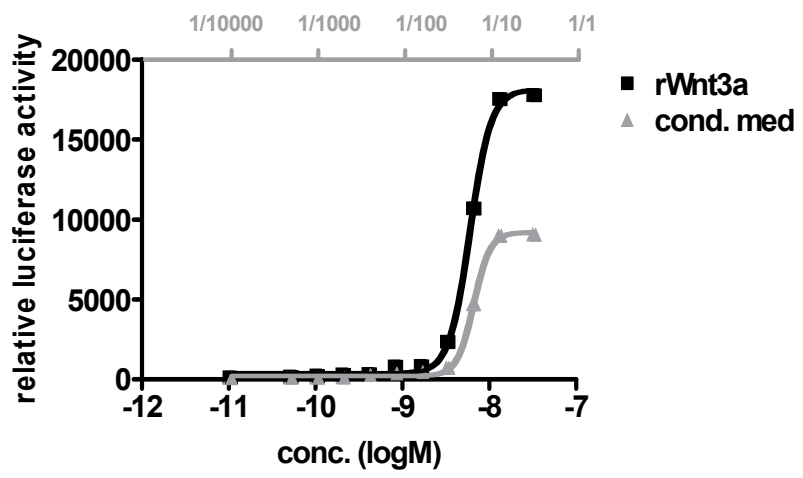

Fig 1: The $\beta$-catenin dependent signaling as determined with the luciferase read-out in HEK cells. This concentration curve compares rWnt3a concentrations with different dilutions of the conditioned medium. (X-axis below is for $\mathrm{rWnt3a}$, X-axis above is for the conditioned medium, with different dilution steps). Data presented are the means of 6 independent experiments and shown with standard error of the mean (SEM).

\subsection{Wnt3a inhibition by Wnt5a}

For both Wnt3a and Wnt5a, concentration effect curves were recorded. At any concentration did Wnt5a show $\beta$-catenin dependent activity (Not shown).

On the other hand, we observed a clear concentration dependent inhibitory effect of Wnt5a on the $\beta$-catenin dependent activity of Wnt3a (Fig 2). This is in accordance with a report of Mikels et al. ${ }^{16}$, stating that Wnt5a has an antagonistic effect on the $\beta$-catenin dependent activity of Wnt3a.

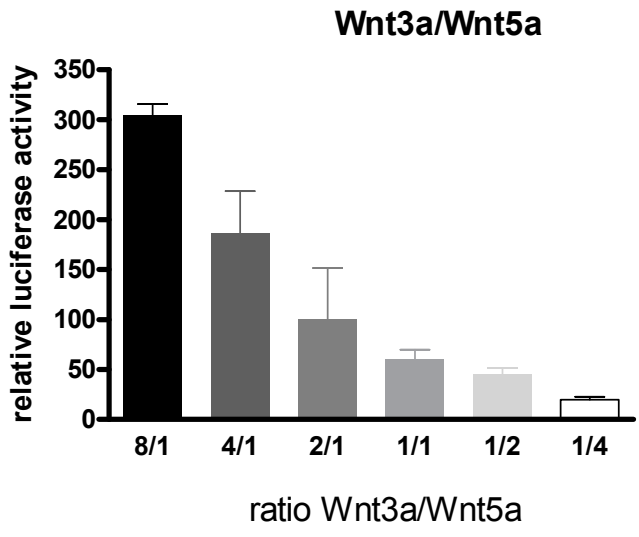

Fig 2: Competition between Wnt3a and Wnt5a for the activation of $\beta$-catenin dependent signaling. The data indicated that Wnt5a is an inhibitor of the $\beta$-catenin dependent activity of Wnt3a. On the X-axis are the ratios of Wnt3a/Wnt5a. Data presented are the means of 6 independent experiments and shown with SEM. 


\subsection{The pharmacology of 11 Wnts in combination with rFzd-1 and rFzd-2}

The most commonly studied Wnts are Wnt3a and Wnt5a. To study the pharmacology of rFzd-1 and rFzd-2 more completely, we included Wnt 1, 2, 3, 4, 5b, $6,7 \mathrm{a}, 7 \mathrm{~b}$ and $10 \mathrm{a}$ in our experimental set-up. In order to be able to compare the results obtained with the different Wnts, we used transfection of Wnt constructs, also for Wnt3a and 5a. Both rFzd-1 and rFzd-2 showed the same patterns of activation (Fig 3A-B). Wnt1, 3a, 3 and 10a are clearly $\beta$-catenin dependent, whereas Wnt $2,4,5 a / b, 6$ and $7 a / b$ are $\beta$-catenin independent when tested on $r F z d-1$ and rFzd-2.

rFzd-1

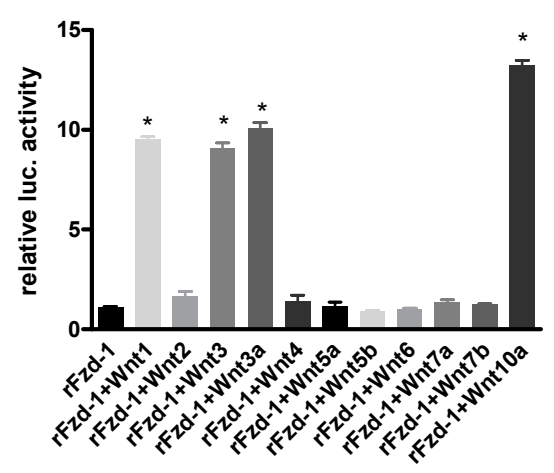

rFzd-2

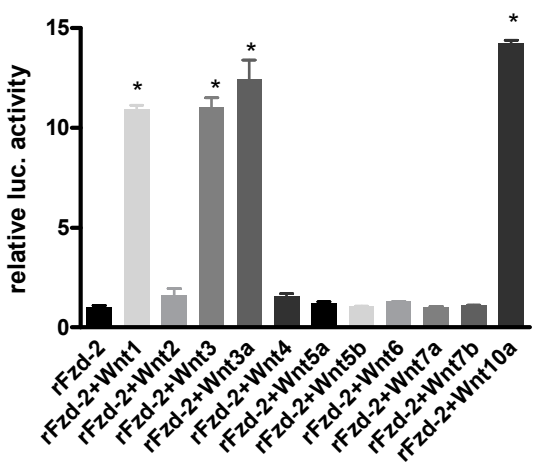

Fig 3: Activation of $\beta$-catenin dependent signaling by different Wnts. The panels show the combinations of rFrizzled-1 and rFrizzled-2 with eleven different Wnts. This luciferase experiment indicated that Wnt1, 3, 3a and 10a, are $\beta$-catenin dependent Wnts. Data presented are the means of 6 independent experiments and shown with SEM ( $* 0<0.001$ in comparison to control).

\section{The Frizzled receptor}

\subsection{Species differences in Frizzled-1 and -2}

We studied some aspects of Fzd-1 and Fzd-2, in combination with two Wnts, i.e. the $\beta$-catenin dependent Wnt3a and the $\beta$-catenin independent Wnt5a. For some first experiments, we used rat Fzd. As shown in Fig 4A; control, being empty vector transfection, and the receptors $\mathrm{rFzd}-1$ and $\mathrm{rFzd}-2$ without Wnt proteins, had no effect. Wnt3a, on the other hand, significantly increased luciferase activity, whereas $W n t 5 a$ had no effect on the $\beta$-catenin dependent pathway. Also in the absence of rFzd-1 or rFzd-2, Wnt3a showed an effect on the $\beta$-catenin dependent activity, which is due to the presence of endogenous receptors (this chapter: Fig $4 \mathrm{C}$ and section 4.2). This confirmed literature data that showed that Wnt3a is a $\beta$-catenin dependent $W n t$, where $W n t 5 a$ is a $\beta$-catenin independent $W_{n t}{ }^{17,18}$. Wnt5a still exerted no effect after additional transfection of either Fzd-1 or Fzd-2. The effect of 
Wnt3a on endogenous Fzds was also seen with additional transfection of Frizzled-1 and was even enhanced after additional transfection of Fzd-2.

A

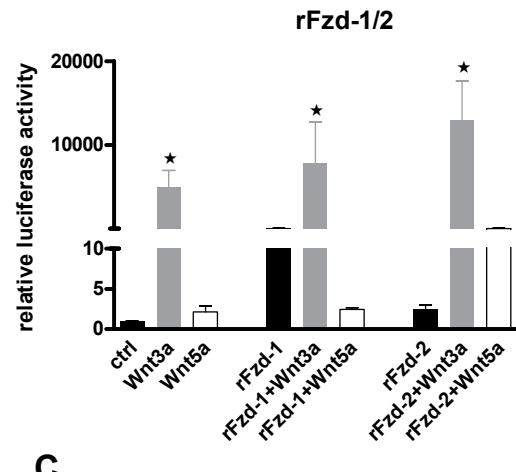

C

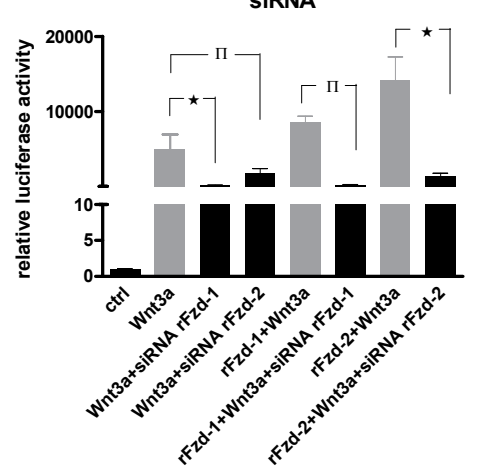

B

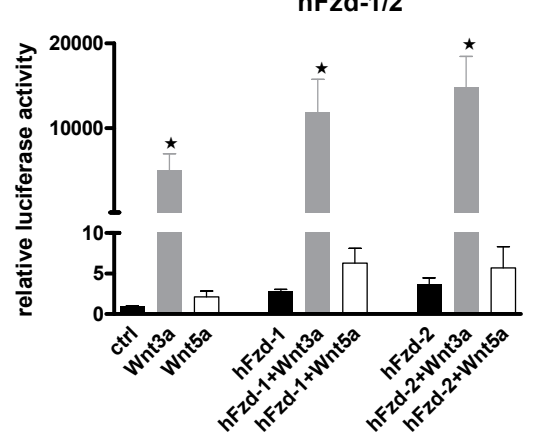

Fig 4: A. The effect of rat Frizzled-1 and -2 on luciferase activity, either alone or in combinations with the two classes of Wnt proteins. These results confirm that Wnt3a is a $\beta$-catenin dependent Wnt, where Wnt5a is $\beta$-catenin independent B. Data found with rat Fzds were confirmed with human Fzds. C. The activity of Wnt3a, without additional transfection of an Fzd, was examined. The results with siRNAs indicated that this basal activity of the ligand alone was indeed the consequence of the presence of endogenous Frizzleds. Data presented are the means of 6 independent experiments in HEK cells and shown with SEM ( ${ }^{*} p<0.001$ in comparison to control or as indicated and ${ }^{n} p<0.01$ ).

Whereas Frizzleds are well preserved receptors throughout the animal kingdom, there are slight differences between mouse, rat and human Frizzleds. Therefore, we repeated the first series of experiments done with rat receptors also with human and mouse receptors. As shown in Fig 4B, the human receptors had the same activation pattern as the rat receptors; this pattern was also shown by the mouse receptors (Not shown).

To further confirm that increased activity after Wnt3a addition is due to the presence of endogenous receptors, we used siRNAs for both Fzd-1 and Fzd-2. Fig 4C shows that siRNAs block the effects of endogenous receptors. The specificity of 
these siRNAs was tested on qPCR in cells overexpressing either rFzd-1 or rFzd-2. GFP-siRNA, used as a negative control, exerted no effect on the luciferase activity (Not shown).

\section{2 hFrizzled-4 and hFrizzled-5}

hFrizzled-4 and hFrizzled-5 were also studied as described above for rFzd-1 and rFzd-2. These experiments indicated that hFzd-4 and hFzd-5, when combined with Wnt5a, do not activate the $\beta$-catenin dependent pathway (Fig 5A/B). Wnt3ainduced activation of luciferase expression was significantly lower in HEK cells transfected with hFzd-4 or hFzd-5, compared to untransfected Wnt3a controls (Fig $5 A / B)$. This indicates that both hFzd-4 and hFzd-5 do not activate $\beta$-catenin dependent signaling upon Wnt3a and Wnt5a activation.

A

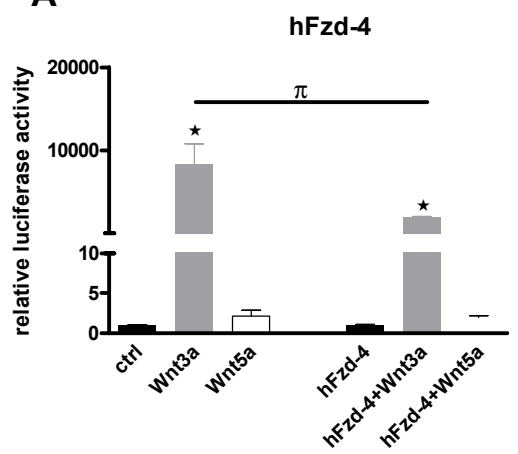

B

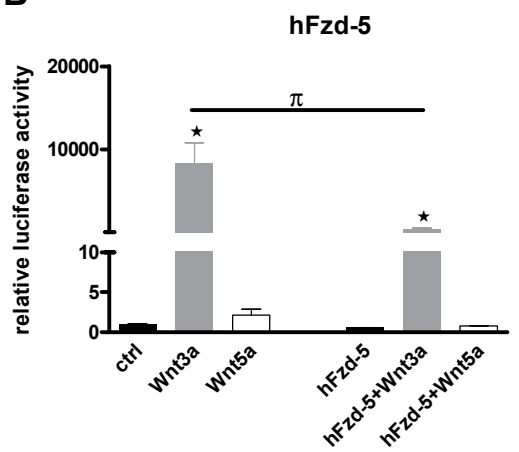

Fig 5: Examination of the luciferase activity of hFzd-4 and hFzd-5 in combination with Wnt3a and Wnt5a A. The influences of hFzd-4 in combination with the two classes of Wnt proteins. These results confirm that Wnt3a is a $\beta$-catenin dependent Wnt, and Wnt5a is not. B. Data found with hFzd-5. Same pattern could be found as for Fzd-4. Data presented are the means of 6 independent experiments and shown with SEM ( ${ }^{*} p<0.001$ in comparison to control or as indicated and $\left.{ }^{n} p<0.01\right)$.

\section{The co-receptor LRP5/6}

As stated in the Introduction, not only the Wnt/Fzd complex plays an important role in the activation of the $\beta$-catenin dependent pathway, but also the co-receptors LRP5/6. The literature is not consistent about the involvement of these coreceptors; it is not clear whether the co-receptor alone can signal or that the intracellular part or the extracellular part of the co-receptor is important for signaling.

We used three different constructs, i.e. LRP5, LRP6 and one, lacking the intracellular part, i.e. LRP $6 \triangle \mathrm{C}$. Fig 6 shows our data obtained on the $\beta$-catenin dependent signaling for Fzd-2 with Wnt3a, when combined with the three LRPs. These results 
show that LRP5 and LRP6 exhibited the same synergistic effect on Fzd-2 with Wnt3a addition, namely an increase of the $\beta$-catenin dependent signaling. LRP $6 \triangle C$, on the other hand, had no clear effect on the $\beta$-catenin dependent signaling after $\mathrm{rFzd}-2$ transfection with Wnt3a addition.

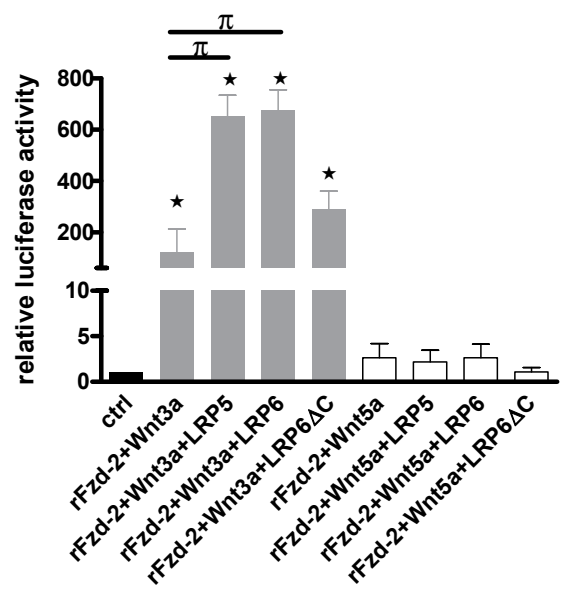

Fig 6: The effects of overexpression of the coreceptors LRP5, LRP6 and LRP6 $\triangle C$; on the $\beta$-catenin dependent activity of $\mathrm{Wnt} 3 \mathrm{a}$ and $\beta$-catenin independent activity of Wnt5a were tested in combination with rFzd-1 and rFzd-2. Full length LRP5/6 increased luciferase activity upon Wnt3a stimulation, but not upon Wnt5a stimulation. LRP $6 \Delta C$ only slightly increased luciferase activity upon Wnt3a stimulation and had no effect on Wnt5a stimulation. Data presented are the means of 6 independent experiments and shown with SEM $(* p<0,001$ in comparison to control and ${ }^{\pi} p<0.001$ in comparison to rFzd-2+Wnt3a).

Furthermore, we tested whether LRPs could influence the $\beta$-catenin dependent signaling capacity of Wnt5a. The results of these tests employing rFzd- 2 with Wnt5a in combination with a co-receptor indicated that the presence of LRPs had no influence on the type of signaling pathway. All these experiments were repeated for rFzd-1 and similar patterns could be observed as for rFzd-2 (Not shown).

\section{Differences between cell lines}

\subsection{Activation of the B-catenin dependent pathway}

The majority of the in vitro studies in the Wnt/Fzd field have been conducted in the HEK cell line (Fig 7A). The cells of this line are easy to culture and to transfect. Nevertheless, there are indications that the pharmacology and signal transduction pathway are dependent upon the cell line used ${ }^{14,15}$. To clarify this issue of cell line specificity, we studied three cell lines, i.e. HEK cells, $\mathrm{CHO}$ cells and COS-7 cells. These cells are all easy to culture and to transfect. In Fig 7B, the results of a luciferase experiment performed in the $\mathrm{CHO}$ cell line, as measurement for $\beta$-catenin dependent activity, are shown. As seen with the HEK cell line, the calcium agonist, BayK8644 and antagonist, ( \pm )-verapamil hydrochloride had, as expected, no influence on $\beta$-catenin dependent activity in CHO cells. B-catenin and the GSK-3 $\beta$ inhibitor valproate showed a remarkable increase in luciferase activity, which was also seen when Wnt3a was tested with or without receptors additionally 
transfected. On the other hand, Wnt5a acted clearly also in this cell line as a $\beta$ catenin independent Wnt.

A

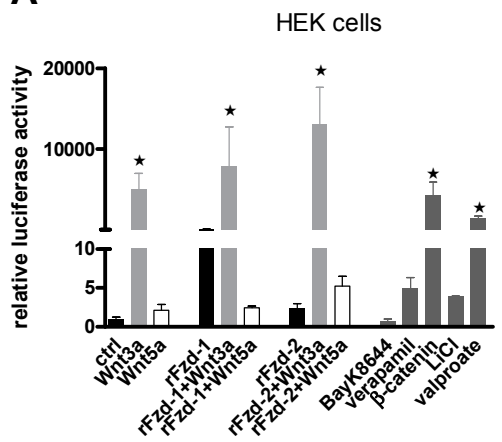

C

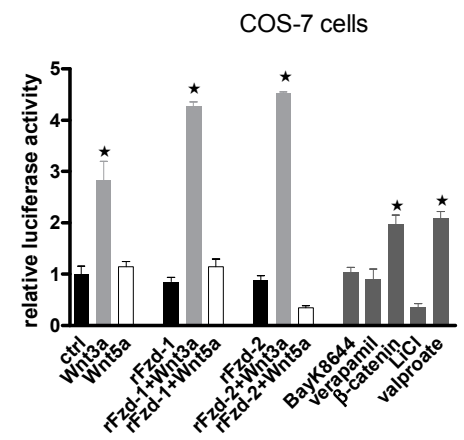

B

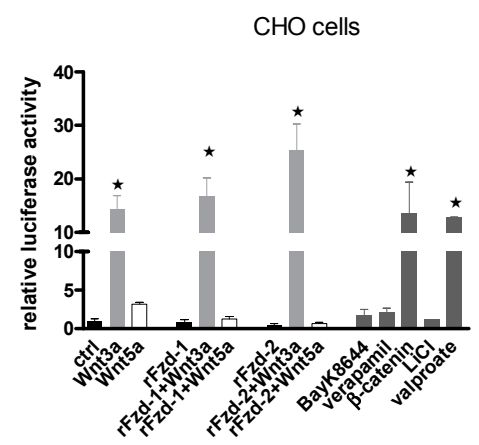

Fig 7: The luciferase read-out for A. HEK cells. B. $\mathrm{CHO}$ cells and C. COS-7 cells. The influences of Wnt3a and Wnt5a on the $\beta$-catenin dependent pathway were tested in combination with rFzd-1 and -2 overexpression, as were different components of the downstream pathway of Wnt/Fzd. Data presented are the means of 6 independent experiments and shown with SEM.

The third and last cell line tested was one from the kidney of an African green monkey (COS-7). This cell line showed the same activation pattern as the other two ones (Fig 7C). The level of luciferase activity was however, remarkably higher in the HEK cells than the $\mathrm{CHO}$ cells; these cells had on their turn higher levels than the COS-7 cells. To find whether these differences could be explained by varying mRNA and protein levels of the Wnt/Frizzled signal transduction components, some qPCRs and Western blots were performed.

\subsection{Endogenous Fzds}

As stated above, we assume that the basal activity we observed upon using the Wnt proteins alone is probably due to the presence of endogenous receptors. To corroborate this assumption, we collected mRNA samples of the three cell lines 
discussed above and compared their amount of endogenous Frizzleds. All cell lines expressed both Fzd-1 and -2 at a relatively high level. The only other detectable Fzd receptor was Fzd-4 (Fig 8).

It is only lately that many groups are focusing on a newly identified Wnt receptor, called ROR2. As expected, also this receptor was present in all cell lines, but again no difference in expression levels between the cell lines was measured (Fig 8).

We subsequently studied the co-receptors low density lipoprotein receptor $5 / 6$ (LRP5/6). Whereas here too, no difference between the cell lines could be found, we observed yet in all of these cell lines a higher amount of LRP5 than of LRP6 (Fig 8).

Fzd-1

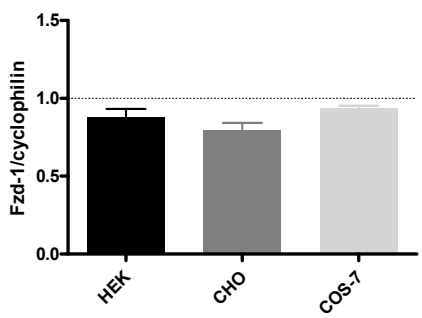

Fzd-4

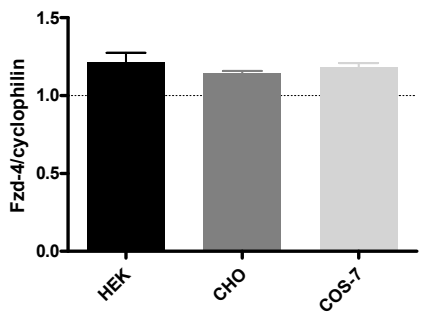

LRP5

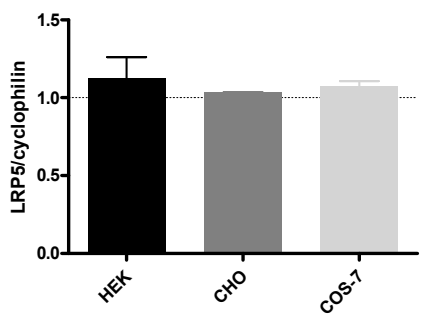

Fzd-2

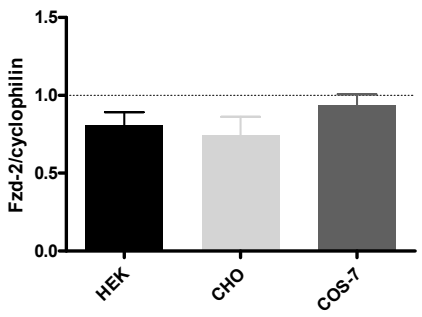

ROR2

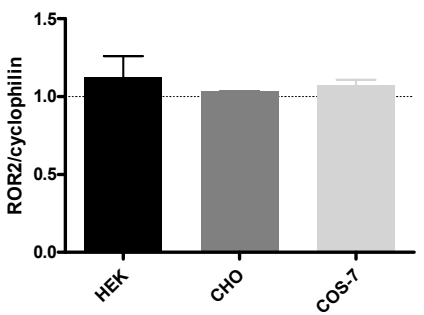

LRP6

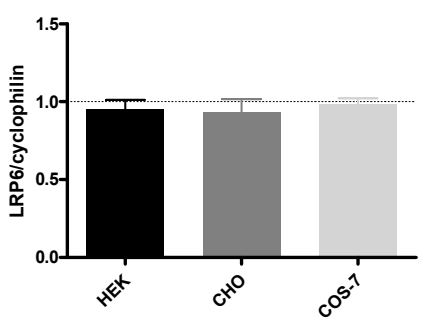

Fig 8: The qPCR results on the presence of endogenous Wnt receptors in three cell lines namely; HEK, $\mathrm{CHO}$ and COS-7. All detectable Fzds are depicted, as also the other Wnt receptors, ROR2, LRP5 and LRP6. No significant differences between the cell lines could be detected. Data presented are the means of 6 independent experiments and shown with SEM. 
To see whether there is a difference at the level of the Wnt expression in these cell lines, we determined the presence of Wnt3a and its inhibitor Wnt5a. However, no differences between the cell lines were found on mRNA level (Not shown).

\subsection{The signal transduction cascade}

\subsection{1 qPCR results}

As stated above, we hypothesize that one of the possible explanations for the observed differences of luciferase activity might be at the level of signal transduction components. We therefore looked into dishevelled mRNA levels. This protein is one of the most upstream intracellular components of the Wnt/Fzd signal transduction pathway to be activated. We examined the levels of Dvl 1, 2 and 3. Dvl 1 expression, however, was too low to be detected. The observed levels of Dvl 2 and Dvl 3, indicated that cell lines with higher levels of Dvl 2 and Dvl 3 also have higher luciferase activity (Fig 9). This confirms the notion that Dvl 2 and Dvl 3 are central components in the activation of the $\beta$-catenin dependent pathway.

Dvl 2

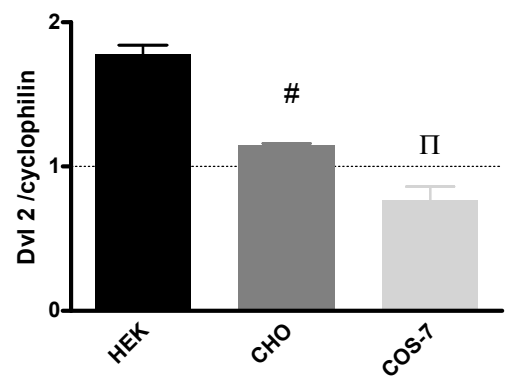

Dvl 3

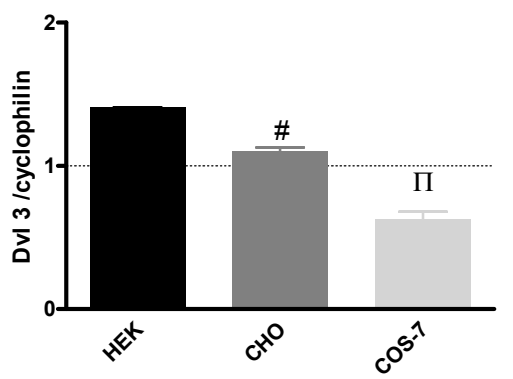

Fig 9: The levels of a signaling component of the Wnt/Fzd pathway, namely Dvl, determined by qPCR in the three cell lines; HEK, CHO and COS-7. Dvl 2 is depicted on the left, Dvl 3 on the right. Dvl 1 was too low to detect. All these data were corrected for the housekeeping gene cyclophilin. The graphs showed reduced Dvl 2 and 3 levels in CHO and COS-7, compared to HEK293. Data presented are the means of 6 independent experiments and shown with SEM ( ${ }^{\#} p<0.05$ and $\left.{ }^{\pi} p<0.01\right)$.

\subsubsection{Western blotting}

Because mRNA levels are not always a good measure of the corresponding protein levels, the proteins levels of GSK-3 $\beta$ and $\beta$-catenin were examined by Western blotting. $\beta$-catenin levels in the HEK cell line were first examined under different conditions and later on confirmed and compared to the corresponding protein levels in other cell lines. In all the conditions with the $\beta$-catenin dependent ligand Wnt3a, namely Wnt3a, Fzd-1+Wnt3a and Fzd-2+Wnt3a; $\beta$-catenin protein levels were upregulated (Fig 10A). These data were confirmed by transient transfection of the $\beta$-catenin construct which also increased $\beta$-catenin protein levels, as expected. 
The $\beta$-catenin independent Wnt5a, either alone or in combination with Fzd-1 or Fzd2 showed even the opposite effect, with a decreased level of $\beta$-catenin.

Next, we examined the ratio between active and total GSK-3 $\beta$. As expected, this ratio showed that the higher the amount of active GSK-3 $\beta$ was, the less $\beta$-catenin was measured (Fig 10B).

A

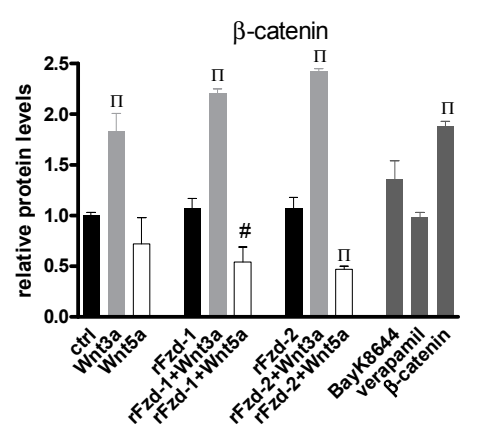

B

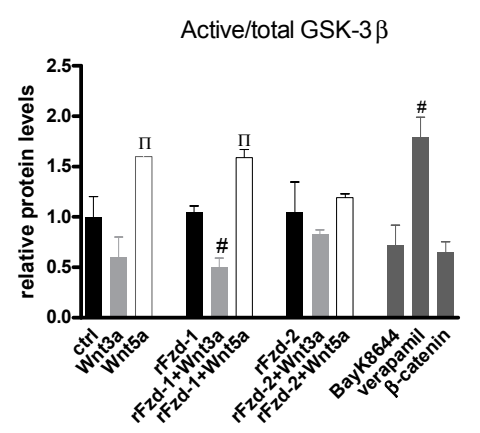

Fig 10: Determination of amounts of $\beta$-catenin and GSK-3 $\beta$ protein in HEK cells using Western blot. Activation of the $\beta$-catenin dependent pathway by either Wnt3a or $\beta$-catenin resulted in an increased amount of $\beta$-catenin and decreased GSK-3 $\beta$ activity. All data were corrected with the protein content of GAPDH, the house keeping protein. Data presented are the means of 6 independent experiments and shown with SEM ( ${ }^{\#} p<0.05$ and $\left.{ }^{\pi} p<0.01\right)$.

These data in combination with previously found mRNA results, confirmed that Wnt3a acts as a $\beta$-catenin dependent Wnt, whereas Wnt5a is a $\beta$-catenin independent Wnt. Both pathways have clearly separated components.

Furthermore, we looked whether the protein data obtained in the HEK cell line for the ratio active/total $\beta$-catenin and GSK-3 $\beta$ were comparable to those of the two other cell lines, $\mathrm{CHO}$ and COS-7. These results were indeed confirming our notion that, independent of the cell line, Wnt3a is $\beta$-catenin dependent (Not shown).

The differences in the mRNA levels observed in Dvl 2 and Dvl 3 correspond with the differences observed in the protein levels of these cell lines: $\mathrm{CHO}$ showed lower protein levels of the $\beta$-catenin dependent components GSK-3 $\beta$ and $\beta$-catenin than HEK, explaining the lower activities measured in the former cell line. COS-7, in its turn, had even lower levels than $\mathrm{CHO}$.

\section{Discussion}

Whereas the $\beta$-catenin dependent pathway has been extensively studied, little is known about the nature of the Wnt-Fzd interaction, the involvement of the co- 
receptors in this interaction and the possible differences between species with regard to mRNA and protein levels of signaling components ${ }^{19,20}$. In this study, we have provided evidence supporting the following conclusions: a) in combination with Fzd-1 and Fzd-2 only a minority of the Wnts, namely Wnt1, Wnt3, Wnt3a and Wnt10a, are $\beta$-catenin dependent, b) co-receptors facilitate the binding of Wnts to Fzds and c) $\beta$-catenin dependent signaling is independent of the species.

The TOP- and FOPFlash constructs are a widespread screening tool in the Wnt/Fzd field to look into the $\beta$-catenin dependent pathway ${ }^{21}$. Currently, Wnt conditioned medium is being used in order to avoid a further transfection load in the cell line and to minimize aspecific effects ${ }^{11,18}$. However, this conditioned medium is used without proper quantification. Therefore, we quantified the protein content in the medium by correlation studies using recombinant Wnt3a.

In this chapter, we observed a clear concentration dependent $\beta$-catenin activation by Wnt3a and a dose dependent inhibition of the Wnt3a activity upon Wnt5a addition. This is in accordance by a report of Mikels et al. ${ }^{16}$, stating that Wnt5a has an antagonistic effect on the $\beta$-catenin dependent activity of Wnt3a.

Next, we examined eleven Wnt constructs, i.e. Wnt 1, 2, 3, 3a, 4, 5a-b, 6, 7a-b and 10a, in the HEK cell line. Only Wnt1, Wnt3, Wnt3a and Wnt10a could stimulate the $\beta$-catenin dependent signaling. What remains to be done is to determine which of the $\beta$-catenin independent pathways are involved upon receptor activation by Wnts that do not stimulate the $\beta$-catenin dependent signaling ${ }^{22}$.

On basis of the mRNA screening, it was clear that both Fzd-1 and Fzd-2 are abundantly present in the three cell lines studied, CHO, COS-7 and HEK, explaining the basal activity of Wnt3a. This finding was confirmed by knock-down experiments using siRNAs.

Literature mentioning the use of overexpressing Frizzled systems are not always specific on the species of the receptor used ${ }^{23}$. To find out whether conflicting literature data are due to species differences, we compared rat, mouse and human receptors in a $\beta$-catenin dependent activation system in the HEK cell line. Our data indicated that Frizzleds from different species are similar with respect to activation of the $\beta$-catenin dependent activation

Conflicting results were also found with regard to the contribution of the coreceptors $L R P 5 / 6^{24-27}$. Our results indicate that the potency of LRP6 is equal to that of LRP5 in the HEK cell line. Indeed, full length LRP5 and LRP6 increased Wnt3a mediated TCF/LEF activity, whereas the intracellular part is not necessary for signaling. These results are in agreement with data presented by Mi et al. ${ }^{26}$.

The last aspect we studied was the possible difference between cell lines. Therefore, we repeated the experiments using Frizzled-1 and Frizzled-2 in combination with either Wnt3a or Wnt5a, in two other cell lines, namely Chinese hamster ovary cells, $\mathrm{CHO}$ and African kidney green monkey cells, COS-7. After validation of the luciferase system, Fzd-1 and -2 were examined with the $\beta$-catenin 
dependent Wnt3a and $\beta$-catenin independent Wnt5a. These experiments confirmed literature data, stating that upregulation of nuclear $\beta$-catenin occurs upon Wnt3a stimulation and that no significant differences are observed in activation of the $\beta$ catenin dependent pathway upon Wnt5a addition ${ }^{28}$. Our findings were also cell line independent. Furthermore, Wnt3a alone and without additional transfection of an Fzd, showed already an upregulation of luciferase activity. qPCR experiments revealed that both Fzd-1 and -2 are abundantly present in all cell lines, explaining the basal activity of Wnt3a, albeit with a different maximal activation level.

We also looked into other Wnt receptors, like Fzd-4 and ROR2. Both appeared to be equally present in all of these cell lines. The co-receptors LRP5 and LRP6, responsible for the amplification of the Wnt signal ${ }^{22}$, were also equally expressed in all these cell lines. Therefore, a possible explanation for the conflicting literature data has to be sought more downstream in the signaling pathway. To that end, we looked first at the endogenous amounts of the signaling protein $\mathrm{Dvl}^{29}$. Significantly higher amount of DVl 2 and 3 were present in HEK than in the other cell lines, and more in $\mathrm{CHO}$ than COS-7.

The results obtained with qPCRs were further confirmed by Western blotting. Protein levels of the more downstream elements GSK-3 $\beta$ and $\beta$-catenin revealed a linear correlation between luciferase activity and the presence of these signal components $^{30,31}$. The Western blotting also confirmed earlier observations that Wnt3a is a $\beta$-catenin dependent Wnt and Wnt5a a $\beta$-catenin independent Wnt.

These results indicate that of the cell lines studied the HEK cell line is for two reasons the screening tool of choice for the exploration of Wnt/Frizzled interactions. It features the adequate presence of all of the central components of the Wnt/Fzd signal transduction cascade. This is of importance as low levels of signal transduction components might lead to false negative results. Secondly, these cells are easy to transfect and to culture.

Low levels of signal transduction components partially explain the conflicting literature data found. To address this issue, one should transfect the Dvl 2 and Dvl 3 in $\mathrm{CHO}$ and COS-7 cells and compare the resulting luciferase activity. If this activity changes by transfection, one than could conclude that Dvl is indeed the determining factor in the diminished luciferase activity.

In this chapter, we provide some more insight into the $\beta$-catenin dependent pathway activation in Fzd-1 and -2 transfected cells. Wnt 1, 3, 3a and 10a are $\beta$ catenin independent Wnts in combination with Fzd-1 and -2; co-receptors can augment this effect provided that adequate levels of downstream signaling components are present in the cell.

\section{Funding}

This work was supported by BSIK 03033; Molecular Imaging of Ischemic heart disease. 


\section{References}

1. Mulholland, D.J., Dedhar, S., Coetzee, G.A. \& Nelson, C.C. Interaction of nuclear receptors with the Wnt/beta-catenin/Tcf signaling axis: Wnt you like to know? Endocr Rev 2005; 26:898-915.

2. Moon, R.T. Wnt/beta-catenin pathway. SCi STKE 2005.

3. Kohn, A.D. \& Moon, R.T. Wht and calcium signaling: beta-Catenin-independent pathways. Cell Calcium 2005;38:439-46.

4. Wang, Y. \& Nathans, J. Tissue/planar cell polarity in vertebrates: new insights and new questions. Development 2007;134:647-58.

5. Logan, C.Y. \& Nusse, R. The Wnt signaling pathway in development and disease. Annu Rev Cell Dev Biol 2007; 20:781-810

6. He, X., Semenov, M., Tamai, K. \& Zeng, X. LDL receptor-related proteins 5 and 6 in Wnt/beta-catenin signaling: arrows point the way. Development 2004;131:1663-77.

7. Binnerts, M.E. et al. R-Spondin1 regulates Wnt signaling by inhibiting internalization of LRP6. Proc Natl Acad Sci U S A 2007;104:14700-5.

8. Dann, C.E. et al. Insights into Wnt binding and signalling from the structures of two Frizzled cysteinerich domains. Nature 2001;412:86-90.

9. Li, Y., Cam, J. \& Bu, G. Low-density lipoprotein receptor family: endocytosis and signal transduction. Mol Neurobiol 2001;23:53-67.

10. Holmen, S.L., Salic, A., Zylstra, C.R., Kirschner, M.W. \& Williams, B.O. A novel set of Wnt-Frizzled fusion proteins identifies receptor components that activate beta -catenin-dependent signaling. $J$ Biol Chem 2002;277:34727-35.

11. Green, J.L., Kuntz, S.G. \& Sternberg, P.W. Ror receptor tyrosine kinases: orphans no more. Trends Cell Biol 2008;18:536-44.

12. Mikels, A., Minami, Y. \& Nusse, R. The Ror2 receptor requires tyrosine kinase activity to mediate Wnt5a signaling. J Biol Chem 2009;284:30167-76.

13. Sato, A., Yamamoto, H., Sakane, H., Koyama, H. \& Kikuchi, A. Wnt5a regulates distinct signalling pathways by binding to Frizzled2. EMBO J 29:41-54.

14. $\mathrm{Xu}, \mathrm{Q}$. et al. Vascular development in the retina and inner ear: control by Norrin and Frizzled-4, a high-affinity ligand-receptor pair. Cell 2004;116:883-95.

15. Cheng, C.W., Yeh, J.C., Fan, T.P., Smith, S.K. \& Charnock-Jones, D.S. Wnt5a-mediated non-canonical Wnt signalling regulates human endothelial cell proliferation and migration. Biochem Biophys Res Commun 2008;365:285-90.

16. Mikels, A.J. \& Nusse, R. Purified Wnt5a protein activates or inhibits beta-catenin-TCF signaling depending on receptor context. PLoS Biol 2006;4:e115.

17. Cadigan, K.M. Wnt-beta-catenin signaling. Curr Biol 2008;18:R943-7.

18. Moon, R.T., Bowerman, B., Boutros, M. \& Perrimon, N. The promise and perils of Wnt signaling through beta-catenin. Science 2002;296:1644-6.

19. He, X. \& Axelrod, J.D. A WNTer wonderland in Snowbird. Development 133, 2597-603 (2006).

20. Heeg-Truesdell, E. \& LaBonne, C. Wnt signaling: a shaggy dogma tale. Curr Biol 2006;16:R62-4.

21. DasGupta, R., Kaykas, A., Moon, R.T. \& Perrimon, N. Functional genomic analysis of the Wnt-wingless signaling pathway. Science 2005;308:826-33.

22. Semenov, M.V., Habas, R., Macdonald, B.T. \& He, X. SnapShot: Noncanonical Wnt Signaling Pathways. Cell 2007;131:1378.

23. Cadigan, K.M. \& Liu, Y.I. Wnt signaling: complexity at the surface. J Cell Sci 2006;119: 395-402.

24. Mao, J. et al. Low-density lipoprotein receptor-related protein-5 binds to Axin and regulates the canonical Wnt signaling pathway. Mol Cell 2001;7:801-9.

25. Cong, F., Schweizer, L. \& Varmus, H. Wnt signals across the plasma membrane to activate the betacatenin pathway by forming oligomers containing its receptors, Frizzled and LRP. Development 2004;131:5103-15. 
26. Mi, K. \& Johnson, G.V. Role of the intracellular domains of LRP5 and LRP6 in activating the Wnt canonical pathway. J Cell Biochem 2005;95:328-38.

27. Liu, T. et al. G protein signaling from activated rat frizzled-1 to the beta-catenin-Lef-Tcf pathway. Science 2001;292:1718-22.

28. Yokoyama, N., Yin, D. \& Malbon, C.C. Abundance, complexation, and trafficking of Wnt/beta-catenin signaling elements in response to Wnt3. J Mol Signal 2007;2:11.

29. Lee, Y.N., Gao, Y. \& Wang, H.Y. Differential mediation of the Wnt canonical pathway by mammalian Dishevelleds-1, -2, and -3. Cell Signal 2008;20:443-52.

30. Ferkey, D.M. \& Kimelman, D. GSK-3: new thoughts on an old enzyme. Dev Biol 2000;225:471-9.

31. Cong, F., Schweizer, L., Chamorro, M. \& Varmus, H. Requirement for a nuclear function of betacatenin in Wnt signaling. Mol Cell Biol 2003;23:8462-70. 



\section{Wnt/Frizzled signaling modulates the migration and differentiation of immortalized cardiac fibroblasts}

Laeremans H., Rensen S.S., Ottenheijm H.C.J., Smits J.F.M., Blankesteijn W.M. Accepted: cardiovascular research 


\begin{abstract}
The Wnt/Frizzled signal transduction cascade has been implicated in the proliferation, differentiation and migration of many cell types, but the role of this pathway in cardiac fibroblast differentiation is not known. Our lab previously showed an upregulation of Frizzled-1 and -2 expressions in myofibroblasts after myocardial infarction, indicating a potential role for the Frizzled in the fibroblastsmyofibroblast differentiation. The present study was performed to further define the role of specific Wnt and Frizzled proteins in the proliferation, migration and differentiation of cardiac fibroblasts. Because primary fibroblasts become senescent after a few passages and are difficult to transfect, we immortalized rat cardiac fibroblasts with telomerase (CFIT: cardiac fibroblasts immortalized with telomerase). Proliferation of CFIT was not significantly influenced by Wnt/Frizzled signaling. The migration, however, was attenuated by all Wnt/Frizzled combinations tested. Also, specific Wnt/Frizzled combinations modulated the expression of the following myofibroblast markers: collagen l $\alpha 1$, collagen III, fibronectin and his splice variants, and $\alpha$-smooth muscle actin. The results indicate that myofibroblast migration and differentiation, but not proliferation can be modulated by interventions in Wnt/Frizzled signaling. Therefore Wnt/Frizzled signaling may serve as a novel therapeutic target to ameliorate wound healing after myocardial infarction.
\end{abstract}

\title{
Keywords
}

Myofibroblast; heart; Wnt/Frizzled signaling; differentiation; migration 


\section{Introduction}

Myocardial infarction (MI) is one of the main causes of mortality and morbidity in Western countries. Many patients survive the acute phase after MI as a result of improved treatment. Therefore, more patients enter the wound healing phase after MI. In this process the dead cardiomyocytes are replaced by granulation tissue, which eventually matures into a scar ${ }^{1,2}$. Inadequate wound healing will lead to dilatation of the heart and loss of cardiac function, resulting in heart failure ${ }^{2,3}$. Because current pharmacological therapies slow down the progressive deterioration of cardiac function but can not reverse this process, the only rational therapy for heart failure is to prevent its development ${ }^{4,5}$.

Myofibroblasts play an important role in wound healing in many organs including the heart ${ }^{6}$. These cells migrate into the infarct area in the second week after MI, where they form granulation tissue. Their contractile properties, combined with their synthesis of extracellular matrix proteins, are thought to prevent infarct expansion ${ }^{7}$. The sustained presence and ongoing activity of myofibroblasts in the scar tissue in a well-healed infarct suggests an important role of these cells in the maintenance of the extracellular matrix that has been deposited in the infarct area $^{8-10}$

The process of differentiation and migration of (myo)fibroblasts in the infarct area is far from completely elucidated. Next to a role for TGF- $\beta$ and mechanical stretch $^{6}$, accumulating evidence suggests a role for Wnt/Frizzled (Fzd) signaling in this context. During their migration into the infarct area, Fzd-1 and -2 and the intracellular signal transduction molecule Dishevelled-1 (Dvl-1) are expressed in myofibroblasts area ${ }^{11,12}$. Moreover, overexpression of soluble Fzd-related protein (sFRP) or the second messenger $\beta$-catenin have been shown to reduce infarct expansion and improve cardiac function after $\mathrm{MI}^{13-16}$.

Wnts are highly conserved secreted glycoproteins, with an important function during development and disease ${ }^{17,18}$. Fzds are the predominant receptors for these Wnt ligands, with a seven transmembrane structure ${ }^{19}$. The Wnt/Fzd signaling is very complex and can be subdivided into $\beta$-catenin dependent and independent pathways $^{20}$. Calcium serves as a second messenger in the latter pathway ${ }^{21-24}$.

The aim of the present study was to further elucidate the role of Wnt/Fzd signaling in the proliferation, differentiation and migration of cardiac (myo)fibroblasts in vitro. So far, this research was hampered by three adverse characteristics of primary cardiac fibroblasts in culture: 1) spontaneous differentiation to myofibroblast phenotype when cultured on rigid culture dishes ${ }^{25}$; 2) poor transfection efficiency ${ }^{26}$; and 3 ) senescence after $\sim 5$ passages ${ }^{27,28}$. To overcome these problems, we have developed an immortalized cardiac fibroblast cell line by stably overexpressing telomerase in these cells ${ }^{29}$. This cell line which we named CFIT (cardiac fibroblasts immortalized with telomerase) exhibits a fibroblast 
phenotype even after multiple passages and shows high transfection efficiency. These characteristics make this cell line an excellent tool to study the effects of Wnt/Fzd signaling on cardiac fibroblast proliferation, migration and differentiation.

\section{Materials and Methods}

\section{$1 \quad$ Materials}

The following chemicals were used ( \pm )-verapamil hydrochloride, a calcium antagonist (Sigma-Aldrich, Saint Louis, IL, USA), and BayK8644 (Bayer, Mijdrecht, The Netherlands), a calcium agonist. For the proliferation assay , 5-bromo-2'deoxyuridine ( $\mathrm{BrdU})$ and $\mathrm{BrdU}$ antibody, diaminobenzidine tetrahydrochloride $(D A B)$, as well as the secondary antibody rabbit-anti-mouse biotin were used (Sigma-Aldrich, Saint Louis, IL, USA). siRNAs directed against Fzd-1 and -2 are all pools obtained from Dharmacon, Chicago, IL, USA. siRNA directed against GFP was used as a negative control. Recombinant Wnt3a (rWnt3a) was obtained from R\&D systems, Abingdon, United Kingdom.

\section{Cell culture and transient transfection}

The development of the CFIT cell line has been described elsewhere ${ }^{29}$. Briefly, cardiac fibroblasts were isolated from male Lewis rats, as previously described ${ }^{30}$ and transfected with the pGRN145 plasmid $^{31}$ containing human telomerase reverse transcriptase (ATCC, Middlesex, UK). These experiments were performed under conditions stated in "the guide for the care and use of laboratory animals published by the US National Institutes of Health (NIH Publication No. 85-23, revised 1996)" and approved by the Universities Ethics Review Board of Maastricht University.

CFIT were cultured in $75 \mathrm{~cm}^{2}$ culture flasks (Costar Corning, Schiphol, the Netherlands) in Dulbecco's modified essential medium with L-glutamine (2mM), $10 \%$ fetal calf serum (Invitrogen, Merelbeke, Belgium), and $50 \mathrm{mg} / \mathrm{ml}$ gentamycin (Sigma-Aldrich). Before starting the experiment, the cell line was treated with plasmocin $25 \mu \mathrm{g} / \mathrm{ml}$ (Invivogen, Toulouse, France) and tested with a mycoalert mycoplasma detection kit (Lonza, Rockland, ME, USA). CFIT were transiently transfected with pcDNA3.1/hygro (Invitrogen, Merelbeke, Belgium) containing either Wnt3a, rFzd-1 or -2, with pcDNA3.0 (Invitrogen) containing $\beta$-catenin or hFzd5 or with siRNA. Transient transfections were performed with Fugene6 (Roche, Indianapolis, IN, USA) and $1 \mu \mathrm{g} / \mathrm{ml}$ plasmid DNA. After transfection, the cells were cultured for 2 more days, before the experiments started. Conditioned medium was collected from the L-cells that stably overexpress either Wnt3a or 5a (Invitrogen), as described previously ${ }^{32,33}$. Conditioned medium from unmanipulated L-cells was used 
as control. A TOPFlash luciferase assay (See "Calcium and luciferase assay") was used to calculate the amount of Wnt in the conditioned medium. We constructed a calibration curve generated with purified recombinant Wnt3a protein and compared the luciferase activity of our conditioned medium with it. This procedure was repeated for all new batches to guaranty the use of equal amounts of Wnt3a protein in all experiments. For all experiment a final Wnt concentration of $1.10^{-8} \mathrm{M}$ was used.

\section{Proliferation assay}

On the first day, cells were plated and the next day, at $70 \%$ confluence, these cells were transfected or treated. Proliferation rates were measured after 48hours with a BrdU incorporation assays. Cells were incubated with $100 \mu \mathrm{M}$ BrdU for 1 hour and afterwards fixated with methanol/acetone (1:1) for $20 \mathrm{~min}$ at $4^{\circ} \mathrm{C}$. After washing three times with PBS, cells were incubated in $2 \mathrm{~N} \mathrm{HCl}$ for $20 \mathrm{~min}$ at $37^{\circ} \mathrm{C}$, washed three times with water and incubated in $0.1 \mathrm{M}$ sodium borate $(\mathrm{pH}=8.5)$ for $10 \mathrm{~min}$ at room temperature. After washings in PBS, the cells were incubated with primary monoclonal anti-BrdU antibody (1:1000 in PBS/1\%BSA/0.1\%Tween-20, SigmaAldrich) for $30 \mathrm{~min}$ at $37^{\circ} \mathrm{C}$, washed three times with PBS and incubated with biotinylated rabbit anti-mouse antibody (1:400, DAKO, Glostrup, Denmark) for $30 \mathrm{~min}$ at room temperature. After washing five times with PBS, the cells were incubated in ABC-AP solution and the labeled products were visualized using $5 \mathrm{mg} / \mathrm{ml}$ (DAB), $10 \% 0.1 \mathrm{M}$ imidazol, $50 \mu \mathrm{l}$ of $30 \%$ hydrogen peroxide in $100 \mathrm{ml}$ of $0.05 \mathrm{M}$ Tris/ $\mathrm{HCl}$ buffer $(\mathrm{pH}=7.6)$.

\section{$4 \quad$ Wound assay}

Cells were plated on day 0 and cultured until $70 \%$ confluence before transfection or treatment (see above). The following substances were used: ( \pm )-verapamil hydrochloride $(1 \mu \mathrm{M})$ and BayK8644 $(10 \mu \mathrm{M})$. Migration assays started 48hours after transfection and/or treatment by scratching the monolayer with a pipette tip $(1 \mathrm{~mm}$ width). The time point were the scratch was made, was taken as Ohours. Scratch width was measured at this time point, and after 6, 12 and 24hours. For all the results the scratch at Ohours was set as $100 \%$ wound width and further results were expressed relative to this value.

\section{Differentiation assay}

Same timelines and protocols were used as described above. RNA was isolated using the Trizol method (Invitrogen), and CDNA prepared with the iscript ${ }^{\mathrm{TM}}{ }_{\mathrm{CDNA}}$ kit (Bio-Rad, Hercules, CA, USA). qPCR was performed as described previously ${ }^{34}$. The 
following myofibroblasts markers were determined: $\alpha$-smooth muscle actin ( $\alpha$ SMA), $\alpha 1$ type I collagen (Col1 $\alpha 2$ ), type III collagen, total fibronectin and its EDA and EDB splice variants (FN-EDA and FN-EDB). Cyclophilin served as the house keeping gene. Further, qPCRs were performed on all samples, with a TGF- $\beta$, Fzd-1 and -2, and Wnt3a and Wnt5a primer set. (For primer sequences see table 1 )

Table 1: Primers

\begin{tabular}{lll}
\hline Genes & Forward primer & Reverse primer \\
\hline$\alpha$-SMA & AACTGGTATTGTGCTGGACTCTGG & CACGGACGATCTCACGCTCAG \\
Collagen l 11 & TCGATTCACCTACAGCACGC & GACTGTCTTGCCCCAAGTTCC \\
Collagen III & TCCTGAACATGTCCTTTGATGTA & TTCAGAGACTTCTTTACATTGCCATT \\
Cyclophilin & TTCCTCCTTTCACAGAATTATTCCA & CCACCAGTGCCATTATGG \\
Fibronectin & CGGTTATCTGACTCTGGCTTTAAG & TCTCCCTGACGATCCCACTTC \\
Fibronectin EDA & GCATTCACTGATGTGGATGTC & CTCTGCCGTGTCCTCGTC \\
Fibronectin EDB & AGTAGTTGCGGCAGGAGAAGG & CGTTTGCTGTGTCAGTGTAGTAGG \\
\hline
\end{tabular}

Forward and reverse sequences of all primers stated in this chapter.

For Western blot, cells were harvested with trypsine, pelleted and placed in $500 \mu \mathrm{l}$ ice-cold Laemmli buffer (6.6\% glycerol, $1.5 \% \mathrm{SDS}, 4.15 \mathrm{mmol} / \mathrm{I} \mathrm{Tris} / \mathrm{HCl}, \mathrm{pH}=8.0$ ) and homogenized. After $30 \mathrm{~min}$ on ice and centrifugation, the supernatants were collected and protein content was measured using the BCA protein assay (Pierce Biotechnology Inc., Rockford, IL, USA); 10 $\mu \mathrm{g}$ of total protein was denatured by boiling in Laemmli sample buffer (Bio-Rad, Hercules, CA, USA), separated on a $10 \%$ SDS-page gel, and transferred onto a Hybond $C$ nitrocellulose membrane (Amersham Biosciences). After blocking ( $5 \%$ non-fat dry milk (Bio-Rad), 0.1\% Tween in TBS) for 1hour, membranes were incubated overnight at $4^{\circ} \mathrm{C}$ with primary antibodies directed against $\beta$-catenin 1/2000 (BD Biosciences, Franklin Lakes, NJ, USA), $\alpha$-SMA, total collagen and $\beta$-actin $1 / 2000$ (Sigma-Aldrich, Saint Louis, IL, USA). Anti-rabbit or mouse immunoglobulin G $1 / 5000$ (Vector laboratories, Burlingame, CA, USA) was used as the secondary antibody, and the membranes were developed using the Supersignal West Pico chemiluminescence kit (Pierce). Images of the blots were analyzed with image analysis software (Leica QWin, Cambridge, UK).

\section{Immunofluorescence}

Same timelines and protocols were used as described above. Cells were washed with PBS and fixed with methanol/acetone (1:1). After incubation for $5 \mathrm{~min}$ with $0.5 \%$ Triton, cells where washed with PBS/glycine and incubated with $2 \%$ BSA. Overnight, the cells were incubated with the primary $\alpha$-SMA antibody (SigmaAldrich) and 2hours with secondary Alexa fluor 488 goat anti-mouse antibody (Vector labs). Cell nuclei were visualized by vectashield mounting medium with DAPI 
(Vector labs). Photos were taken with a Leica CTR500 camera and analyzed with the Quantimet program (Leica QWin/QGo).

\section{Determination of collagen excretion}

Cells were pretreated as described above. $250 \mu$ l of cell suspension was mixed with $1.25 \mathrm{ml}$ color reagent $(250 \mathrm{mg}$ Sirius red solved in $250 \mathrm{ml}$ picirinic acid with $1.25 \mathrm{ml}$ triton $\mathrm{X}-100)$. The solution was centrifuged (3minutes at $5.000 \mathrm{~g}$ ) and the color reagent was discarded. The pellet was resuspended in $0.3 \mathrm{ml} 0.5 \mathrm{M} \mathrm{NaOH}$, this solution was incubated for 10 minutes and measured with an extinction of $540 \mathrm{~nm}$.

\section{Collagen gel contraction}

Collagen gel contraction experiments were performed according to the method described by Lijnen et al. ${ }^{35,36}$. The wells were coated with $1 \%$ BSA for 1 hour at $37^{\circ} \mathrm{C}$. In the mean time, CFIT were harvested and resuspended in a final volume of $1 \times 10^{6}$ cells/ml. Prior to this experiment, cells were pretreated as described above. The BSA was aspirated from the plate, the collagen mix $(50 \% 3 \mathrm{mg} / \mathrm{ml}$ collagen I (Invitrogen) and $50 \% 2 x$ DMEM) was added to the cells immediately before plating. Gels were made floating by nudging with a pipette tip and placed at $37^{\circ} \mathrm{C}$ for 24 hours, before the gels were assessed. The gel diameter was used as a measure of myofibroblast contraction.

\section{Calcium and luciferase assay}

Calcium measurements were performed at different time points after treatment or transfection, using the Fluo-4NW calcium assay kit (Invitrogen, Merelbeke, Belgium). For the luciferase experiments, the cells were additionally transfected with a TOPFlash construct consisting of 16 TCF/LEF binding sites cloned stably into the Mlu1 site of a pTA-Luc vector. The construct was kindly provided by Dr. J. Nathans, Baltimore, MD, USA. Luciferase activity was measured using a luciferase assay system (Promega, Madison, WI, USA).

\section{Statistical analysis}

All values are shown as mean \pm S.E.M. Differences between groups were examined for statistical significance using two-way ANOVA with the Bonferroni posthoc-test. A $P$ value less than 0.05 was considered to indicate a statistically significant difference. 


\section{Results}

\section{Effect of Wnt/Fzd signaling on CFIT proliferation}

Cells were exposed to either Wnt3a or Wnt5a conditioned culture medium $\left(1.10^{-8}\right.$ $\mathrm{M})$ either alone or in combination with $\mathrm{rFzd}-1$ or -2 transfection. All experiments were repeated with purified recombinant Wnt ( $\mathrm{WWnt}$ ) and the Wnt constructs, to exclude non-specific effects of the conditioned medium. The contribution of downstream signaling components was investigated by overexpression of $\beta$-catenin or by administration of the calcium agonist BayK8644 or the calcium antagonist ( \pm )verapamil. As shown in Fig 1, neither of the combinations of Wnts and Fzds induced a significant change in the proliferation rate of CFIT compared to the unmanipulated control. No effect on CFIT proliferation was observed by interventions in the downstream signaling.

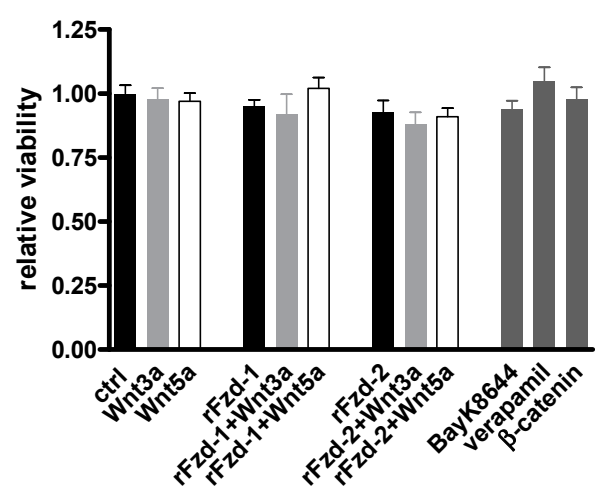

Fig 1: Proliferation of the CFIT, validated with a BrdU incorporation study. All data are the main of three independent measurements and are represented with SEM. No significant differences were observed between any of the conditions tested.

\section{Effect of Wnt/Fzd signaling on CFIT migration}

Migration of CFIT was determined using an in vitro wound assay, in which the closure of a scratch in the cell layer was followed in time. In Fig 2A, the attenuation of wound closure by Wnt3a or Wnt5a is shown. Transfection of either rFzd-1 (Fig 2B) or rFzd-2 (Fig 2C) also induced the attenuation of the wound closure of CFIT, which was further enhanced by the addition of Wnt3a or Wnt5a. Administration of recombinant Wnts or transient Wnt transfection yielded similar results (Not shown). In Fig 2D, we further investigated the downstream signaling pathways involved in the anti-migratory effect of Wnt/Fzd signaling. Overexpression of $\beta$-catenin, the second messenger of $\beta$-catenin dependent Wnt signaling pathway, did not affect the migration of CFIT. In contrast, the calcium antagonist ( \pm )-verapamil attenuated the migration to a similar extent as the interventions in Wnt/Fzd signaling. These 
results suggest that calcium-mediated Fzd signaling, rather than $\beta$-catenin-mediated signaling, is responsible for the inhibitory effect on CFIT migration.

A

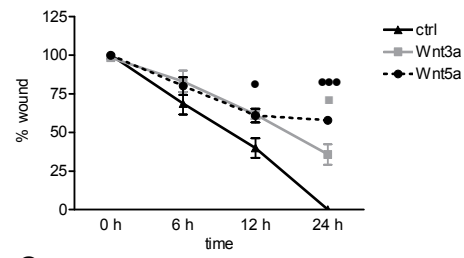

C

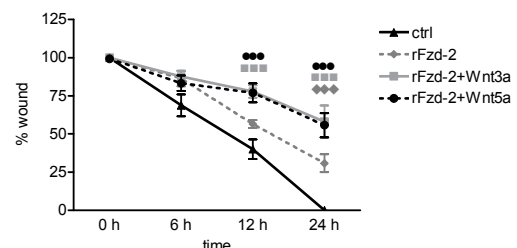

E

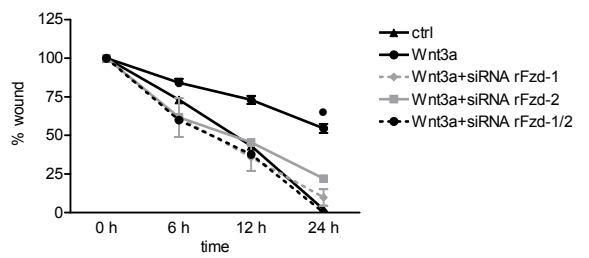

B

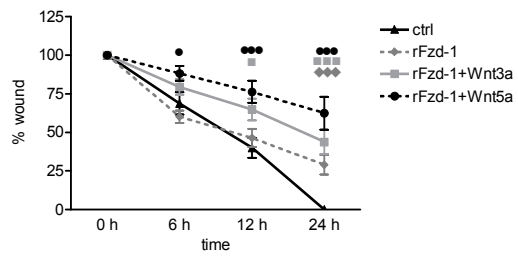

D

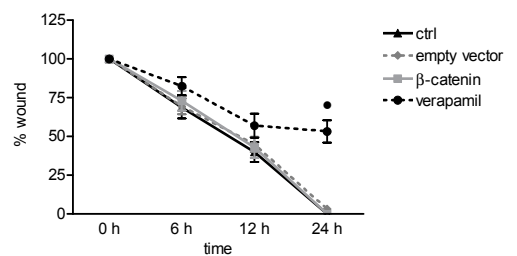

$\mathbf{F}$

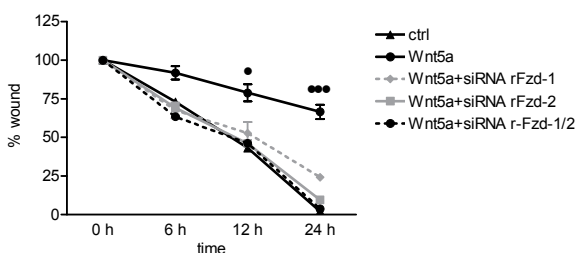

Fig 2: Migration of CFIT into a scratch in a confluent cell layer. A. Wnt3a and Wnt5a induced a significant delay of migration at 12 hours compared to control, which was even more pronounced at 24 hours. B. Effects of rFzd-1, either alone or in combination with Wnt3a or Wnt5a, on CFIT migration. RFzd-1 by itself delayed CFIT migration, and the effect was even more pronounced when combined with Wnt3a or Wnt5a $(\mathrm{N}=5)$. C. A similar pattern of inhibition was observed for rFzd-2 ( $N=5)$. D. Empty vector and $\beta$ catenin, had no influence on CFIT migration. ( \pm )-Verapamil hydrochloride, on the other hand, delayed the migration significantly. E. Effect of inhibition of the rFzd-1 and -2 expression on the anti-migratory effects of Wnt3a. The combination of the two siRNAs completely prevented the effects of Wnt3a on the delay of CFIT migration. F. For Wnt5a, siRNAs exhibited the same effect as shown for Wnt3a. All data are as mean with SEM $(\bullet p<0.05$ and $\bullet \bullet \bullet p<0.001)$.

To assess the contribution of the endogenous Fzds to the effects of Wnt3a and 5a, siRNAs for rFzd-1 and rFzd-2 were transfected into CFIT (Fig 2E/F). Transfection of either of the siRNAs reduced the effect of Wnt3a or Wnt5a administration, whereas combined transfection of the siRNAs completely abolished the effect of Wnt3a and Wnt5a on CFIT migration. These experiments suggest that both endogenous $\mathrm{rFzd}-1$ and -2 are involved in the effects of Wnt3a and Wnt5a on CFIT migration. 
Because high concentrations of siRNAs could inhibit protein synthesis or lead to non-specific reactions, we also tested a siRNA directed against GFP. This siRNA did not affect the migration of CFIT (Not shown).

To find out whether the delayed wound closure is a consequence of a migratory effect or a combination of delayed migration and decreased proliferation at the site of injury, CFIT were exposed to BrdU during the migration. No significant differences in proliferation rate could be observed (Not shown). This indicated that the delayed CFIT wound closure is the sole consequence of a migratory effect.

\section{Effect of Wnt/Fzd signaling on CFIT differentiation}

To determine the effect of activation of Wnt/Fzd signaling on fibroblast-tomyofibroblast differentiation of CFIT, we determined the expression levels of different myofibroblast markers including alpha smooth muscle actin ( $\alpha$-SMA), Collagen la1 and III, fibronectin (FN) and its splice variant EDA and EDB using qPCR (Fig 3A-F). Administration of Wnt3a to the culture medium significantly reduced the expression of all differentiation markers except EDB fibronectin, whereas administration of Wnt5a had no effect. Overexpression of either rFzd1 or -2 alone did not affect the expression of any of the differentiation markers.

Combination of Fzd overexpression and Wnt administration revealed opposite effects for rFzd-1 and -2 . In CFIT cells overexpressing rFzd-1, Wnt3a addition stimulated the expression of myofibroblast markers whereas Wnt5a administration showed an inhibitory effect. In contrast, in CFIT overexpressing rFzd-2, Wnt3a inhibited the expression of myofibroblast markers whereas Wnt5a showed a stimulatory effect. All these experiments were repeated with recombinant Wnt protein and with transient transfection of the Wnt constructs, yielding similar results as obtained with conditioned culture medium. A direct activation of $\beta$ catenin-mediated Fzd signaling by $\beta$-catenin overexpression induced myofibroblast

differentiation. A similar result was obtained by activation of $\mathrm{Ca}^{2+}$ signaling by BayK8644, whereas the $\mathrm{Ca}^{2+}$ antagonist $( \pm)$-verapamil hydrochloride induced a fibroblast phenotype with low levels of $\alpha$-SMA.

\section{Analysis of the differentiation at the protein level}

Immunocytochemistry for $\alpha$-SMA was performed on CFIT cell cultures stimulated with Wnt3a or Wnt5a. As shown in Fig 4A, addition of Wnt5a induced the expression of $\alpha$-SMA whereas Wnt3a treatment did not. In Fig 4B, protein levels of $\alpha$-SMA as determined by Western blotting are presented. A combination of transfection of rFzd-1 and Wnt3a, and transfection of rFzd-2 and Wnt5a induced $\alpha$ SMA expression. These data confirm the pattern observed for the $\alpha$-SMA expression at the mRNA level (Fig 3A). 
A

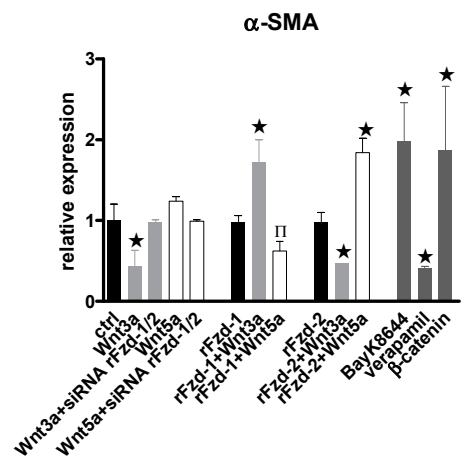

C

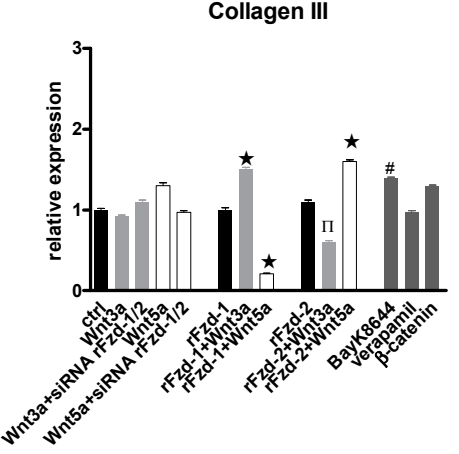

E

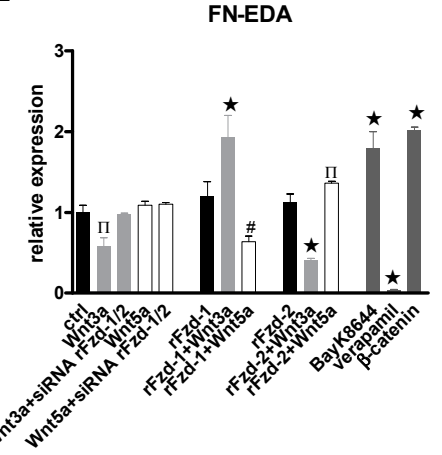

B

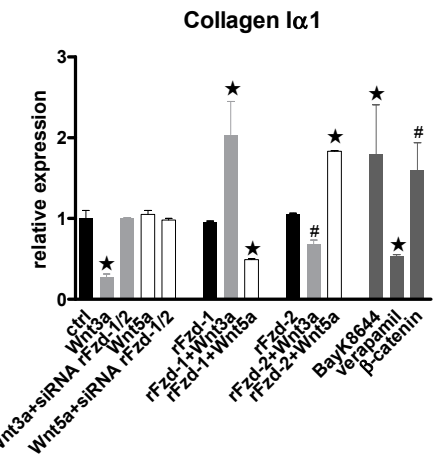

D

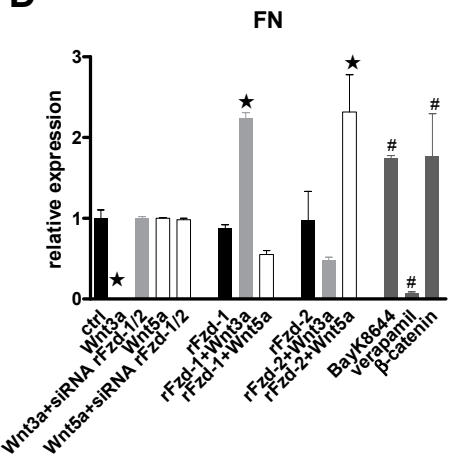

$F$

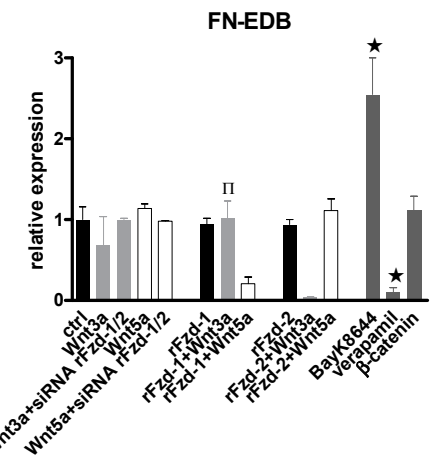

Fig 3: Effect of Wnt/Fzd signaling on the expression of myofibroblast differentiation markers in CFIT, determined by qPCR. Expression levels are corrected for cyclophilin expression and normalized to the control values. The results are the mean of ten different measurements of five different transfection rounds ( ${ }^{\#} p<0.05 ;{ }^{\pi} p<0.01$ and $\left.{ }^{*} p<0.001\right)$. The different differentiation markers are A: $\alpha$-SMA, B: Col l $\alpha 1$, C: collagen III D: Fibronectin, E: FN-EDA and F: FN-EDB. Overexpression of the Fzds alone had no effect. In combination with Wnt ligands, we observed ligand/receptor specificity for the differentiation. Overexpression of $\beta$-catenin and administration of BayK8644 stimulated the expression of myofibroblast differentiation markers, whereas $( \pm)$-verapamil hydrochloride potently inhibited the expression of most of the differentiation markers. 
Furthermore, the protein levels of total collagen were determined by Western blotting (Fig $4 \mathrm{C}$ ), confirming the differentiation patterns as presented in Fig $3 \mathrm{~A}$ and 4 $A / B$. A similar pattern of collagen levels could be observed in the CFIT culture medium (Fig 4D).

To correlate the increased expression levels of myofibroblast markers with a more contractile phenotype of the CFIT, collagen contraction assays were performed. CFIT cells were transfected and cultured for 48hours, detached from their culture dish and added to a collagen gel. These experiments showed that elevated $\alpha$-SMA protein levels led to a decreased gel size, where reduced $\alpha$-SMA protein levels to increased gel size, as compared to unmanipulated controls (Fig 4E).

\section{Activation of different intracellular signal transduction cascades}

To elucidate the opposing effects of Wnt3a and Wnt5a on the differentiation of CFIT, the activation of the two main signaling transduction cascades were studied. B-catenin mediated signaling was assessed by determining the activity of luciferase produced by a TCF/LEF-luciferase construct (TOPFlash assay). Addition of Wnt3a increased luciferase activity whereas Wnt5a did not. These results confirm the literature where Wnt3a-mediated signaling is considered to be $\beta$-catenin dependent, where Wnt5a signaling is $\beta$-catenin independent (Fig 5A). However, this activation pattern showed no correlation with the differentiation pattern. Therefore, intracellular calcium levels were determined as a measure of $\beta$-catenin independent Wnt signaling (Fig 5B). Calcium levels clearly correlated with CFIT differentiation, indicating that the second messenger calcium was the main controller of the differentiation of these cells. To confirm that the second messenger of the $\beta$-catenin independent pathway had no direct influence on the $\beta$ catenin dependent signaling, $\beta$-catenin protein levels were examined by Western blotting. These data confirm that the TOPFlash assay was an accurate functional assessment of $\beta$-catenin dependent activity and that the $\beta$-catenin dependent pathway was not the main pathway in the migration and differentiation (Fig $5 \mathrm{C}$ ).

Next, we studied a possible interaction between Wnt signaling and TGF- $\beta$, a growth factor known to influence the differentiation of fibroblast to myofibroblast. Manipulation of neither $\beta$-catenin dependent or independent Wnt signaling affected the mRNA levels of TGF- $\beta$. This indicated that the Wnt/Fzd pathway is independent of the TGF- $\beta$ pathway (Not shown).

\section{Specificity of the Fzd receptors involved in CFIT migration and differentiation}

To study the selectivity of the observed effects, we subsequently tested the effect of overexpression of hFzd-5 on CFIT migration. Overexpression of hFzd-5 alone did 
not attenuate the migration, whereas the attenuating effect of Wnt3a or Wnt5a on CFIT migration, shown in Fig 2, was not modified by the overexpression of hFzd-5 (Fig 6A). Overexpression of hFzd-5 also did not alter the expression of $\alpha$-SMA on both protein (Not shown) and mRNA level (Fig 6B), either alone or in combination with Wnt3a or Wnt5a. This indicates that hFzd-5 is not capable of transducing the Wnt signals in CFIT.

A.

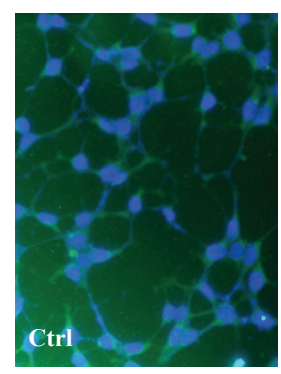

B.

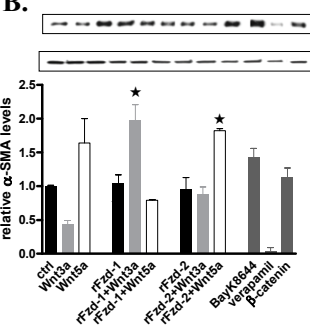

D.

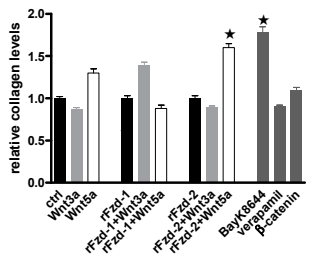

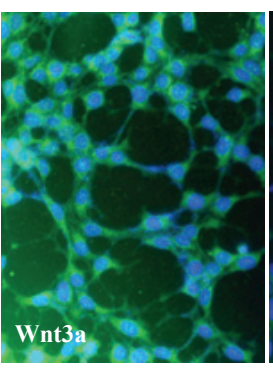

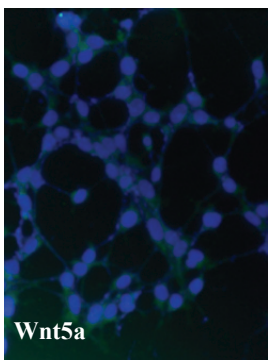

C.

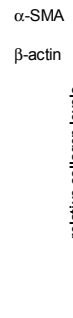

C.

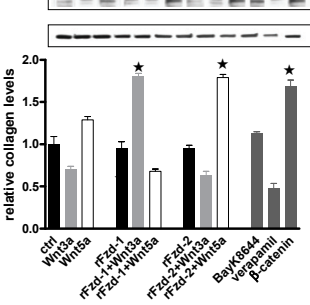

E.

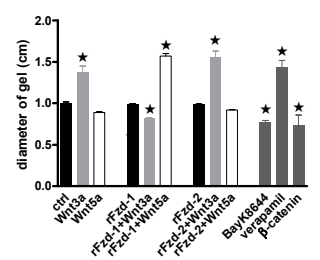

Fig 4: Effects of Wht administration on the differentiation of CFIT cells on protein level. A. Immunocytochemistry for $\alpha$-SMA is shown in absence and presence of either Wnt3a or Wnt5a. It is clear that the total amount of $\alpha$-SMA is increased after Wnt3a conditioned medium and decreased after treatment with Wnt5a conditioned medium, compared to control. B. A Western blotting for $\alpha$-SMA and C: total collagen, were performed. The effects of different Wnt/Fzd combinations on $\alpha$-SMA protein were similar to that observed on mRNA level (Fig 3A/B/C). D. Relative collagen content in the medium of CFIT exposed to different Wnt/Fzd combinations. These data confirm the Western blotting data, in which intracellular collagen content was determined. All results shown are means with SEM and were obtained from 3 independent measurements of six different transfections $(* p<0.001)$. E. A collagen gel assay was used to assess the contractile properties of CFIT under different conditions. Gels were measured after 24 hours and their dimensions related to gels cultured under control conditions. All results shown are means with SEM and were obtained from 2 independent measurements of four different transfections. 
A

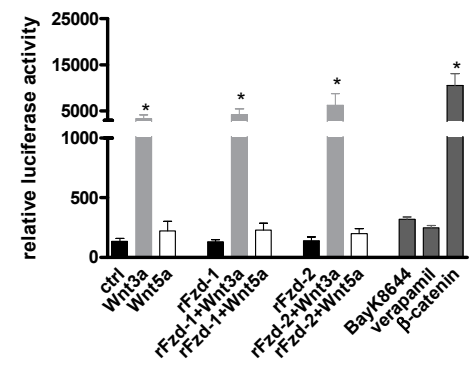

C

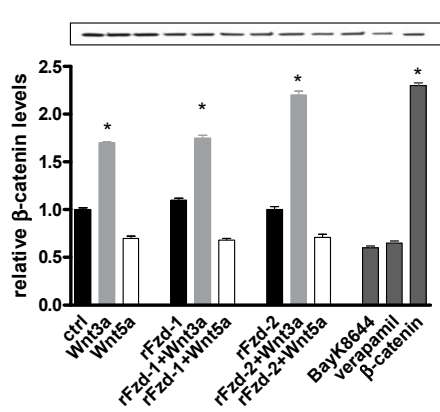

B

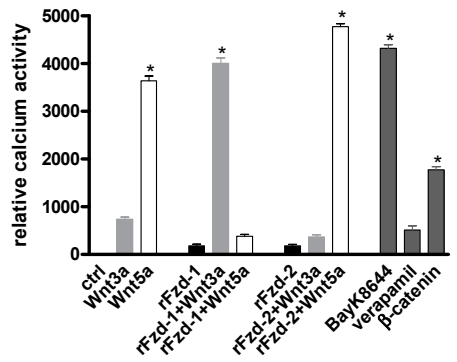

$\beta$-catenin

$\beta$-actin

Fig 5: Assessment of different intracellular signaling pathways activated in CFIT cells by different Wnt/Fzd combinations. A. TOPFlash assays confirm that Wnt3a could activate $\beta$-catenin-mediated Wnt signaling whereas Wnt5a could not. B. The $\beta$-catenin independent signaling was studied using a calcium assay. Intracellular calcium levels exhibited the same pattern as shown for the differentiation, indicating that the $\beta$-catenin independent pathway is the main controller of CFIT differentiation. C. To confirm that differentiation is not controlled by $\beta$-catenin, we determined the content of this protein by Western blotting. These data were in agreement with results from the TOPFlash assays. All results shown are means with SEM and were obtained from 3 independent measurements of six different transfections $\left({ }^{*} p<0.001\right)$.

A

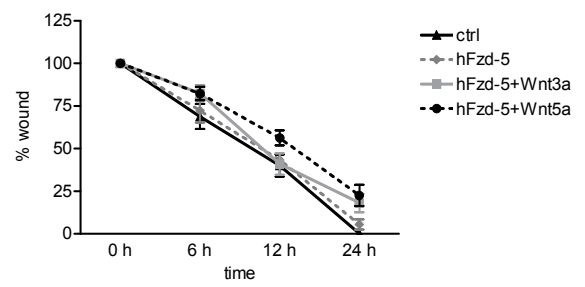

B

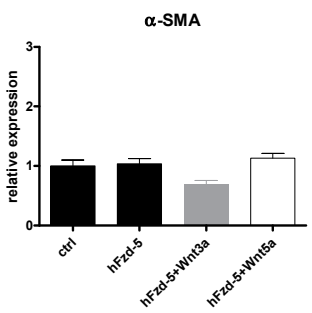

Fig 6A: Transfection of hFzd-5 had little effect on CFIT migration. All data are a mean of three independent experiments. B. Differentiation of CFIT was not affected by hFzd-5 overexpression. These experiments are a combination of three different transfections and a total of six samples $(\mathrm{N}=6)$. The error bars represent SEM. 


\section{Discussion}

A significant fraction of $\mathrm{MI}$ patients develops heart failure, a condition that is due to the development of excessive dilatation of the infarct area, the so called infarct expansion $^{37,38}$. It is therefore of vital importance to better understand the wound healing process after $\mathrm{MI}$ and to identify new therapeutic targets that can help to improve this process ${ }^{1,3}$. We and others have demonstrated the crucial role of the myofibroblast in the prevention of cardiac dilatation after $\mathrm{MI}^{6,7,39,40}$. So far the signaling pathways involved in myofibroblast differentiation are not fully elucidated. In the infarcted heart, myofibroblasts can be observed in the infarct area but also in areas remote from the ischemic zone ${ }^{40}$. In the infarct area, these cells serve a dual role: they contract similar to smooth muscle cells and subsequently deposit extracellular matrix proteins. These actions result in a smaller and stronger scar area that helps to prevent infarct expansion and ventricular dilatation. The presence of myofibroblasts in the infarct area is important to ensure maintenance of the extracellular matrix which is subjected to wear and tear in the beating heart ${ }^{37}$. However, excessive matrix deposition in remote areas contributes to stiffening of the ventricular wall and adverse remodeling, leading to heart failure ${ }^{41}$. The involvement of local angiotensin production in the fibrotic response has been firmly established ${ }^{42}$ and inhibitors of the renin-angiotensin system are capable of limiting this remote fibrosis ${ }^{43,44}$. However, these drugs can not prevent heart failure development in a significant fraction of the MI patients and have been reported to have pleiotropic effects ${ }^{5}$. This underscores the importance of identifying novel therapeutic targets for adverse cardiac remodeling.

One of the aims of the present study was to elucidate the role of Wnt/Fzd signaling in the fibroblast-to-myofibroblast differentiation. After an initial report by our group describing the overexpression of $\mathrm{rFzd}-2$ and Dvl-1 in myofibroblasts in the healing rat infarct ${ }^{11,45}$, Barandon et al. demonstrated that overexpression of FrzA, a member of the soluble Fzd related protein family, improved infarct healing in mice 13. This family of proteins is thought to interfere with Wnt/Fzd signaling by scavenging Wnt proteins, although alternative signaling routes have been suggested

46. Subsequently, this observation has been confirmed by other groups ${ }^{12,14,15}$. In addressing the aim of the present study, we realized that in vivo studies are not well suited to sort out the underlying molecular mechanisms of wound healing, since many cell types and signaling pathways are active at the same time.

To this end, we developed a cardiac fibroblast cell line that is immortalized with telomerase $^{29}$. In contrast to primary cultures of cardiac fibroblasts, this cell line shows little spontaneous differentiation into myofibroblasts, making it a suitable tool to study the effect of Wnt/Fzd signaling on myofibroblast differentiation. We observed that overexpression of $\mathrm{rFzd}-1$ or -2 , either alone or in combination with Wnt3a or Wnt5a administration, had no effect on CFIT proliferation. In contrast, 
CFIT migration was clearly attenuated by either rFzd-1 or -2 overexpression, and this effect could be enhanced by additional administration of Wnt3a or Wnt5a to the cells. The effect could be mimicked by interventions in the $\mathrm{Ca}^{2+}$-metabolism, but overexpression of $\beta$-catenin had no effect on CFIT migration. This indicates that non- $\beta$-catenin-mediated rather than $\beta$-catenin-mediated Wnt/Fzd signaling is responsible for the attenuation of CFIT migration. We also observed attenuated CFIT migration when Wnt3a or Wnt5a were administered alone, without overexpression of Fzds. Blocking of $\mathrm{rFzd}-1$ and $\mathrm{rFzd}-2$ expression by siRNA transfection showed that this effect could be attributed to the activation of endogenous rFzd-1 and rFzd-2.

Migration of (myo)fibroblasts into the areas of myocyte loss is an important step in the process of wound healing. Chemotactic factors released by inflammatory cells stimulate the migration of these cells into the infarct area ${ }^{47}$. Mechanisms that control the process of migration, however, are largely unknown. The results of the present study show that activation of Wnt/Fzd signaling attenuates the CFIT migration. From these data we conclude that fibrosis can be controlled not only at the level of fibroblast proliferation and differentiation into myofibroblasts, but also at the level of migration of these cells into the injured areas of the heart.

Interventions in Wnt/Fzd signaling also modulated the differentiation of CFIT into a myofibroblast phenotype. However, opposite effects were observed for different combinations of Wnts and Fzds: differentiation was stimulated with the combinations $\mathrm{rFzd}-1 / \mathrm{Wnt} 3 \mathrm{a}$ and $\mathrm{rFzd}-2 / \mathrm{Wnt} 5 \mathrm{a}$, whereas the combinations $\mathrm{rFzd}$ 1/Wnt5a and $\mathrm{rFzd}-2 / \mathrm{Wnt} 3 \mathrm{a}$ exerted an anti-differentiating effect. This underlines the complexity of the Wnt/Fzd signaling in the induction of myofibroblast differentiation. Interventions in $\mathrm{Ca}^{2+}$-metabolism were shown to affect CFIT differentiation whereas overexpression of $\beta$-catenin had no effect. Therefore our data suggest that the $\beta$-catenin independent signaling is the main pathway for the effects of Wnt on the differentiation of CFIT. One has to conclude that our current knowledge of the pharmacology of the Wnt/Fzd pathway and their preferential activation of either of the different signal transduction pathways induced by different combinations of Wnts and Fzds is far from complete ${ }^{48}$, which sometimes can lead to seemingly contradictory results. However, our data increase the knowledge of the effect of $\beta$-catenin independent signaling on fibroblast migration and differentiation.

Recently, telomerase has been shown to modulate Wnt signaling in both in vivo and in embryonic stem cells by interacting with $\beta$-catenin target gene transcription $^{49}$. This mechanism, however, is not likely to influence the outcome of the experiments reported here, since all experimental groups in the present study were derived from identical batches of CFIT. Moreover, the effects of Wnt signaling on CFIT migration could be attributed to non- $\beta$-catenin mediated Wnt signaling 
whereas the modulation of differentiation resulted from both $\beta$-catenin mediated and non- $\beta$-catenin mediated Wnt signaling.

In conclusion, interventions at the level of Wnt/Fzd signaling have an effect on the migration and the differentiation of cardiac fibroblasts. These results reported here combined with the in vivo data presented above underscore that appropriate interventions in Wnt/Fzd signaling at the level of the (myo)fibroblast can serve as a novel therapeutic approach to prevent excessive dilatation of the infarct area and preserve cardiac function after MI.

\section{Acknowledgements}

The authors thank Peter M. Lijnen and Lily T.M. Vervoort for their expert technical assistance.

\section{Funding}

This work was supported by BSIK 03033; Molecular Imaging of Ischemic heart disease.

\section{References}

1. Ertl G, Frantz S. Healing after myocardial infarction. Cardiovasc Res 2005;66:22-32.

2. Frangogiannis NG. The mechanistic basis of infarct healing. Antioxid Redox Signal 2006;8:1907-39.

3. Pfeffer MA, Braunwald E. Ventricular remodeling after myocardial infarction. Experimental observations and clinical implications. Circulation 1990;81:1161-72.

4. Cleutjens JP, Blankesteijn WM, Daemen MJ, Smits JF. The infarcted myocardium: simply dead tissue, or a lively target for therapeutic interventions. Cardiovasc Res 1999;44:232-41.

5. Jugdutt BI. Pleiotropic effects of cardiac drugs on healing post-MI. The good, bad, and ugly. Heart Fail Rev 2008;13:439-52.

6. Hinz B. Formation and function of the myofibroblast during tissue repair. J Invest Dermatol 2007;127:526-37.

7. van den Borne SW, van de Schans VA, Strzelecka AE, Vervoort-Peters HT, Lijnen PM, Cleutjens JP et al. Mouse strain determines the outcome of wound healing after myocardial infarction. Cardiovasc Res 2009;84:273-82.

8. Willems IE, Havenith MG, De Mey JG, Daemen MJ. The alpha-smooth muscle actin-positive cells in healing human myocardial scars. Am J Pathol 1994;145:868-75.

9. Blankesteijn WM, Creemers E, Lutgens E, Cleutjens JP, Daemen MJ, Smits JF. Dynamics of cardiac wound healing following myocardial infarction: observations in genetically altered mice. Acta Physiol Scand 2001;173:75-82.

10. Sun Y, Kiani MF, Postlethwaite AE, Weber KT. Infarct scar as living tissue. Basic Res Cardiol 2002;97:343-7.

11. Blankesteijn WM, Essers-Janssen YP, Verluyten MJ, Daemen MJ, Smits JF. A homologue of Drosophila tissue polarity gene frizzled is expressed in migrating myofibroblasts in the infarcted rat heart. Nat Med 1997;3:541-4.

12. Chen L, Wu Q, Guo F, Xia B,Zuo J. Expression of Dishevelled-1 in wound healing after acute myocardial infarction: possible involvement in myofibroblast proliferation and migration. $J \mathrm{Cell} \mathrm{Mol}$ Med 2004;8:257-64. 
13. Barandon L, Couffinhal T, Ezan J, Dufourcq P, Costet P, Alzieu P et al. Reduction of infarct size and prevention of cardiac rupture in transgenic mice overexpressing FrzA. Circulation 2003;108:2282-9.

14. Kobayashi K, Luo M, Zhang Y, Wilkes DC, Ge G, Grieskamp T et al. Secreted Frizzled-related protein 2 is a procollagen $C$ proteinase enhancer with a role in fibrosis associated with myocardial infarction. Nat Cell Biol 2009;11:46-55.

15. Alfaro MP, Pagni M, Vincent A, Atkinson J, Hill MF, Cates J et al. The Wnt modulator sFRP2 enhances mesenchymal stem cell engraftment, granulation tissue formation and myocardial repair. Proc Natl Acad Sci U S A 2008;105:18366-71.

16. Hahn JY, Cho HJ, Bae JW, Yuk HS, Kim KI, Park KW et al. beta -catenin overexpression reduces myocardial infarct size through differential effects on cardiomyocytes and cardiac fibroblasts. $J$ Biol Chem 2006;281:30979-30989.

17. Cadigan KM, Nusse R. Wnt signaling: a common theme in animal development. Genes Dev 1997;11:3286-305.

18. Moon RT, Bowerman B, Boutros M,Perrimon N. The promise and perils of Wnt signaling through beta-catenin. Science 2002;296:1644-6.

19. Wang HY, Liu T, Malbon CC. Structure-function analysis of Frizzleds. Cell Signal 2006;18:934-41.

20. He X. Unwinding a Path to Nuclear beta-Catenin. Cell 2006;127:40-2.

21. Nusse R. Wnt signaling in disease and in development. Cell Res 2005;15:28-32.

22. Huelsken J,Behrens J. The Wnt signalling pathway. J Cell Sci 2002;115:3977-8.

23. Oloumi A, Syam S,Dedhar S. Modulation of Wnt3a-mediated nuclear beta-catenin accumulation and activation by integrin-linked kinase in mammalian cells. Oncogene 2006;25:7747-7757.

24. Mikels AJ, Nusse R. Purified Wnt5a protein activates or inhibits beta-catenin-TCF signaling depending on receptor context. PLoS Biol 2006;4:e115.

25. Hinz B. Masters and servants of the force: the role of matrix adhesions in myofibroblast force perception and transmission. Eur J Cell Biol 2006;85:175-81.

26. Jordan ET, Collins M, Terefe J, Ugozzoli L, Rubio T. Optimizing electroporation conditions in primary and other difficult-to-transfect cells. J Biomol Tech 2008;19:328-34.

27. Harms W, Rothamel T, Miller K, Harste G, Grassmann M, Heim A. Characterization of human myocardial fibroblasts immortalized by HPV16 E6--E7 genes. Exp Cell Res 2001;268:252-61.

28. Petrov VV, van Pelt JF, Vermeesch JR, Van Duppen VJ, Vekemans K, Fagard RH et al. TGF-beta1induced cardiac myofibroblasts are nonproliferating functional cells carrying DNA damages. Exp Cell Res 2008;314:1480-94.

29. Janhunen S, Laeremans H, Rensen S, Smits J, Blankesteijn W. A novel telomerase-immortalized cardiac fibroblast cell line. Naunyn-Schmied Arch Pharmacol 2009;379:205.

30. Linssen MC, Vork MM, de Jong YF, Glatz JF, van der Vusse GJ. Fatty acid oxidation capacity and fatty acid-binding protein content of different cell types isolated from rat heart. Mol Cell Biochem 1990;98:19-25.

31. Bodnar AG, Ouellette M, Frolkis M, Holt SE, Chiu CP, Morin GB et al. Extension of life-span by introduction of telomerase into normal human cells. Science 1998;279:349-52.

32. Chen W, ten Berge D, Brown J, Ahn S, Hu LA, Miller WE et al. Dishevelled 2 recruits beta-arrestin 2 to mediate Wnt5A-stimulated endocytosis of Frizzled 4. Science 2003;301:1391-4.

33. Willert K, Brown JD, Danenberg E, Duncan AW, Weissman IL, Reya T et al. Wnt proteins are lipidmodified and can act as stem cell growth factors. Nature 2003;423:448-52.

34. van de Schans VA, van den Borne SW, Strzelecka AE, Janssen BJ, van der Velden JL, Langen RC et al. Interruption of Wnt signaling attenuates the onset of pressure overload-induced cardiac hypertrophy. Hypertension 2007;49:473-80.

35. Lijnen P, Petrov V, Fagard R. In vitro assay of collagen gel contraction by cardiac fibroblasts in serumfree conditions. Methods Fund Exp Clin Pharmacol 2001;23:377-82.

36. Grinnell F. Fibroblasts, myofibroblasts, and wound contraction. J Cell Biol 1994;124:401-4.

37. van den Borne SW, Diez J, Blankesteijn WM, Verjans J, Hofstra L, Narula J. Myocardial remodeling after infarction: the role of myofibroblasts. Nat Rev Cardiol 2010;7:30-7. 
38. Hutchins GM, Bulkley BH. Infarct expansion versus extension: two different complications of acute myocardial infarction. Am J Cardiol 1978;41:1127-32.

39. Gabbiani G. Evolution and clinical implications of the myofibroblast concept. Cardiovasc Res 1998;38:545-8.

40. Sun Y, Weber KT. Infarct scar: a dynamic tissue. Cardiovasc Res 2000;46:250-6.

41. Beltrami CA, Finato N, Rocco M, Feruglio GA, Puricelli C, Cigola E et al. Structural basis of end-stage failure in ischemic cardiomyopathy in humans. Circulation 1994;89:151-63.

42. Weber KT, Sun Y, Katwa LC. Myofibroblasts and local angiotensin II in rat cardiac tissue repair. Int $J$ Biochem Cell Biol 1997;29:31-42.

43. Smits JF, van Krimpen C, Schoemaker RG, Cleutjens JP,Daemen MJ. Angiotensin II receptor blockade after myocardial infarction in rats: effects on hemodynamics, myocardial DNA synthesis, and interstitial collagen content. J Cardiovasc Pharmacol 1992;20:772-8.

44. van Krimpen C, Smits JF, Cleutjens JP, Debets JJ, Schoemaker RG, Struyker Boudier HA et al. DNA synthesis in the non-infarcted cardiac interstitium after left coronary artery ligation in the rat: effects of captopril. J Mol Cell Cardiol 1991;23:1245-53.

45. van de Schans VA, Smits JF,Blankesteijn WM. The Wnt/frizzled pathway in cardiovascular development and disease: Friend or foe? Eur J Pharmacol 2008;585:338-345

46. Kawano Y,Kypta R. Secreted antagonists of the Wnt signalling pathway. J Cell Sci 2003;116:2627-34.

47. Brown RD, Ambler SK, Mitchell MD, Long CS. The cardiac fibroblast: therapeutic target in myocardial remodeling and failure. Annu Rev Pharmacol Toxicol 2005;45:657-87.

48. Schulte G,Bryja V. The Frizzled family of unconventional G-protein-coupled receptors. Trends Pharmacol Sci 2007;28:518-25.

49. Park JI, Venteicher AS, Hong JY, Choi J, Jun S, Shkreli M et al. Telomerase modulates Wnt signalling by association with target gene chromatin. Nature 2009;460:66-72. 



\section{Differentiation of muscle cell lines} is modulated by activation of Wnt/Frizzled signaling

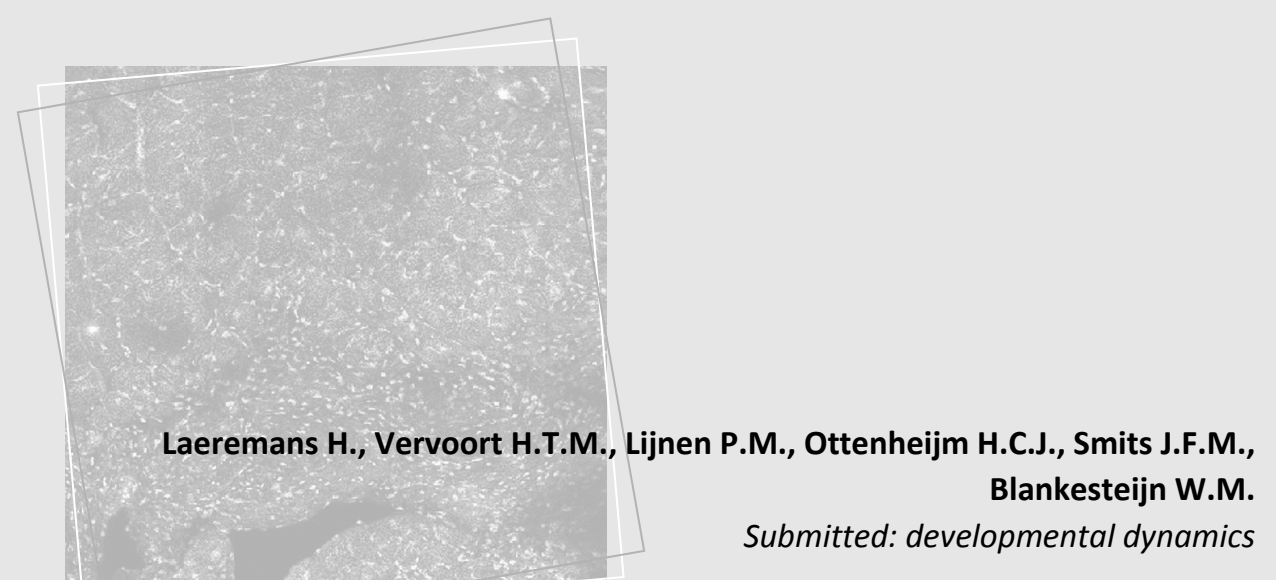




\begin{abstract}
The regeneration of muscle cells is one of the most important steps in the healing of muscle injuries. Understanding of the pathways that control muscle regeneration is incomplete. Here we studied the effect of activation of Wnt/Frizzled signaling on the differentiation of smooth (A7r5 and PAC) and skeletal (C2C12 and L6) muscle cell lines by overexpressing Frizzled-1 or -2 combined with administration of either Wnt3a or Wnt5a. In Frizzled-1 overexpressing cells, Wnt3a promoted the expression of differentiation markers whereas in Frizzled-2 overexpressing cells this was observed after addition of Wnt5a. These results could not be fully explained by the expression pattern of $\beta$-catenin, a second messenger in the $\beta$-catenin dependent Wnt signaling. From these data we conclude that both $\beta$-catenin dependent and independent signaling is involved in the regulation of muscle differentiation by Wnts.
\end{abstract}

\title{
Keywords
}

Wnt/Frizzled; muscle injuries; smooth muscle; skeletal muscle; proliferation; differentiation 


\section{Introduction}

Injury of muscle cells is one of the most frequent traumas in man. After injury, muscle healing occurs through three different phases, including 1) degeneration and inflammation, 2) regeneration and 3) fibrosis, leading to scar formation ${ }^{1}$. The first phase is characterized by removal of the injured muscle tissue by inflammatory cells. These cells also produce different growth factors that regulate the proliferation and differentiation of satellite cells into myotubes, which eventually form the regenerated myofibers. The formation of scar tissue on the other hand is an unfavorable event because it can hamper muscle function. To optimize the healing process after muscle injury one would like to promote the regeneration of muscle and prevent the formation of a scar ${ }^{1}$. However, our understanding of the signaling pathways that govern the different phases of muscle regeneration is far from complete, complicating the development of novel therapeutic approaches for muscle regeneration.

Muscle regeneration is generally thought to recapitulate the process of myogenesis during embryogenesis ${ }^{2}$. One of the signal transduction pathways that is active during muscle formation is the Wnt/Frizzled signal transduction pathway ${ }^{3}$. In this pathway, proteins from the Wnt family can activate receptors from the Frizzled family to convey their signal. Frizzled, in turn, can activate different intracellular signal transduction pathways, including $\beta$-catenin mediated signaling and two $\beta$ catenin independent pathways involving $\mathrm{Ca}^{2+}$ and Rho kinase, respectively ${ }^{4,5}$.

The aim of this study was to investigate the effect of activation of Wnt/Frizzled signaling on muscle cell differentiation. To this end, the smooth muscle cell lines A7r5 and PAC, and the skeletal muscle cell lines, C2C12 and L6, were transfected with Frizzled-1 or Frizzled-2 and exposed to either Wnt3a or Wnt5a. We have focused on Frizzled-1 and Frizzled- 2 in this study because these receptors are expressed during the development of muscle cells and reactivated during the hypertrophic response of cardiac muscle cells ${ }^{3,6}$. We have analyzed the effect of different combinations of Frizzled and Wnt ligands on the expression of muscle differentiation markers and analyzed the signal transduction pathways that were activated in the muscle cell lines.

\section{Materials and Methods}

\section{$1 \quad$ Materials}

The following chemicals were used $( \pm$ )-verapamil hydrochloride (Sigma-Aldrich, Saint Louis, IL, USA), and BayK8644 (Bayer, Mijdrecht, The Netherlands). 5'-bromo2 '-deoxyuridine $(\mathrm{BrdU})$ and the mouse $\mathrm{BrdU}$ antibody, diaminobenzidine tetra- 
hydrochloride (DAB), as well as the secondary antibody rabbit-anti-mouse (SigmaAldrich) were used for the proliferation assay. C2C12, mouse fibroblast-like skeletal muscle cells and A7r5, rat smooth muscle cells, were kindly provided by $\mathrm{Dr}$. T. Ayoubi, department of Genetics, Maastricht University, The Netherlands. L6, rat skeletal muscles and PAC, rat smooth muscle cells were kindly provided by R. Lange, department of Pulmonology, Maastricht University, the Netherlands.

\section{Cell culture and transient transfection}

The cell lines were cultured in $75 \mathrm{~cm}^{2}$ culture flasks (Costar Corning, Schiphol, The Netherlands) in Dulbeco's modified essential medium with L-glutamine (2mM), 10\% fetal calf serum (Invitrogen, Merelbeke, Belgium), and gentamycin (Sigma-Aldrich). Before the start of the experiment, the cells were treated with plasmocin $25 \mu \mathrm{g} / \mathrm{ml}$ (Invivogen, Toulouse, France) and were tested with a mycoalert mycoplasma detection kit (Lonza, Rockland, ME, USA). If tests were negative, treatment was stopped and the mycoalert test was repeated every two months. The muscle cells were transiently transfected with plasmid DNA, pcDNA3.1/hygro (Invitrogen) containing the coding region of Fzd-1 or Fzd-2 or with plasmid DNA, pcDNA3.0 (Invitrogen) containing the gene for $\beta$-catenin. Transient transfections were preformed with $3 \mu$ l Fugene6 (Roche, Indianapolis, IN, USA) and $1 \mu \mathrm{g} / \mathrm{ml}$ plasmid DNA. After transfection, the cells were cultured for 2 more days in low glucose medium, before the cells were harvested. Conditioned medium was collected from L-cells, either untransfected or stably transfected with either Wnt3a or 5a (Invitrogen).

\section{Proliferation assay}

Cells were plated in a 12 well plate and after 24 hours, at $70 \%$ confluence, these cells were transfected with $\beta$-catenin/Fzd-1/2 and/or treated with Wnts. Proliferation rates were measured after 48 hours with a BrdU incorporation assay. Cells were incubated with $100 \mu \mathrm{M}$ BrdU for one hour and afterwards fixed with methanol/acetone (1:1). After washing with PBS, cells were incubated in $2 \mathrm{~N} \mathrm{HCl}$, washed with water and incubated in $0.1 \mathrm{M}$ sodium borate $(\mathrm{pH} 8.5)$. Next, the cells were incubated with primary monoclonal mouse anti-BrdU antibody (1:1000), washed and incubated with secondary antibody rabbit anti-mouse biotin (1:400, DAKO, Glostrup, Denmark). After washing, the cells were incubated in ABC-AP solution and the labelled products were visualized using a color solution consisting

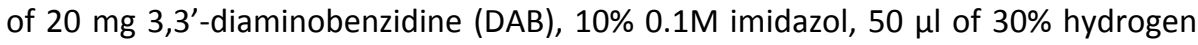
peroxide in $100 \mathrm{ml}$ of $0.05 \mathrm{M}$ Tris- $\mathrm{HCl}$ buffer ( $\mathrm{pH} 7.6)$. 


\section{Differentiation assay}

The same protocols and time lines were used for the creation of the different cell environments as described under "proliferation assay". RNA was isolated using Trizol (Invitrogen), and RNA levels and purity were defined before cDNA preparation. For the RT-PCR, the iscript ${ }^{\mathrm{TM}}{ }_{\mathrm{CDNA}}$ synthesis kit (Bio-Rad, Hercules, CA, USA) was used. With random quantitative $P C R$, the main myofibroblasts markers were determined: $\alpha$-smooth muscle actin ( $\alpha$-SMA), Mrf4, Myf5, myogenin, MyoD, desmin and vimentin. Cyclophilin served as the house keeping gene (table 1). For Western blot, cells were harvested with trypsine, pelleted and placed in $500 \mu \mathrm{l}$ icecold Laemmli buffer (6.6\% glycerol, $1.5 \%$ SDS, $4.15 \mathrm{mmol} / \mathrm{l} \mathrm{Tris} / \mathrm{HCl}, \mathrm{pH}=8.0)$ and homogenized. After $30 \mathrm{~min}$ on ice and centrifugation, the supernatants were collected and protein content was measured using the BCA protein assay (Pierce Biotechnology Inc., Rockford, ME, USA); $10 \mu \mathrm{g}$ of total protein was denatured by boiling in Laemmli sample buffer (Bio-Rad, Hercules, CA, USA), separated on a $10 \%$ SDS-page gel, and transferred onto a Hybond $C$ nitrocellulose membrane (Amersham Biosciences). After blocking ( $5 \%$ non-fat dry milk (Bio-Rad), 0.1\% Tween in TBS) for 1hour, membranes were incubated overnight at $4^{\circ} \mathrm{C}$ with primary antibodies directed against $\beta$-catenin 1/2000 (BD Biosciences, Franklin Lakes, NJ, USA), desmin, vimentin and $\beta$-actin $1 / 2000$ (Sigma-Aldrich, Saint Louis, IL, USA). Anti-rabbit or mouse immunoglobulin G 1/5000 (Vector laboratories, Burlingame, CA, USA) was used as the secondary antibody, and the membranes were developed using the Supersignal West Pico chemiluminescence kit (Pierce). Images of the blots were analyzed with image analysis software (Leica QWin, Cambridge, UK).

Table 1: Primer sequences

\begin{tabular}{lll}
\hline Genes & Forward primer & Reverse primer \\
\hline$\alpha$-SMA & AACTGGTATTGTGCTGGACTCTGG & CACGGACGATCTCACGCTCAG \\
Cyclophilin & TTCCTCCTTTCACAGAATTATTCCA & CCACCAGTGCCATTATGG \\
Desmin & TCTCCCGTGTTCCCT & ATACGAGCTAGAGTGGCA \\
Mrf4 & TGCCATCCGCTACATTGAGAG & CCGGGGTAGCAGGCTGTGAGTTG \\
Myf5 & CTGCGCGAAAGGAGGAGACTAAAG & ATGGAAGAAAGGCGCTGAAGACTG \\
MyoD & GCCCGCGTCCAACTGCTCTGAT & CCTACGGTGGTGCGCCCTCTGC \\
Myogenin & GGGCCCCTGGAAGAAAAG & AGGAGGCGCTGTGGGAGT \\
Vimentin & TGACAATGCTTCTCTGGCAC & TCCAGCAGCTTCCTGTAGGT \\
\hline
\end{tabular}

Forward and reverse sequences of all primers stated in this chapter. 


\section{$5 \quad$ Immunofluorescence}

The same protocols and time lines were used for the creation of the different cell environments as for the differentiation, proliferation and protein assays. Cells were washed and fixed with methanol/acetone (1:1). After incubation for 5 minutes with $0.5 \%$ Triton, cells where washed with PBS/glycine and incubated with $2 \%$ BSA. The cells were incubated overnight with the primary antibody, desmin or vimentin (Sigma-Aldrich) and 2 hours with secondary Alexa 488goat anti-mouse antibody (vector laboratories, Burlingam, CA, USA). Photos were taken with a camera (Leica CTR500, 63x/0.85) and analyzed with the Quantimet program (QWin/QGo, Leica).

\section{$6 \quad$ Luciferase experiments}

For the luciferase experiments, the cells were additionally transfected with a TOPFlash construct, 16 TCF/LEF binding sites cloned into the Mlu1 site of a pTA-Luc vector, kindly provided by Dr. J. Nathans. Luciferase activity was measured using a luciferase assay system (Promega, Madison, WI, USA).

\section{Statistical analysis}

All values are shown as means \pm S.E.M. Differences between groups were examined for statistical significance using two-way ANOVA with the Bonferroni post-test (Graph Pad Prism, Graph Pad Inc., La Jolla, USA). A $P$ value less than 0.05 was considered to indicate a statistically significant difference.

\section{Results}

\section{Effect of Wnt/Frizzled signaling on the proliferation}

The effect of activation of Wnt/Frizzled signaling on proliferation of the muscle cell lines was assessed using 5'-bromo-2'-deoxyuridine (BrdU) incorporation. As shown in Fig 1, the overexpression of Frizzled-1 or Frizzled-2 (rFzd-1 or -2) did not significantly affect the proliferation rate, neither by itself nor in combination with Wnt3a or Wnt5a. Direct overexpression of $\beta$-catenin or modulation of $\mathrm{Ca}^{2+}$-signaling using the calcium agonist, BayK8644 or the calcium antagonist, $( \pm$ )-verapamil hydrochloride also had no effect on the BrdU incorporation of smooth (A7r5 and PAC) and skeletal (C2C12 and L6) muscle cell lines (Fig 1). 
A

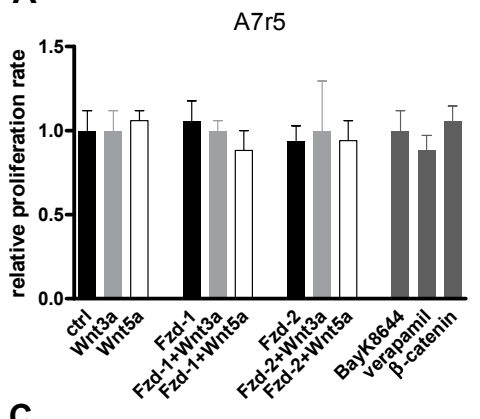

C2C12

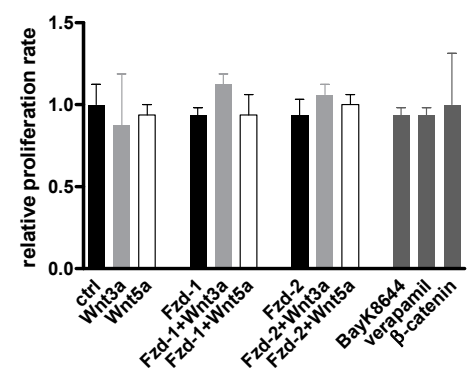

B

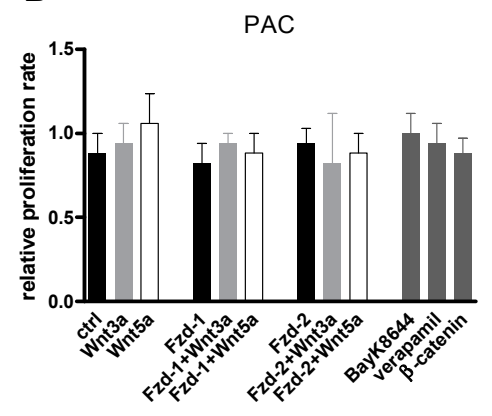

L6

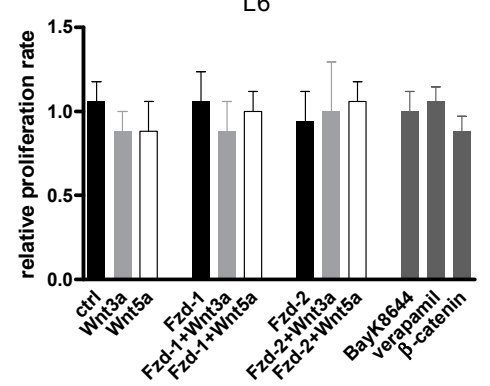

Fig 1: The proliferation rates of A. A7r5 and B. PAC, smooth muscle cells, and C. C2C12 and D. L6, skeletal muscle cells, as determined by BrdU incorporation. The proliferation rate of the cells relative to the control is shown. No significant differences to the control could be observed for either the smooth or skeletal cell lines. The data shown are a mean of three independent measurements with SEM.

\section{Effect of Wnt/Frizzled signaling on the differentiation}

The differentiation of smooth (A7r5 and PAC) and skeletal (C2C12 and L6) muscle cells was monitored by the expression of different markers for smooth and skeletal muscle, including vimentin, desmin and $\alpha$-smooth muscle actin (Fig 2). MyoD and Mrf4 (Fig 3), specific differentiation markers for skeletal muscle, were determined in both $\mathrm{A} 7 \mathrm{r} 5$ and $\mathrm{C} 2 \mathrm{C} 12$ cell lines by $\mathrm{qPCR}$. Myf5 and myogenin, two other differentiation markers for skeletal muscle, on the other hand, were below detection level (Not shown). Overexpression of rFzd-1 or -2 by itself did not affect the mRNA levels of these markers. Wnt3a and Wnt5a, however, exerted an effect on their own. These effects could be blocked completely by a combination of both rFzd-1 and -2 siRNA, indicating that this effect is due to the presence of endogenous rFzd-1 and rFzd-2 (Not shown). However, overexpression of the Fzd-1 and Fzd-2 in combination with Wnt3a or -5 a addition significantly modulated the expression patterns to a greater extent than the ligands on their own. In cells overexpressing 
A A7r5
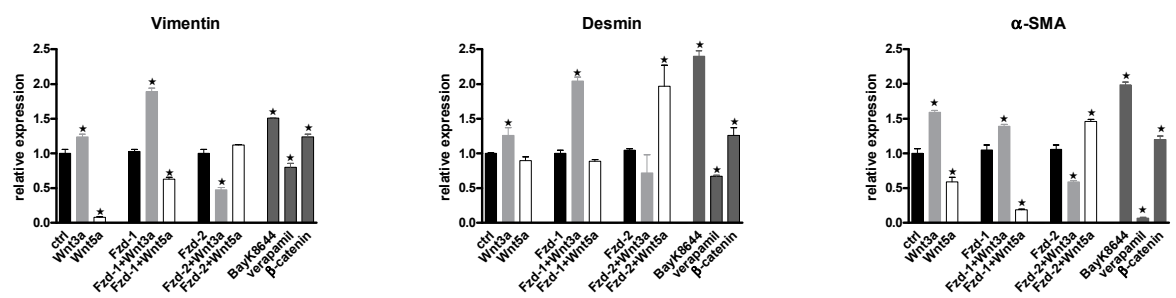

\section{B PAC}
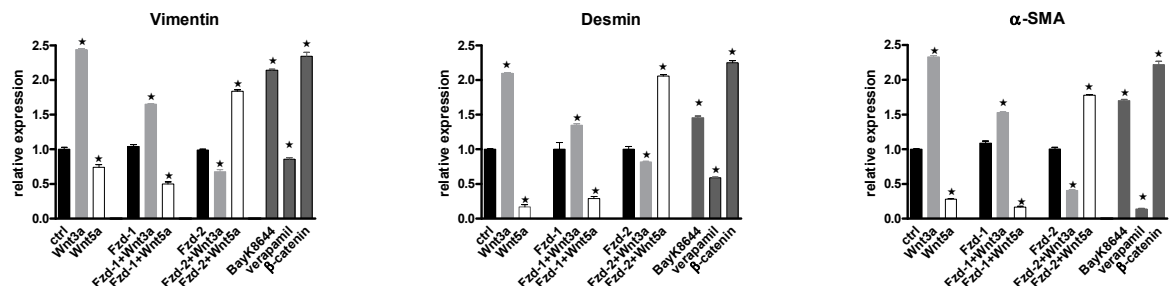

\section{C2C12}
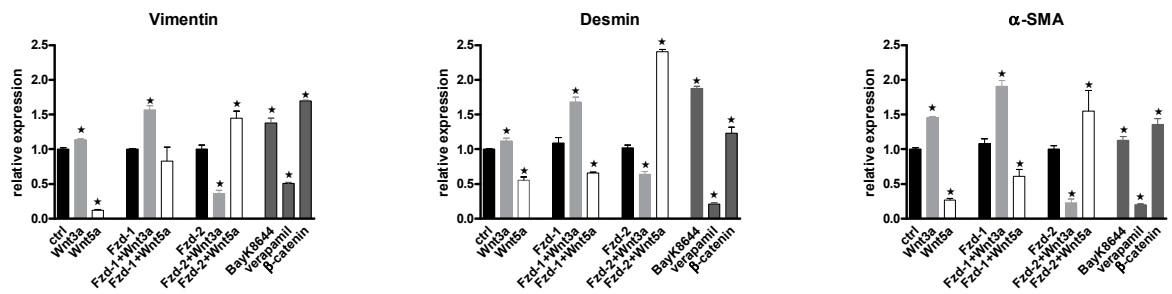

D L6
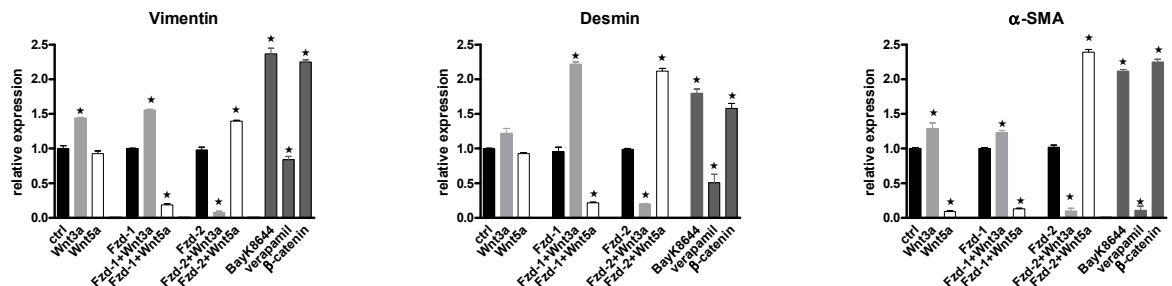

Fig 2: The differentiation of A. A7r5 and B. PAC, smooth muscle cells, and, skeletal muscle cells, C. C2C12 and D. L6. The mRNA levels of the differentiation markers were determined by qPCR and are expressed as a relative increase or decrease as compared to control. Left graphs show the differentiation marker vimentin, the middle desmin and the right $\alpha$-smooth muscle actin ( $\alpha$-SMA). All data were obtained from 6 independent experiments, all performed in duplicate. Means \pm SEM are shown; ${ }^{*}$ indicates a significant difference with the control of $p<0.001$. 


\section{A A7r5}

B C2C12

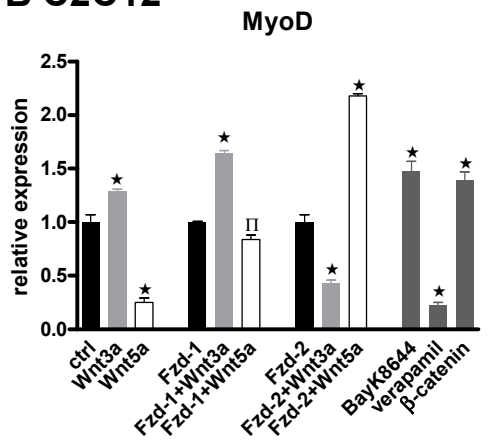

Mrf4
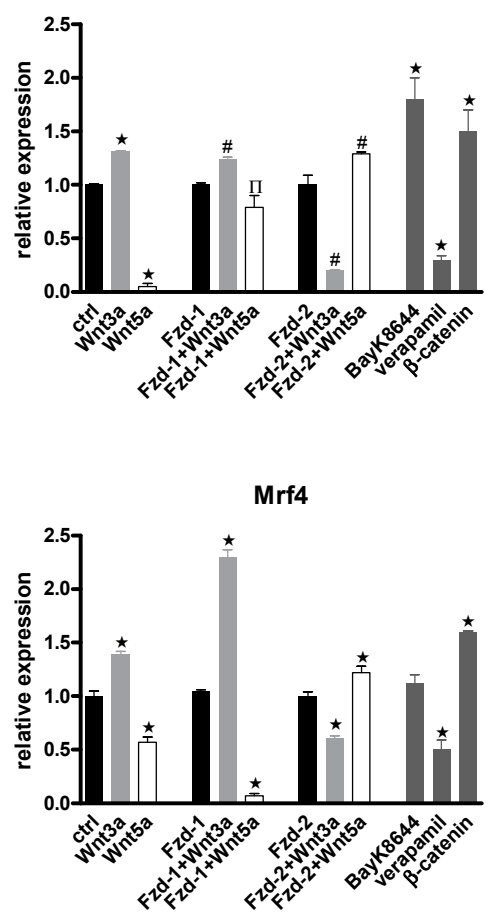

Fig 3: The differentiation of A. $\mathrm{A} 7 \mathrm{r} 5$ and B. $\mathrm{C} 2 \mathrm{C} 12$. The differentiation markers are determined by $\mathrm{qPCR}$ and expressed as a relative increase or decrease compared to control. The left graph shows the differentiation marker MyoD and the right graph, the differentiation marker Mrf4. All data were obtained from 6 independent experiments, all performed in duplicate. Means \pm SEM are shown; * indicates a significant difference to control of $p<0.001,{ }^{\#} p<0.01$ and ${ }^{\pi} p<0.05$.

rFzd-1, Wnt3a had a positive and Wnt5a a negative effect on the expression of markers for smooth and skeletal muscles. The opposite pattern was observed in cells overexpressing rFzd-2 receptors: in this case Wnt3a had a negative and Wnt5a a positive effect on the expression of markers for smooth and skeletal muscle. Overexpression of $\beta$-catenin had a positive effect on the expression of muscle markers, an effect that was also observed with the $\mathrm{Ca}^{2+}$-agonist BayK8644. The $\mathrm{Ca}^{2+}$ antagonist $( \pm)$-verapamil hydrochloride reduced the expression of these markers. Western blotting analysis of the protein levels of vimentin and desmin confirmed the expression patterns observed at the mRNA level for most part of the experimental conditions (Fig 4). 
A A7r5

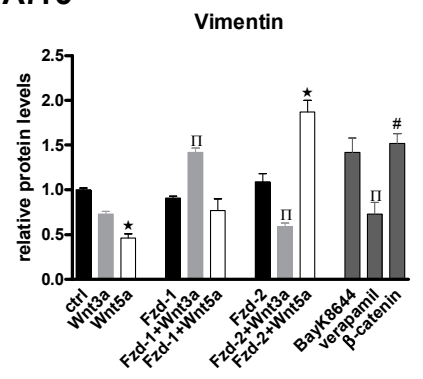

B PAC

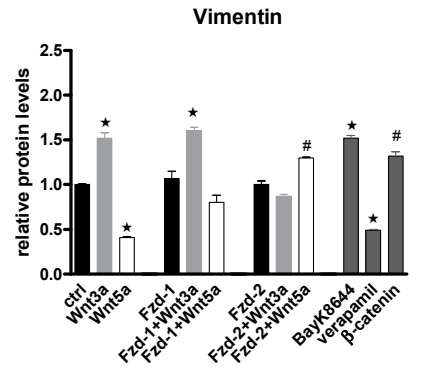

C $\mathrm{C} 2 \mathrm{C} 12$

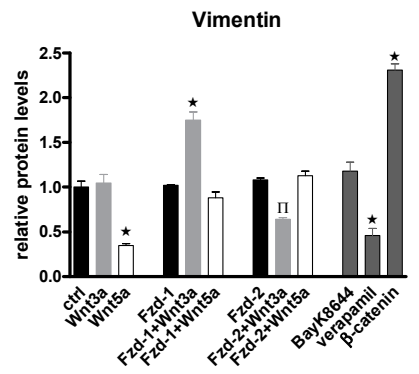

D L6

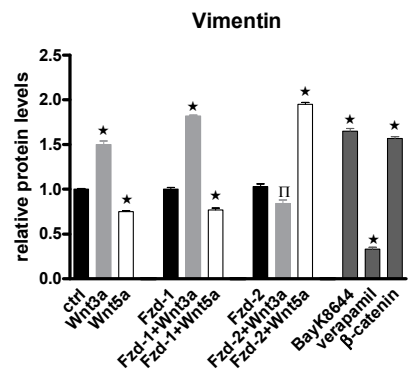

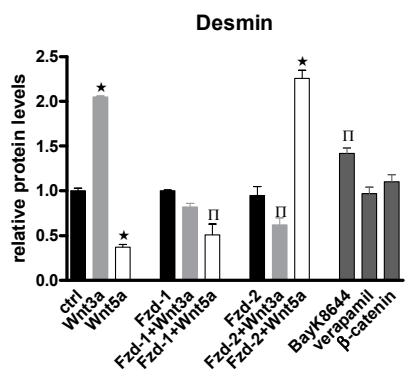

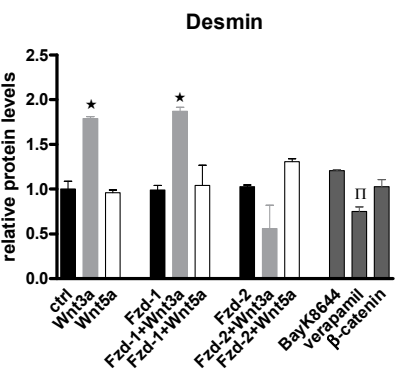

Fig 4: The protein levels of the differentiation markers vimentin and desmin in A. A7r5 and C. $\mathrm{C} 2 \mathrm{C} 12$ and vimentin in B. PAC and D. L6, as determined by Western blotting. Data were obtained from 6 independent experiments and shown as means $\pm \operatorname{SEM}\left({ }^{*} p<0.001 ;{ }^{\#} p<0.01,{ }^{\pi} p<0.05\right)$. 
The effect of rFzd-1 and Wnt3a on the differentiation of $\mathrm{C} 2 \mathrm{C} 12$ cells, studied by immunohistochemical staining for vimentin and desmin, is shown in Fig 5 . The differentiated phenotype of the $\mathrm{rFzd}-1 / \mathrm{Wnt} 3 \mathrm{a}$ treated cells was clearly visible. Similar results were obtained by treating the cells with a combination of Fzd-2 and Wnt5a (Not shown). The A7r5 cells exhibited the same differentiation pattern (Not shown).

A

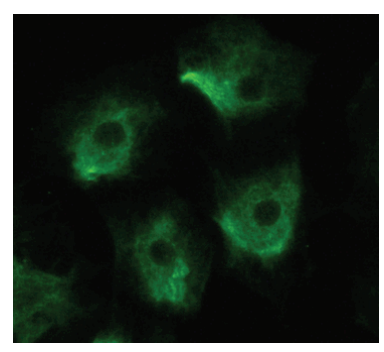

C

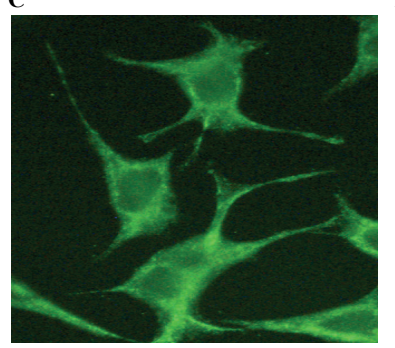

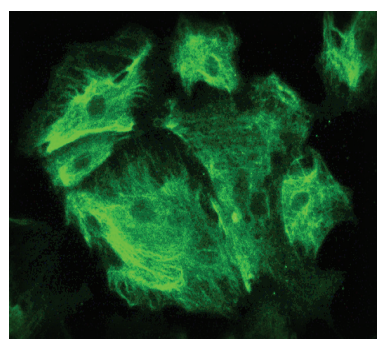

D

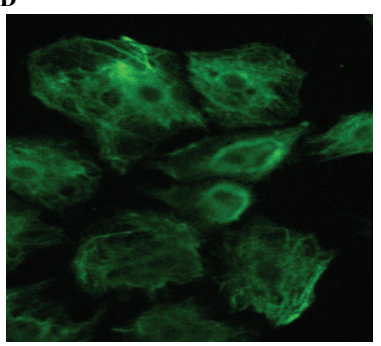

Fig 5: Representative images of immunohistochemistry using a vimentin (top) or desmin (bottom) antibody in $\mathrm{C} 2 \mathrm{C} 12$ cells. Fig $5 \mathrm{~A}$ and $\mathbf{C}$ show staining of untreated control cells, whereas in panels 5B and 5D cells treated with $\mathrm{rFzd}-1 / \mathrm{Wnt} 3 \mathrm{a}$ are shown. The latter images are representative for all the treatments that induce increased levels of vimentin and desmin.

\section{Assessment of $\boldsymbol{\beta}$-catenin mediated Wnt signaling}

B-catenin mediated Wnt signaling was assessed by studying the levels of $\beta$-catenin expression at the mRNA (qPCR, Fig 6) and protein (Western blotting, Fig 7) levels. In contrast to the differentiation experiments, here Wnt3a alone or in combination with $\mathrm{rFzd}-1$ or -2 overexpression resulted in increased $\beta$-catenin levels, whereas Wnt5a alone or in combination with Fzd-1 or -2 overexpression led to decreased $\beta$ catenin levels. As expected, transfection with a $\beta$-catenin construct induced a rise in 
$\beta$-catenin mRNA and protein levels. Interestingly, treatment with the $\mathrm{Ca}^{2+}$-agonist BayK8644 induced a rise in $\beta$-catenin levels that was similar to overexpression of the $\beta$-catenin construct, whereas the $\mathrm{Ca}^{2+}$-antagonist $( \pm)$-verapamil hydrochloride induced a marked drop in $\beta$-catenin expression.

A

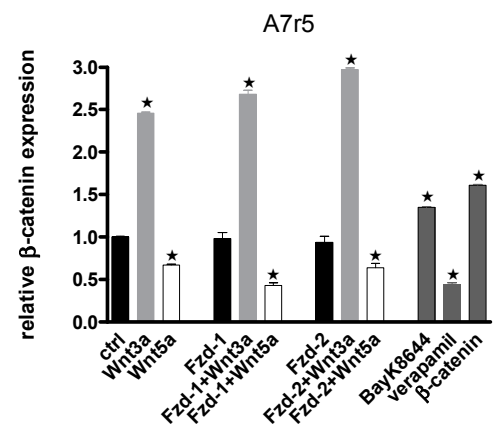

B

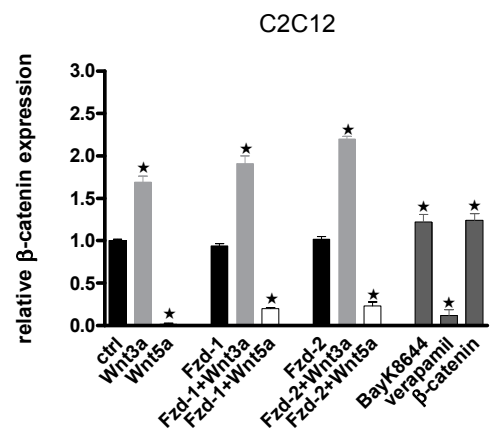

Fig 6: mRNA levels of $\beta$-catenin in A. A7r5 and B. $\mathrm{C} 2 \mathrm{C} 12$, determined by qPCR. The figure shows a significant upregulation of $\beta$-catenin after Wnt3a addition. Wnt5a, on the other hand, has an effect opposite to Wnt3a. All data were performed in 6 independent experiments, means +/- SEM are shown. All were significantly different from control $(* p<0.001)$ except for $\mathrm{rFzd}-1$ and $\mathrm{rFzd}-2$. 
A

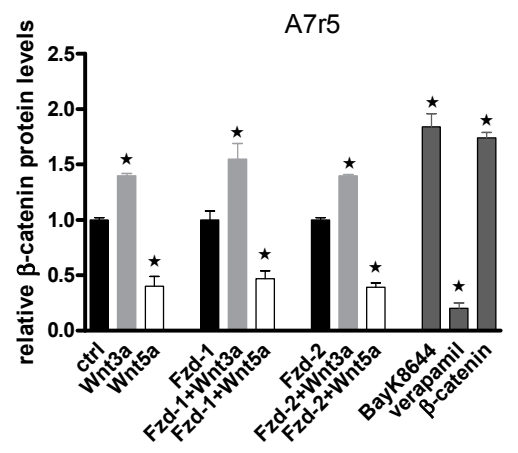

C

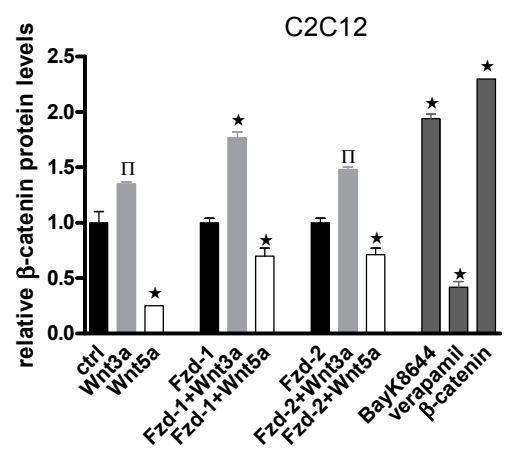

B

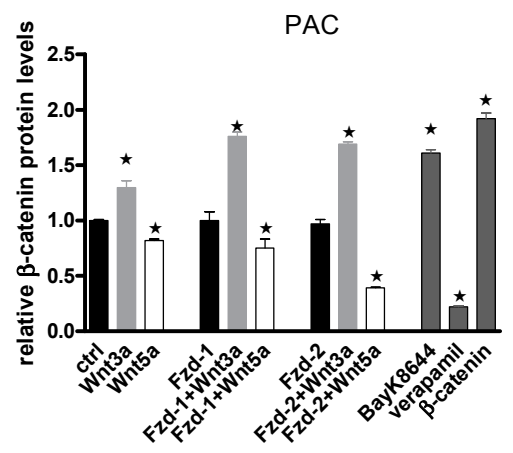

D

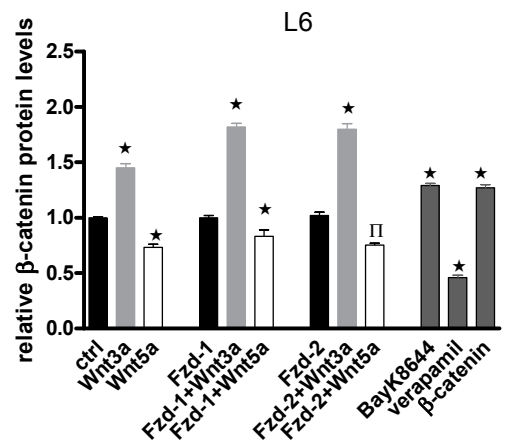

Fig 7: Protein levels of $\beta$-catenin in A. A7r5 and B. PAC, smooth muscle cells, and C. C2C12 and D. L6, skeletal muscle cells, determined by Western Blotting. The protein data confirmed the mRNA data shown in Fig. 6. All data were obtained from 6 independent experiments; means +/- SEM are shown $\left({ }^{*} p<0.001\right.$ and $\left.{ }^{\#} p<0.01\right)$.

To study the functional effect of these modulations of the $\beta$-catenin levels, we cotransfected a luciferase reporter construct under the control of TCF/LEF responsive elements (the TOPFlash reporter construct). As shown in Fig 8, Wnt3a, either alone or in combination with Fzd-1 or -2 overexpression, activated the TOPFlash reporter, whereas Wnt5a had little effect. BayK8644 and ( \pm )-verapamil hydrochloride also did not affect the TOPFlash activity, whereas transfection with the $\beta$-catenin construct induced an increase in TOPFlash activity (Fig 8). 
A

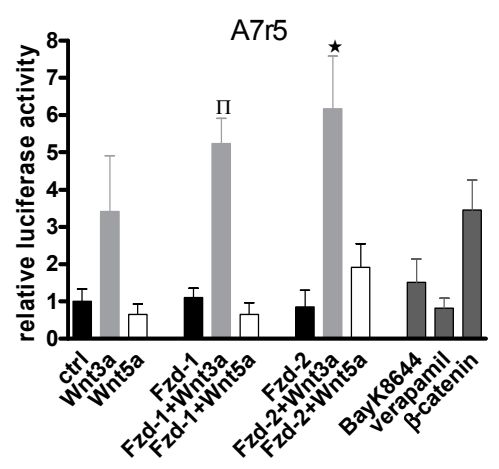

B

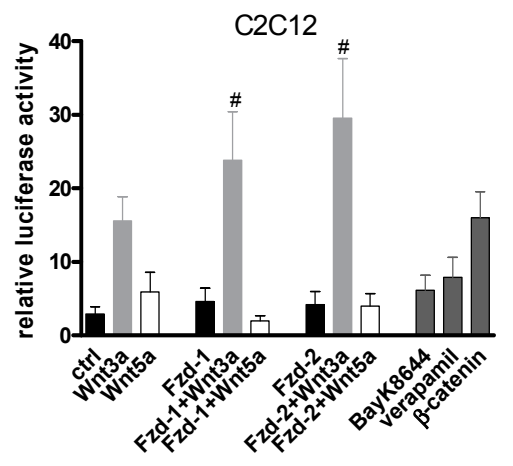

Fig 8: Activity of the TOPFlash reporter construct in A7r5 (left) and C2C12 (right) cells. All these data were performed in 6 independent experiments, means + - SEM are shown $\left({ }^{*} p<0.001 ;{ }^{\#} p<0.01,{ }^{\pi} p<0.05\right)$.

\section{Discussion}

Muscle injuries present a challenging problem in traumatology, as muscle tissue heals very slowly and often with incomplete functional recovery. After injury, muscle healing occurs in different phases, including degeneration and inflammation, muscle regeneration, and development of fibrosis ${ }^{1}$. Regeneration can be subdivided into two different processes, the first process being proliferation and the second differentiation of the muscle cells. The main finding of the present study is that different combinations of Fzd-1 and Fzd-2 with Wnt3a or -5a ligands can either stimulate or inhibit the differentiation of all muscle cell lines, both smooth and skeletal muscles.

In the present study, we subsequently focused on the signal transduction pathways that lead to smooth and skeletal muscle cell differentiation. We observed that overexpression of $\beta$-catenin promoted the expression of smooth and skeletal muscle differentiation markers. On the other hand, modulation of $\mathrm{Ca}^{2+}$-levels by either BayK8644 or ( \pm )-verapamil hydrochloride also had a strong effect on the expression of smooth and skeletal muscle differentiation markers. This suggests that the differentiation of muscle cells can be controlled by both $\beta$-catenindependent and -independent mechanisms. This may explain why certain Wnt/Frizzled combinations, e.g. Fzd-1/Wnt3a and Fzd-2/Wnt5a, have a similar positive effect on muscle differentiation but an opposite effect on $\beta$-catenin accumulation in the cells.

Wnt3a and Wnt5a were found to have opposite effects on $\beta$-catenin accumulation and activation of the TOPFlash reporter. This opposite effect was 
observed irrespective of the Frizzled that was transfected. These opposite effects of Wnt3a and Wnt5a on $\beta$-catenin mediated Wnt signaling have previously been described $^{7,8}$. Using HEK293 cells stably overexpressing the TOPFlash construct, we and other groups have observed that activation of the TOPFlash reporter by Wnt3a can effectively be counteracted by the addition of Wnt $5 \mathrm{a}^{7}$. In this respect, Wnt5a can therefore be considered to functionally antagonize the $\beta$-catenin mediated Wnt signaling activated by Wnt3a.

$\beta$-catenin mediated Wnt signaling during regeneration of smooth and skeletal muscle has been elegantly demonstrated by Brack et al, using the TOPGAL reporter mouse. They observed a temporal switch from Notch to Wnt signaling during the myogenesis of muscle stem cells ${ }^{9}$. The same group also reported a Wnt-dependent switch from a myogenic to a fibrogenic lineage in old animals ${ }^{10}$. However, these studies did not define which Wnts/Frizzleds are involved and what signal transduction pathways are activated. A role for $\beta$-catenin dependent Wnt signaling in satellite cell proliferation and differentiation has also been described ${ }^{11}$. Other studies have shown myogenic effects of Wnt1, Wnt3a, Wnt5a and Wnt5b ${ }^{11-13}$, whereas conflicting data have been presented on the myogenic effects of Wnt $4^{11,14}$. Moreover, Descamps et al. have reported inhibition of myoblast differentiation by the secreted frizzled-related proteins SFRP-1 and -2 , which are known to inactivate Wnt proteins by scavenging ${ }^{15}$. Taken together, these studies support the modulatory role of Wnt/Frizzled signaling in the differentiation of muscle cells as observed in the present study.

Modulating the $\mathrm{Ca}^{2+}$ signaling using BayK8644 or $( \pm)$-verapamil hydrochloride showed an effect on the mRNA and protein levels of $\beta$-catenin. However, in contrast to $\mathrm{Wnt} /$ Frizzled mediated modulation of $\beta$-catenin, this did not result in a change in the TOPFlash readout. This can be explained by $\beta$-catenin moving to the cadherin/catenin cell adhesion complex in the plasma membrane rather than to the nucleus where it can affect the expression of the TOPFlash construct. Because the cell adhesion complex by itself also can modulate the muscle differentiation ${ }^{16,17}$, this represents an alternative mechanism for $\beta$-catenin independent Wnt signaling in this context.

It is interesting to note that the smooth muscle cell line A7r5 and L6 can differentiate into a skeletal muscle phenotype. A7r5 and L6 cells express the skeletal muscle differentiation markers MyoD and Mrf4 after differentiation. This switch from smooth to skeletal muscle cell has been reported before ${ }^{18}$. Insulin-like growth factor (IGF) was responsible for the differentiation of A7r5 cells into cells with a skeletal phenotype. Since IGF is a known inhibitor of the $\beta$-catenin mediated Wnt signaling pathway ${ }^{19}$ it is not surprising that modulation of Wnt signaling is capable of inducing elevated expression of skeletal muscle markers in A7r5 and L6 cells as was observed in the present study. 
In conclusion, we have shown that activation of Wnt/Frizzled signaling in smooth and skeletal muscle cell lines can modulate the differentiation of these cells. These effects could not be attributed to a single signal transduction pathway, but probably are mediated by both $\beta$-catenin dependent and $\beta$-catenin independent mechanisms. The findings suggest that Wnt/Frizzled signaling forms an interesting novel therapeutic target for muscle differentiation. However, care should be taken that the appropriate subtypes of Wnt ligands and Frizzleds are affected to avoid inappropriate differentiation effects ${ }^{20}$.

\section{Funding}

This work was supported by BSIK 03033; Molecular Imaging of Ischemic heart disease.

\section{References}

1. Huard J, Li Y, Fu FH. Muscle injuries and repair: current trends in research. J Bone Joint Surg Am 2002;84-A:822-32.

2. Zhao J, Kim KA, Abo A. Tipping the balance: modulating the Wnt pathway for tissue repair. Trends Biotechnol 2009;27:131-6.

3. Christ B,Huang R. Wnts in muscle development in Wnt signaling in development (ed. Kuhl, M.) 146155 (Kluwer academic press, New York USA, 2003).

4. Cadigan KM. Wnt-beta-catenin signaling. Curr Biol 2008;18:R943-7.

5. Wang HY, Malbon CC. Wnt-frizzled signaling to G-protein-coupled effectors. Cell Mol Life Sci 2004;61:69-75.

6. Blankesteijn WM, van de Schans VA, Ter Horst P, Smits JF. The Wnt/frizzled/GSK-3beta pathway: a novel therapeutic target for cardiac hypertrophy. Trends Pharmacol Sci 2008;585:338-345

7. Mikels AJ, Nusse R. Purified Wnt5a protein activates or inhibits beta-catenin-TCF signaling depending on receptor context. PLoS Biol 2006;4:e115.

8. Yokoyama N, Yin D,Malbon CC. Abundance, complexation, and trafficking of Wnt/beta-catenin signaling elements in response to Wnt3. J Mol Signal 2007;2:11.

9. Brack AS, Conboy IM, Conboy MJ, Shen J, Rando TA. A temporal switch from notch to Wnt signaling in muscle stem cells is necessary for normal adult myogenesis. Cell Stem Cell 2008;2:50-9.

10. Brack AS, Conboy MJ, Roy S, Lee M, Kuo CJ, Keller C et al. Increased Wnt signaling during aging alters muscle stem cell fate and increases fibrosis. Science 2007;317:807-10.

11. Otto A, Schmidt C, Luke G, Allen S, Valasek P, Muntoni F et al. Canonical Wnt signalling induces satellite-cell proliferation during adult skeletal muscle regeneration. J Cell Sci 2008;121:2939-50.

12. Ridgeway AG, Petropoulos $\mathrm{H}$, Wilton $\mathrm{S}$, Skerjanc IS. Wnt signaling regulates the function of MyoD and myogenin. J Biol Chem 2000;275:32398-405.

13. Rochat A, Fernandez A, Vandromme M, Moles JP, Bouschet T, Carnac G et al. Insulin and wnt1 pathways cooperate to induce reserve cell activation in differentiation and myotube hypertrophy. Mol Biol Cell 2004;15:4544-55.

14. Takata H, Terada K, Oka H, Sunada Y, Moriguchi T,Nohno T. Involvement of Wnt4 signaling during myogenic proliferation and differentiation of skeletal muscle. Dev Dyn 2007;236:2800-7.

15. Descamps S, Arzouk H, Bacou F, Bernardi H, Fedon Y, Gay S et al. Inhibition of myoblast differentiation by Sfrp1 and Sfrp2. Cell Tissue Res 2008;332:299-306. 
16. Redfield A, Nieman MT, Knudsen KA. Cadherins promote skeletal muscle differentiation in threedimensional cultures. J Cell Biol 1997;138:1323-31.

17. Zeschnigk M, Kozian D, Kuch C, Schmoll M,Starzinski-Powitz A. Involvement of M-cadherin in terminal differentiation of skeletal muscle cells. J Cell Sci 1995;108 ( Pt 9):2973-81.

18. Graves DC, Yablonka-Reuveni Z. Vascular smooth muscle cells spontaneously adopt a skeletal muscle phenotype: a unique Myf5(-)/MyoD(+) myogenic program. J Histochem Cytochem 2000;48:1173-93.

19. Zhu W, Shiojima I, Ito Y, Li Z, Ikeda H, Yoshida M et al. IGFBP-4 is an inhibitor of canonical Wnt signalling required for cardiogenesis. Nature 2008;454:345-9.

20. Chien AJ, Conrad WH, Moon RT. A Wnt survival guide: from flies to human disease. J Invest Dermatol 2009;129:1614-27. 



\section{A fragment of Wnt5a blocks Frizzled- 1 and -2 with high affinity in vitro and in vivo}

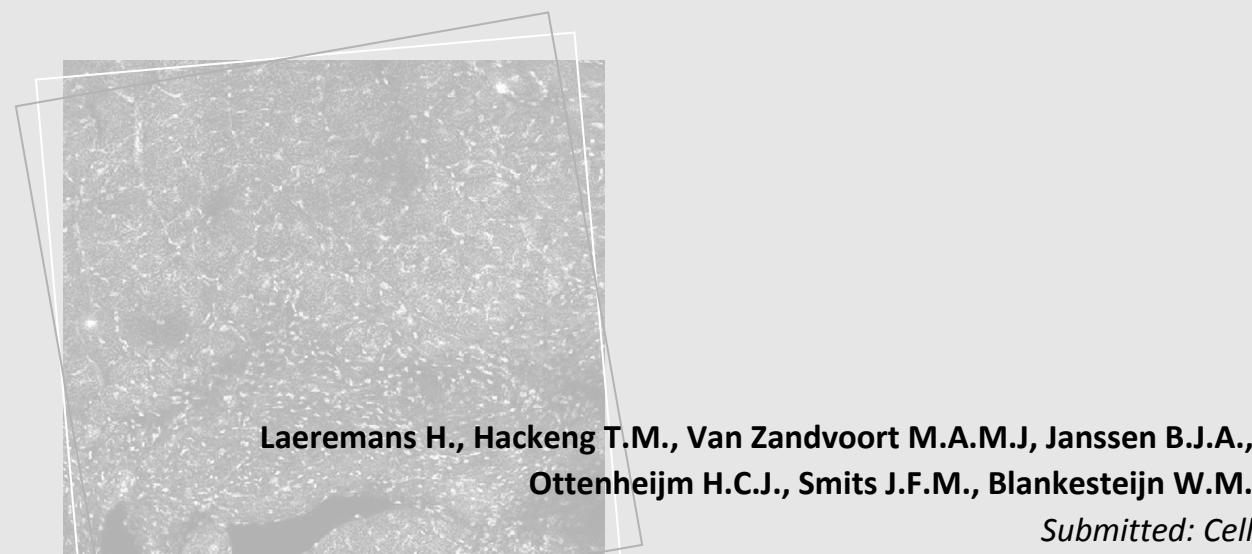




\begin{abstract}
Wnt/Frizzled signaling has been studied for decades, but low molecular weight ligands that bind to Frizzled-1 and Frizzled-2 are still lacking. Here we describe the rational design of three peptides derived from areas of high homology between Wnt3a and Wnt5a, known ligands for Frizzled-1 and -2. UM206, the peptide with the highest affinity, could block the effect of Wnt3a and Wnt5a in different in vitro assays. UM206 binding could be prevented by either UM207 or Wnt3a, suggesting a shared binding site on their receptor. Administration of this compound to mice for up to 5 weeks, starting immediately after the induction of myocardial infarction, reduced infarct size, increased capillary and myofibroblast numbers in the infarct area and completely prevented heart failure development. These findings highlight the potential of the Frizzled-1 and -2 as a new target for pharmacotherapy of cardiac remodeling after myocardial infarction.
\end{abstract}

\title{
Key words
}

Frizzled-1 and Frizzled-2; low molecular weight ligand; myocardial infarction; heart failure 


\section{Introduction}

The importance of Wnt signaling in developmental processes like cell proliferation, differentiation and migration has been recognized for decades ${ }^{1}$. More recently, Wnt signaling has also been implicated in a rapidly growing number of pathological conditions, and the role of aberrant Wnt signaling in several types of cancer has been firmly established ${ }^{2}$. Although less well studied, there is growing evidence for a role for Wnt signaling in cardiovascular diseases, particularly in the remodeling of the heart that takes place in response to an increased workload or myocardial infarction $(\mathrm{MI})^{3-5}$. The underlying mechanism of $\mathrm{Wnt}$ signaling in cardiovascular diseases, however, is fundamentally different from that in e.g. colon cancer, where mutations in the downstream signaling pathway lead to deregulation of the signaling and contribute to an uncontrolled cell proliferation in the primary tumor ${ }^{6}$. In cardiovascular diseases, no such mutations have been found to date. Instead, the expression of components of the Wnt signaling pathway is increased, suggesting an activation of this pathway rather than a deregulation ${ }^{3,4}$.

The involvement of Wnt signaling in multiple disease processes has fuelled an intensive search for compounds that can modulate the activity of this pathway ${ }^{7}$. The major focus of this research has been on the signal transduction pathway where $\beta$ catenin acts as a second messenger. The degradation of $\beta$-catenin is controlled by a complex containing casein kinase I (CK1), glycogen synthase kinase $3 \beta$ (GSK-3 $\beta$ ), axin and adenomatous polyposis coli gene product $(A P C)^{8}$. Several well-known compounds have been found to attenuate Wnt signaling, including $\mathrm{LiCl}$, Vitamins $\mathrm{A}$ and $D$ and non-steroidal anti-inflammatory drugs (NSAIDs) ${ }^{9}$. Moreover, novel drugs that inhibit GSK-3 $\beta$ or intervene in the interaction of $\beta$-catenin and TCF have been described $^{10}$. These compounds hold great promise in the treatment of cancer, where $\beta$-catenin accumulation due to a defective degradation complex is a hallmark $^{11}$. In diseases characterized by an activated rather than a defective Wnt signaling, a direct intervention at the level of the Wnt receptor Frizzled appears to be preferable to avoid side effects.

To activate signaling, Wnt proteins bind to a receptor complex formed by a member of the Frizzled family and an LDL receptor-like protein (LRP) ${ }^{11,12}$. This can evoke different intracellular responses, involving either $\beta$-catenin ${ }^{8}, \mathrm{Ca}^{2+}$ or Rho kinase as a second messenger ${ }^{13}$. Apart from the interactions between $\mathrm{Wnt} 3 \mathrm{a} / 5 \mathrm{a}$ and Frizzled-1 and -2, knowledge about the specific interactions between members of the Wnt family (19 members) and Frizzled (10 isoforms) is limited ${ }^{12,14}$. Research on these interactions has been hampered significantly so far by the lack of specific ligands.

The aim of the present study was to identify small peptidergic ligands with high affinity for Fzd-1 and -2 and to characterize their pharmacological properties. To this end, we identified areas of high homology between Wnt3a and $5 a$ that contained at 
least two cysteines. Regions necessary for excretion or post-translational modification of Wnt5a were excluded. This rational approach yielded three peptides, ranging from 13-22 amino acids in length. We tested their pharmacological properties in HEK293 superTOPFlash cells and immortalized cardiac fibroblasts, and selected the peptide with highest affinity, UM206. We subsequently determined the pharmacokinetic properties of UM206, and studied the effect of UM206 administration to the wound healing process after MI in mice. Finally, we confirmed that the peptide fragments utilize the Wnt3a binding site on Fzd-1 and -2 .

\section{Methods}

\section{$1 \quad$ Materials}

The HEK293 superTOPFlash line was kindly provided by J. Nathans and $\mathrm{CHO}$ and COS-7 were obtained from DSMZ, Braunschweig, Germany. The CFIT cell line was developed and characterized in our lab ${ }^{15,16}$. The TOPFlash construct was also kindly provided by J. Nathans. First batches of peptide were made by our lab; larger second batch was order (ChemPep, Maimi, FL, USA). UM208 was dissolved in medium with guanidine $(0.1 \mathrm{M} \mathrm{pH}=7.4)$ to improve solubility before HPLC.

\section{Cell culture and transient transfection}

The cell lines were cultured in $75 \mathrm{~cm}^{2}$ culture flasks (Corning, Schiphol, the Netherlands) in Dulbeco's modified essential medium with L-glutamine (2mM), 10\% fetal calf serum (Invitrogen, Merelbeke, Belgium), and 1\% gentamycin (Sigma-Aldrich, Zwijndrecht, The Netherlands). Before starting the experiment, the cell lines were treated with plasmocin $25 \mu \mathrm{g} / \mathrm{ml}$ (Invivogen, Toulouse, France) and tested with a mycoalert mycoplasma detection kit (Lonza, Rockland, ME, USA). Cells were transiently transfected with Fugene6 (Roche, Indianapolis, IN, USA) with plasmid DNA, pcDNA3.1/hygro (Invitrogen) with Frizzled-1/2/4 or Wnts 3a-5a (developed in our lab by W.M. Blankesteijn) or with pcDNA3.0 (Invitrogen) containing the $\beta$-catenin or Frizzled-5 sequence. After transfection, the cells were cultured for 24 hours in conditioned medium, collected from the cultured L-cells, L-cells with Wnt3a or $5 \mathrm{a}$ (Invitrogen). At the same moment the antagonist was added.

\section{$3 \quad$ HPLC}

Analytical HPLC was performed using a Vydac C18 RP-HPLC column (4.6 mm × 150 $\mathrm{mm}, 1 \mathrm{~mL} / \mathrm{min}$ flow rate) connected to a Varian Prostar system consisting of two Varian Prostar 215 delivery modules and a Varian Prostar 320 UV/Vis detector (214 
$\mathrm{nm})$. A linear gradient of $0-67 \%$ buffer $B$ in buffer $A$ over 30 minutes was used, where buffer $A=0.1 \mathrm{v}-\%$ TFA in $\mathrm{H}_{2} \mathrm{O}$ and buffer $B=0.1 \mathrm{v}-\%$ TFA, $10 \mathrm{v}-\% \mathrm{H}_{2} \mathrm{O}$ in $\mathrm{CH}_{3} \mathrm{CN}$.

Semi-preparative HPLC was performed using Vydac C18 RP-HPLC columns (10 $\mathrm{mm} \times 250 \mathrm{~mm}, 5 \mathrm{~mL} / \mathrm{min}$ flow rate or $22 \mathrm{~mm} \times 250 \mathrm{~mm}, 10 \mathrm{~mL} / \mathrm{min}$ flow rate) connected to a Waters Deltaprep System consisting of a Waters Prep LC Controller and a Waters 2487 Dual wavelength Absorbance Detector (214 nm). Peptides were eluted using a shallow gradient of B in A, based on an exploratory analytical HPLC run (vide supra).

Product containing fractions were analyzed by Electrospray lonization Mass Spectrometry (ESI-MS) (vide infra), pooled and lyophilized Mass Spectrometry. ESIMS was performed on an Applied Biosystems SCIEX API 150 EX electrospray ionization quadrupole (ESI-Q) mass spectrometer. Peptide masses were calculated from the experimental mass to charge $(\mathrm{m} / \mathrm{z})$ ratios from all the protonation states observed in the ESI-MS spectrum of a peptide using Analyst 1.4.2 software (Sciex).

\section{$4 \quad$ Peptide Fragment Synthesis}

All peptide fragments were synthesized by manual solid-phase peptide synthesis on a 0.3-0.4 mmol scale using the in situ neutralization/activation procedure for Boc/Bzl- peptide synthesis as previously described ${ }^{17,18}$, but using HCTU instead of HBTU as a coupling reagent. MBHA-polystyrene resin (1 meq/g) was used as the solid support. Rhodamine was added as a common peptide.

The peptides were deprotected and cleaved from the resin by treatment with anhydrous $\mathrm{HF}$ for $1 \mathrm{~h}$ at $0^{\circ} \mathrm{C}$, using $4 \mathrm{v}-\% \mathrm{p}$-cresol as a scavenger. Following cleavage, the peptides were precipitated with ice-cold diethylether, filtered, dissolved in aqueous buffer containing $6 \mathrm{M}$ Guanidine. $\mathrm{HCl}, 0.1 \mathrm{M}$ sodium acetate buffer $(\mathrm{pH} 4)$ and purified by semi-preparative reversed-phase HPLC. Fractions containing the desired product were identified by ESI-MS, pooled and lyophilized ${ }^{17,18}$.

\section{$5 \quad$ Luciferase experiments}

For the luciferase experiments in not HEK cells, the cells were additionally transfected with a TOPFlash construct, 16 TCF/LEF binding sites cloned into the pTA-Luc vector. Luciferase activity was measured using luciferase assay system (Promega, Madison, WI, USA).

\section{Migration assay}

Cells were plate on day 0 , and cultured until $70 \%$ confluence before transfection or treatment. Migration assays started 48 hours after transfection and/or treatment. 
The time point were the scratch was made, is indicated as 0 hours. Scratch width was measured at this time point, and also after 6-12-24 hours.

\section{Quantative PCR}

RNA was isolated using the Trizol method (Invitrogen). For the RT-PCR, the RNA was transcripted to cDNA with iscript ${ }^{T M}{ }{ }^{2} D N A$ synthesis kit (Bio-Rad, Hercules, CA, USA), Syber green (Eurogentec, Ghent, Belgium) was used for the detection of cDNA levels and cyclophilin served as the house keeping gene. In Table 1, the primer sequences are shown.

Table 1: Primer sequences.

\begin{tabular}{lll}
\hline Genes & Primers forward & Primers reverse \\
\hline$\alpha$-actin & CAGCTGAGAGGGAAATCGTG & CGTTGCCAATAGTGATGACC \\
Ascl-2 & AAGCACACCTTGACTGGTACG & AAGTGGACGTTTGCACCTTCA \\
$\alpha$-SMA & AACTGGTATTGTGCTGGACTCTGG & CACGGACGATCTCACGCTCAG \\
Axin 2 & TGACTCTCCTTCCAGATCCCA & TGCCCACATAGGCTGACA \\
CD 44 & TCTGCCATCTAGCACTAAGAGC & GTCTGGGTATTGAAAGGTTTAGC \\
Collagen l 11 & TCGATTCACCTACAGCACGC & GACTGTCTTGCCCCAAGTTCC \\
Collagen III & TCCTGAACATGTCCTTTGATGTA & TTCAGAGACTTCTTTACATTGCCATT \\
Cyclophilin & TTCCTCCTTTCACAGAATTATTCCA & CCGCCAGTGCCATTATGG \\
Dickkopf 1 & TAGTCCCACCCGCGGAGGGGA & CTTCTGGAATACCCATCCAA \\
Dickkopf 2 & GGATCTTCAGCCTGCATGGT & GGGCAACACATCCCATCTCT \\
Dickkopf 3 & TCAGGAGGAAGCTACGCTCAA & GGTCACCTCAGAGGACGTTCTAG \\
Dvl 2 & ACTGGTGCGGTCTAGGTTTTA & GGAAGACGTGCCCAAGGA \\
Fibronectin & TGTCACCCACCACCTTGA & CTGATTGTTCTTCAGTGCGA \\
Fibronectin ED-A & ACCATTGAAGGTTTGCAACC & GGAGGTGCTGTCTGGAGAAA \\
Fibronectin ED-B & AGAATAACCACCACCCCA & TGTTAGGACCACGGCGTT \\
Inos & CATCCAGAGTGAGCTGGTAGG & GCTGGTAGGGGCAAAAATAGAGGAACATCT \\
Itm 2A & AGGAGAGCCATACTTTCTGCC & GCCGGATCGCTATCAGAGAGA \\
LEF & CACACATCCCGTCAGATGTC & TGATGGGATAAACAGGCTGA \\
MMP 7 & CTGCCACTGTCCCAGGAAG & GGGAGAGTTTTCCAGTCATCG \\
Twist & CTCGGACAAGCTGAGCAAG & ACGGAGAAGGCGTAGCTGAG \\
\hline
\end{tabular}

Forward and reverse sequences of all primers stated in this chapter.

\section{Western blots}

For Western blot, cells were homogenized in ice-cold Laemmli buffer and protein content was measured using the BCA protein assay (Pierce Biotechnology Inc., Rockford, IL, USA); proteins were denatured by boiling, separated on a $10 \%$ SDSpage gel, and transferred onto a Hybond $C$ nitrocellulose membrane (Amersham Biosciences, Little Chalfont, United Kingdom). After blocking, membranes were incubated overnight at $4^{\circ} \mathrm{C}$ with primary antibodies against $\beta$-catenin, $\alpha$-SMA (both 1:2000, BD Biosciences, Franklin Lakes, NJ, USA) or $\beta$-actin (1:2000 Sigma, Bornem, Belgium). Anti-mouse immunoglobulin G $1 / 5000$ (Vector Labs Inc.) was used as the 
secondary antibody, and the membranes were developed using the Supersignal West Pico chemiluminescence kit (Pierce). Images of the blots were analyzed with image analysis software (Qwin Leica, Cambridge, United Kingdom).

\section{Animal surgery}

Male Swiss mice were used (10-12 weeks of age. Charles River, Maastricht, The Netherlands). The animals were randomly included into the three different experimental groups. For the pharmacokinetics, animals had a venous canule, where a bolus injection of UM206 was given and blood samples were collected. In the treatment study, either UM206 (6 $\mathrm{\mu g} / \mathrm{kg} /$ day) or saline were administrated by an osmotic minipump (Alzet 2002 or 2006 for 2 and 5 weeks treatment, respectively; Alzet, Maastricht, the Netherlands). MI was induced, under isoflurane anesthesia as previously described ${ }^{19}$. All experimental procedures were approved by the Committee for Animal Research of Maastricht University.

\section{Echocardiography}

All animals were subjected to extensive echocardiography studies for the assessment of myocardial infarct size, LV cavity dimensions and ventricular function. Echocardiography examination was preformed under $2 \%$ isoflurane. Echocardiograms were recorded with Philips Sonos 5500 ultrasound system (Philips, Eindhoven, the Netherlands) using a $20-\mathrm{MHz}$ linear probe.

\section{Hemodynamic measurements}

The animals were anaesthetized with urethane $(2.5 \mathrm{~m} / \mathrm{g}$ body weight, i.p., SigmaAldrich) followed by intubation and connected to a rodent ventilator (Hugo Sachs, March-Hugstetten, Germany). Body temperature was maintained at $37^{\circ} \mathrm{C}$. The mice were then allowed to stabilize prior to hemodynamic measurements. A high-fidelity catheter tip micromanometer (Mikro-tip1.4F, SPR-671; Millar Instruments, Houston, TX, USA) was inserted through the right carotid artery into the left ventricular cavity. Ventricular pressure was measured. Maximal positive and negative pressure development $(+\mathrm{dP} / \mathrm{dt}$ and $-\mathrm{dP} / \mathrm{dt})$ and heart rate were determined on a beat-tobeat basis. The heart was then stimulated by an i.v. ramp-infusion of dobutamine (Sigma) using a micro-injection pump (Model 200 Series, KdScientific, Boston, MA, USA). 
One half of the hearts of the mice was embedded in paraffin and cut in $4 \mu \mathrm{m}$ sections. The paraffin sections were rehydrated and washed in PBS. One section was stained with AZAN, allowing an accurate determination of the infarct size. To visualize the myofibroblasts in the infarct area, the sections were incubated with an antibody directed against $\alpha$-smooth muscle actin (Sigma-Aldrich), followed by incubation with the peroxidase-conjugated secondary antibody (Vector laboratories, Burlingame, CA, USA). Nuclei were visualized by haematoxylin. Photos were taken with a Leica (CTR500, 63x/0.85) camera and analyzed with the Quantimet program (QWin/QGo). An examiner blinded to the groups of the animals obtained all measurements. For the experiments with Rhodamine-labeled UM206 frozen sections $(4 \mu \mathrm{m})$ of mouse kidney and small intestine were used.

\section{Statistical analysis}

All values are shown as mean \pm S.E.M. Differences between groups were examined for statistical significance using two-way ANOVA with the Bonferroni post-test or unpaired student T-test (Graph Pad Prism). A $P$ value less than 0.05 was considered as a statistically significant difference.

\section{Results}

\section{Identification and pharmacological characterization of the peptidergic Frizzled antagonists}

The alignment of Wnt3a and 5a is shown in Fig 1A. Three areas of high homology that contained 2 cysteines are indicated in blue (UM207), green (UM208) and red (UM206). In Fig 1B-D, the inhibitory effect of these three peptides on Wnt3ainduced luciferase activity in HEK293 superTOPFlash is shown. In each figure, the left set of columns shows that none of the three peptides by itself could induce an increase in luciferase activity in these cells, whereas addition of Wnt3a increases luciferase activity $\sim 450$-fold. Transfection of $\mathrm{rFzd}-1$ (middle set of columns) or $\mathrm{rFzd}-2$ (right set of columns) further increased the Wnt3a-induced luciferase activity, an effect that could be blocked almost completely by administration of either UM206 (Fig 1B), UM207 (Fig 1C) or UM208 (Fig 1D) at a concentration of $100 \mathrm{nM}$. A complete inhibition of Wnt3a-induced TOPFlash activation was also observed in $\mathrm{CHO}$ and COS-7 cells overexpressing either rFzd-1 or -2 (Fig 2A and B), albeit that the fold induction of luciferase activity was considerably lower in these cells. Again, the peptides by themselves had no effect on the luciferase activity. Peptides derived from other regions showed no activity at concentrations up to $10 \mu \mathrm{M}$ (Fig 2 table 2). 

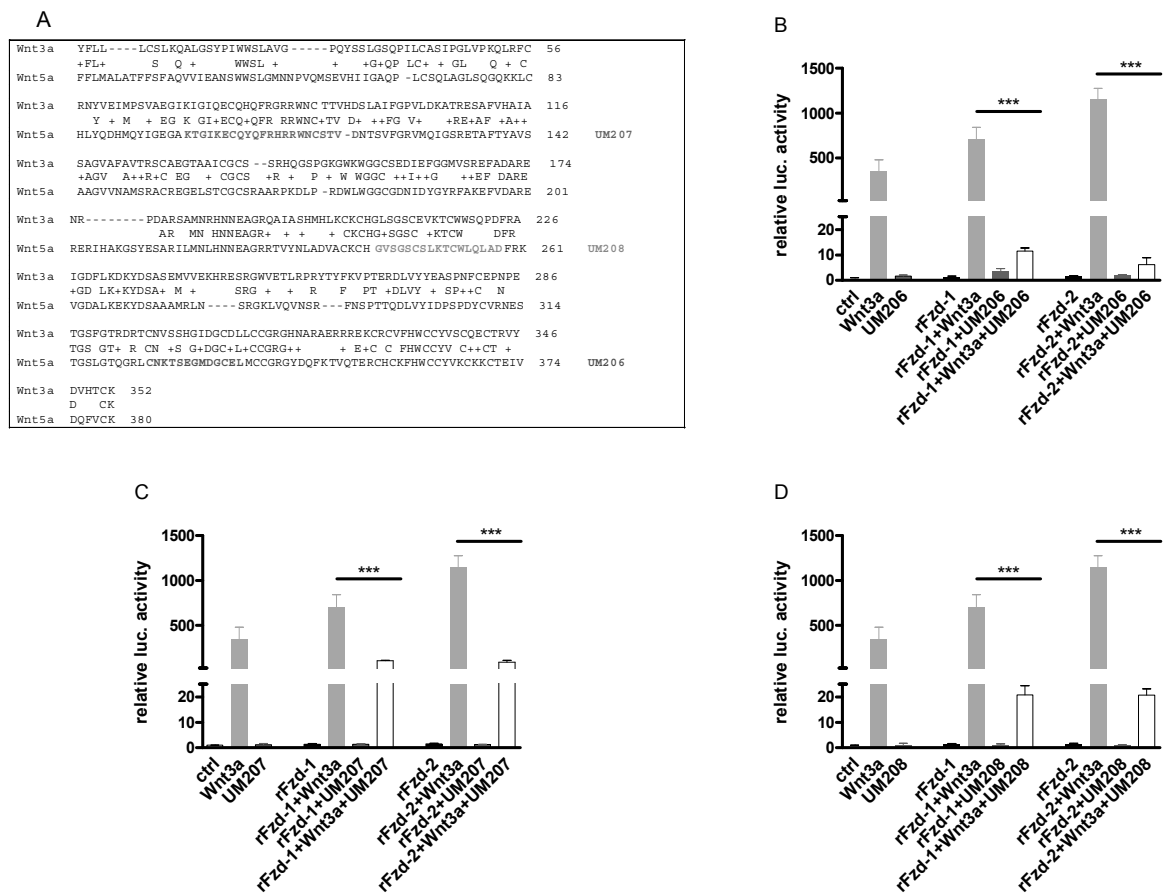

Fig 1: A. The alignments of Wnt3a and Wnt5a, two members of the Wnt family that both can bind to Frizzled-1 and Frizzled-2. B.-D. The inhibitory effects of respectively UM206, UM207 and UM208 tested in a HEK superTOPFlash cell line. The cells were transfected with either Fzd-1 or -2 as indicated; peptide concentration was $10 \mathrm{nM}$. All results are the average of three independent measurements and are represented as means + - SEM $(* * * \mathrm{P}<0.001)$. 


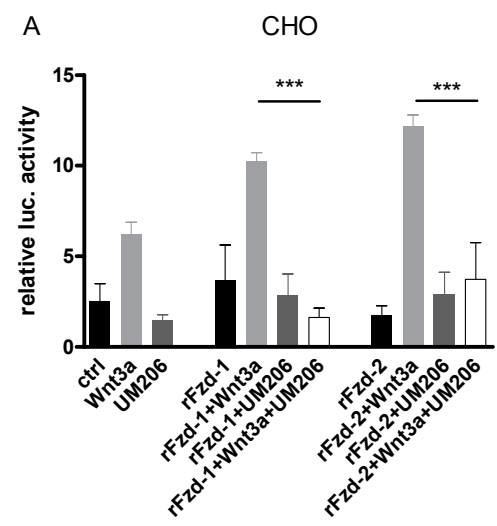

B

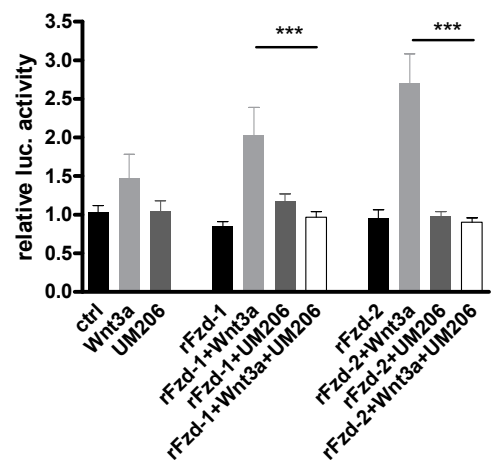

C Table 2
Fig 2: A.-B. TOPFlash experiments to determine the effects of UM206 on the $\beta$ catenin dependent Wnt/Fzd pathway were repeated in two other cell lines. The data confirmed the HEK superTOPFlash data, namely that UM206 can selectively block $\beta$-catenin dependent Wnt/Fzd-1/2 signaling activated. All results are the average of three independent measurements and are represented as means +/SEM (*** $\mathrm{P}<0.001)$. C. A table of alternative peptides that were tested, but were unable to influence the Wnt/Fzd signal transduction cascade. Please note that the sequences of these peptides do not comply with our criteria for Fzd ligands.

\begin{tabular}{l|l}
\hline & sequence \\
\hline Peptide 1 & Ac-CKCHGVSGSCTVKTCW-NH \\
Peptide 2 & Ac-MNRHNNEAGR-NH \\
Peptide 3 & Ac-IEECQHQFRDRRWNC-NH 2 \\
Peptide 4 & Ac-GDWEW GECSDNI-NH \\
Peptide 5 & Ac-DLVYFELSPDFCA-NH \\
Peptide 6 & Ac-GSKGTQGRACN-NH \\
Peptide 7 & Ac-CNKSGMDGCEL-NH \\
\hline
\end{tabular}

To determine the inhibitory constants of UM206-8, HEK293 superTOPFlash cells were transfected with either rFzd-1 or -2 and incubated with Wnt3a (1 nM) in the presence of increasing concentrations of either of the peptides (Fig 3). For UM206, a biphasic inhibition curve was observed that was best fitted with a 2 binding state model. In HEK293 superTOPFlash cells transfected with $\mathrm{rFzd}-2$, the high affinity site with an $\mathrm{IC}_{50}$ of $1.69 \pm 0.0410^{-11} \mathrm{M}$ was most prominent, whereas in $\mathrm{rFzd}-1$ transfected cells, the binding site with an IC50 of $2.10 \pm 0.1810^{-9} \mathrm{M}$ was the major binding site. This suggests that UM206 binds to rFzd-2 with a 100 fold higher 
affinity than to rFzd-1. In contrast, the inhibition curves for UM207 and UM208 were best fitted with a single binding site model; the $\mathrm{IC}_{50}$ values for Fzd- 2 were 1.52 $\pm 0.0810^{-8} \mathrm{M}$ and $2.11 \pm 0.1110^{-6}$, and for Fzd-1, $4.00 \pm 0.0710^{-8} \mathrm{M}$ and $2.06 \pm 0.09$ $10^{-6} \mathrm{M}$, respectively. These results clearly show that UM206 has the highest affinity for $\mathrm{rFzd}-1$ and -2 , so in the remainder of the experiments this antagonist was used.
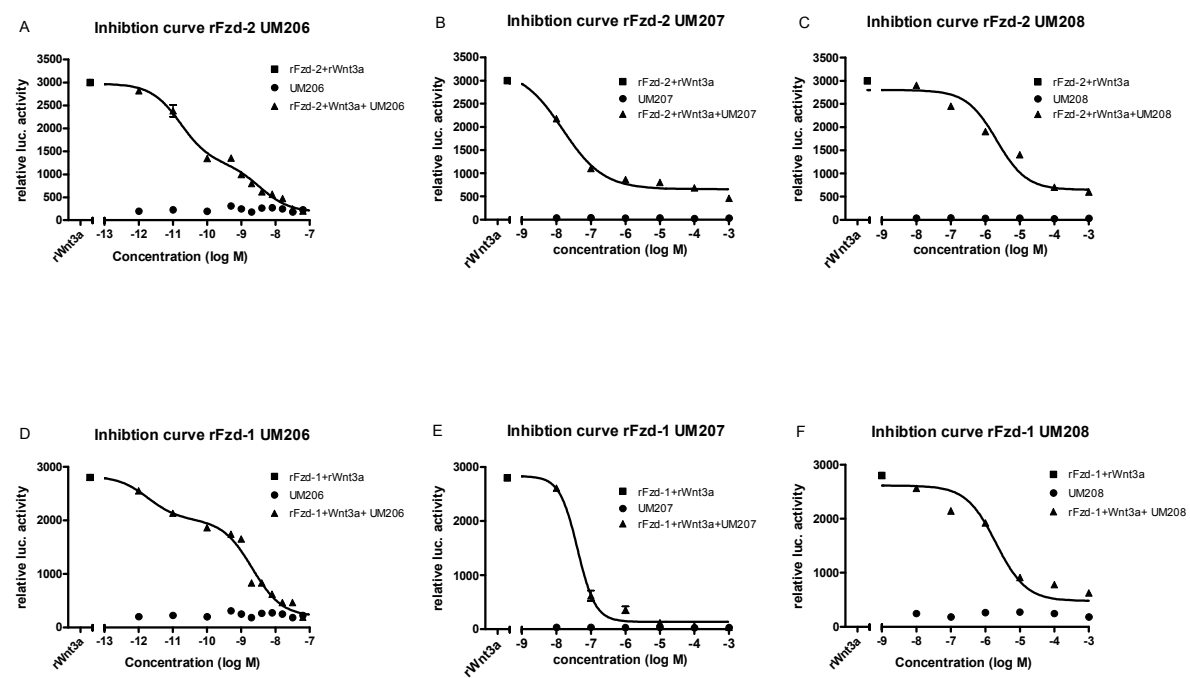

Fig 3: A.-C. Inhibition curves for UM206, UM207 and UM208 on HEK293-TOPFlash overexpressing cells, transfected with the rFzd-2 receptor and activated with Wnt3a. Curve A was significantly better fitted with by a two site model, leading to the reported $I C_{50}$ values for the transfected Fzd-2 receptor. D.-F. Same experiments with rFzd-1 overexpression. For these experiments, UM208 was dissolved in medium with guanidine to improve solubility. All results are the average of three independent measurements and are represented as means $+/-\operatorname{SEM}(* * * \mathrm{P}<0.001)$.

\section{UM206 is selective for Frizzled-1 and -2}

In Fig 4A, the efficacy of UM206 to block the Wnt3a-induced activation of luciferase activity in HEK293 superTOPFlash cells transfected with different Frizzled is shown. Addition of UM206 in a concentration of $1.10^{-8} \mathrm{M}$ abolished the induction of luciferase activity almost completely in cells overexpressing rFzd-1 and -2 , but had no effect on cells overexpressing hFzd-4 or -5 . This was not due to species differences, because UM206 was fully effective in antagonizing the activation of mouse and human Fzd-1 and -2 by Wnt3a as well (Not shown). From these results we conclude that UM206 is a high affinity antagonist for Fzd-1 and -2 but that it does not block Fzd-4 and -5 in a relevant concentration range. 


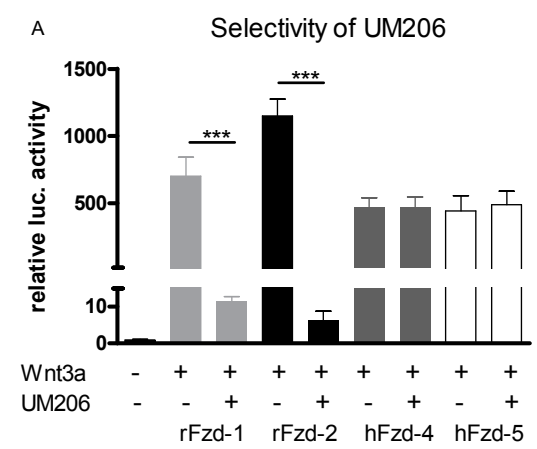

B Table 3

\begin{tabular}{|c|c|c|}
\hline & $\%$ of inhibition for $\mathrm{Fz} d-1$ & $\%$ of inhibition for $\mathrm{Fz} d-2$ \\
\hline Wnt3a & $0 \%$ & $0 \%$ \\
\hline Wnt3a+ UM206 & $72.2 \%$ & $85.1 \%$ \\
\hline $\mathrm{Wnt} 3 \mathrm{a}+\mathrm{UM} 206\left(\mathrm{C}^{1} \rightarrow \mathrm{A}\right)$ & $70.8 \%$ & $82.6 \%$ \\
\hline Wnt3a + UM206 $\left(\mathrm{N}^{2} \rightarrow \mathrm{A}\right)$ & $67.9 \%$ & $79.5 \%$ \\
\hline Wnt3a + UM206 $\left(K^{3} \rightarrow A\right)$ & $70.8 \%$ & $84.9 \%$ \\
\hline $\mathbf{W n t 3 a}+\operatorname{UM206}\left(\mathrm{T}^{4} \rightarrow \mathbf{A}\right)$ & $28.1 \%$ & $59.4 \%$ \\
\hline Wnt3a + UM2 $206\left(S^{5} \rightarrow A\right)$ & $74.3 \%$ & $87.3 \%$ \\
\hline Wnt3a+UM206 $\left(E^{6} \rightarrow A\right)$ & $70.8 \%$ & $84.7 \%$ \\
\hline Wnt3a + UM206 $\left(\mathrm{G}^{7} \rightarrow \mathbf{A}\right)$ & $52.6 \%$ & $63.1 \%$ \\
\hline Wnt3a + UM206 $\left(M^{8} \rightarrow A\right)$ & $67.6 \%$ & $85.0 \%$ \\
\hline Wnt3a + UM206 $\left(D^{9} \rightarrow \mathbf{A}\right)$ & $40.5 \%$ & $60.5 \%$ \\
\hline Wnt3a+UM206 $\left(D^{10} \rightarrow A\right)$ & $69.9 \%$ & $83.3 \%$ \\
\hline Wnt3a+ UM206 $\left(\mathrm{C}^{11} \rightarrow \mathrm{A}\right)$ & $67.2 \%$ & $84.9 \%$ \\
\hline Wnt3a + UM206 $\left(\mathrm{E}^{12} \rightarrow \mathrm{A}\right)$ & $65.9 \%$ & $85.5 \%$ \\
\hline Wnt3a + UM206 $\left(L^{13} \rightarrow A\right)$ & $65.9 \%$ & $86.5 \%$ \\
\hline Wnt3a + UM206 $(C \rightarrow A)$ & & $8.4 \%$ \\
\hline Wnt3a + UM206 (C $\rightarrow C$-alkyl $)$ & $1 \%$ & $\begin{array}{l}.0 .4 \% \\
12.4 \%\end{array}$ \\
\hline Wnt3a + UM206 $(C \rightarrow S)$ & $0 \%$ & $17.0 \%$ \\
\hline Wnt3a + UM206 - & $18.0 \%$ & $61.2 \%$ \\
\hline $\mathbf{W n t 3 a}+\mathbf{U M 2 0 6}\left(E^{12} L^{13} \rightarrow \mathbf{A A}\right)$ & $66.8 \%$ & $74.3 \%$ \\
\hline $\mathbf{W n t} 3 \mathbf{a}+\mathbf{U M 2 0 6}\left(\mathrm{T}^{4} \rightarrow \mathbf{A} \mathrm{G}^{7} \rightarrow \mathbf{A} \mathrm{D}^{9} \rightarrow \mathbf{A}\right)$ & $11.2 \%$ & $17.5 \%$ \\
\hline Wnt3a+CNVSSHGIDGCDL & $45.3 \%$ & $62.4 \%$ \\
\hline
\end{tabular}

Fig 4: A. Selectivity of UM206 for four different Frizzleds. These results indicate that UM206 at a concentration of $10 \mathrm{nM}$ specifically blocks Fzd-1 and -2. B. Table 3: Essential amino acids for antagonistic activity of UM206 were determined by an Ala scan; furthermore, some additional modifications were tested. All peptides were tested at a concentration of $10 \mathrm{nM}$. These results highlighted four important amino acids, namely: Cys, Thr, Asp and Gly. Replacement of both cysteines by Ala or Ser, or alkylation of both Cys, abolished the antagonistic properties of UM206. Simultaneous replacement of Thr, Asp and Gly by Ala strongly reduced the antagonistic properties of UM206. The peptide CNVSSHGIDGCDL, derived from the area of Wnt3a homologous to UM206, showed antagonistic properties too, albeit that the potency was lower than that of UM206. All results are the average of three independent measurements and are represented as means +/SEM (*** $\mathrm{P}<0.001)$.

\section{Structure-activity relationship of UM206}

In Fig 4B Table 3, the effect of substitution of each of the individual amino acids by Ala on Wnt3a-induced luciferase activity is shown. In this experiment, the antagonists were tested in a concentration of $10 \mathrm{nM}$, allowing the detection of more subtle changes in antagonistic properties that could remain unnoticed at a concentration of $1.10^{-9} \mathrm{M}$. This Ala-scan showed that replacement of $\mathrm{Thr}^{4}$, Gly ${ }^{7}$ and Asp ${ }^{9}$ affected the inhibitory properties of UM206 most strongly. The combination of these three replacements abolished the antagonizing properties almost completely. Substitution of either of the Cys residues at position 1 or 11 did not affect the antagonistic effect of UM206, but simultaneous substitution of both Cys residues by either Ala or Ser rendered UM206 completely ineffective. Substitution of the C-terminal Glu and Leu by an Ala-Ala sequence reduced the inhibitory properties of UM206 only slightly, whereas deletion of the C-terminal Glu and Leu sequence led to a significant reduction of the potency of UM206. Therefore, we tentatively conclude that the antagonistic activity of UM206 is largely due to the proper spatial positioning of the three amino acid residues Thr, Gly and Asp and to the presence of at least one Cys residue. 
The overexpression of Fzd-1 and -2 in migrating (myo)fibroblasts during infarct healing was one of the first reports of activation of Wnt/Frizzled signaling in cardiovascular remodeling ${ }^{20}$. To assess the functional relevance of Wnt/Frizzled signaling on cardiac fibroblast proliferation, migration and differentiation, a cardiac fibroblast cell line immortalized with telomerase was used, as previously described ${ }^{16}$. As shown in Fig 5, administration of either Wnt3a or Wnt5a attenuated the migration of cardiac fibroblasts immortalized with telomerase (CFIT) overexpressing either rFzd-1 or -2 (panel A and B, respectively). The effects of Wnt proteins on cell migration were blocked almost completely by addition of UM206 (10 nM) to the culture medium.
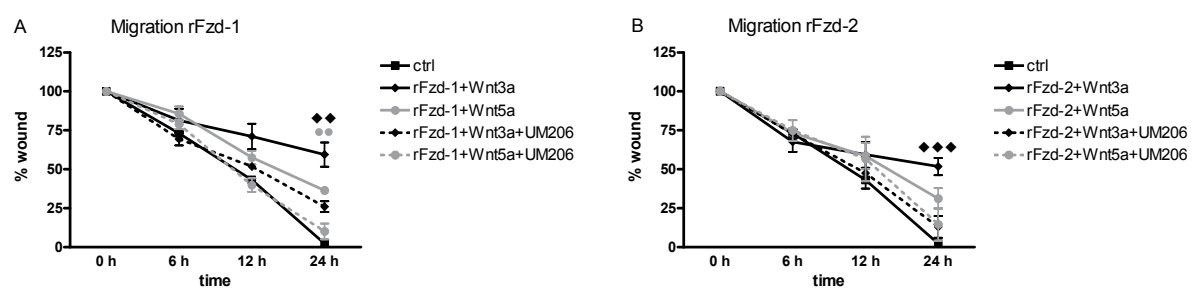

Fig 5: A.-B. Wound assay in which the migration of cardiac fibroblasts immortalized with telomerase (CFIT) into a scratch in the cell layer was studied under different conditions. Overexpression of Fzd-1 or -2 alone or in combination with Wnt3a or Wnt5a significantly attenuated the CFIT migration. This attenuation of the migration could be counteracted by addition of UM206 $\left(1.10^{-8} \mathrm{M}\right)$. All results are the average of three independent measurements and are represented as means +/- SEM (** $\mathrm{p}<0.01$ and *** $\mathrm{P}<0.001)$.

\section{UM206 reduced ventricular remodeling and prevented heart failure development after myocardial infarction in mice}

In order to determine the pharmacokinetic properties of UM206, we injected $15 \mathrm{ng}$ of the compound into the tail vein of mice and monitored the concentration in the blood at different time points. The half-life turned out to be $84 \pm 2 \mathrm{~min}$ ( $\mathrm{n}=24$; Fig 6). This half-life, combined with the high affinity of UM206 allowed us to test its effects on infarct healing in mice. To this end, we administered UM206 subcutaneously by an osmotic minipump (6 microgram $/ \mathrm{kg} /$ day); the control group was equipped with a saline-filled minipump. The minipumps were implanted the time of infarct induction and infusion lasted for up to 5 weeks. UM206 administration offered a dramatic improvement of survival: at 5 weeks after MI $35 \%$ of the salinetreated mice had died whereas not a single mouse had died in the UM206-treated group (Fig 7A). Post-mortem analysis revealed that the mortality in the salinetreated group was due to heart failure, as diagnosed by a wet, foamy aspect of the 
lungs and severely elevated wet lung weight. In the surviving saline-treated mice wet lung weight was $40 \%$ higher than in the UM206-treated mice at 5 weeks post$\mathrm{MI}$, suggesting development of heart failure in the surviving saline-treated mice as well (Fig 7B). Echocardiography showed a $50 \%$ less reduction of the ejection fraction and a $40 \%$ reduction in end diastolic volume of the left ventricle in the UM206treated group, all indicative for a better preservation of cardiac function (Fig 7 C12). Further details of the echocardiographic analysis are provided in Table 4. Cardiac function was further assessed using a Millar pressure recording catheter inserted into the left ventricle. The tangents on the pressure time curve were significantly steeper in the UM206-treated groups, resulting in a higher positive $\mathrm{dP} / \mathrm{dt}$ and a lower negative $\mathrm{dP} / \mathrm{dt}$ value (Fig $7 \mathrm{D} 1-2$ ). Additional hemodynamic parameters are presented in Table 5. These observations further underscore the beneficial effect of UM206 treatment on cardiac function post-MI.

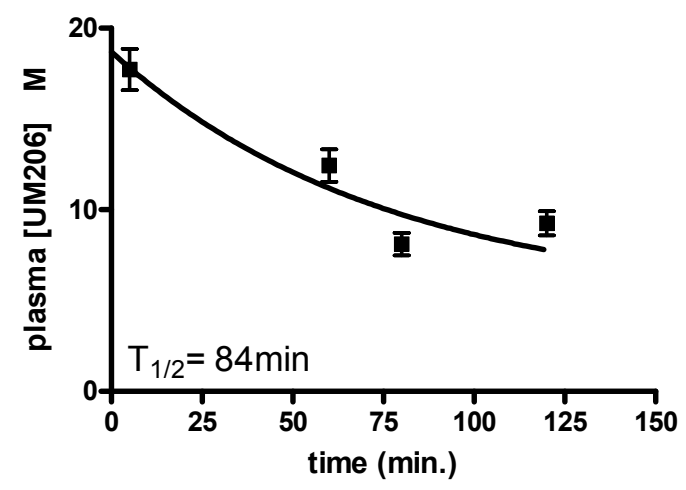

Fig 6: Pharmacokinetic study, in which UM206 (15 ng) was injected into the tail vein of mice. Blood was sampled at the indicated time points and the amount of UM206 was determined using HPLC, revealing a half life of $84 \pm 2$ minutes. 

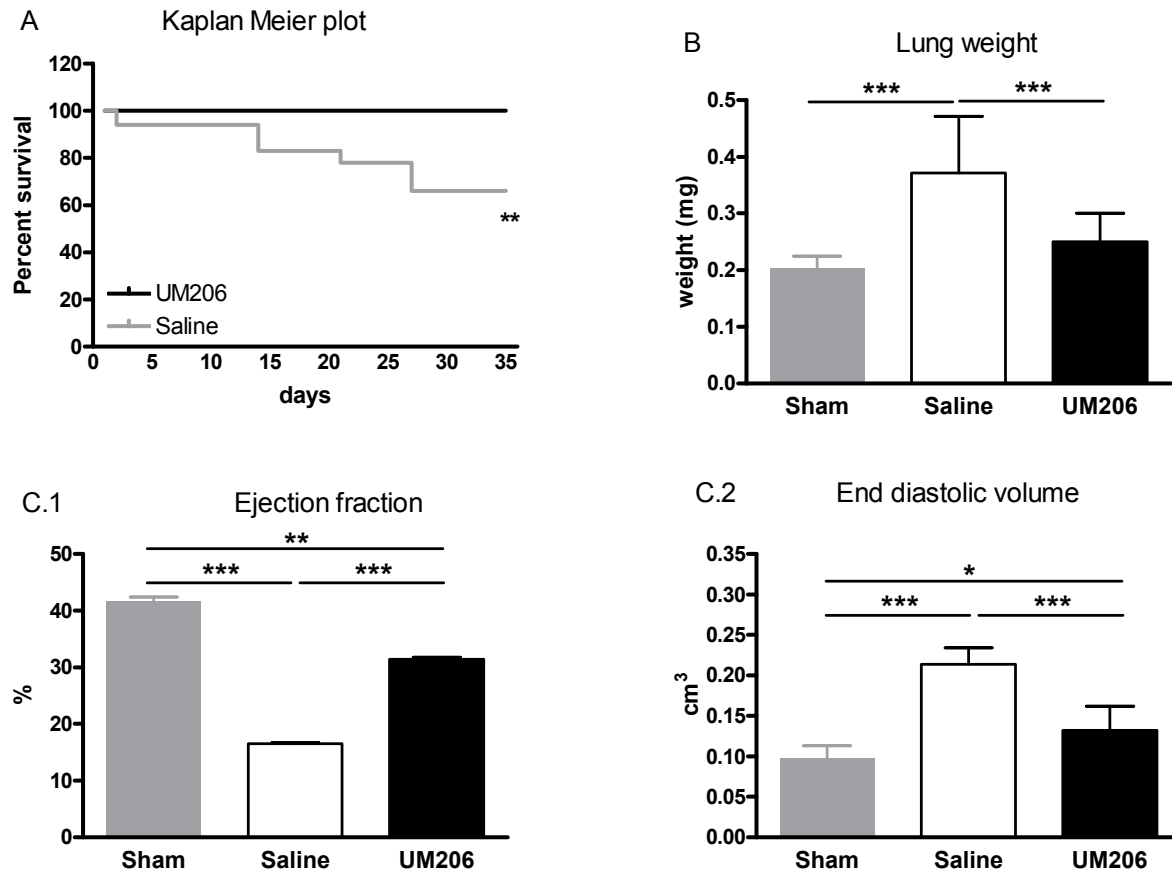

C.2 End diastolic volume
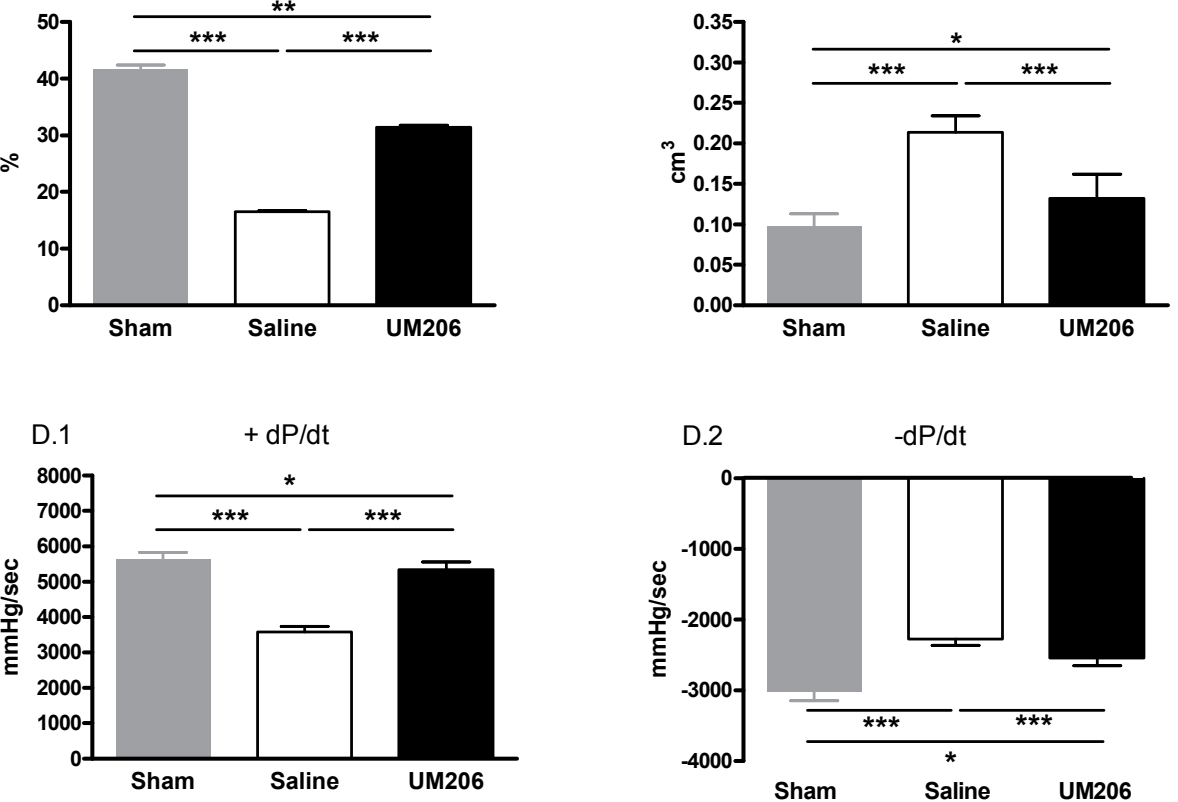

Fig 7: A. The Kaplan Meier plot of the effect of UM206 treatment on the survival rate of mice in which myocardial infarction was induced at $\mathrm{t}=0$. UM206 treatment completely prevented the mortality after infarction, whereas in saline-treated mice the mortality was $~ 35 \%$ after 5 weeks B. UM206 reduced heart failure in the mice that survived for 5 weeks after $\mathrm{MI}$, as shown by the increased lung weights in the saline-treated group. C.1-2 Echocardiographical measurements, like for example ejection fraction and end diastolic volume, are indicative of an improved cardiac function in the UM206-treated group. D.1-2 Hemodynamic measurements indicate that cardiac function was significantly better preserved after UM206 treatment. All results are the mean of 26 animals and are represented as means $+/-$ SEM ( ${ }^{*} \mathrm{p}<$ $0.05, * * \mathrm{p}<0.01$ and $* * * \mathrm{P}<0.001)$. 
Table 4: Echocardiographic parameters of mice treated with UM206 compared to saline-treated mice.

\begin{tabular}{ll|lllllll}
\hline & & \multicolumn{2}{c}{ Sham } & \multicolumn{2}{c}{ Saline } & \multicolumn{2}{c}{ UM206 } & P-value \\
& & AVG & SEM & AVG & SEM & AVG & SEM & \\
\hline LVLd & $\mathrm{cm}$ & 0.89 & 0.06 & 1.01 & 0.02 & 0.95 & 0.02 & $<0.001$ \\
LVLs & $\mathrm{cm}$ & 0.78 & 0.04 & 0.97 & 0.01 & 0.89 & 0.02 & $<0.001$ \\
LVAs & $\mathrm{cm}^{2}$ & 0.20 & 0.02 & 0.44 & 0.01 & 0.30 & 0.01 & $<0.001$ \\
LVLs & $\mathrm{cm}$ & 0.86 & 0.02 & 0.93 & 0.10 & 0.86 & 0.10 & $<0.001$ \\
IVSd posterior wall & $\mathrm{cm}$ & 0.09 & 0.01 & 0.07 & 0.01 & 0.09 & 0.01 & $<0.001$ \\
LVIDd & $\mathrm{cm}$ & 0.49 & 0.02 & 0.71 & 0.01 & 0.59 & 0.01 & $<0.001$ \\
IVSs posterior wall & $\mathrm{cm}$ & 0.13 & 0.01 & 0.10 & 0.01 & 0.14 & 0.01 & $<0.001$ \\
LVIDs & $\mathrm{cm}$ & 0.36 & 0.02 & 0.65 & 0.01 & 0.52 & 0.01 & $<0.001$ \\
EDV_L & $\mathrm{cm}$ & 0.088 & 0.006 & 0.214 & 0.02 & 0.132 & 0.02 & $<0.001$ \\
ESV_L & $\mathrm{cm}$ & 0.041 & 0.007 & 0.179 & 0.007 & 0.090 & 0.007 & $<0.001$ \\
SV_L & $\mathrm{cm}$ & 0.043 & 0.008 & 0.035 & 0.005 & 0.041 & 0.005 & $>0.05$ \\
EF_L & $\%$ & 51.1 & 0.68 & 16.50 & 0.30 & 31.4 & 0.30 & $<0.001$ \\
FS & $\%$ & 25.19 & 0.39 & 8.60 & 0.50 & 13.20 & 0.50 & $<0.001$ \\
AoD & $\mathrm{cm}$ & 0.16 & 0.006 & 0.19 & 0.01 & 0.18 & 0.01 & $>0.05$ \\
\hline
\end{tabular}

Table 5: Hemodynamic measurements. All results are the mean of 26 animals and are presented as means +/- SEM.

\begin{tabular}{|c|c|c|c|c|c|c|c|c|}
\hline & & & nam & & line & & 1206 & P-values \\
\hline & & AVG & SEM & AVG & SEM & AVG & SEM & \\
\hline Heart rate & Beats/min & 449 & 27 & 512 & 36 & 502 & 47 & $>0.05$ \\
\hline Systolic pressure & $\mathrm{mmHG}$ & 66 & 11 & 77 & 4 & 72 & 7 & $>0.05$ \\
\hline Diastolic pressure & $\mathrm{mmHG}$ & 3.4 & 1.5 & 6.9 & 3.1 & 4.8 & 3.2 & $>0.05$ \\
\hline $\begin{array}{l}\text { Left ventricular } \\
\text { pressure }\end{array}$ & $\mathrm{mmHG}$ & 27.3 & 2.8 & 27.2 & 2.9 & 27.8 & 4.1 & $>0.05$ \\
\hline $\begin{array}{l}\text { Maximum positive } \\
\text { slope }\end{array}$ & $\mathrm{mmHG}$ & 6646 & 183 & 3584 & 167 & 5343 & 229 & $<0.001$ \\
\hline $\begin{array}{l}\text { Maximum negative } \\
\text { slope }\end{array}$ & $\mathrm{mmHG}$ & -3025 & 41 & -2276 & 88 & -2542 & 59 & $<0.001$ \\
\hline
\end{tabular}

\section{UM206 treatment improved the characteristics of the infarct area}

Macroscopic analysis of longitudinal sections of the infarcted hearts revealed that UM206 treatment profoundly reduced infarct expansion and ventricular dilatation (Fig 8 A1-2) compared to saline treatment. This was confirmed by histological analysis of the infarct area. The infarct areas were significantly smaller in UM206treated compared to saline-treated mice (Fig 8B), both at 2 and 5 weeks after MI. Moreover, as shown in Fig $8 \mathrm{C}$ the infarct areas were significantly thicker in the UM206-treated mice at both time points. Myofibroblast numbers were more than 4-fold higher in the UM206-treated mice at 2 weeks post-MI as compared to salinetreated mice. In both groups, we observed a similar decline in myofibroblast numbers between 2 and 5 weeks post-MI, resulting in a significantly elevated number at 5 weeks post-MI in the UM206-treated group (Fig 8D). The higher myofibroblast numbers in the UM206-treated group could be confirmed by significantly higher $\alpha$ - 
SMA levels in the 5-week old UM206-treated infarcts, as determined by qPCR (Fig $8 \mathrm{E} .1$ ) and Western blotting (Fig 8E.2). These results suggest that an increased myofibroblast content contributes to the reduced infarct expansion and subsequent ventricular dilation in the UM206-treated groups. Moreover, UM206 treatment (5 weeks) resulted in an increase amount of blood vessels (Fig $8 \mathrm{~F}$ ) and reduced collagen levels (Fig 8G) in the infarct area, compared to saline treatment. In our experiments we did not observe any effects of UM206 on other organs known to contain Fzd-2, including kidney and small intestine. QPCR of several Wnt target genes revealed no difference in the expression levels of these genes in animals treated with UM206 for 5 weeks (Table 6-7). 

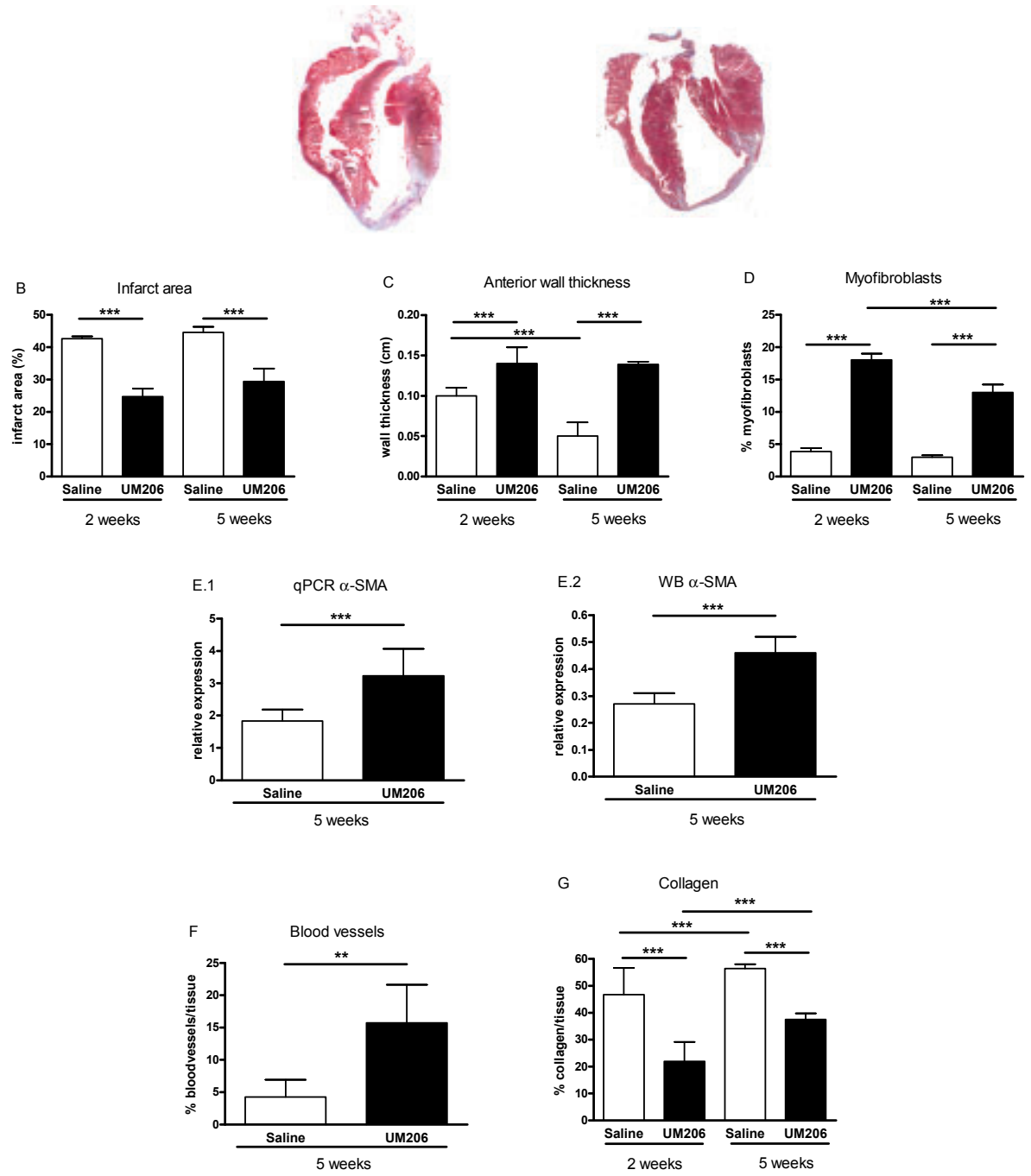

Fig 8: A. 1-2 Transverse sections of an UM206-treated and saline-treated heart, stained with haematoxyline-eosine. The infarcts were less expanded and thicker after UM206 treatment. B. Infarct expansion was decreased, both after 2 and 5 weeks. C. Wall thickness of the infarct area, however, was increased in UM206-treated mice. D. The infarct area of UM206-treated mice contained 4-fold more myofibroblasts, cells that can actively counteract the dilatation of the infarct area. E.1-2 To support the histological data, $\alpha$-SMA levels were determined both on mRNA ( $q P C R$ ) and protein (Western blot) level. These results confirm the immunohistochemical data, where myofibroblast numbers were found to be increased after UM206 treatment. F. UM206 treatment increased the neovascularization of the infarct area, as reflected by an increased blood vessel/tissue area ratio. G. Collagen content was decreased after UM206 treatment, leading to a less stiff infarct area. All results are the mean of 26 animals and are represented as means $+/-$ SEM ( $* p<0.05, * * p<0.01$ and $* * * P<0.001)$. 
A Table 6: Expression patterns of different genes in the small intestine, to study any potential effect of long-term UM206 administration on intestinal tissue. These data indicate that UM206 had no influence on the expression patterns in the small intestine.

\begin{tabular}{l|ccccc}
\hline Gene & \multicolumn{2}{|c}{ Saline } & \multicolumn{2}{c}{ UM206 } & Significance \\
& Rel. exp. & SEM & Rel. exp. & SEM & \\
\hline Ascl 2 & 1.44 & 0.01 & 1.42 & 0.01 & - \\
Dvl 2 & 1.13 & 0.03 & 1.13 & 0.04 & - \\
Inos & 1.19 & 0.01 & 1.18 & 0.02 & - \\
Col I & 1.35 & 0.01 & 1.32 & 0.01 & - \\
CD 44 & 1.27 & 0.02 & 1.22 & 0.02 & - \\
Axin 2 & 1.08 & 0.04 & 1.05 & 0.04 & - \\
Itm 2A & 0.99 & 0.05 & 0.97 & 0.05 & - \\
Mmp 2 & 1.34 & 0.01 & 1.32 & 0.01 & - \\
\hline
\end{tabular}

B Table 7: Similar experiment on kidney. These data indicate that UM206 had no influence on gene expression in the kidney.

\begin{tabular}{|c|c|c|c|c|c|}
\hline \multirow[t]{2}{*}{ Gene } & \multicolumn{2}{|c|}{ Saline } & \multicolumn{2}{|c|}{ UM206 } & \multirow[t]{2}{*}{ Significance } \\
\hline & Rel. exp. & SEM & Rel. exp. & SEM & \\
\hline Twist & 1.45 & 0.03 & 1.49 & 0.03 & - \\
\hline$\alpha$-actin & 1.04 & 0.01 & 1.06 & 0.02 & - \\
\hline LEF & 1.66 & 0.02 & 1.70 & 0.09 & - \\
\hline FN & 1.62 & 0.01 & 1.66 & 0.01 & - \\
\hline Coll I & 1.38 & 0.03 & 1.39 & 0.01 & - \\
\hline$\alpha$-SMA & 1.18 & 0.03 & 1.21 & 0.04 & - \\
\hline DDK 1 & 1.83 & 0.01 & 1.87 & 0.01 & - \\
\hline DDK 2 & 1.40 & 0.01 & 1.44 & 0.01 & - \\
\hline DDK 3 & 0.85 & 0.01 & 0.87 & 0.01 & - \\
\hline
\end{tabular}

\section{Blocking of Rhodamine-labeled UM206 binding by UM207 and Wnt3a}

To demonstrate that the binding site of UM206 on the Fzd-1 and -2 is shared with UM207 and Wnt3a, we developed rhodamine-labeled UM206. Attachment of rhodamine to Lys $^{3}$ of UM206 did not affect its $\mathrm{IC}_{50}$ value for blocking Wnt3a-induced luciferase expression in HEK293 superTOPFlash cells (Not shown). As shown in Fig 9, incubation of frozen sections of mouse kidney and gut with UM206-rhodamine (10 $\mathrm{nM}$ ) for 15 minutes, followed by rinsing in ice-cold PBS, revealed staining of tubular epithelium and panneth cells as assessed by 2-foton microscopy. Specificity of the binding site was confirmed by prior incubation of the tissue sections with UM207 $\left(1.10^{-7} \mathrm{M}\right)$ or recombinant Wnt3a $(10 \mathrm{nM})$. Both compounds completely abolished the binding of UM206-rhodamine to its receptors but left the green autofluorescence of blood vessels unaffected. These data strongly suggest that UM206 and UM207 utilize a binding site on Fzd-1 and Fzd-2 that is also occupied by Wnt3a. 


\section{A UM206-Rhodamine}

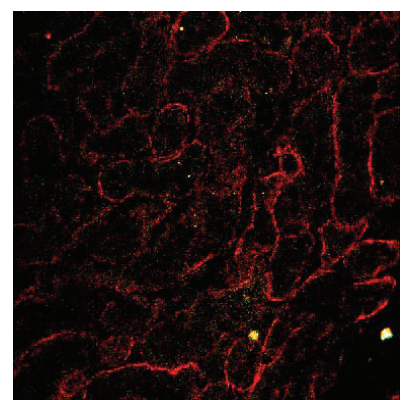

Small intestine

B Pre-incubation UM207

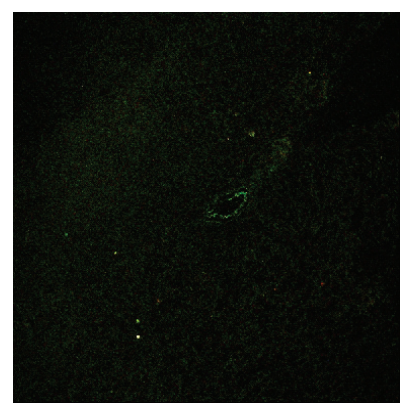

Small intestine

C Pre-incubation rWnt3a

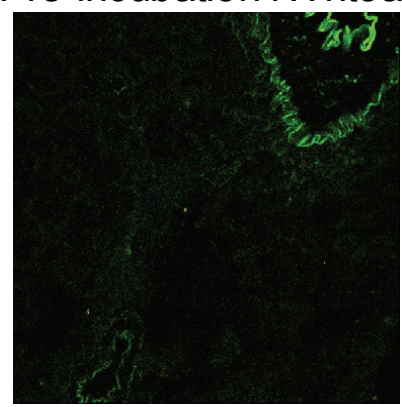

Small intestine

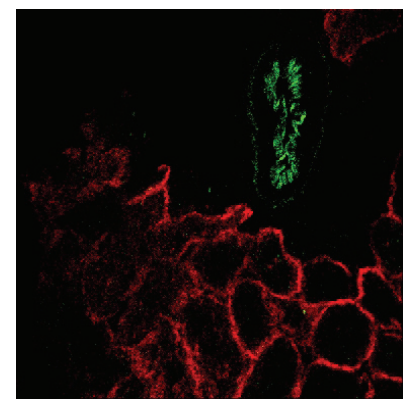

Kidney

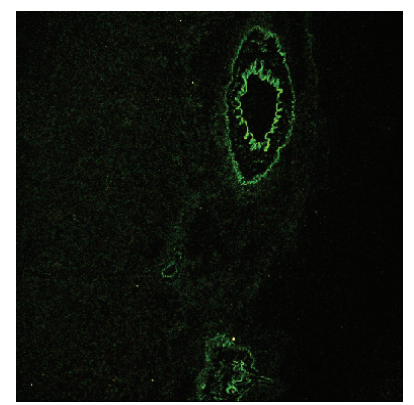

Kidney

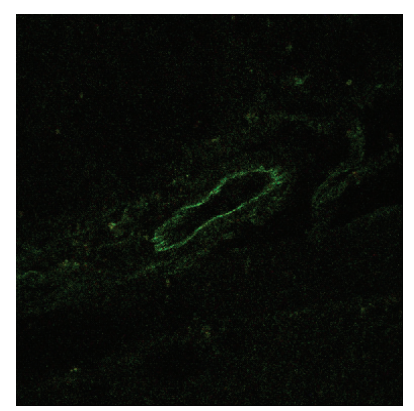

Kidney

Fig 9: Blocking of UM206-Rhodamine binding to Frizzled-1 and -2 by UM207 and Wnt3a. A. Fluorescent signal of UM206-Rhodamine binding to small intestine and kidney is shown in red; green represents autofluorescence of the blood vessels in the tissue. B. Small intestine and kidney imaging after preincubation with a high concentration of UM207 and C. Small intestine and kidney after pre-incubation with the natural ligand Wnt3a. These images confirm the specificity of UM206 binding. 


\section{Discussion}

In this article we describe the design of antagonists for Fzd-1 and -2, based on areas of high homology between Wnt3a and -5a. Based on a set of pre-defined criteria, we identified three peptidergic antagonists which all could block the activation of Fzd-1 and $-2 \backslash$ by Wnt3a and Wnt5a; we named the peptides UM206-8. Because the $\mathrm{IC}_{50}$-value of UM206 for Fzd-1 and -2 receptors was lower than that of UM207 and UM208, we focused on UM206 in the remainder of the studies. All three peptides feature 2 cysteines separated by 4-10 amino acids. The Gly, Asp and Thr residues are present in all three peptides and were shown to be important in the blocking effect of UM206. Either of the two cysteines of UM206 could be replaced by Ala with little consequences for the binding, but replacing or blocking both cysteines caused complete loss of activity. This finding, together, with the obtained high affinity of UM206, may suggest a covalent interaction between cysteines of the compound and the CRD of the receptor. UM206 blocked Fzd-1 and - 2 mediated Wnt signaling effectively in HEK293 superTOPFlash, COS7 and CHO cells as well as cardiac fibroblasts immortalized with telomerase. Moreover, UM206 administration had a beneficial effect on infarct healing by increasing myofibroblast and blood vessel numbers in the infarct area, preventing dilatation of the left ventricle, improving cardiac function and completely preventing heart failure, leading to increased survival. Finally, by using rhodamine-labeled UM206 we could show that UM206 and UM207 occupy the same binding site, which is also used by Wnt3a.

Because of the lack of pharmacological tools to intervene in Wnt/Frizzled signaling in vivo, only genetic interventions have been reported so far in studies on the role of Wnt signaling in infarct healing. Barandon et al. were the first to show a beneficial effect of overexpression on infarct healing of FrzA, a bovine homologue of soluble frizzled-related protein-1 (sFRP1). They observed a decreased infarct size with elevated numbers of myofibroblasts and increased angiogenesis in the infarcted FrzA transgenic mice ${ }^{21}$ which could be confirmed in the present study using an Fzd-1 and -2 antagonist. Interestingly, a reduction in infarct rupture frequency was also observed in the FrzA transgenic mice. In contrast, UM206 treatment of 12956 mice, a mouse strain with infarct rupture frequency of $\sim 60 \%{ }^{19}$, did not reduce the number of ruptured infarcts ( $H$. Laeremans, unpublished observations). This suggests that sFRP may not solely act by blocking of Wnt signaling but by additional mechanisms as well. In the mean time, the beneficial effects of sFRP overexpression on infarct healing have been confirmed by Kobayashi et al. ${ }^{22}$. Taken together, these reports support the observations of the present study and point to a beneficial effect of inhibiting Wnt/Frizzled signaling on the wound healing process after MI. We did not observe any adverse effects of chronic UM206 administration, indicating that this therapeutic intervention is safe and does not interfere with normal physiological processes. 
One of the most likely molecular targets of UM206 appears to reside in the myofibroblasts in the infarct area. The role of myofibroblasts in wound healing and tissue repair is well established. These cells are responsible for the contraction of skin wounds, thereby limiting the size of the scar that is formed at the site of injury ${ }^{23,24}$. More recently, a similar role has been described for myofibroblasts in the infarct $\operatorname{area}^{24-27}$, thereby preventing expansion of the infarct area ${ }^{25}$. In a study on the effect of genetic background on infarct healing in the mouse, we observed an inverse relationship between myofibroblast content and infarct dilatation ${ }^{19}$. Moreover, myofibroblasts remain present in well-healed human infarcts for decades, but are scarce in dilated infarcts obtained from heart failure patients ${ }^{29,30}$. Previously, we have shown that myofibroblasts express Fzd-1 and -2 during their migration into the infarct area $^{20}$. Overexpression of components of the Wnt/Frizzled pathway affect the differentiation and migration of cardiac fibroblasts immortalized with telomerase $^{16}$. Therefore, we conclude that the Fzd-1 and -2 expressed on myofibroblasts during infarct healing play a functional role in the wound healing process after $\mathrm{MI}$ and can serve as a therapeutic target for intervention in this process. Moreover, the results of the present study highlight the importance of targeting (myo)fibroblasts to preserve cardiac function in the remodeling heart ${ }^{26,27}$. UM206 may well serve as a lead for the development of drugs that address this target. This is of particular importance because the pharmaceutical tools that are currently available to treat infarct healing post-MI have pleiotropic effects on inflammation, extracellular matrix deposition and cardiac remodeling ${ }^{28}$.

In this study we used rhodamine-labeled UM206 to investigate the binding site of UM206 and UM207 on Fzd-1 and -2 in kidney and small intestine. The binding of rhodamine-labeled UM206 could be prevented by preincubation with either Wnt3a or UM207. These experiments provide the pharmacological evidence that UM206 and UM207 use the same binding site on the Frizzled protein. Moreover, this binding site is also used by Wnt3a. These data suggest that UM206 and UM207 act as competitive antagonists for Wnt3a.

The biological activity of peptides derived from the same region of Wnt5a that rendered UM206 has been shown previously by Säfholm et al. ${ }^{29}$. In this study, an anti-migratory effect of these peptides on breast cancer cells was observed. Although their peptides, named FOXY5, identical to the C-terminal 6 amino acids of UM206, its site of action appears to be distinct from that of UM206 for several reasons: 1) The activity of FOXY5 and peptide 175 was sensitive to a Fzd-5 blocking antibody, whereas UM206 interacts with Fzd-1 and -2 but not with Fzd-5. 2). Substitution of the only Cys residue in FOXY5 with Ala did not affect its binding, whereas in UM206 at least one Cys has to be present for biological activity. 3) FOXY5 actively inhibited breast cancer cell migration, thereby acting as a Wnt5a mimetic, whereas UM206 alone had no effect on cell migration and acts as a Wnt3a/5a antagonist. 4) FOXY5 and related peptides are active at concentrations of $10-100 \mu \mathrm{M}$, whereas the 
$\mathrm{IC}_{50}$ for UM206 is in the (sub)nanomolar range. In mean time, it has been shown that replacement of the $\mathrm{N}$-terminal formyl group at $\mathrm{t}$-boc moiety transfers the compound into an antagonist for Wnt5a-induced melanoma cell migration ${ }^{30}$.

In conclusion, the results of the present study clearly show that pharmacological targeting of Frizzled can be a successful and safe approach to intervene in pathological processes such as myocardial infarction. In the mean time, the role of Wnt/Frizzled signaling has been implicated in processes as diverse as stem cell differentiation $^{31}$, tumor metastasis ${ }^{32}$, bone metabolism ${ }^{33}$ and various neurological disorders ${ }^{34}$. This calls for an extensive search for ligands for the different Frizzled subtypes involved in these diseases.

\section{Acknowledgements}

The authors would like to acknowledge the skilful technical assistance of Agnieszka Brouns-Strzelecka, Lily Vervoort-Peeters, Peter Lijnen and Dennis Suylen.

\section{Funding}

This work was supported by BSIK 03033; Molecular Imaging of Ischemic heart disease.

\section{References}

1. Nelson, W.J. \& Nusse, R. Convergence of Wnt, beta-catenin, and cadherin pathways. Science 2004;303:1483-7.

2. DeAlmeida, V.I. et al. The soluble wnt receptor Frizzled8CRD-hFc inhibits the growth of teratocarcinomas in vivo. Cancer Res 2007;67:5371-9.

3. Blankesteijn, W.M., van de Schans, V.A., ter Horst, P. \& Smits, J.F. The Wnt/frizzled/GSK-3 beta pathway: a novel therapeutic target for cardiac hypertrophy. Trends Pharmacol Sci 2008;29:175-80.

4. van de Schans, V.A., Smits, J.F. \& Blankesteijn, W.M. The Wnt/frizzled pathway in cardiovascular development and disease: friend or foe? Eur J Pharmacol 2008;585:338-45.

5. Brade, T., Manner, J. \& Kuhl, M. The role of Wnt signalling in cardiac development and tissue remodelling in the mature heart. Cardiovasc Res 2006;72:198-209.

6. van Es, J.H. \& Clevers, H. Notch and Wnt inhibitors as potential new drugs for intestinal neoplastic disease. Trends Mol Med 2005;11:496-502.

7. Nusse, R. Wnt signaling in disease and in development. Cell Res 2005;15:28-32.

8. MacDonald, B.T., Tamai, K. \& He, X. Wnt/beta-catenin signaling: components, mechanisms, and diseases. Dev Cell 2009;17:9-26.

9. Barker, N. \& Clevers, H. Mining the Wnt pathway for cancer therapeutics. Nat Rev Drug Discov 2006;5:997-1014.

10. Takahashi-Yanaga, F. \& Sasaguri, T. Drug development targeting the glycogen synthase kinase-3beta (GSK-3beta)-mediated signal transduction pathway: inhibitors of the Wnt/beta-catenin signaling pathway as novel anticancer drugs. J Pharmacol Sci 2009;109:179-83.

11. Clevers, H. Wnt/beta-catenin signaling in development and disease. Cell 2006,127:469-80.

12. Schulte, G. \& Bryja, V. The Frizzled family of unconventional G-protein-coupled receptors. Trends Pharmacol Sci 2007;28:518-25. 
13. Wang, Y. \& Nathans, J. Tissue/planar cell polarity in vertebrates: new insights and new questions. Development 2007;134:647-58.

14. Hendrickx, M. \& Leyns, L. Non-conventional Frizzled ligands and Wnt receptors. Dev Growth Differ 2008;50:229-43.

15. Janhunen, S., Laeremans, H., Rensen, S., Smits, J. \& Blankesteijn, W. A novel telomeraseimmortalized cardiac fibroblast cell line. Naunyn-Schmied Arch Pharmacol 2009;379:205.

16. Laeremans, H., Rensen, S.S., Ottenheijm, H.C.J., Smits, J.F.M. \& Blankesteijn, W.M. Wnt/Frizzled signaling modulates the migration and differentiation of immortalizedcardiac fibroblasts. Cardiovasc Res 2010.

17. Schnolzer, M., Alewood, P., Jones, A., Alewood, D. \& Kent, S.B. In situ neutralization in Boc-chemistry solid phase peptide synthesis. Rapid, high yield assembly of difficult sequences. Int J Pept Protein Res 1992;40:180-93.

18. M.W.Pennington \& Dunn, B.N. Peptide synthesis protocols, Human Press, Totowa, New Jersey, 1994.

19. van den Borne, S.W. et al. Mouse strain determines the outcome of wound healing after myocardial infarction. Cardiovasc Res 2009;84:273-82.

20. Blankesteijn, W.M., Essers-Janssen, Y.P., Verluyten, M.J., Daemen, M.J. \& Smits, J.F. A homologue of Drosophila tissue polarity gene frizzled is expressed in migrating myofibroblasts in the infarcted rat heart. Nat Med 1997;3:541-4.

21. Barandon, L. et al. Reduction of infarct size and prevention of cardiac rupture in transgenic mice overexpressing FrzA. Circulation 2003;108:2282-9.

22. Kobayashi, K. et al. Secreted Frizzled-related protein 2 is a procollagen $C$ proteinase enhancer with a role in fibrosis associated with myocardial infarction. Nat Cell Biol 2009;11:46-55.

23. Hinz, B. Formation and function of the myofibroblast during tissue repair. J Invest Dermatol 2007;127:526-37.

24. Hinz, B. et al. The myofibroblast: one function, multiple origins. Am J Pathol 2007;170:1807-16.

25. Hutchins, G.M. \& Bulkley, B.H. Infarct expansion versus extension: two different complications of acute myocardial infarction. Am J Cardiol 1978;41:1127-32.

26. Brown, R.D., Ambler, S.K., Mitchell, M.D. \& Long, C.S. The cardiac fibroblast: therapeutic target in myocardial remodeling and failure. Annu Rev Pharmacol Toxicol 2005;45:657-87.

27. Sun, Y., Kiani, M.F., Postlethwaite, A.E. \& Weber, K.T. Infarct scar as living tissue. Basic Res Cardiol 2002;97:343-7.

28. Jugdutt, B.I. Limiting fibrosis after myocardial infarction. N Engl J Med 2009;360:1567-9.

29. Safholm, A. et al. A formylated hexapeptide ligand mimics the ability of Wnt-5a to impair migration of human breast epithelial cells. J Biol Chem 2006;281:2740-9.

30 Jenei V, Sherwood V, Howlin J, Linnskog R, Säfholm A, Axelsson L, Andersson T. A tbutyloxycarbonyl-modified Wnt5a-derived hexapeptide as a potent antagonist of Wnt5adependent melanoma cell invasion. Proc Natl Acad Sci U S A. 2009;106(46):19473-8.

31. Reya, T. \& Clevers, H. Wnt signalling in stem cells and cancer. Nature 2005;434:843-50.

32. Lai, S.L., Chien, A.J. \& Moon, R.T. Wnt/Fz signaling and the cytoskeleton: potential roles in tumorigenesis. Cell Res 2009;19:532-45.

33. Piters, E., Boudin, E. \& Van Hul, W. Wht signaling: a win for bone. Arch Biochem Biophys 2008;473:112-6.

34. De Ferrari, G.V. \& Moon, R.T. The ups and downs of Wnt signaling in prevalent neurological disorders. Oncogene 2006;25:7545-53. 


\section{Development of tools for visualization of Frizzled-1 and -2}

Laeremans H., Broers J.L., Suylen, D., Ottenheijm H.C.J., Smits J.F.M., Hackeng T.M., Van Zandvoort M.A.M.J, Blankesteijn W.M. 


\begin{abstract}
The Wnt/Frizzled signaling system has been implicated in embryonic development and in a wide range of pathologies including myocardial infarction, where Frizzled-1 and Frizzled-2 are upregulated in cardiac myofibroblasts. These cells help limit ventricular dilatation and may contribute to the prevention of heart failure. The availability of contrast agents that can visualize myofibroblasts, can help in stratification of patients at risk for development of ventricular dilatation following myocardial infarction.

In the present study we developed tools for visualizing Frizzled in vitro and in vivo by generating a Frizzled-2 specific antibody and labeling of UM206, a low molecular weight peptidergic ligand for Frizzled-1 and Frizzled-2. The latter was labeled with either rhodamine, or biotin, where biotin was coupled to UM206 in 3 different manners. Although 2 of the biotin-UM206 compounds retained their Wnt3a-antagonistic activity in a luciferase assay system, none of the biotin-labeled molecules stained Fzd-2 in vitro. Rhodamine coupled UM206 also retained its Wnt3a antagonistic activity and did label Fzd-2 in vitro.

In vitro HEK cells transiently overexpressing Fzd-2 exhibited staining after addition of rhodamine-UM206. Interestingly, fluorescence was not confined to the cellmembrane, suggesting receptor internalization. UM206 dependency of this phenomenon was confirmed by the observation that UM206 also induced internalization of a Frizzled-2/GFP construct.

We examined the distribution of Frizzled-1 and Frizzled-2 in Frizzled rich organs, like intestine and kidney. Both the anti-Frizzled-2 antibody and rhodamine-UM206 showed intense and specific staining patterns. Moreover, rhodamine-UM206 stained myofibroblasts in the myocardial infarct of mice subjected to coronary artery ligation.

The two tools developed here for the visualization of Frizzled in vitro and in vivo, provide a basis for the development of contrast-agents for myofibroblasts.
\end{abstract}

\title{
Keywords
}

Visualization of Frizzled; antibody versus low molecular weight ligand; internalization 


\section{Introduction}

Wnt/Frizzled (Fzd) signaling is crucial for embryonic development in all animal species studied to date ${ }^{1,2}$. Moreover, evidence is accumulating for a role of Wnt/Fzd in a wide range of pathological processes ${ }^{3,4}$, amongst which the development of heart failure following myocardial infarction.

A major complication of myocardial infarction is ventricular dilatation, resulting in progressive heart failure. Such dilatation may be limited by myofibroblasts, which invade the infarct during wound healing. These cells do not only produce extracellular matrix proteins, but also possess contractile properties. Thereby they may limit dilatation, which is supported by the observation of a negative relationship between the number of myofibroblasts in myocardial infarcts and the degree of dilatation ${ }^{5,6}$. Hence quantification of the number of myofibroblasts in infarcts might help in identifying patients at risk for ventricular dilatation following infarction.

In a previous study we observed expression of Fzd-2 in myofibroblasts, following myocardial infarction in rats and mice ${ }^{7}$. Therefore, Fzd-2 could serve as a biomarker for myofibroblasts. The natural ligands for Fzds are Wnt proteins. These are large glycoproteins, which are very sticky and bind to the extracellular matrix. This makes Wnt proteins poor candidates as ligands for visualization ${ }^{8}$.

In the present study we examined several potential alternative ligands. We synthesized 4 ligands based upon UM206, a low-molecular weight Fzd-1 and Fzd-2 antagonist (see chapter 5), characterized their binding properties and compared their usefulness for visualization of Fzd-2 in vitro and in vivo with that of an antibody directed against Fzd-2. Results suggest that UM206-based ligands are highly suitable for receptor visualization and may thus provide a basis for the development of contrast agents.

\section{Materials and Methods}

\section{$1 \quad$ Materials}

$\mathrm{DAB}$, diaminobenzidine tetrahydrochloride, as well as the secondary antibody rabbit-anti-mouse were used for the antibody assay (Sigma-Aldrich, Saint Louis, ME, USA). The Fzd-2 GFP construct and Fzd-2 antibody were synthesized and developed by collaborators at MSD Research labs; the secondary Texas red goat anti-mouse antibody was bought (vector laboratories, Burlingame, CA, USA). First batches of UM206 were synthesized in our lab; a larger second batch of peptide was purchased (Chempep Inc., Miami, FL, USA). 
The HEKstv cell line was cultured in $75 \mathrm{~cm}^{2}$ culture flasks (Costar Corning, Schiphol, the Netherlands) in Dulbeco's modified essential medium with L-glutamine (2mM), $10 \%$ fetal calf serum (Invitrogen, Merelbeke, Belgium), and gentamycin (SigmaAldrich, Zwijndrecht, The Netherlands). Before the start of the experiment, the cell line was treated with plasmocin $25 \mu \mathrm{g} / \mathrm{ml}$ (Invivogen, Toulouse, France) and was tested with a mycoalert mycoplasma detection kit (Lonza, Rockland, NY, USA). When tests were negative, treatment was stopped and the mycoalert test was repeated every two months. The cells were transiently transfected with plasmid DNA, pcDNA3.1/hygro (Invitrogen, Merelbeke, Belgium) containing the gene of rFzd-1(-GFP), rFzd-2(-GFP) and hFzd-4 or pcDNA3.0/hygro (Invitrogen) containing the gene of hFzd-5. Transient transfections were performed with $3 \mu$ l Fugene6 (Roche, Indianapolis, IN, USA) and $1 \mu \mathrm{g} / \mathrm{ml}$ plasmid DNA. 24 hours after transfection, the UM206 with or without the rhodamine label was added and after an additional 24 hours, the cells were collected.

\section{Peptide Fragment Synthesis}

All peptide fragments were synthesized by manual solid-phase peptide synthesis on a 0.3-0.4 mmol scale using the in situ neutralization/activation procedure for Boc/Bzl- peptide synthesis as previously described ${ }^{9,10}$ but using HCTU instead of HBTU as a coupling reagent. MBHA-polystyrene resin (1 meq/g) was used as the solid support. Rhodamine and biotin were coupled as described for regular amino acids.

The peptides were de-protected and cleaved from the resin by treatment with anhydrous $\mathrm{HF}$ for $1 \mathrm{~h}$ at $0^{\circ} \mathrm{C}$, using $4 \mathrm{v}-\% \mathrm{p}$-cresol as a scavenger.

Following cleavage, the peptides were precipitated with ice-cold diethylether, filtered, dissolved in aqueous buffer containing $6 \mathrm{M}$ Guanidine. $\mathrm{HCl}, 0.1 \mathrm{M}$ sodium acetate buffer $(\mathrm{pH} 4)$ and purified by semi-preparative reversed-phase HPLC. Fractions containing the desired product were identified by ESI-MS, pooled and lyophilized $^{9,10}$.

\section{HPLC}

Analytical HPLC was performed using a Vydac C18 RP-HPLC column (4.6 mm $\times 150$ $\mathrm{mm}, 1 \mathrm{~mL} / \mathrm{min}$ flow rate) connected to a Varian Prostar system consisting of two Varian Prostar 215 delivery modules and a Varian Prostar 320 UV/Vis detector (214 $\mathrm{nm})$. A linear gradient of $0-67 \%$ buffer $B$ in buffer $A$ over 30 minutes was used, where buffer $A=0.1 \mathrm{v}-\%$ TFA in $\mathrm{H} 2 \mathrm{O}$ and buffer $\mathrm{B}=0.1 \mathrm{v}-\%$ TFA, $10 \mathrm{v}-\% \mathrm{H}_{2} \mathrm{O}$ in $\mathrm{CH}_{3} \mathrm{CN}$.

Semi-preparative HPLC was performed using Vydac C18 RP-HPLC columns (10 $\mathrm{mm} \times 250 \mathrm{~mm}, 5 \mathrm{~mL} / \mathrm{min}$ flow rate or $22 \mathrm{~mm} \times 250 \mathrm{~mm}, 10 \mathrm{~mL} / \mathrm{min}$ flow rate) 
connected to a Waters Deltaprep System consisting of a Waters Prep LC Controller and a Waters 2487 Dual wavelength Absorbance Detector (214 nm). Peptides were eluted using a shallow gradient of B in A, based on an exploratory analytical HPLC run (vide supra).

Product containing fractions were analyzed by Electrospray lonization Mass Spectrometry (ESI-MS) (vide infra), pooled and lyophilized Mass Spectrometry. ESIMS was performed on an Applied Biosystems SCIEX API 150 EX electrospray ionization quadrupole (ESI-Q) mass spectrometer. Peptide masses were calculated from the experimental mass to charge $(\mathrm{m} / \mathrm{z})$ ratios from all the protonation states observed in the ESI-MS spectrum of a peptide using Analyst 1.4.2 software (Sciex).

\section{$5 \quad$ Luciferase experiments}

For the luciferase experiments, the cells were additionally transfected with a TOPFlash construct (16 TCF/LEF binding sites cloned into the Mlu1 site of a pTA-Luc vector) kindly provided by Dr. J. Nathans. Luciferase activity was measured using a commercial luciferase assay system (Promega, Madison, WI, USA).

\section{Immunofluorescence}

Cells

The cells were transfected with rFzd-1(-GFP) or rFzd-2(-GFP) 48 hours before the start of the staining procedures. 24 hours after transfection, the UM206 with or without the rhodamine label was added and after an additional 24 hours, the cells were collected.

Cells were washed and fixated with methanol/acetone (1:1). After incubation for 5 minutes with $0.5 \%$ Triton, cells where washed with PBS/glycine and incubated with 2\% BSA. Photos were taken with a Zeiss microscope, excitation BP450-490 emission LP520 for GFP and excitation KP560 emission LP630 for Texas red, with a Leica CTR500 camera $(63 \times / 0.85)$ and analyzed with the Quantimet program (QWin/QGo, Leica).

Ex vivo

The intestines, kidneys and hearts were immediately frozen upon sacrifice. Sections were incubated for fifteen minutes with $10^{-8} \mathrm{M}$ Rhodamine-UM206 dissolved in phosphate buffered saline or incubated overnight with the primary rabbit anti$\mathrm{mFzd}-2$ and 2 hours with secondary biotin-labeled mouse antibody (Vector Laboratories, Burlingame, CA, USA).

In vivo

Mice without a myocardial infarction were injected with the primary antibody $10 \mu \mathrm{l}$ in the tail vein and the animals were left anesthetized during $1 \mathrm{~h}$ before the intestines and kidneys were collected and frozen sections were prepared. These sections 
were incubated for 2 hours with secondary Texas red goat anti-mouse antibody and photos were taken with a Leica CTR500 camera.

A second group of mice used for ex vivo staining of the heart, kidney and intestine; had a two week old MI or a sham operation. MI was induced, under isoflurane anesthesia as previously described ${ }^{11}$. All experimental procedures were approved by the Committee for Animal Research of Maastricht University.

\section{Western blots}

For Western blot analysis, samples of the cells or organs, namely intestine; were placed in $500 \mu \mathrm{l}$ ice-cold Laemmli buffer $(6.6 \%$ glycerol, $1.5 \%$ SDS, $4.15 \mathrm{mmol} / \mathrm{l}$ Tris/ $\mathrm{HCl}, \mathrm{pH}=8.0$ ) and homogenized. After $30 \mathrm{~min}$ on ice and centrifugation, the supernatant was collected and protein content was measured using the BCA protein assay (Pierce Biotechnology Inc., Rockford, IL, USA); 10 $\mu$ g of total protein was denatured by boiling in Laemmli sample buffer (BioRad, Hercules, CA, USA), separated on a $10 \%$ SDS-page gel, and transferred onto a Hybond $C$ nitrocellulose membrane (Amersham Biosciences, Little Chalfont, United Kingdom). After blocking (5\% non-fat dry milk (BioRad), $0.1 \%$ Tween in TBS) for $1 \mathrm{~h}$, membranes were incubated overnight at $4^{\circ} \mathrm{C}$ with primary antibodies directed against Fzd-2 $1 / 2000$ and $\beta$-actin $1 / 2000$ (Sigma, Bornem, Belgium). Anti-rabbit or mouse immunoglobulin G 1/5000 (Vector Labs Inc.) was used as the secondary antibody, and the membranes were developed using the Supersignal West Pico chemiluminescence kit (Pierce). Images of the blots were analyzed with image analysis software (Qwin Leica, Cambridge, United Kingdom).

\section{Statistical analysis}

All values are shown as means \pm S.E.M. Differences between groups were examined for statistical significance using two-way ANOVA with a Bonferroni post-hoc test (Graph Pad Prism). A $P$ value less than 0.05 was considered to indicate a statistically significant difference.

\section{Results}

\section{UM206 labeling and validation}

UM206 was labeled with biotin or a rhodamine. The biotin label was added either directly on Lys ${ }^{3}$ of UM206, on a Lys that was located at the end of a 5-Gly spacer attached to the C-terminal part of UM206 (CNKTSEGMDGCEL[G5L-biotin]) or on a Lys at the end of a 12-Gly spacer (CNK[G12L-biotin]TSEGMDGCEL) (Fig 1). The 
rhodamine was attached directly to Lys $^{3}$ (Fig 1D). After synthesis, the peptide sequences were verified with HPLC and mass spectrometry. To test whether modified UM206 molecules retained their affinity for Fzd-1 and -2, a TOPFlash assay was performed and their antagonistic properties were compared to that of unmodified UM206 (Fig 2). As shown in Fig 2, CNKTSEGMDGCEL[GL5-biotin] had lost its antagonistic properties. The other peptides retained their antagonistic properties. CNKTSEGMDGCEL[G5-biotin] was not further studied.

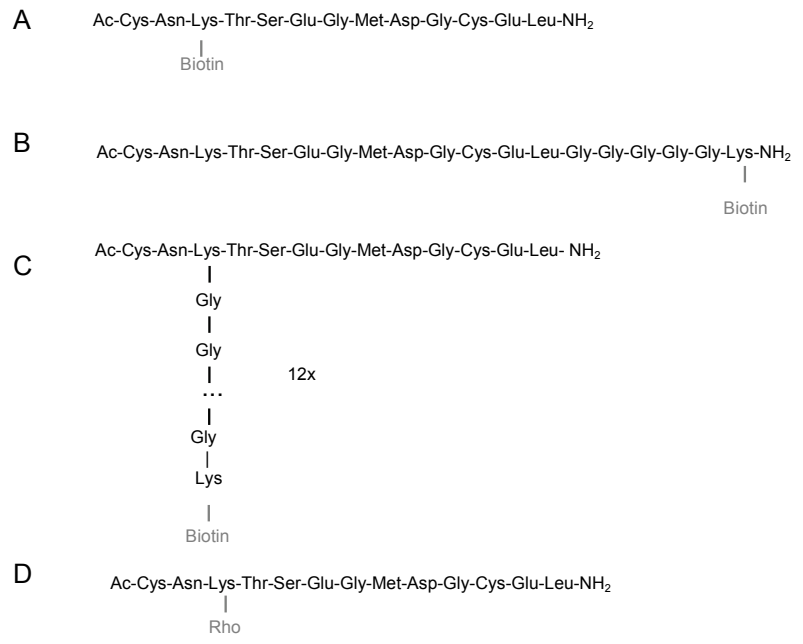

Fig 1: Labeling of UM206, with either biotin or rhodamine (TAMRA).

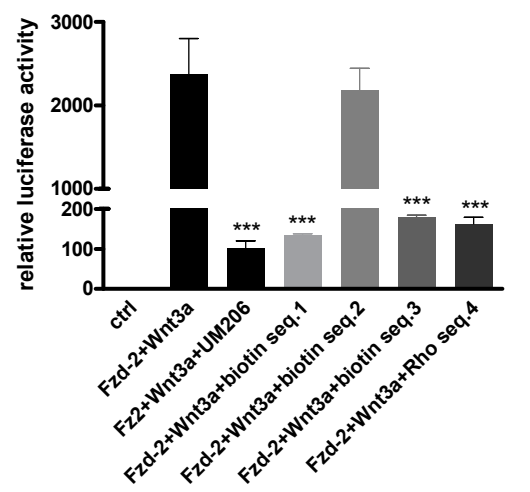

Fig 2: Relative luciferase activity in comparison to control. All data are the means of three independent measurements and are represented with SEM. Significant decrease in comparison to $\mathrm{rFzd}-2+\mathrm{Wnt} 3 \mathrm{a}$ are indicated $(* * * p<0.001)$. 
The two biotin-labeled UM206 peptides were subsequently tested in cultured cells, transiently transfected with rFzd-2. The biotin-labeled peptides did not stain (Not shown). In contrast, cells did stain with UM206-Rhodamine (Fig 3A), although staining was not limited to the cell membrane. Cells transfected with rFzd-1, showed the same staining pattern, whereas cells transfected with hFzd- 4 or -5 , were blank (Not shown), proving the specificity of the ligand. Untransfected cells served as a negative control and did not stain.

The diffuse staining of the rFzd-1 and $\mathrm{rFzd}-2$ transfected cells suggests receptorinternalization. To verify this, we studied the localization of GFP-coupled rFzd-2. As shown in Fig 3B, GFP fluorescence was localized on the cell membrane. However, upon addition of UM206, the receptor was internalized (Fig 3C), generating the same staining as seen in Fig $3 \mathrm{~A}$.
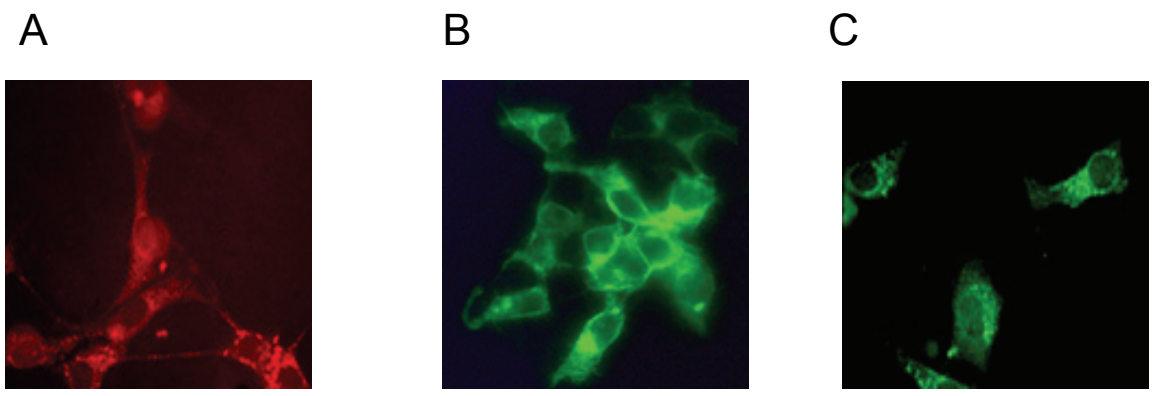

Fig 3: Fluorescence in HEK cells transiently transfected with A. Fzd-2 and stained with UM206-Rho; B. GFP-Fzd-2 and C. GFP-Fzd-2 treated with UM206. Photographs were taken using a fluorescent Leica microscope, at a magnification of $200 x$.

\section{Western blot}

We developed an antibody that was raised in a rabbit against the mouse third extracellular loop of Fzd-2. On Western blot, a $64 \mathrm{kD}$ band was seen in transfected cells, corresponding to the molecular weight of the natural Fzd protein (Fig 4). In the intestine, however, one prominent band is seen at 50kD. 


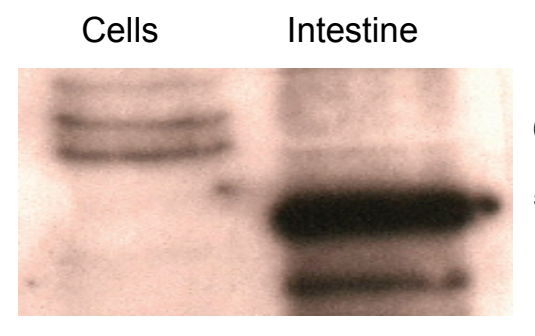

Fig 4: Western blot of HEK cells transiently transfected with Fzd-2 and the small intestine of a mouse.

$64 k D$

$50 \mathrm{kD}$

\section{$4 \quad$ Ex vivo and in vivo staining}

\subsection{Antibody}

Mice were injected with the antibody and organs were collected after $1 \mathrm{~h}$. An Fzd-2 rich tissue, for example the small intestine, was stained with a biotin-labeled secondary antibody (Fig 5), showing intense staining of the intestinal villi. These data were confirmed with stainings of frozen sections of small intestine and kidney of mice that were not injected with the antibody. Primary and fluorescent secondary antibody staining were performed on the frozen sections. Staining patterns in Fig 6 indicate that Fzd is present on the tubuli of the kidney and the goblet cells of the small intestine.

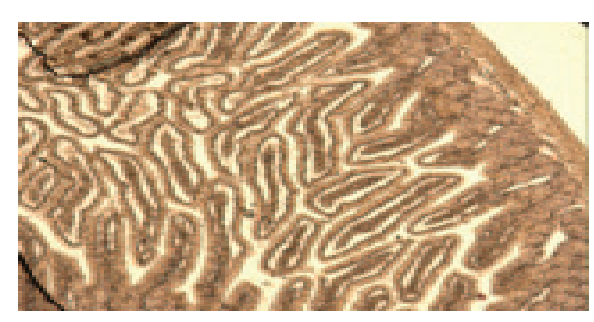

Fig 5: Immunohistochemical staining of mouse small intestine after injection of the rabbit antimouse Fzd-2 antibody in the tail vein of mice (200x).

A

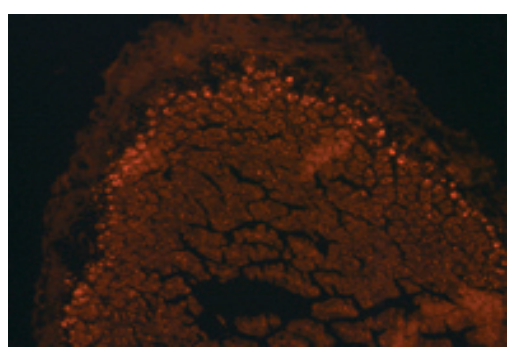

B

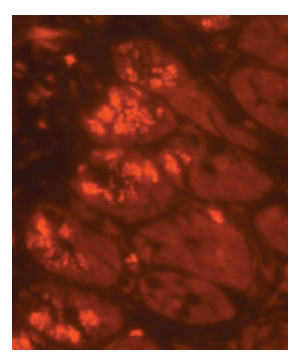

C

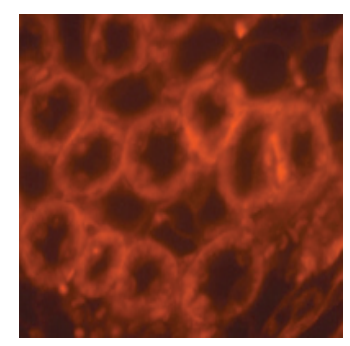

Fig 6: Immunohistochemical staining of frozen sections of different tissues with rabbit anti-mouse Fzd-2 antibody A. small intestine (25x) B. small intestine (200x) and C. kidney (200x). 


\subsection{Rhodamine-labeled UM206}

Rhodamine-labeled UM206 was added to frozen sections of the control mice and mice that had been subjected to myocardial infarction (14days MI). Fig 7 shows both a healthy and an infarcted heart. In the normal healthy heart, only the blood vessels are stained. In the infarcted heart, however, the infarct area is stained bright red, indicating the presence of Fzd-2. In the magnified image, staining can be attributed to spindle shaped cells, which are myofibroblasts.
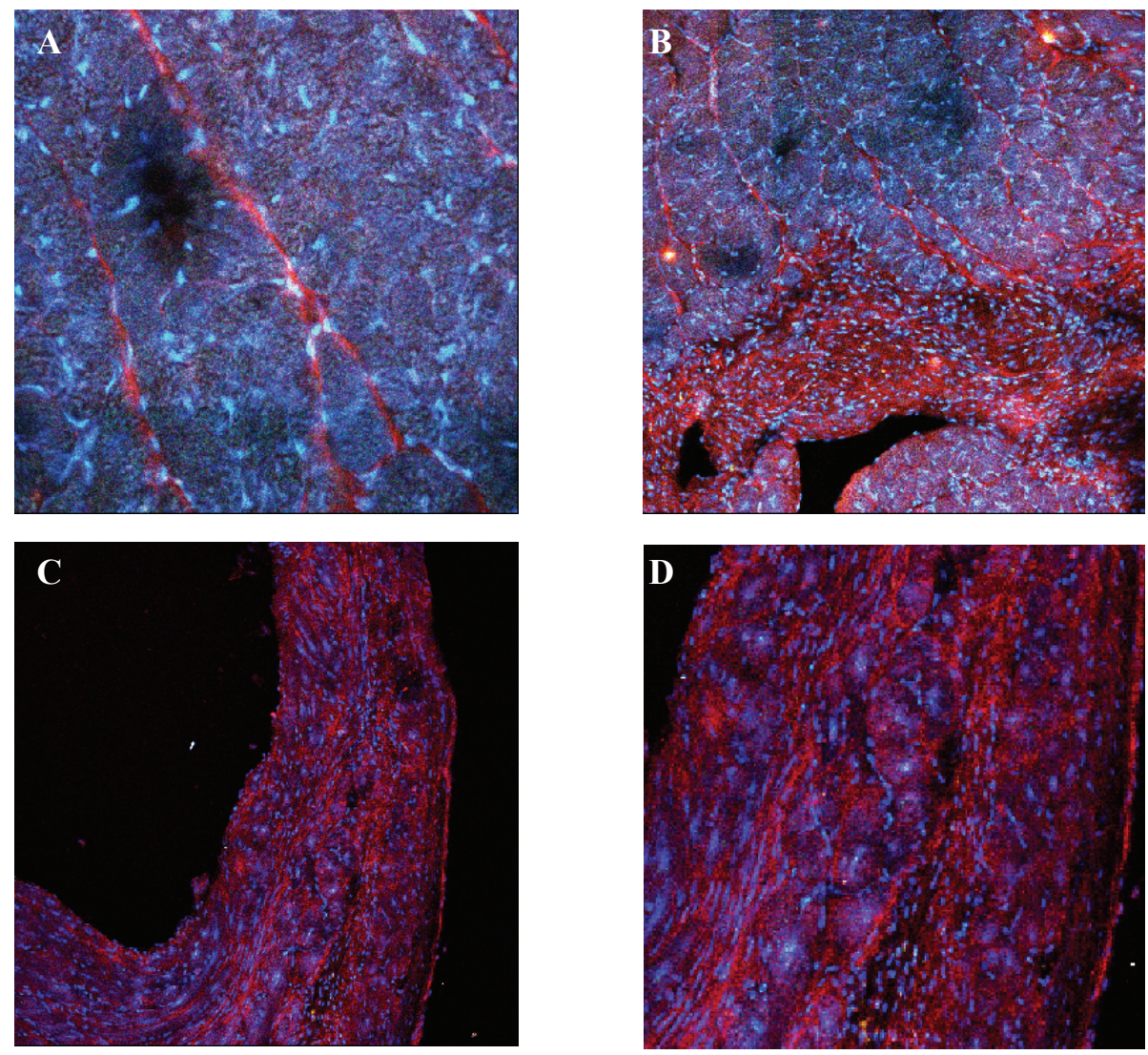

Fig 7: Confocal microscopic images of different tissues with rhodamine-labeled UM206-Rho. A. normal heart; B. heart with myocardial infarction stained in bright red C. Infarcted area which is enlarged D. where the spindle-shaped structures represent myofibroblasts.

\section{Discussion}

Receptor imaging is the localization of a labeled compound that binds to cellular sites with a high degree of affinity and specificity ${ }^{12}$. It can be accomplished with 
both antibodies and labeled low molecular weight ligands with high affinity and specificity for the target receptor. In this study, we have developed an Fzd-2 antibody and a rhodamine labeled peptidergic ligand, called UM206-Rho, an antagonist of Fzd-1 and Fzd-2 (see chapter 5). These visualization tools were compared and have provided evidence supporting the following conclusions: a) intestine and kidney are Fzd-2 rich organs; b) Fzd-2 in upregulated in the myofibroblasts after myocardial infarction and c) Fzd-2 is internalized upon UM206 binding.

UM206, a peptidergic antagonistic ligand developed in our lab based on regions with high homology between natural Fzd-2 ligands, is the first low molecular weight ligand and was validated in chapter 5. In the present study we labeled UM206 in four different manners and examined their activity in a luciferase assay. Coupling of UM206 to biotin using a terminal Gly spacer abolished the antagonistic properties of UM206, possibly through steric effects. The two other biotin coupled variants were effective in the luciferase assay, yet, when used for staining in Fzd-2 overexpressing cells, no staining was exhibited. A possible explanation for this absence of staining might again be steric hindrance, preventing the binding of the streptavidin to the biotin. Linking rhodamine to UM206, however, did not affect its antagonistic properties and Fzd- 2 could be visualized in the cells. In chapter 5 , we already showed UM206- rhodamine stainings on sections of several mouse tissues. Briefly, UM206rhodamine was localized in the intestine and kidney and could be competively blocked with recombinant Wnt3a or UM207, another Wnt5a fragment with affinity for Fzd-1 and -2, providing evidence for the specificity of UM206 binding.

As an alternative for the low molecular weight ligands we used an anti-Fzd-2 antibody that was raised in rabbits against the third extracellular loop of the receptor molecule. When used for Western blotting of the HEK cell line a band around 64kD was observed, which is in accordance to the size of the native receptor. On the other hand, the most prominent band in intestinal material was seen at $50 \mathrm{kD}$. This can depend upon the loss of the glycolysation sites ${ }^{13}$. The observation on the material from HEK cells that were transiently transfected with Fzd-2 does, however, indicate specificity of the antibody.

The same antibody was used for the visualization of Fzd-2 with immunohistochemistry. In sections from intestine and kidney there was intense specific staining. Subsequently, the antibody was tested in vivo. The intestine and kidney staining revealed the same distribution pattern as seen in the ex vivo slices, hereby confirming that the antibody can also be used in vivo.

Our group has previously shown that Fzd-2 is upregulated after myocardial infarction using qPCR and in situ hybridization ${ }^{14}$. Until now however, these data could not be confirmed at the protein level. Staining of Fzd-2 with UM206-Rho in the infarcted area, confirmed the upregulation of this receptor in myofibroblasts after myocardial infarction. In normal, healthy heart tissue Fzd-2 could only be observed in the blood vessels. 
An unexplained phenomenon is the UM206-induced receptor-internalization that was observed in HEK cells, overexpressing Fzd-2. Internalization of Fzd-2 was observed earlier. For example; the inhibitory action of Wnt5a on Wnt3a $\beta$-catenin dependent signaling depends upon Wnt5a induced internalization of the Fzd- $2^{15}$. This was explained by activation of a $\beta$-catenin independent, Rac-dependent pathway. Agonist dependent internalization of $G$ protein-coupled receptors (GPCRs) is a well characterized phenomenon that is believed to contribute to receptor desensitization $^{16,17}$. However, antagonist dependent internalization has, so far, not been described. Thus UM206 may activate an unknown pathway or, alternatively, may steric changes in the Fzd-2 molecule that promote its internalization.

The present study provides two tools for the in vitro and in vivo visualization of Fzd-2, namely an antibody and a low molecular weight peptidergic ligand. Fzd-2 was visualized in the kidney, intestine and blood vessels in the heart in normal circumstances and in cardiac myofibroblasts after myocardial infarction, confirming data from our own group and from literature. This provides a basis for the further development of contrast agents for the visualization of Fzd-2. The UM206-induced internalization of Fzd-2 deserves further attention.

\section{Funding}

This work was supported by BSIK 03033; Molecular Imaging of Ischemic heart disease.

\section{References}

1. Nusse, R. Wnt signaling in disease and in development. Cell Res 2005;15:28-32.

2. van Amerongen, R. \& Nusse, R. Towards an integrated view of Wnt signaling in development. Development 2009;136:3205-14.

3. MacDonald, B.T., Tamai, K. \& He, X. Wnt/beta-catenin signaling: components, mechanisms, and diseases. Dev Cell 2009;17:9-26.

4. Freese, J.L., Pino, D. \& Pleasure, S.J. Wnt signaling in development and disease. Neurobiol Dis (2009).

5. Squires, C.E. et al. Altered fibroblast function following myocardial infarction. J Mol Cell Cardiol 2005;39:699-707.

6. van den Borne, S.W. et al. Myocardial remodeling after infarction: the role of myofibroblasts. Nat Rev Cardiol 2010;7:30-7.

7. Blankesteijn, W.M., Essers-Janssen, Y.P., Verluyten, M.J., Daemen, M.J. \& Smits, J.F. A homologue of Drosophila tissue polarity gene frizzled is expressed in migrating myofibroblasts in the infarcted rat heart. Nat Med 1997;3:541-4.

8. Mikels, A.J. \& Nusse, R. Wnts as ligands: processing, secretion and reception. Oncogene 2006;25: 7461-8.

9. M.W.Pennington \& Dunn, B.N. Peptide synthesis protocols, Human Press, Totowa, New Jersey, 1994.

10. Schnolzer, M., Alewood, P., Jones, A., Alewood, D. \& Kent, S.B. In situ neutralization in Boc-chemistry solid phase peptide synthesis. Rapid, high yield assembly of difficult sequences. Int J Pept Protein Res 19932;40:180-93. 
11. van den Borne, S.W. et al. Mouse strain determines the outcome of wound healing after myocardial infarction. Cardiovasc Res 2009;84:273-82.

12. Goldsmith, S.J. Receptor imaging: competitive or complementary to antibody imaging? Semin NuCl Med 1997;27:85-93.

13. Stiegler, A.L., Burden, S.J. \& Hubbard, S.R. Crystal structure of the frizzled-like cysteine-rich domain of the receptor tyrosine kinase MuSK. J Mol Biol 2009;393:1-9.

14. Blankesteijn, W.M., Essers-Janssen, Y.P., Ulrich, M.M. \& Smits, J.F. Increased expression of a homologue of drosophila tissue polarity gene "frizzled" in left ventricular hypertrophy in the rat, as identified by subtractive hybridization. J Mol Cell Cardiol 1996;28:1187-91.

15. Sato, A., Yamamoto, H., Sakane, H., Koyama, H. \& Kikuchi, A. Wnt5a regulates distinct signalling pathways by binding to Frizzled2. Embo J 29:41-54.

16. Sibley, D.R., Benovic, J.L., Caron, M.G. \& Lefkowitz, R.J. Regulation of transmembrane signaling by receptor phosphorylation. Cell 1987;48:913-22.

17. Fukunaga, S., Setoguchi, S., Hirasawa, A. \& Tsujimoto, G. Monitoring ligand-mediated internalization of $\mathrm{G}$ protein-coupled receptor as a novel pharmacological approach. Life Sci 2006;80:17-23. 



\section{The role of Wnt/Frizzled in atherosclerosis}

Laeremans H., Lutgens E., Ottenheijm H.C.J., Smits J.F.M., Blankesteijn W.M. 


\begin{abstract}
Atherosclerosis is a common disease in industrialized countries. The disease is characterized by fatty deposits in the inner lining of arteries, covered by a fibrous cap. Atherosclerotic plaques can be classified as either vulnerable or stable. The vulnerable plaques are prone to rupture, releasing the contents of the plaque into the lumen of the artery. This can lead to acute coronary symptoms or stroke. In this chapter, the effect of blocking Wnt/Frizzled signaling on plaque size and stability is described. To this end, we used a peptide fragment of Wnt5a, UM206, which was previously shown to be a potent antagonist of Frizzled-1 and -2. The results indicate that the total plaque area was increased but, remarkably, that the thickness of the cap was also increased. This is indicative for a more stable plaque phenotype. Therefore, we conclude that inhibition of the Wnt/Frizzled pathway may lead to a reduction in plaque rupture and therefore could serve as a novel therapeutic target for the prevention of acute coronary events and stroke.
\end{abstract}

\title{
Keywords
}

Wnt/Frizzled; atherosclerosis; fibrous cap; vulnerable plaque 


\section{Introduction}

Atherosclerosis is a progressive disease that affects nearly all individuals in the Western world ${ }^{1}$. The disease is characterized by the accumulation of lipids and fibrous elements in the intimal layer of arteries. Following endothelial injury, the lesion develops to a fatty streak consisting mainly of lipid rich macrophages and progresses to atherosclerosis over many years before the disease becomes manifest ${ }^{2}$. Atherosclerotic plaques can be classified by a system proposed by the American Heart Association. In this classification, "complicated lesions" are responsible for most of the mortality and morbidity. However, Virmani et al. updated this classification and gave a more detailed description of atherothrombotic plaques and plaque rupture, and therefore also of the complicated lesions ${ }^{3}$. Atherothrombotic events can be distinguished into plaque rupture, erosion and eruptive calcified nodules. Complicated lesions are therefore depicted as lesions where the fibrous cap is thin ${ }^{4}$. These lesions are commonly referred to as vulnerable plaques. Rupture of these plaques causes life-treating events like acute coronary syndrome or stroke. Coronary plaque rupture is responsible for approximately $75 \%$ of coronary thrombi that lead to myocardial infarction and/or death. The clinical events caused by atherosclerosis remain the primary cause of death in Western society.

Currently, three main molecular systems are studied in atherosclerosis, namely the vascular endothelial growth factor (VEGF) system, the plasminogen system, and the coagulation system ${ }^{5,6,7}$. Looking for potential other, more specific, pathways in atherosclerosis via a micro-array screen has led to the identification of components of the Wnt/Frizzled pathway. Frizzleds are seven transmembrane receptors with a cysteine-rich domain (CRD). This CRD is involved in the binding of its ligand; Wnt. Wnts are large, highly conserved glycoproteins. Binding of a Wnt protein to Frizzled can lead to the activation of either the $\beta$-catenin dependent pathway or the $\beta$ catenin independent pathway, with second messenger calcium. The Wnt/Frizzled signal transduction cascade is involved in development and a wide range of diseases, wherein the embryonic gene program is reactivated ${ }^{8}$.

The aim of this chapter was to investigate the functional role of Wnt/Frizzled signaling in plaque development and phenotype. To this end, we administered UM206, a high affinity Frizzled-1 and -2 antagonist (see chapter 5), to LDL-receptor deficient $\left(\mathrm{LDLR}^{-/}\right)$mice in which atherosclerosis was induced by collars around the carotid arteries. We compared these plaques to those of mice that were treated similarly but received saline rather than UM206. 


\section{Materials and Methods}

\section{Animals}

$\mathrm{LDLR}^{-/}$mice on a B6.129S7 background were obtained from Jackson laboratories (Campbell, VA, USA). During the experiment period, mice were fed with a Western diet $(0.21 \%$ cholesterol; Abdiets, Woerden) starting 3 weeks before collar placement. The diet was continued for 9 weeks until the mice were sacrificed. Carotid intimal thickening was induced by constrictive perivascular collar placement. The mice were initially anesthetized with $3 \%$ isoflurane and maintained anesthetized with $2 \%$ isoflurane during placement of the collar. Anaesthesia gas was delivered using a face mask. The right and left carotid arteries were prepared free from the surrounding connective tissue, and stiff collars (Helix mark silicon tubing, inner diameter $0.31 \mathrm{~mm}$, outer diameter $0.64 \mathrm{~mm}$, and length $2 \mathrm{~mm}$ ) were placed around the right and left carotid arteries proximal to the bifurcation. All mice received an osmotic minipump with either saline or UM206 (10 $\mathrm{\mu g} /$ day) (Alzet, Cupertino, CA, USA). 6 weeks after the placement of the collars, the mice were sacrificed.

\section{Tissue processing}

Mice were killed after 6 weeks of collar and 9 weeks of Western diet. The arterial tree was perfused, through a catheter inserted into the left ventricular apex, for 3 min with phosphate-buffered saline (PBS), and for $3 \mathrm{~min}$ with $10 \%$ phosphatebuffered formalin, $\mathrm{pH} 7.4$, both containing $0.1 \mathrm{mg} / \mathrm{ml}$ sodium nitroprusside (Sigma). The aortic arch, including its main branchpoints (brachiocephalic trunk, left common carotid artery and left subclavian artery), as well as the thoracic and abdominal aorta were removed and fixed in $10 \%$ phosphate-buffered formalin. All vessels were processed and embedded longitudinally in paraffin. The entire right carotid artery was cut and 6 sections were collected on 1 glass, representing $520 \mu \mathrm{m}$ of the length of the blood vessel.

\section{$3 \quad$ Histology and morphometry}

For histological analyses, six sections (104 $\mu \mathrm{m}$ apart) were stained with haematoxylin. Atherosclerotic lesions of both saline- and UM206-treated mice were then analyzed and classified as either initial or advanced lesions, based on histological criteria, defined by the American Heart Association. The number of atherosclerotic plaques, the presence or absence of lipid cores and calcification, and the total number of cells per lesion were also determined. Lawson staining (modified Elastica von Giesson, Verhoef staining), which exclusively stains the elastic laminae, was used to delineate the internal elastic lamina, to permit an easier distinction be- 
tween media and intima. Six Lawson-stained sections (104 $\mu \mathrm{m}$ apart) were used for morphometrical analysis. All morphometric parameters were determined using a microscope coupled to a computerized morphometry system (Quantimet 570, Leica, and the Netherlands).

Plaque area, excluding the underlying media, was determined for each individual plaque. The relative lipid core content was determined by dividing lipid core area by plaque area. The relative fibrous cap thickness was calculated by dividing fibrous cap thickness at the centre of the lesion by lesion thickness. The ratio of fibrous cap to lipid core was calculated by dividing fibrous cap thickness by lipid core thickness, both determined at the centre of the atherosclerotic lesion. The number of cells per $\mathrm{mm}^{2}$ lesion area was also determined. The relative collagen area (that is, the percentage of area that stained positive for Sirius Red) was determined for each atherosclerotic plaque, using the same morphometry system.

\section{$4 \quad$ Immunohistochemistry}

Sections were immunolabeled with $\alpha$-smooth muscle actin ( $\alpha$-SMA monoclonal antibody, 1:500 dilution; Sigma) as a marker for vascular smooth muscle cells. The relative area of the atherosclerotic plaque positive for $\alpha$-smooth muscle actin was determined by dividing the $\alpha$-SMA-positive area by total plaque area, using the morphometry system. All measurements were made by the same observer. In separate experiments, the intra-observer variation was less than $10 \%$.

\section{$5 \quad$ Statistical analysis}

All values are shown as mean \pm S.E.M. Differences between groups were examined for statistical significance using two-way ANOVA with the Bonferroni posthoc-test. A $P$ value less than 0.05 was considered to indicate a statistically significant difference.

\section{Results}

\section{In vivo validation}

Survival rates of both saline treated and UM206 treated mice were $100 \%$ in both groups. Body weights were similar, saline group 29.1+/-2.4 g and UM206 treated group $28.5+/-1.4 \mathrm{~g}$. Autopsy revealed no macroscopic abnormalities in the major organs. The right carotid artery displayed a larger plaque than the left carotid artery and therefore was analyzed in the remainder of this study. Furthermore, the UM206 treated group showed larger plaques both in carotid artery and aortic arch. 


\section{Plaque burden}

UM206 treated mice showed a 54\% increase in total plaque volume $\left(17.93 \mathrm{~mm}^{3}\right.$ [range: 9.962 to 15.23 ] compared to $3.61 \mathrm{~mm}^{3}$ [range: 1.168 to 4.197 ] in salinetreated mice, $\mathrm{P}<0.001$; see Fig $1 \mathrm{~A}$ ). Media, intima, wall and total vessel volume were not significantly different between the treated and untreated groups (Not shown). However, in accordance with the larger plaque area, total cholesterol volume was significantly increased in UM206 treated animals (Fig 1B).
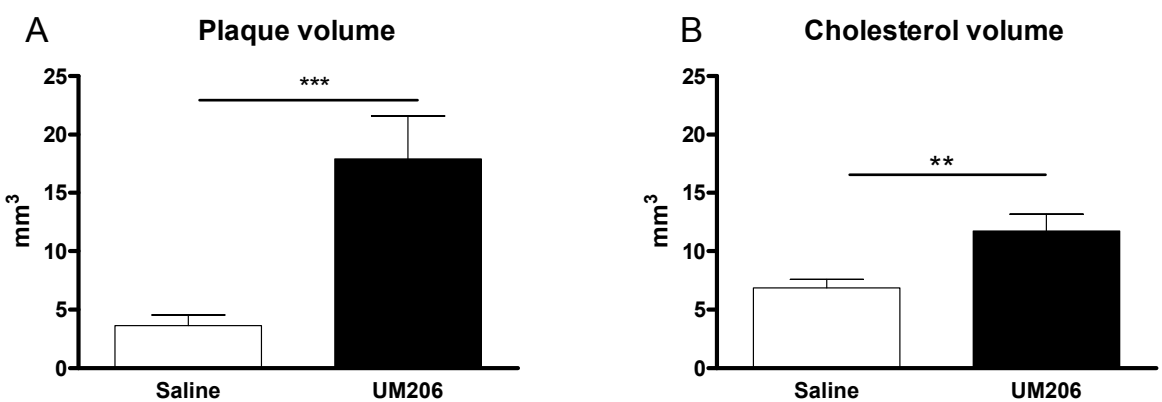

Fig 1: Bar graphs showing the plaque burden data of the right carotid artery. A. Total plaque volume and B. cholesterol volume were significantly increased in UM206 treated animals in comparison to saline treated mice. Values are the mean of 20 animals and are represented with SEM (** $\mathrm{P}<0.01$ and $* * *$ $\mathrm{P}<0.001)$.

Other significant differences in vessel characteristics are depicted in Fig 2. An increased internal elastic layer and decreased external elastic layer were observed in the UM206-treated group (Fig 2A-B) and the intima to media ratio was increased after UM206 treatment (Fig 2C). Next, we quantified the total wall area relative to the vessel area, which was significantly increased in the UM206- treated group (Fig 2D).

\section{$3 \quad$ Plaque composition}

In addition to the increase in plaque volume, significant differences in plaque composition between UM206- and saline-treated mice were observed. As expected on basis of previous studies by our group in the heart, UM206 had a profound effect on $\alpha$-smooth muscle actin ( $\alpha$-SMA) and collagen levels of the plaque extracellular matrix content. $\alpha$-SMA content was more than 3-fold higher after UM206 treatment, suggesting higher levels of "synthetic" smooth muscle cells and therefore a more stable cap (Fig 3A). Collagen content was significantly lower after UM206 treatment, suggesting less advanced plaques in this group (Fig 3B). 
A

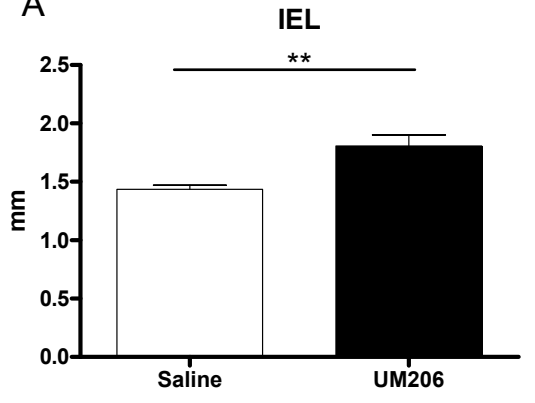

C

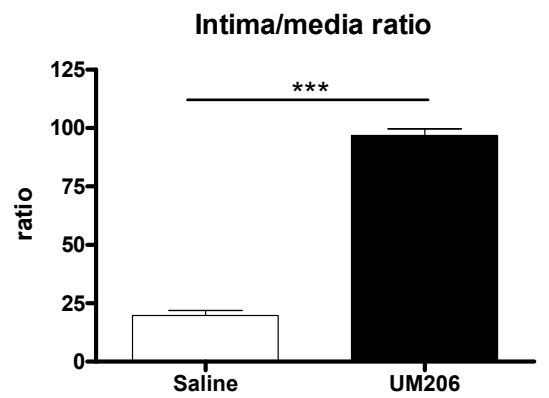

B

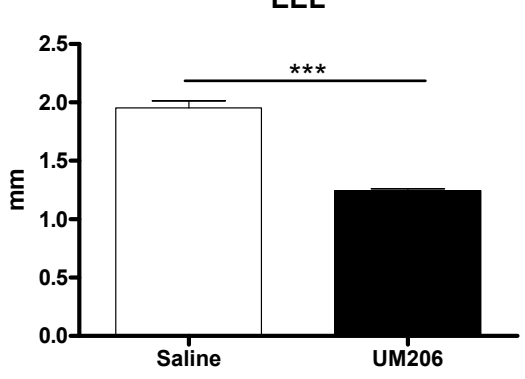

D

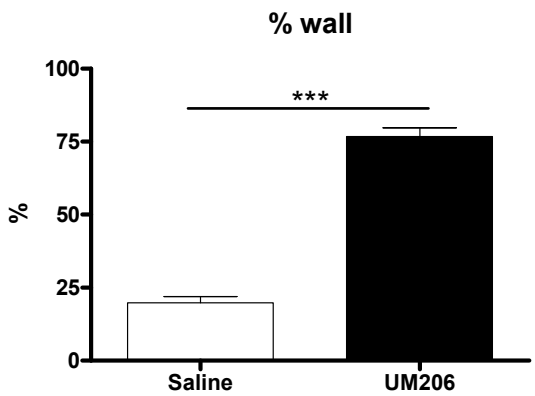

Fig 2: Bar graphs showing plaque burden data. UM206 had opposite effects on the length of the internal A. and external B. elastic layer: The internal layer length was significantly increased, where the external layer length was decreased. C. UM206 treatment severely increased the intima/media ratio D. percentage of wall elements in the plaque, was also increased by UM206 treatment. Values are the mean of 20 different animals and are represented with SEM $(* * P<0.01$ and $* * * P<0.001)$.
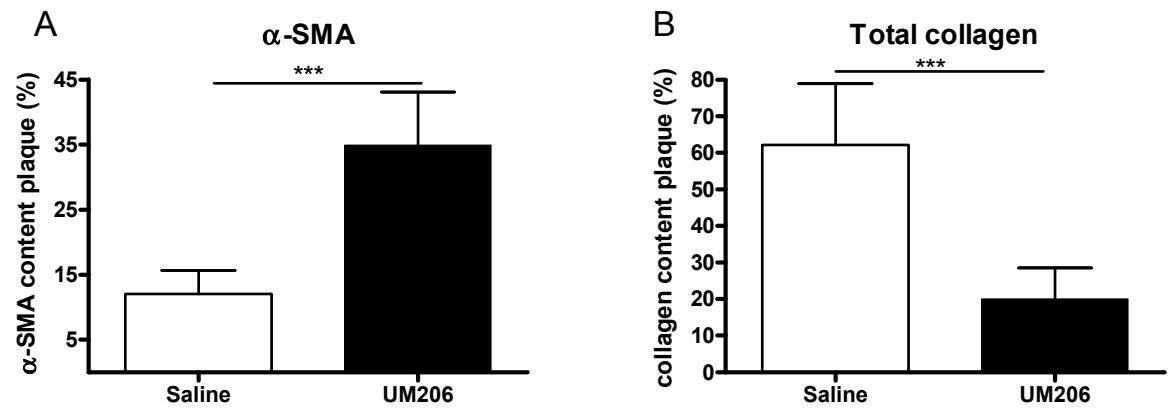

Fig 3: Relative composition of the plaque. A. The percentage of $\alpha$-SMA positive cells in the plaque was significantly increased after UM206 treatment. B. Total collagen content, on the other hand, was decreased after UM206 treatment. Values are the mean of 20 animals and are represented with SEM $(* * * \mathrm{P}<0.001)$. 


\section{Discussion}

Recent studies point to an important role of the Wnt/Frizzled signaling pathways in differentiation of smooth muscle cells and fibroblasts (chapters 3 and 4 of this thesis). Because micro-array data suggested that this pathway is also involved in atherosclerosis, we studied the effect of our Frizzled-1 and -2 antagonist, UM206, on plaque development and progression in $\mathrm{LDLR}^{-/-}$mice on a Western style diet. Treatment with UM206 induced larger plaques that contain more cholesterol, but also have more $\alpha$-SMA expressing cells suggesting the induction of a more stable plaque phenotype.

Only a few papers have addressed Wnt/Frizzled signaling in atherosclerosis until now. Chrisman et al. have demonstrated the presence of Wnt5a in the macrophagerich regions in the centre of plaques obtained from mice and humans ${ }^{9}$, but they did not address the functional consequences of this finding with respect to plaque progression and differentiation. Moreover, Ueland et al. have shown that Dickkopf1 , an endogenous LRP5/6 antagonist, is expressed in atherosclerotic plaques, particularly in advanced and unstable lesions ${ }^{10}$. Expression of Dickkopf-1 was localized in macrophages and endothelial cells in atherosclerotic plaques ${ }^{11}$. Moreover, Wnt5a and its receptor Frizzled-5 have been shown to regulate inflammatory responses of human mononuclear cells induced by microbial stimulation, presumably by activating Toll-like receptor signaling ${ }^{12}$. These observations support a role for Wnt signaling in inflammatory diseases as diverse as microbial-induced inflammation, diabetes mellitus, rheumatoid arthritis and atherosclerosis.

The high mortality rate due to atherosclerosis is not correlated to plaque area, but it is the rupture of an unstable plaque that causes the acute clinical consequences of atherosclerosis. Therefore, the increased stability of the plaque after UM206 treatment may be beneficial to decrease mortality rates as a consequence of atherosclerosis. The results of this study not only demonstrate the involvement of the Wnt/Frizzled pathway in plaque development and progression, but also suggest a potential application of this pathway as a therapeutic target to prevent plaque rupture. Further experiments will have to define the therapeutic window of this approach and the downstream signaling pathways involved.

\section{Funding}

This work was supported by BSIK 03033; Molecular Imaging of Ischemic heart disease. 


\section{References}

1. Eijgelaar WJ, Heeneman S, Daemen MJ. The vulnerable patient: refocusing on the plaque? Thromb Haemost 2009; 102: 231-239.

2. Ohashi R, Mu H, Yao Q, Chen C. Cellular and molecular mechanisms of atherosclerosis with mouse models. Trends Cardiovasc Med 2004; 14: 187-190.

3. Virmani R, Kolodgie FD, Burke AP, Farb A, Schwartz SM. Lessons from sudden coronary death: a comprehensive morphological classification scheme for atherosclerotic lesions. Arterioscler Thromb Vasc Biol 2000; 20: 1262-1275.

4. Lutgens $\mathrm{E}$, van Suylen RJ, Faber BC et al. Atherosclerotic plaque rupture: local or systemic process? Arterioscler Thromb Vasc Biol 2003; 23: 2123-2130.

5. Kuzuya M, Satake S, Esaki T et al. Induction of angiogenesis by smooth muscle cell-derived factor: possible role in neovascularization in atherosclerotic plaque. J Cell Physiol 1995; 164: 658-667.

6. Plow EF, Herren T, Redlitz A, Miles LA, Hoover-Plow JL. The cell biology of the plasminogen system. FASEB J 1995; 9: 939-945.

7. Carmeliet P, Collen D. Molecular analysis of blood vessel formation and disease. Am J Physiol 1997; 273: H2091-2104.

8. van de Schans VA, Smits JF, Blankesteijn WM. The Wnt/frizzled pathway in cardiovascular development and disease: Friend or foe? Eur J Pharmacol 2008; 585: 338-345

9. Christman MA, 2nd, Goetz DJ, Dickerson E et al. Wnt5a is expressed in murine and human atherosclerotic lesions. Am J Physiol Heart Circ Physiol 2008; 294: H2864-2870.

10. Ueland T, Otterdal K, Lekva T et al. Dickkopf-1 enhances inflammatory interaction between platelets and endothelial cells and shows increased expression in atherosclerosis. Arterioscler Thromb Vasc Biol 2009; 29: 1228-1234.

11. Pereira $\mathrm{CP}$, Bachli EB, Schoedon G. The wnt pathway: a macrophage effector molecule that triggers inflammation. Curr Atheroscler Rep 2009; 11: 236-242.

12. Blumenthal A, Ehlers S, Lauber J et al. The Wingless homolog WNT5A and its receptor Frizzled-5 regulate inflammatory responses of human mononuclear cells induced by microbial stimulation. Blood 2006; 108: 965-973. 



\section{8}

General discussion and conclusions 
Over the last years, the interest in the Wnt/Frizzled signal transduction pathway has increased. So far, the main focus has been on the complex signal transduction cascade of the pathway. Less effort has been put into sorting out the pharmacology of the Frizzled ( $\mathrm{Fzd}$ ), like e.g. the specificity of the interactions between the different members of the Wnt and Fzd protein families. Moreover, compounds that can block the interaction between Wnts and Fzds have not been described to date. Throughout this thesis, we focus on Fzd-1 and -2 because previous research has revealed that these Fzds are overexpressed in different forms of cardiac remodeling.

In chapter $\mathbf{2}$ of this thesis, we compared different cell lines for their usefulness as a screening tool for the Wnt/Fzd signal transduction cascade. Marked differences in the efficiency of signal transduction were observed between the different cell lines, which could be attributed to lower levels of components of the intracellular signaling cascade. This indicates that careful selection of the appropriate cell lines is necessary. Moreover, we tested different combinations of Wnts and Fzd-1 and -2 to gain more insight in the pharmacology of the pathway. Wnt1, 3, 3a and 10a turned out to activate $\beta$-catenin mediated signaling, whereas $W n t 2,4,5 a / b, 6$ and $7 a / b$ did not. This suggests that these Wnts either signal through a $\beta$-catenin independent pathway, or do not activate Fzd-1 and -2 at all. For Wnt5a, we could show that it can activate $\beta$-catenin independent signaling, but also block the Wnt3a-induced $\beta$ catenin mediated signaling. We consistently observed similar patterns of activation with Fzd-1 and -2 .

We subsequently compared the Wnt-mediated activation of Fzd-1 and -2 from different species, i.e. mouse, rat and human. No species differences were observed, suggesting that Fzd-1 and -2 are not only genetically but also functionally well conserved in evolution. Transfection of LRPs was shown to augment $\beta$-catenin mediated Wnt/Fzd signaling, presumably by facilitating Wnt binding to the receptor complex rather than by Fzd-independent LRP signaling because a LRP6 mutant lacking the intracellular receptor part showed the same effect as native LRP6. Finally, we propose a method for standardizing the amount of active Wnt3a protein in conditioned media obtained from Wnt3a overexpressing L-cells by comparing its biological activity to a calibration curve constructed with purified recombinant Wnt3a protein. All these experiments set the stage for the screening of peptide fragments of Wnts as blockers for the Wnt/Fzd interaction, described in Chapter 5 .

The effects of Wnt/Frizzled signaling on migration, proliferation and differentiation were studied in cell lines of cardiac fibroblasts (Chapter $\mathbf{3}$ ) and smooth and skeletal muscle cells (Chapter 4). Primary cardiac fibroblasts can be isolated from different species and put in culture. Two major disadvantages are, however, the limited proliferation and the low transfection efficiency of less than $1 \%$. For these reasons, we developed a cell line of rat-derived cardiac fibroblasts immortalized with telom- 
erase (CFIT). CFIT are still proliferating after 40 passages and have a transfection efficiency of more than $70 \%$. The CFIT are therefore an excellent research tool to study the Wnt/Fzd pathway in the proliferation, differentiation and migration of cardiac fibroblasts. Activation of Wnt/Fzd signaling with either Wnt3a or -5a had no effect on CFIT proliferation, but significantly delayed migration of these cells, suggesting the involvement of a $\beta$-catenin independent pathway. This could be confirmed by using a calcium agonist and antagonist. The effect of Wnt/Fzd signaling on the differentiation of the CFIT cells was complex, depending on specific Wnt/Fzd combinations. A more detailed study on the signaling pathways involved indicated that higher amounts of calcium induce a myofibroblast like phenotype. Generally, we can conclude that the Wnt/Fzd pathway is involved in the fine tuning of the delicate balance between fibroblast and myofibroblasts.

We subsequently tested the effect of Wnt/Fzd signaling on the differentiation of smooth muscle cells (Chapter 4). The patterns that we observed were quite similar in their complexity to those observed in the CFIT cells. Skeletal muscle cells (Chapter 4) exhibited a differentiation pattern similar to the smooth muscle cells. In neither of the cell lines, an effect on the proliferation rate was observed, again confirming the results obtained with CFIT. Therefore we conclude that the differentiation of smooth muscle cells and skeletal muscle cells requires a complex interplay between the activation and deactivation of $\beta$-catenin dependent pathways.

The Wnt/Frizzled signal transduction cascade is implicated in a broad field of developmental processes as well as diseases. As indicated above, compounds that specifically block the Wnt/Fzd interaction by binding to the Fzd protein are not yet described. However, such compounds would be attractive to use as therapeutic agents, but could also be applied for the visualization of Fzd proteins in diseased tissue where components of the Wnt/Fzd pathway are upregulated. Wnts by themselves are poor candidates for these applications, because they stick to all kinds of surfaces, may lack sufficient specificity and are difficult to purify. A low molecular weight ligand would provide an ideal screening tool and a potentially specific therapeutic. In chapter 5, we describe the characterization of three fragments of Wnt5a as ligands for Fzd-1 and -2. These peptides were named UM206, UM207 and UM208. These peptides acted as antagonists on Fzd-1 and -2 with $\mathrm{IC}_{50}$ values ranging from $10^{-6}$ to $10^{-11} \mathrm{M}$. The peptides contained two cysteines, and structure activity studies showed that at least one cysteine is essential for binding. UM206, the peptide with the highest affinity, had an $\mathrm{IC}_{50}$ in the range of $10^{-9} \mathrm{M}$ for Fzd-1 and ${ }^{10-}{ }^{11}$ for Fzd-2, and was used in all subsequent experiments. This high affinity, combined with the need for at least one cysteine in the peptide, may suggest the formation of a disulfide bridge between UM206 and the Fzd protein. The peptides showed no binding to Fzd-4 or -5 , suggesting specificity for Fzd-1 and -2. Specificity 
of the binding of UM206 to Fzd-1 and - 2 could further be demonstrated by competition experiments with UM207 and Wnt3a, which effectively blocked the binding of labeled UM206 to these receptors.

Because previous studies with Fzd- 2 knock-out animals revealed that inhibition of the Fzd-2 ameliorated the wound healing after myocardial infarction, we wanted to test this hypothesis with UM206 in a relevant in vitro system. Therefore, we tested the effect of UM206 on CFIT cells and observed a complete abolishment of the effects of the Wnt/Frizzled signal transduction cascade on the migration and differentiation of the CFIT cells. This confirms the antagonistic properties of UM206, both for $\beta$-catenin dependent and independent signaling.

We subsequently determined the pharmacokinetic properties of UM206 after a single intravenous bolus injection. The half-life of the compound turned out to be $\sim 90 \mathrm{~min}$ in rats and mice, sufficient for chronic subcutaneous administration by osmotic minipump. Administration of UM206 significantly decreased the size of the infarct area and increased the wall thickness; after 5 weeks of UM206 treatment mortality due to heart failure was completely prevented. Immunohistochemical staining with antibodies binding to alpha smooth muscle actin ( $\alpha$-SMA) revealed up to 5 -fold more myofibroblasts in the infarct area. Moreover, cardiac function was significantly improved and cardiac dilatation was significantly attenuated in UM206treated compared to saline-treated mice. Taken together, these data show that blocking Fzd-1 and -2 shows a promising new therapeutic approach for myocardial infarction. UM206 was shown to increase the myofibroblast numbers in the infarct area, thereby preventing infarct expansion and dilatation of the left ventricle.

Because myofibroblasts express Fzd-1 and -2 , the binding of a labeled ligand to these receptors forms an attractive approach to visualize these cells. As shown in the previous chapters, large numbers of myofibroblasts in the infarct area are beneficial for the preservation of an adequate pump function of the infarcted heart, but also in other diseases in which Fzd-1 and -2 upregulation takes place. UM206 tagged with rhodamine was shown to retain its affinity for Fzd-1 and -2 . Using this compound, we could visualize the Fzd-1 and -2 in small intestine, kidney and blood vessels, but also in the infarcted heart. The results were compared with those obtained with an Fzd-2 antibody, developed by our collaborators at MSD Research labs. After injection of this antibody in the tail vein of mice, we observed staining patterns that were similar to those obtained with UM206-rhodamine. The results suggest that labeling of Fzd-1 and -2 can be a successful approach to monitor the quality of infarct healing by determining myofibroblast numbers, allowing the identification of patients with poor infarct healing before they develop clinical symptoms of heart failure (Chapter 6 ).

The beneficial effect of UM206 on infarct healing calls for the application of this therapy to other cardiovascular diseases in which activation of Wnt/Fzd signaling has been reported. DNA array experiments, performed by researchers from the 
Department of Pathology, MUMC, indicated the upregulation of components of Wnt/Frizzled signaling in atherosclerotic plaques. Until now, suitable tools to study the functional relevance of Wnt/Frizzled in atherosclerosis were lacking, but UM206 can easily be applied to answer this question (chapter 7). UM206 treatment of $\mathrm{LDLR}^{-/-}$mice on a Western style diet, in which carotid collars were placed to induce atherosclerosis, was found to increase total plaque area and cholesterol content significantly. On the other hand the number of "synthetic" smooth muscle cells in the atherosclerotic plaque also increased significantly, suggesting the induction of a more stable plaque phenotype. These results underscore the importance of Wnt/Fzd signaling in the development of atherosclerotic plaques.

\section{Outlook}

In this thesis, we studied several aspects of Wnt/Frizzled signaling in vitro and in vivo. Moreover, we developed the synthetic ligand for Fzd-1 and -2, UM206, which has excellent potential both as a therapeutic and as an imaging tool. Future experiments will have to unravel the optimal therapeutic window in infarct healing. Moreover, the applicability of this compound to other diseases in which fibrosis plays a prominent role should be evaluated.

The value of UM206 as an imaging tool has to be further examined in vivo. To this end, UM206 will have to be labeled with tags that can be detected with PET or MRI. These experiments eventually should help to establish myofibroblast density in the infarct area as an early predictor of ventricular dilatation and hart failure.

Also in vitro, labeled UM206 can be helpful in solving questions regarding the internalization and dimerization of Fzd proteins. Further in-depth clarification of the signal transduction cascade could be facilitated by blocking Fzd-1 and -2 receptors with this compound.

At the chemical level, the positioning of essential amino acids and the optimal length of UM206 should be further evaluated. Plasma half life could be extended by attaching albumin and/or glycine. Until now, UM206 has been administered subcutaneously, but this is not optimal for chronic administration. Therefore different routes of administration (e.g. percutaneous or intranasal administration) should be further explored. Another approach would be to develop non-peptidergic Fzd-1 and -2 ligands that are orally active. To this end, we started computer modeling of the binding pockets on Frizzled-1 and -2, in collaboration with Dr. G. Nicolaes, Dept of Biochemistry, MUMC. An initial virtual screening has led to the identification of two binding pockets and 2500 potential chemical compounds for Frizzled-1. These compounds will have to be tested, validated and optimized. 
In conclusion, UM206 is the first synthetic Fzd-1 and -2 ligand in what can be anticipated to become a new family of compounds. These compounds will be indispensable tools for research on Wnt/Frizzled signaling, both in vitro and in vivo. We expect that these compounds will find applications as therapeutics, both within and outside the area of cardiovascular disease. Moreover, these compounds can be expected to be used as molecular imaging tools. The monitoring of disease processes before clinical symptoms become apparent would allow early and more specific interventions aimed at slowing down or even reversing progression of the disease. 
9

Summary

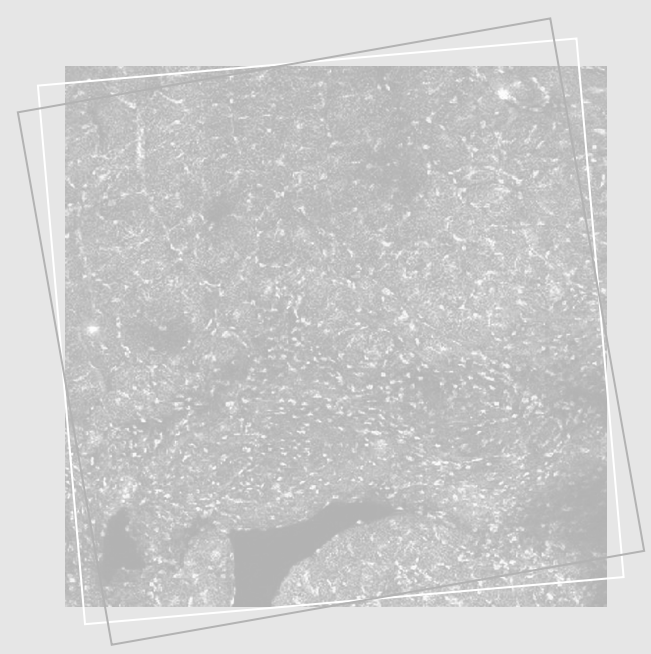


Myocardial infarction (MI) is a common pathology in Western countries. Most people will survive the acute phase of myocardial infarction and enter the phase of wound healing. Wound healing is a very complex process that, when not proceeding adequately, can lead to a wide range of complications. The body will try to counteract the deteriorating cardiac function by activating compensatory mechanisms. Initially, these compensatory mechanisms will lead to sustained cardiac function, but in long term this can result in heart failure.

Many different signal transduction cascades are involved in wound healing. In this thesis, one of these signal transduction cascades will be highlighted, namely the Wnt/Frizzled (Fzd) signal transduction cascade. This signal transduction cascade caught our interest, because previous experiments in our lab indicated that expression of specifically Fzd-1 and -2, were upregulated after MI.

Although Wnt/Fzd has been examined for a long time, many deficiencies still exist in the knowledge of specific Wnt/Fzd pharmacology. To evaluate this experimentally, we had to search for an appropriate cell line (Chapter 2). Our experiments indicate that the human embryonic kidney cells, HEK293, were most suitable. All elements of both the $\beta$-catenin dependent and independent signal transduction pathways are present in the HEK cells. Furthermore, the presence of high levels of the different components of the signal transduction cascade, prove the suitability of this cell line. Next step was to examine possible differences between different sources of Wnt proteins. To this end, we compared recombinant proteins, conditioned medium and plasmid constructs containing Wnt sequences. The results were similar, so we decided to use the conditioned medium.

Because studying the interactions between all $19 \mathrm{Wnts}$ and 10 Frizzleds was beyond our capabilities, we focused on Fzd-1 and -2 because these receptors are upregulated in MI. This study led to the conclusion that both Fzd-1 and -2 preferably bind Wnt3a and Wnt5a, whereby Wnt3a can activate both the $\beta$-catenin dependent and independent pathway, whereas Wnt5a can only activate the $\beta$-catenin independent pathway. Furthermore, Wnt5a can act as a natural antagonist for Wnt3a in $\beta$ catenin dependent signaling. No differences could be detected in the activity of Fzd proteins from different species. We also proved that the co-receptors LRP5/6 mainly function to facilitate the binding of Wnt to Fzd and the intracellular part of LRP could enhance the signal. Furthermore, LRP6 seemed more potent than LRP5 (Chapter 2).

The next step was to test Wnt-Fzd signaling in a clinically more relevant cell system. To this end, we studied the most important cell type in the heart, namely the fibroblast. A cardiac fibroblast cell line immortalized with telomerase, that we called 
CFIT, was developed in our lab. We studied the influences of Wnt/Fzd on CFIT proliferation, differentiation and migration (Chapter 3 ). These experiments showed that proliferation was unaffected by Wnt/Fzd signaling. Migration was delayed by Fzd-1 and -2 alone or in combination with either Wnt3a or Wnt5a, and this could be attributed to non- $\beta$-catenin mediated signaling. The CFIT differentiation was studied using myofibroblast differentiation markers, where we observed both stimulatory and inhibitory effects of different combinations of Wnts and Fzds. Therefore, we can conclude that Wnt/Fzd signaling is very complex, whereby specific Wnt/Fzd combination and the activated signal transduction pathway play a crucial role.

In Chapter 4, we studied the effects of Wnt/Fzd signaling in smooth and skeletal muscles. Wnt/Fzd had no influence on the proliferation. Differentiation, on the other hand, was controlled by Wnt/Fzd in a manner similar to that observed in CFIT. Both Fzd-1 and -2 could influence the differentiation of the muscle cells. Furthermore, these data confirm previous reports in the literature that smooth muscle cells could differentiate into skeletal muscle cells. These data also support the idea of the $\beta$-catenin independent pathway as main controller of migration.

The results of this thesis, combined with the literature, suggest that blocking Wnt/Fzd signaling can improve cardiac remodeling after MI. Because Wnts are very large and sticky proteins that usually act as agonist rather than antagonists, they are not suitable for in vivo therapy and visualization. This led to the development of peptidergic antagonists, which specifically interact with Fzd-1 and -2 and were derived from their natural ligands Wnt3a and -5a (Chapter 5). These peptides were called: UM206, UM207 and UM208. UM206 was easiest to dissolve and had the highest affinity for Fzd-1 and $-2, I C_{50}$ of $10^{-9} \mathrm{M}$ and $10^{-11} \mathrm{M}$, respectively. The amino acids Gly, Thr and Asp were shown to be critical, as well as the presence of at least one cysteine. All these peptides displayed a high specificity; no reactivity could be measured with Fzd-4 and -5. UM206 was also tested in CFIT and showed significant inhibition of the effect of Wnt/Fzd on the migration and differentiation. These results indicate that both the $\beta$-catenin dependent and independent pathway can be blocked by UM206. Furthermore, these effects were species independent and active on recombinant protein, conditioned medium and constructs.

The in vitro data indicate that UM206 is an excellent candidate for in vivo testing (Chapter 5). Pharmacokinetic experiments showed that UM206 was stable and had a plasma half-life of around $90 \mathrm{~min}$. Because of this favorable pharmacokinetics and high efficacy, UM206 was administered in the mouse MI model for 2 and 5 weeks, starting at the moment of infarction. Infarct area was significantly reduced and infarct wall thickness was increased in UM206-treated animals. The amount of myofibroblasts was also significantly increased. These were all indicators of favor- 
able cardiac remodeling. Moreover, in the 5 week treatment group, the development of heart failure could be prevented completely. In these animals, end diastolic volume was decreased, the ejection fraction was elevated and pump function was improved compared to the untreated mice. Collagen content was however decreased, preventing stiffening of the heart. All these studies indicate that UM206 can prevent heart failure and improve cardiac function after $\mathrm{Ml}$; the most likely mechanism of action is a reduced infarct expansion because of an augmented myofibroblast content of the infarct area.

One of the aims of the present project was to test the validity of Fzd-1 and -2 as a marker for the quality of infarct healing. To this end, we developed two different tools, namely rhodamine-labeled UM206 and an Fzd-2 antibody, in our research group (Chapter 6). Tests on different cell lines exhibited that the activity and specificity of UM206-rhodamine were preserved after labeling. This substance was tested on paraffin and frozen sections of kidney and small intestine, organs known to contain Fzd-1 and Fzd-2. These results could be confirmed by immunohistochemistry, using the Fzd-2 specific antibody. Moreover, in vitro experiments revealed that stimulation with Wnt3a or Wnt5a, activating either the $\beta$-catenin dependent or independent pathway, led to internalization of Fzd-1 and -2. Finally, infusion of the Fzd-2 antibody in a mouse was shown to allow visualization of the Fzd-1 and -2 receptors in kidney and small intestine. These results suggest that both UM206derived imaging compounds and the Fzd-2 antibody can be used for in vivo diagnostics, e.g. of the Fzd-1 and/or -2 content of the infarct area as a predictor of excessive dilatation and heart failure development.

In Chapter 7, a pilot experiment on the involvement of Wnt/Fzd signaling in the development of atherosclerosis is described. Using a model in which carotid collars are placed in LDL receptor knockout mice, inhibition of Wnt/Fzd signaling by UM206 led to an increased plaque area with more cholesterol deposits. However, the cap of the plaque was thicker and contained more $\alpha$-smooth muscle actin positive cells, suggesting a more stable plaque phenotype. These data show for the first time that blocking Fzd-1 and -2 mediated signaling can modulate the characteristics of an atherosclerotic plaque, and call for a more in-depth analysis of this phenomenon. In conclusion, in this thesis the development of a substance with high affinity and specificity for Fzd-1 and-2 is described, which was tested and validated in in vitro standard cell lines and more clinical relevant cells as well as in in vivo studies. UM206 is the first low molecular weight ligand that can block the interaction between Wnt proteins and Fzd-1 and -2. This substance may offer a broad range of therapeutic and diagnostic applications in cardiovascular diseases, but also in other conditions where $\mathrm{Fzd}-1$ and -2 signaling plays a role. 
10

Samenvatting

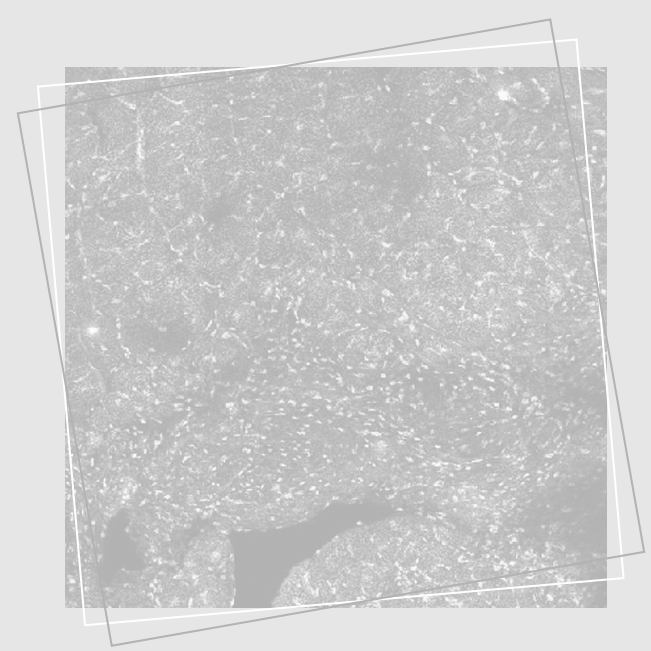


Het myocardinfarct (MI) is een frequente aandoening in de Westerse wereld. De meeste mensen overleven de acute fase van een myocardinfarct, waarna wondgenezing van start gaat. Wondgenezing is een erg complex proces wat kan leiden tot diverse complicaties, indien het niet correct verloopt. Het lichaam zal de verslechterde hartfunctie instantaan compenseren. In het begin zullen deze compensatiemechanismen leiden tot een verbeterde hartfunctie, maar op lange termijn resulteert dit echter vaak in hartfalen.

Bij de wondgenezing zijn verschillende signaaltransductiewegen betrokken. In dit proefschrift zal een van de signaaltransductiewegen, namelijk de Wnt/Frizzled (Fzd) signaaltransductieweg, in detail worden bekeken. Deze signaaltransductieweg wordt hier speciaal in het daglicht gesteld omdat uit vorige experimenten, uitgevoerd in ons laboratorium, is gebleken dat Fzd-1 en -2 sterk opgereguleerd zijn na MI.

Hoewel Wnt/Fzd reeds geruime tijd wordt bestudeerd, zijn er echter nog vele lancunes in de kennis over Wnt/Fzd farmacologie. Om een signaaltransductie weg op een natuurgetrouwe wijze te kunnen evalueren, dient er gezocht te worden naar een geschikte cellijn (Hoofdstuk 2). Uit onze bevindingen blijkt dat humane embryonale niercellijn HEK293, hiervoor het meest geschikt blijkt. Alle elementen voor de $\beta$-catenine afhankelijke en onafhankelijke signalering zijn aanwezig in de HEK cellen. De hoge concentraties van de verschillende componenten van de signaaltransductie weg in vergelijking met andere cellijnen, indiceren tevens de geschiktheid van deze cellijn.

Verder werden de eventuele verschillen tussen diverse bronnen van Wnt eiwitten vergeleken. Uit een vergelijking van recombinante Wnt-eiwitten, geconditioneerd medium en transfectie met plasmides die Wnt genen bevatten, bleek dat er geen verschil is. Daartoe werd voor de verdere experimenten besloten geconditioneerd medium te gebruiken.

Daar het bestuderen van de interacties tussen alle 19 Wnt eiwitten en 10 Frizzleds ons te ver zou voeren, hebben wij ons toegespitst op Fzd-1 and -2 , die beiden opgereguleerd zijn in het myocard infarct. Uit deze studie kunnen we concluderen dat zowel Wnt3a en Wnt5a preferabel binden aan Fzd-1 als - 2 , waarbij Wnt3a de $\beta$ catenine afhankelijke en onafhankelijke weg aanstuurt en Wnt5a alleen de onafhankelijke weg. Wnt5a fungeert tevens als natuurlijke antagonist voor Wnt3a voor de $\beta$-catenine afhankelijke signaaloverdracht. Verder meer werden er geen verschillen gezien in de eigenschappen van Frizzled eiwitten afkomstig van verschillende species.

Als laatste werd aangetoond dat de co-receptoren LRP5/6 voornamelijk fungeren om de binding van Wnt op Fzd te faciliteren, waarbij het intracellulaire deel van de 
coreceptor het signaal kan versterken. Tevens is LRP6 potenter dan LRP5 (Hoofdstuk 2).

De volgende stap was het testen van deze signaaltransductie weg in klinisch relevante celsystemen. Hiertoe werden de celcultuur van de belangrijkste celtype in het hart, namelijk de fibroblasten, bestudeerd. We ontwikkelden en karakteriseerden een met telomerase geïmmortaliseerde cardiale fibroblast-cellijn die we CFIT noemen. De proliferatie, migratie en differentiatie werden onderzocht (Hoofdstuk 3). Uit deze experimenten blijkt dat de proliferatie niet werd beïnvloed door Wnt/Fzd activatie. De migratie, aan de andere zijde, werd vertraagd door zowel Fzd1 als -2 , die de $\beta$-catenine onafhankelijke weg activeerden. Differentiatie van fibroblast in myofibroblasten werd bestudeerd aan de hand van verschillende myofibroblast differentiatie markers. Uit de resultaten bleek dat Wnt/Fzd een grote invloed kan uitoefenen op zowel de differentiatie als de dedifferentatie van CFIT, afhankelijk van de gebruikte Wnt/Fzd combinatie. Uit deze studie kunnen we dan ook concluderen dat Wnt/Fzd een zeer complexe signaaltransductie weg is, waarbij de specifieke Wnt-Fzd koppels en de geäctiveerde signaaltransductie weg een cruciale rol spelen.

In hoofdstuk 4 worden gladde spiercellen en skeletspieren bestudeerd. Hieruit bleek dat ook in deze cellen de Wnt/Fzd geen invloed heeft op de proliferatie. De differentiatie, aan de andere kant, werd op dezelfde complexe manier beïnvloed als bij CFIT. Activatie van zowel Fzd-1 als -2 kan de differentiatie van de spiercellen beïnvloeden. Bovendien werd de theorie bevestigd dat gladde spiercellen onder bepaalde stimulatie kunnen differentïeren tot skeletspieren. De resultaten bevestigen tevens dat de $\beta$-catenine onafhankelijke weg de belangrijkste regulator is van de migratie.

De resultaten gepresenteerd in dit proefschrift, samen met literatuur, duiden aan dat het blokkeren van Fzd-1 en -2 een belangrijk therapeutisch doel is voor de behandeling van MI. Daar Wnts zeer grote en plakkerige proteïnen zijn die bovendien meestal agonistische in plaats van antagonistische eigenschappen hebben, vormen zijn zeer slechte kandidaten voor in vivo therapiëen en visualizering. Dit leidde tot de ontwikkeling van peptiderge liganden. Dit ligand werd ontwikkeld om specifiek te binden aan Fzd-1 en -2, daartoe werden de sequenties van deze peptiden afgeleid van Wnt3a en 5a, beiden natuurlijke liganden van Fzd-1 en -2 (Hoofdstuk 5). Deze drie geïdentificeerde peptide werden UM206, UM207 en UM208 genoemd. Van bovengenoemde bleek UM206 het best oplosbaar en de hoogste affiniteit te vertonen voor Fzd-1 en -2, respectivelijke $I C_{50}$ van $10^{-9} \mathrm{M}$ en $10^{-11} \mathrm{M}$. De aanwezigheid van Gly, Thr en Asp en tenminste één Cys bleek kritisch te zijn voor de werkzaamheid. Al deze peptiden vertoonden tevens een hoge specific- 
iteit, daar er geen reactie met Fzd-4 en -5 kon worden vastgesteld. Verder was dit species onafhankelijk en werkzaam op recombinant eiwit, geconditioneerd medium en constructen. Deze antagonisten inhibeerden de effecten van Wnt/Fzd op zowel de migratie als de differentiatie van CFIT. Deze resultaten tonen aan dat zowel de $\beta$ catenine afhankelijke als onafhankelijke signalering wordt geïnhibeerd door UM206.

De in vitro data tonen aan dat UM206 een uitstekende kandidaat voor in vivo testen is (Hoofdstuk 5). Farmacokinetische experimenten toonden aan dat UM206 stabiel was met een plasma halfwaardetijd van 90 minuten. Door de gunstige farmacokinetiek en hoge efficacy van UM206 werd de stof toegediend in het muis infarctmodel gedurende 2 resp. 5 weken, beginnende op het moment van infarcering. Het infarctgebied was significant verkleind en de wanddikte was toegenomen. Verder meer waren het aantal myofibroblasten sterk verhoogd. Dit alles waren indicatoren voor een verbeterde cardiale remodellering. Bovendien kon UM206 behandeling in de 5-weekse groep het onstaan van hartfalen volledig voorkomen. In deze dieren was het eind diastolische volume minder toegenomen en de ejectiefractie verhoogd, ook de pompfunctie was significant verbeterd. Het collageen gehalte was echter gedaald, zodat stijfheid van het hart kon worden verminderd. Al deze studies toonden echter aan dat UM206 hartfalen kan voorkomen en de functie van het hart kan verbeteren; het meest waarschijnlijke mechanisme is een verminderde expansie van het infarctgebied door een sterke toename van het aantal myofibroblasten.

Een van de doelen van ons onderzoek was om na te gaan of Fzd-1 en -2 kan worden gebruikt als marker voor de kwaliteit van infarctheling. Hiervoor werden binnen onze onderzoeksgroep twee verschillende hulpmiddelen parallel ontwikkeld, namelijk rhodamine-gelabeld UM206 en een Fzd-2 antilichaam (Hoofstuk 6). Testen op verschillende cellijnen toonden aan dat de activiteit en de specificiteit van UM206 na labeling werden behouden. Verder werd deze stof uitvoerig getest op vriessecties van nier en dunne darm, organen die rijk zijn aan Fzd-1 en -2. De resultaten konden worden bevestigd met het Fzd-2 antilichaam. Uit in vitro studies bleek tevens dat stimulatie met ofwel Wnt3a of Wnt5a, leidde tot een internalisatie van de receptor. Middels infusie van het Fzd-2 antilichaam in de muis konden de Fzd-1 en -2 in nier en dunne darm zichtbaar worden gemaakt. Deze resultaten suggereren dat UM206 en het Fzd-2 antilichaam gebruikt kunnen worden voor in vivo diagnostiek, bij voorbeeld voor het bepalen van het Fzd-1 en -2 gehalte van het infarctgebied als voorspeller van excessieve dilatatie die leidt tot hartfalen.

In Hoofdstuk 7 wordt een pilot experiment over de rol van Wnt/Fzd in atherosclerosis beschreven. Hiervoor werden LDR receptor knockout muizen gebruikt waarin een kraag (collar) rond de carotiden werd geplaatst. Inhibitie van Wnt/Fzd signalering met UM206 leidde tot een grotere plaques met meer cholesterol De kap bleek echter ook dikker met meer gladde spiercel actine-positieve cellen, kenmerkend 
voor een stabieler plaque fenotype. Deze studie laat voor het eerst zien dat interventie op het niveau van Fzd-1 en -2 de karakteristieken van atherosclerotische plaques kan beïnvloeden. Dit fenomeen vraagt om een intensieve bestudering.

In conclusie kunnen we stellen dat in dit boekje een stof werd ontwikkeld met een hoge affiniteit en specificiteit voor Fzd-1 and -2, die werd getest en gevalideerd in standaard cellijnen. De resultaten konden ook worden bevestigd in meer klinisch relevante cellen en in vivo studies. UM206 is het eerste laag moleculaire ligand dat de interactie tussen Wnt eiwitten en Fzd-1 en -2 kan blokkeren. Deze stof biedt vele therapeutische en diagnosche mogelijkheden binnen het cardiovasculaire gebied, maar ook in andere aandoeningen waarbij Fzd-1 en -2 signalering een rol speelt. 



\section{1 \\ Dankwoord}

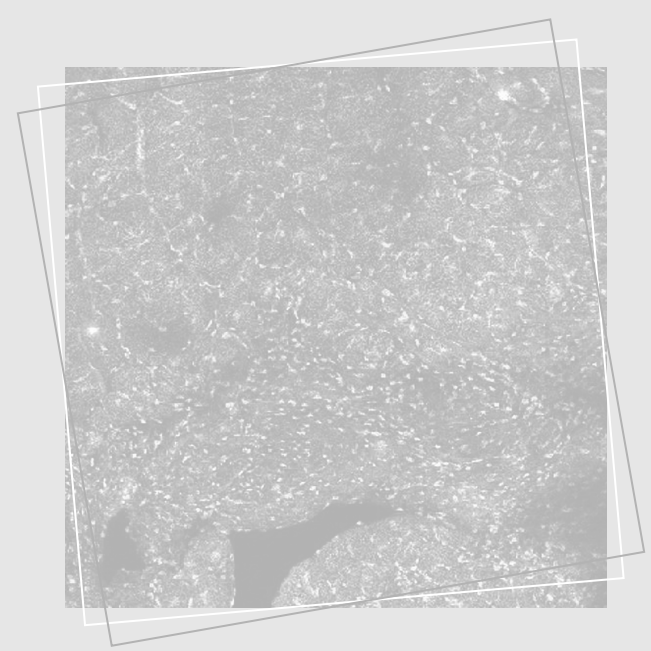


Vooreerst wil ik mijn begeleider Matthijs bedanken. Dankzij hem, heb ik de mogelijkheid gekregen om een brede waaier van nieuwe technieken aan te leren en mijn wetenschappelijk kennis te verruimen. Voor mijn promotie onderzoek was mijn kennis over Wnt/Frizzled zeer beperkt, maar ondertussen ken ik reeds vele windrichtingen van deze interessante signaaltransductie weg.

Verdere wetenschappelijke ondersteuning heb ik gekregen van Jos Smits. Ik wil hem dan ook ten zeerste bedanken voor alle nuttige commentaren en opbouwende kritiek. Door het vinden van een nieuwe baan moest het boekje op korte termijn worden afgerond en ik ben Jos zeer dankbaar dat hij dit zo snel heeft kunnen doen.

Harry, zonder jou was ik hopeloos verloren in de chemische aspecten van mijn proefschrift. Bedankt voor het bijbrengen van al deze informatie. Tevens heb ik het enorm gewaardeerd dat je steeds op een diplomatische wijze commentaren en hulp hebt aangeboden. Verdermeer, heb ik een grote waardering voor je manier van coördineren en motiveren en hoop ik dat ik ooit met evenveel wijsheid dit kan.

Zonder de hulp van analisten, is een AIO voornamelijk in de eerste en laatste maanden van een promotietraject helemaal verloren. Ik heb niet alleen mogen samenwerken, maar ook het bureau delen met onze twee analisten, Peter en Lily. Lily, bedankt voor de vele uren snijden en analyseren, zonder jou waren de laatste proeven nooit afgerond kunnen worden. Ik waardeer het dat je meer dan van je verwacht wordt, hebt doorgewerkt. Tevens wil ik je bedanken voor de vele opbeurende praatjes en de interesse in mijn probleempjes. Niet alleen bij jou, maar ook Peter kon ik terecht. Op regelmatige basis heeft Peter me geholpen in het labo.

Niet alleen de analisten, maar ook alle AIOs en de postdoc van het labo hebben mij enorm geholpen en gesteund. Ik wil eerst en vooral Sander bedanken voor alle hulp tijdens het eerste jaar van mijn promotie. Ook wil ik Veerle en Susanne bedanken voor de mentale steun en de goed raad.

Dit project was een samenwerking tussen de universiteit en Merck. Via deze weg wil ik ook de kans aangrijpen om de mensen van Merck, Guido Zaman, Folkert Verkaar en Jos van Rosmalen, te bedanken voor de wetenschappelijke input.

Toen het project in een stroomversnelling kwam en we konden overgaan naar proefdierstudies, heb ik gelukkig kunnen rekenen op een leuke groep van mensen, eerst en vooral Agnieszka en Jacque, maar ook Ben, Helma en Peter. Bedankt voor de massale en snelle hulp in al deze proefdierstudies. 
Rob Hermans wil ik bedanken voor de input in het chemische deel van dit proefschrift en de hulp bij het opzetten van de in vivo farmacologie. Ik heb ook veel geleerd uit zijn kritische vragen tijdens werkbesprekingen.

Tevens wil ik alle AIOs van de afdeling en in het bijzonder, Jelly, Pieter en Bart, bedanken voor de leuke babbels en mentale steun. Ook de rest van de vakgroep wil ik bedanken voor hun wetenschappelijke input tijdens de werkbesprekingen.

Via deze weg wil ik ook de gelegenheid aangrijpen om de twee secretaressen te bedanken voor al hun hulp.

Het biochemische deel van mijn onderzoek, werd enorm vooruit geholpen door Tilman en Dennis. Bedankt voor de vele uren denken en synthese wat heeft geleid tot de stof waarrond deze thesis is opgebouwd. Verder wil ik Gerry Nicolaes en Mahesh bedanken voor de computer modeling en het aanleveren van de chemical compounds. Marc van Zandvoort en Jos Broers hebben er vervolgens voor gezorgd dat we deze stof konden gebruiken voor het maken van mooie fluorescente plaatjes. Dit project werd tevens uitgebreid naar het veld van atherosclerosis. Ik wil Esther Lutgens bedanken voor de wetenschappelijke input.Ook de afdeling genetica met Florence, Ruben en Torek; wil ik bedanken voor de samenwerking.

Gelukkig waren er ook enkele mensen die me een stukje van Nederland hebben getoond en altijd klaar stonden voor een ontspannend etentje of een borrel. Ik wil in het bijzonder Bea, Erik en Ruben bedanken, voor de vele leuke en gezellige uurtjes samen.

Mijn paranimfen, steun en toeverlaten, niet alleen nu, maar ook vroeger. Kris, bedankt dat je dit wilde doen, maar ook voor de vele etentje, filmpjes en babbels. Veel succes met je promotie en je verdere studie.

Zonder de nodige steun tijdens mijn master studie, was ik nooit zo ver gekomen. Daarom wilde ik via deze weg Michel bedanken voor de enorme steun en het geloof in mijn kunnen wanneer ik dat kwijt was.

Mijn ouders, zonder hen had ik dit nooit kunnen bereiken. Niet alleen de financiële steun was onontbeerlijk, maar ook alle hulp, raad en daad en soms troostende woorden. Louter, dank u zeggen, is verre van voldoende, dus hoop ik dat ik hun trots kan maken met dit proefschrift. Tevens wil ik via deze weg mijn zus en schoonbroer bedanken voor alle steun en goede raad de afgelopen jaren.

Mijn rots in de branding, ver weg en toch zeer dichtbij, bedankt voor het onmetelijke geduld, het aanhoren van al mijn frustraties en gewoon om te zijn wie je bent. 



\section{2}

Curriculum vitae 


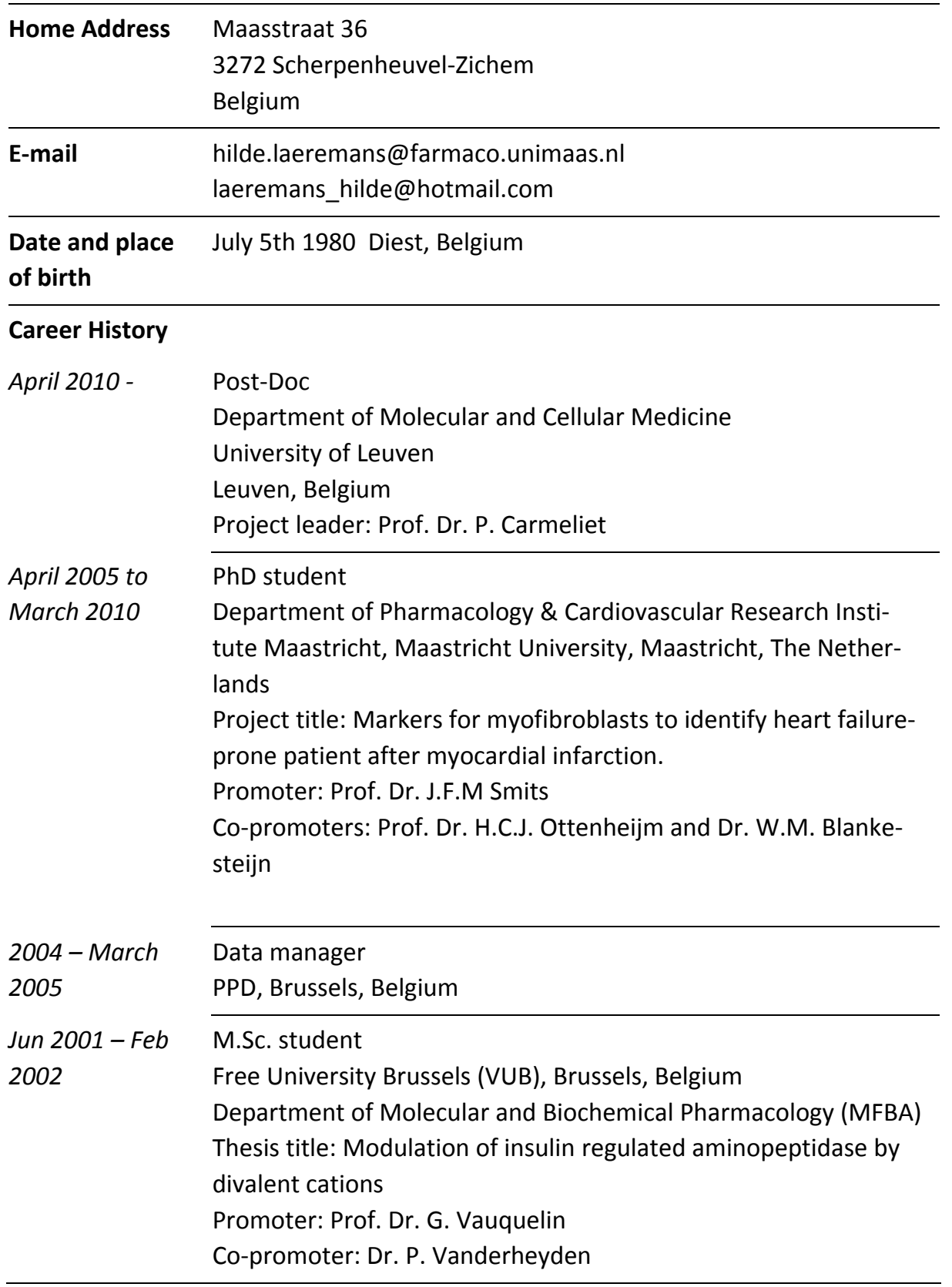




\section{Education}

Oct 2008

PhD training Certificate

Cardiovascular Research School Maastricht-Amsterdam

Courses in heart and circulation biology, physiology, biophysics

and pathology

1999 to 2004 Combined Bachelor and Masters program

Biomedical Sciences

Free University Brussels (VUB), Brussels, Belgium

Obtained Masters degree in 2004

1998 to 2000 Secondary education, graduated on program focussed on; Latin, mathematics and science

Zusters van de Voorzienigheid', Diest, Belgium

Awards
2009, Price for the best oral presentation awarded by the Royal
Dutch Chemical Society (KNCV)
2006, Price for best oral presentation at the symposium of the
joined Dutch-Danish Pharmacology Society
2006, Poster price of the Netherlands Federation for Innovative
Drug Research (Figon), (abstract printed in Figon magazine
'Conceptuur' December $2006 \mathrm{nr}$ 49 p.10)
2010: IUPHAR Copenhagen
2009: Wnt meeting Washington
2009: Pharmacochemistry congress Lunteren
2009: American Heart Association
2008: EPHAR Manchester
2007: Wnt meeting San Diego
2007: Wnt meeting Berlin
2007: American Heart Association (second author)
2006-2007-2008-2009: Dutch pharmacology symposium
2006-2007-2008: Cardiovascular meeting Papendal
2006: Cardiovascular congress Maastricht





\section{3}

List of publications and Patent 
1. LAEREMANS H, DEMAEGDT H, DE BACKER JP, LE MT, KERSEMANS V, MICHOTTE $Y$, VAUQUELIN G, VANDERHEYDEN PM. Metal ion modulation of cystinyl aminopeptidase. Biochem J. 2005; 390; 351-357

2. DEMAEGDT $H$, LAEREMANS $H$, DE BACKER JP, MOSSELMANS S, LE MT, KERSEMANS $V$, MICHOTTE $Y$, VAUQUELIN G, VANDERHEYDEN PM. Synergistic modulation of cystinyl aminopeptidase by divalent cation chelators. Biochem J. 2004; 68; 893-900

3. DEMAEGDT $H$, VANDERHEYDEN P, DE BACKER JP, MOSSELMANS S, LAEREMANS $\mathbf{H}$, LE MT, KERSEMANS V, MICHOTTE Y, VAUQUELIN G. Endogenous cystinyl aminopeptidase in Chinese hamster ovary cells: characterization by [125I]AngIV binding and catalytic activity. Biochem Pharmacol. 2004; 68; 885-892

4. DEMAEGDT H, LENARTS PJ, SWALES J, DE BACKERS JP, LAEREMANS H, LE MT, KERSEMANS K, VOGEL LK, MICHOTE Y, VANDERHEYDEN P, VAUQULIN G. Angiotensin AT(4) receptor ligand interaction with cystinyl aminopeptidase and aminopeptidase N: [(125)I]Angiotensin IV only binds to the cystinyl aminopeptidase apo-enzyme. Eur J Pharmacol. 2006 ;546(1-3):19-27

5. LAEREMANS $\mathbf{H}$, RENSEN SS, LIJNEN PM, OTTENHEIJM HCJ, SMITS JFM, BLANKESTEIJN WM. Wnt/Frizzled signaling can modulate the differentiation and migration of immortalized cardiac fibroblasts. Cardiovasc Res. 2010; accepted

6. TIENEN F., LAEREMANS H., VAN DER KALLEN CJH, SMEETS HJM. Wnt5b stimulates adipogenesis by activating PPARY, and inhibiting the $\beta$-catenin dependent Wnt signaling pathway together with Wnt5a. Biochemical and Biophysical Research Communications 2009 ;387(1):207-11

7. LAEREMANS H., HACKENG TM, van ZANDVOORT MAMJ, JANSSEN BJN, OTTENHEIJM HCJ, SMITS JFM, BLANKESTEIJN WM. A fragment of Wnt5a blocks Fzd-1 and -2 with high affinity in vitro and in vivo. Cell (submitted)

8. LAEREMANS H., OTTENHEIJM HCJ, SMITS JFM, BLANKESTEIJN WM. Differentiation of muscle cell lines is modulated by activation of Wnt/Frizzled signaling. Dev. Dyn. (submitted)

9. JANHUNEN SK, LAEREMANS H, RENSEN SS, LIJNEN PM, OTTENHEIJM HCJ, SMITS JFM, BLANKESTEIJN WM. Journal of cell biology (submitted)

10. VAN DER VELDEN J, LANGEN RCJ, KELDERS MCJM, LAEREMANS $\mathbf{H}$, SCHOLS AMWJ. Wnt3a or inactivation of GSK-3 $\beta$ promote $\beta$-catenin signaling and myotube formation during myogenic differentiation. AJP Cell (submitted)

\section{Patent}

Title: Antagonistic peptides for Frizzled-1 and Frizzled-2 Inventors: $\quad$ Laeremans H., Blankesteijn W.M. and Hackeng T.M. Patent number: 09154475.9-2107 